
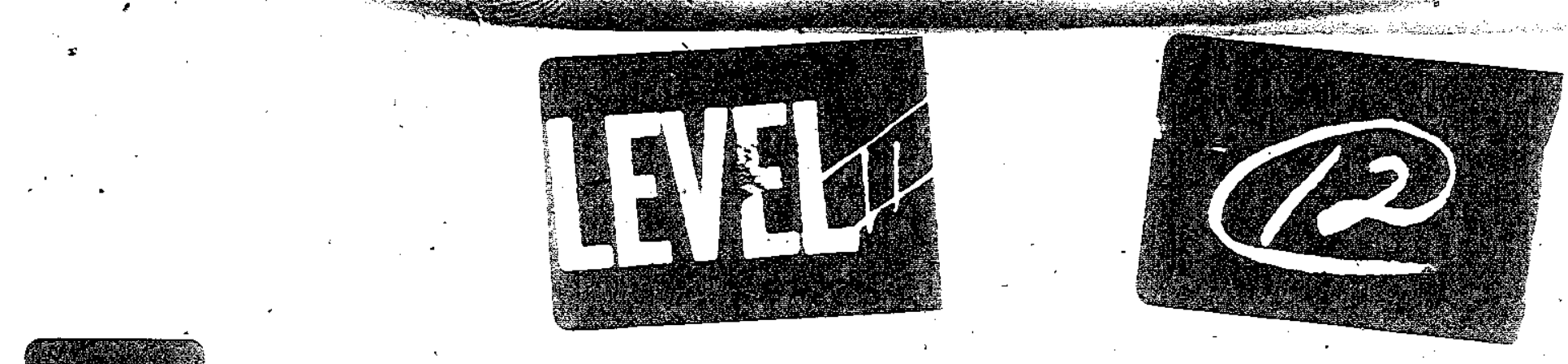

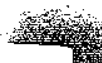

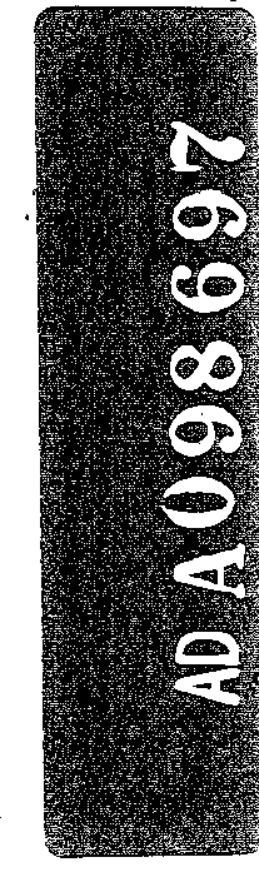

m.
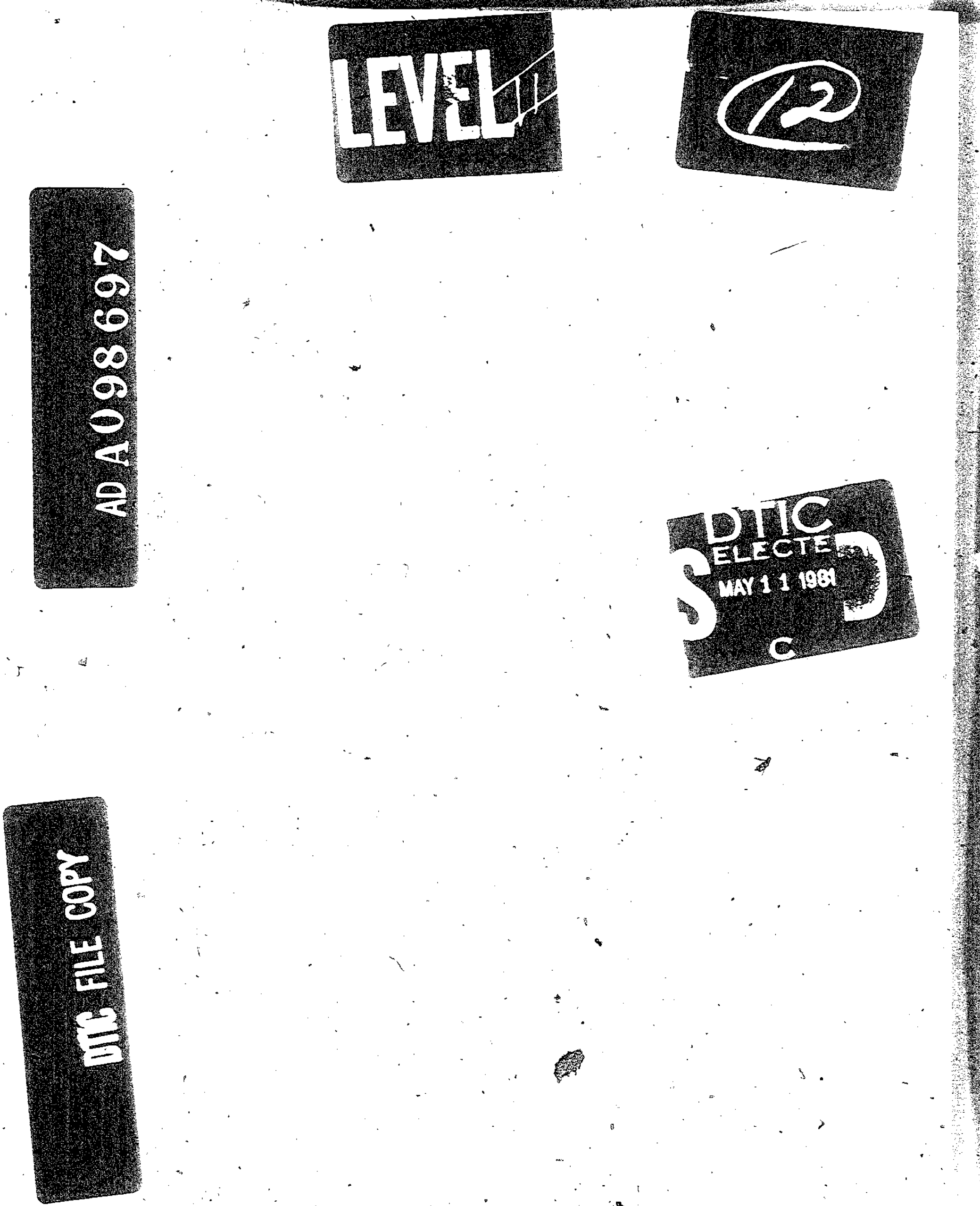
heurological and Neurosurgical Conditions Associated Ifith Aviation Safety.

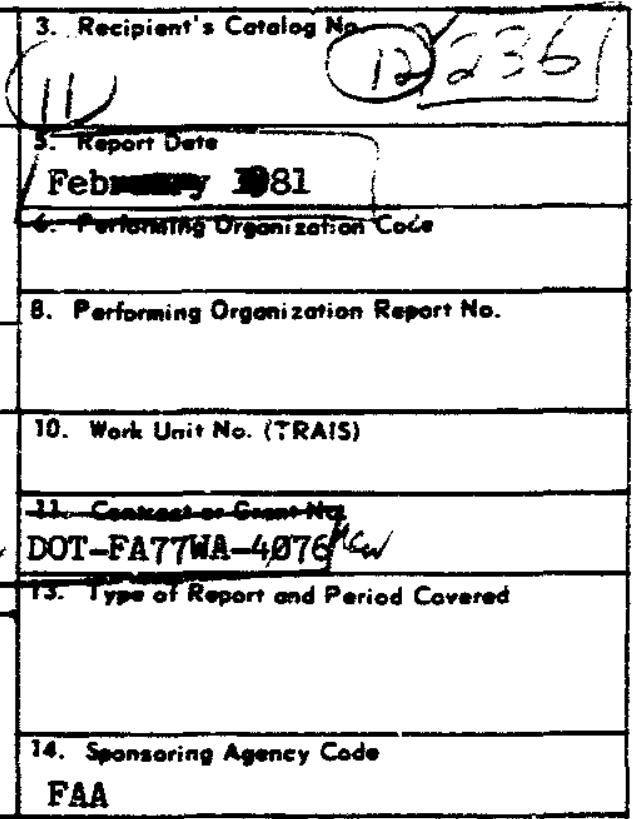

9. Performing Orgenizetion Neme and Addross

9. Performing Orgenizetion Neme and Addross American Medical Association, in collaboration with the American Academy of Neurology and the American Association of Naurological Surgeons

12. Spensering Apancy Momo and Address

Office of Aviation Medicine

Federal Aviation Administration

800 Independence Avemue, S.W.

Washington, D.C. 20591

FAA

This research was supported by Contract No. DOT-EA-7FHA-4076 from the Federal Aviation Administration.

16. Abetreet

The report is an authoritative document conceming the current state and knowledge about selected neurological and neurosurgical conditions.

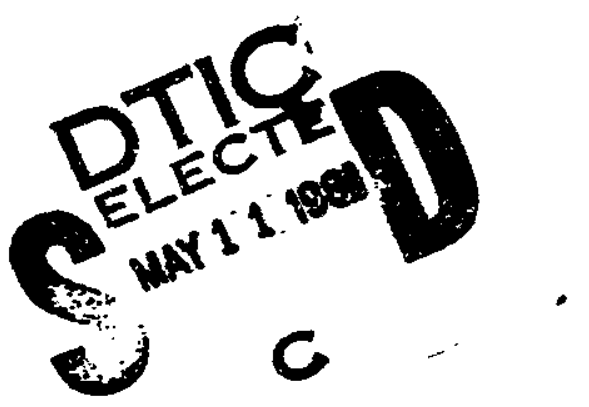

\section{Key werds}

Neurological

Meurosurgical
18. Distribution Stotement

Document is available to the public through the National Technical Infomation Service Springfield, virginia 22161.

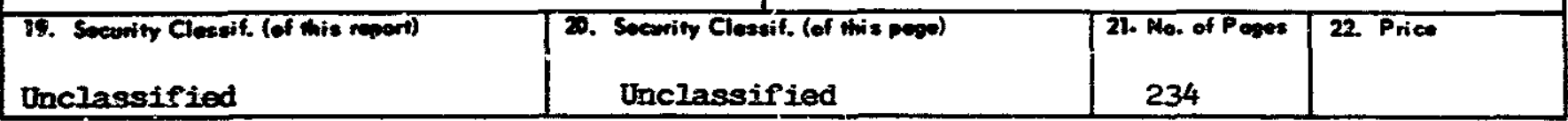

Fon BOT F 770.7 (8-72)

Repreduetion of eserploned pope antworized

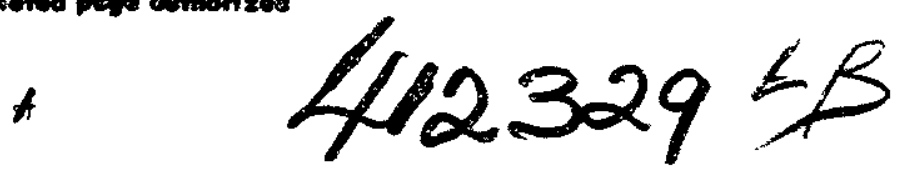




\title{
Neurological and Neurosurgical Conditions Associated with Aviation Safety
}

\author{
A Report of the American Medical Association \\ in Collaboration with the American Academy of Neurotogy \\ and the American Aseociation of Neurological Surgeons
}

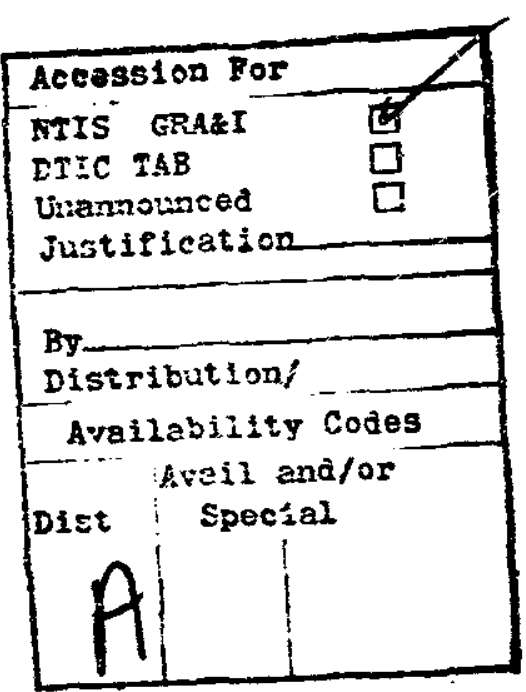




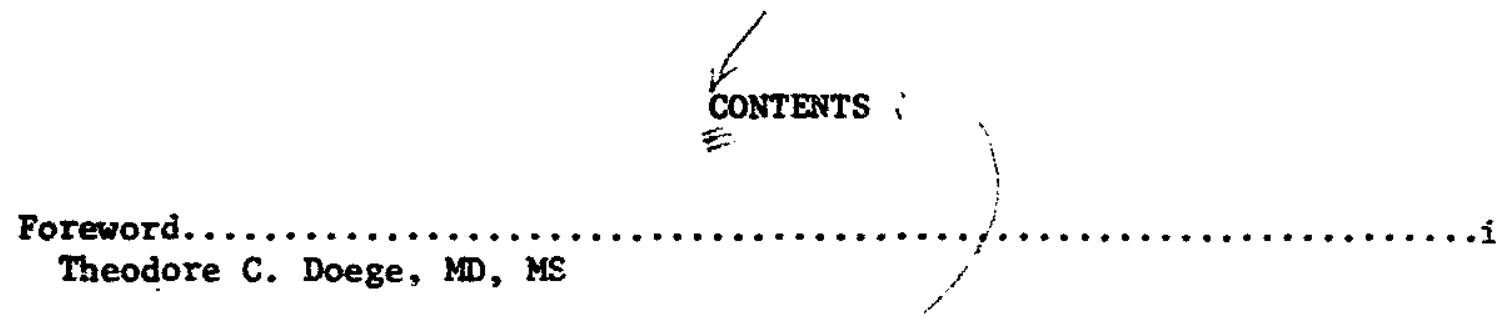

List of Participants.................................

\section{PANEI, STATEMENT}

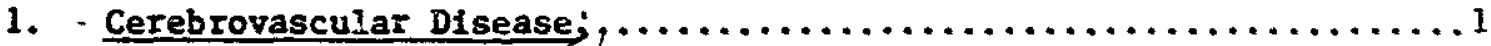

Jack P. Whisnant, MD (Chairman), Robert M. Crowell, MD,

Russel H. Patterson, Jr, MD, Sidney J. Peerless, MD, James

I. Robertson, Adolph L. Sahs, MD, and Frank M. Yatsu, MD

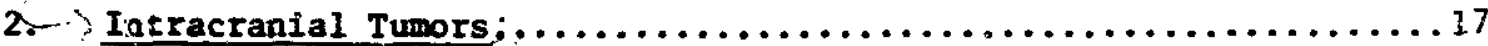

Shelly N. Chou, HD (Chairman), Richard S. Kramer, MD, and

William R. Shapiro, MD

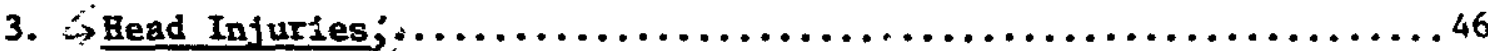

Donald P. Jecker, MD (Chairman), Robert G. Grossman, MD,

Robert L. McLaurin, MD, and William F. Caveness, $\mathrm{ID}$

4- $\rightarrow$ Comon Demyelinating and Degenerative Diseases and

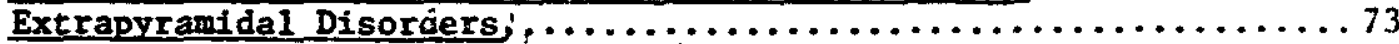
Charles M. Poser, (Chairman), Milton Alter, MD, Robert

D. Gurrier, $M$, and Samuel E. Hunter, iD

5. - Comnon Neuromuscular Disorders and Injuries to the Peripheral

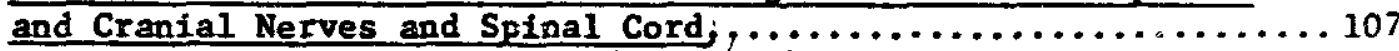
William F. Collins, Jr, (Chaj men), Richard O. Burns, Jr, MD, Thomas R. Johns, Mavid G. Kline, MD, Paul W. Myers, $M$, and George $R$. Nugent, MD

6. - iseizure Disorders and Disturbances of Consciousness, .......... 139 David D. Daly, ND (Chairman), Donald R. Bennett, MD, Paul H. Crandal1, MD, Richard H. Mattson, $M D, J$. Kiffin Penry, MD, and Ted B. Rasmussen, MD

7. Kigraine and Other Headaches; a.n. . . . . . . . . . . . . . . . 145 otto Appenzeller, MD (Chairman), Robert Feldman, MD, and Arnold Friedman, $\mathbf{M D}$

8. Dizziness and Disorders of Equilibriun David A. Drachnan, MD (Chairman), Ronald I. Apfelbaur, MD, and Jerome B. Posner, iD

Index........................................... 220 
The statements and recommendations set forth in this report, including those regarding fiying status, are those of the contributors and do not necessarily reflect the official positions of the American Medical Association, American Academy of Neurology, or American Association of Neurological Surgeons.

Authority to issue or deny civil medical certificates to pilots rests with the Federal Aviation Aduinistration.

This study was supported by Contract DOT-FA77NA-4076 from the Federal Aviation Adainistration. 
FORETORD

On August 16, 1977, the Federal Aviation Administration (FAA) 8o11clted a proposal from the American Medical Assoctetion (MA) for an authoritative document concernlag the current state of knowledge about selected neurological and neurosurgical conditions. This report was required in connectlon witi. FA review of regulatory tandards, examination procedures, and decisions about medical certification of afrman applicants.

AKA recelved the FA proposal on August 22, and DFs. A. J. Finkel and R. J. Jones asked the staff of AKA's Department of Environmental, Public, and Occupational Health to consider it. We noted the proposal called for a rechnical dissertation which outilned plans for the initiation and implementation of the report, together with a tine schedule and cost estimates, of critical Importance was the very short deadline, September 30, for final approval and acceptance by TAA of an AMA proposal.

There were several ressons why department stafi accepted the challenge. First, we belleved AMA thereby could render a valuable scientific service to the nation's pilots and medical practitioners. Then, the proposed study involved aspects of occupational health, a major concern of department members. and flaally, we believed we could work effectively with the wajor professional groups who could help us prepare a truly authoritative document.

From the beginning, we recognized it was essential to involve the fnerican Academy of Neurology (AAN) and the American Asscciation of Neurological Surgeons (AANS). Therefore, on September 8 we met with representatives of AAN and AANS to discuss the proposal and to solicit their assistance. Their representatives were enthusiastic about the profect and the Associations agreed to participate in 1t. With this assurance, the AMA proposal was developed, submitted on September 16, reviewed by the FAA, and accerted on September $30,1977$.

The methods by which the AMA staff developed the project may be instructive. In October, 1977, \& "Steering Conmittee" was formed, composed of two members each, representing the AN, AANS, and AMA. Members of the Steering Comattee, established to provide guidance, support, and coordination of the project, were: Drs. Calvin B. Early and Russel H. Patterson, Jr. , representing ANS; Drs. John R. Calverley and Edward A. Liske, Jr., representing AAN; and Dr. Theodore C. Doege and Mr. Frank . Barton of the AMA staff.

On November 14, the Steering Comittee met at the O'Hare Hilton, near Chicago, to discuss the conditions and diseases which the document should consider and to select medical experts who could lead efforts to develop authoritative statements about these conditions. Also attending the meeting were officers of AAN and AANS, and a representative of FAA. The Steering Comittee agreed to consider 8 major topics, ranging from cancer, through head injury and headache, to syphilis and syringonyelia. They also selected expert physicians to serve as panel chairmen and complled a roster of prospective nembers, from which the chairmen were requested to select neurologists and neurosurgeons for their panels. 
Qualifications and credentials for panel membershio included experience in the fleld, peer recognition, and demonstrated ability to produce scholarly publications. The Steering Comittee also sought broad national representation of educational institutions and geographic areas. Anticipating the pending submission date of the report, the Comittee requested esch panel to review their assigned conditions and subalt, by June 9, 1978, a referenced statement considering criterla and methods for diagnosis, treatment, prognosis, and recommendations.

To aid in reaching consensus and to lend authority to the specific panel reports, the Steering Comsultee planned a conference at the $O^{\prime}$ Hare Marriott Hotel, on July 11-12, 1978, during which panel members, invited guests, and Steering Comittee members discussed previously circulated panel statements and issues arising from them. Later in the two-day confereace, the panels met to revise their statements, considering the discussionz and input of conference varticlpants. Following editing and revision, AHA staff sent a final draft report to the FAA and to panel chalrwen and Steering Committee members for review and coments. The final document was transmitted to the FAl in January, 1979.

Flying, the vocation and avocation of persons who are the subjects of this report, is no small matter in the United States, and without doubt it will become of even greater moment. According to FAA statistics, 1 in 1976 there were 744,246 persons in the U.S. With alrmen's certificates, of wich 45,072 certificates were for air transports and 187,801 were for comerclal flying. In the same year, there existed a passenger-carrying fleet of 2,492 planes and 178,304 other active airplanes. The 45,072 cransport p1lots flying the 2,492 air carriefs among U.S. cities amassed the amazing toral of 145.3 billion, or $145.3 \times 10^{9}$, passenger-miles.

Many American physicians are actively involved in aviation medicine. They examine airline pilots with Class I licenses twice yearly, and commercial pilots with Class II licenses once yearly. In 1976, they sent FAA reports concerning wore than 450,000 wedical examinetions. The sfudy and report which follows is intended to assist such clinical activities.

Most certainly, this study would not have been possible without major comaitments of time and effort by the members of the eight study panels and the Steering Comittee, and the AMA is grateful to those minent neurologists and neurosurgeons. In addition, we acknowledge the encouragement and help of Dr. Willian H. Hark of FA, and the support of Drs. Asher J. Finkei and Richard J. Jones of AMA staff.

Special recognition must go to staff members of the Department of Environmental, Public, and Occupational Health-to Mr. Frank W. Barton, Deputy Project Director, who developed the proposal and guided the project with excellent anagerial skill; to Mrs. Rita $\%$. Palulonis for careful editorial efforts and attention to forwat; to Miss Leatha A. Tiggelear, Adninfstrative Assistant; and to Mss. C. A. Canpbell, B. S. Jansson, and N. T. O'Connor for their efforts in preparing the typescript.

We of AMA believe this study will be valuable in future years as a bench. mark to be used by the Federal Aviation Administration, and perhaps also by tens 
of thouands of the nation's cliniclans. In thst way, we hope it w11 contribuce not only to the bealth of this nation's pilots, but also to the safety and welfare of allions of its other citizens.

Theodore C. Doege, M.D.

Project Director

1. Fedwes Avintion Adidinistration: RA Stetiatical Hendbook of Aviation. Dechlagten, DC, US Dept of Transportation, 1976. 
NEUROLOGICAI AKD REUROSURGICAL CONDITIONS ASSOCIATED WITH AVIATION SAFETY

\author{
INVITED PARTICIPANTS \\ AND \\ PROJECT MEMBERS
}

Milton Alter, ND, PhD (FAAN)

Professor and Chairman

Department of Neurology

Temple University Health

Sciences Center

Philadelphia, Pennsylvania

Ronald I. Apfelbaun, ID (FAANS)

Assistant Professor

Department of Neurosurgery

Albert Einstein College of

Medicine \& Montefiore Hospital

\& Medical Center

Bronx, New York

Otto Appenzeller, MD, PhD (FAAN)

Professor of Neurology and Medicine

University of New Mexico School of Medictine

Albuçuerque, New Mexico

**Frạak W. Barṭoạ, LLB

Deputy Project Director

Associate Director, Department

of Environmental, Public and

Occupational Health

Amertcan Medical Association

Chicago, Illinois

Donald F. Becker, MD (FAANS)

Professor and Chairman

Division of Neurosurgery

Virginia Comsonealth University

Nedical College of Virginia

Richwond, Virginia

Donald R. Bennett, MD (FAAY)

Departwent of Neurology

Creightor- Lebraska Neurology Program

Omaina, Nebraska

*Invited participant

* Yember of steering Comittee

All other persons listed are nembers of study panels
Richard O. Burns, Jr, $\mathrm{ND}$, PhD (FAANS)

Associate Professor of Neurosurgery

University of Illinois at the Medical

Center

Chicago, Iliinois

* Johr R. Calverley, MD (FhAN)

Chairman, Department of Neurology

University of Texas Hedical Branch

Galveston, Texas

*George F. Catlett, MD, President

Aerospace Medical Association

Jamaica, New York

William F. Caveress, MD (FAMN, FAANS)

Consulzant, Neurosurgical Service

National Naval Medica: Center

Bethesda, Karyland

Sheliy N. Chou, MD, PhD (EAANS)

Professor and Head, Department of Neurosurgery

University of Minnesota Hospitals

Minneapolis, Minnesota

William F. Collins, WD (FAANS)

Cushing Professor of Surgery

Chief of Neurosurgery

Yale Jniversity School of Medicine

New Haven, Connecticut

Paul H. Crandall, (FANA)

Professor of Neurological Surgery

UCLA School of Hedicine

Los Angeles, California

Robert M. Crowell, MD (FAAN)

Assistant Professor of Surgery

Farvard Medical School

Boston, Maseachusetts 
Pobert D. Custier, UD (FNAN)

Esofessor and Cheirman

Department of Neurology

Untversicy of uisstseipp1

Hedical Center

Jackson, Hssissippi

David D。 Dely, MD, PhD (FAAN)

Professor of Neurology and

Professor of Comunication Disorders

University of Texas Bealth

Science Ceater

Southwestern Medical School

Dellas, Texas

**Theodore C. Doege, BD, MS (FACPM)

Project Director

Director, Department of

Envirowental, Public and

Occupational Bealth

American Yedical Association

Chicago, Illinois

David A. Drachnan, MD (FAAN)

Professcr and Chairman

Bepartwent of Neurology

University of Massachusetts

Medical Center

Worcester, Massachusetts

*Charles G. Drake, ID

Inediate Past President

Aperican Association of

Neurological Surgeons

London, Cotario, Canada

* Captala Calvia B. Early, MC, USR

Chuirean, Departwent of Meurosurgery

Natlonul Naval Hedical Center

Bethesda, Maryland kobert G. Feldean, ID (FAAN)

Professor and Chairman

Department of Neurology

Boston University School of

Medicins

Chief, Neurology Service

Boston VA Eospits1

Boston, Massachusetts

*Asher J. Finkel, MD, FhD

Group Vice President,

Scientific Affairs

American Yedical Association

Chicago, IIlinois

Arnold P. Friedwan, MD (FAAN)

Neurolojical Associates of Tucson

Adjunct Professor of Neuroiogy

University of Arizora Hedical School

Tucson, Arizona

Robert G. Grossman, ND (FAANS)

Professor of Surgery

Chief of Neurosurgery

Division of Neurosurgery

Untversity of Texas Medical Branch

Galveston, Texas

*William H. Haxk, MD

Office of Aviation Medicine

Federal Aviation Adrinistration

Washington, DC

Ssmuel E. Hunter, WD (FAANS)

Clinical Assistant Professor,

University of Tennessee

Center for bealth Sciences;

Active Staff, Baptist hemoriay.

Hospital

Yiemphis, Temnessee 
Thonas R. Johns, KD (FAAN)

Professor and Chatman

Department of Neurology

University of Virginia Hospital

Charlottesville, Virginia

*RIchard J. Jones, ID

Director, Division of Scientific

Activities

American Medical Association

Chicago, Illinois

David G. Kline, MD (FANSS)

Professor and Head of Neurosurgery

ISU Medical Center

New Orleans, Louisfana

Richard S. Kramer, MD (FAANS)

Assistant Professor

Division of Neurosurgery

Duke University Medical Center

Durhan, North Carolina

**Edward A. Liske, Jx, MD (FAAN)

Consultant in Neurology, EEG \& EMG

Audie Murphy VA Hospital

San Antonio, Texas

*Richard L. Masters, $\mathrm{MD}$

Air Medical Advisor

Air Line Pilots Assn.

Denver, Colorado

Richard H. Mattson, MD (FAAN)

Associate Clinical Professor

Department of Neurology

Yale University

New Haven, Connecticut

Robert L. Mclaurin, MD (FAANS)

Professor of Surgery (Neurosurgery)

University of Cincinnat i

Cincinnati, Ohio

Paul W. Myers, MD (FAANS)

Surgeon General, US Air Force

Washington, DC
G. Robert Nugent, Mi (TAANS)

Professor of Surgery

Chainman, Diviston of Neurogurgery

West Virginia University

Medical Center

Morgantown, West Virginia

**Russel H. Patter'on, Jr, MD (FAANS)

Professor of Surgery (Neuros'rrgery)

New York Hospitai, Cornell Medical Center

New York, New York

Sydney J. Peerless, ND (TRCS) (C)

Professor and Chairman

Diviston of Neurosurgery

Department of Clinical Neurosciences

University lospital

London, Ontario, Canada

J. Kiffin Penry, MD (FAAN)

Chief, Epilepsy Branch

Neurological Disorders Program,

Nationai Institute of Neurological and Cownicative Disorders and Stroke of NIH

Bethesda, Maryland

Charles M. Poser, MD (FACY, FAAN)

Professor and Chairman

Department of Neurology

College of Medicine

University of Vermont

Burlington, Vermont

Jerome 3. Posner, MD (FAAN)

Chassman, Department of Neurology

Menorial Sloan-Kettering Cancer Center

New York, New York

Theodore 3. Rasmussen, MD (FAANS)

Professor, Department of Neurology and Neurcsurgery

AcGill University

Seniior Neurosurgical Consultant,

Montre 3 Neurologicel Institute and Hospital

Montreal, Quebec, Canada 
Jamee T. Robertson, MD (FAAN)

Chalrman, Department of Neurosurgery

Universicy of Temeseee Cen:er for the Henlth Sciences

Menphis, Tennessee

Adolph L. Sahs, id (FAAN)

Professcr Beritus

University of Iowa College of Yedicine

Iowa City, Iowa

* Roland B. Sharburek, WD

Executive Vice President

Aerospace Kedical Association

Washington, DC

William R. Shapiro, MD (FAN)

Cornell Untversity (Ner York City)

Professor of Heurology

Memorial Sloan-Kettering Cancer

Center

Head, Laboratory of Neuro-Oncology

New York, New York

*Robert L. Stockton, MD

Mewber, Aerospace Hedical

Association

Waco, Texas

Jack P. Whisnant, MD (FAAN)

Professor and Chatrman

Department of Neurology

Mayo Clinic \& Mayo Nedical School

Rochester, Minnesota

Frank Y. Yatsu, MD (FAaN)

Professor \& Chairman, Departsent of Heurology

University of Oregon

Health Sclences Center

Portland, Oregon 


\section{CERERrovascular dISEASE - PANEL 1}

Jack P. Whisnant, ID (Chaiman), Robert K. Crowell, ID, Russel H. Patterson, Jr, MD, Sidney J. Peerless, MD, Janes T. Lobertson, ID, Adolph L. Sahs, ID, and Frank M. Yatsu, MD

Symptoms due to cerebrovascular disease may occur suddenly without warning. Residual disability comonly results, and the physical or intellectual impaiment may be severe encugh to deny flying status. The various ischemic and henorrhagic cerebrovascular disorders have been considered from the standpoint of probable recurrence of sudden, unpredictable disability.

In sumary of this report, we fudge ischemic cerebrovascular disorders to recur with a frequency sufficient to justify denial of fiying status except in unusual circunstances. If an ischemic event were caus ad by an embolus from a cardiac source, and that abnormality were corrected, then the judgment concerning flying status would depend on whether there is physical or intellectual impaiment of function.

The prognosis for individuals with primary brain hemorrhage is poor, and there are relatively few survivors. If survival does occur and associated hypertension is controlled, then recurrence is rare, and judgment concerning flying status should be based on residual physical or intellectual impalment.

When subarachnoid henorrhage (SAH) occurs and the bleeding aneurysm is isolated from the circulation, judgment concerning fiying status should be made one year after the SAH. If neither aneurysm nor another cause is found for the SAH, judgment may be made concerning flying status one year after the SAH, using the same criteria as for surgically obliterated aneurysms, with the exception that repeat angiography should not be required at that time.

\section{ISCHEMIC CEREBROVASCULAR DISEASE}

\section{DIAGNOSTIC DNTITIES}

These include transient ischemic attacks (TIAs) of brain; reversible ischenic neurologic deficits (RIN)); and cerebral infarctions, thrombotic and embolic.

\section{MTNIMUM CRITERIAA FOR DIAGNOSIS}

TIAs of brain are focal neurologis deficits which resolve relatively quickly, usually over a periad of minutes to hours; however, minimal neurologic deficits may persist as long as 24 hours.

RINDs are similar in charecter to TIAs of brain, but deficits last longer than 24 hours and may persist for up to three weeks. 
Cerebral infarction way develop within seconds to alnutes as is comwon with ebulic infarction, or it way develop over a perlod of several hours to ceveral days es is chiracteristic of progressing stroke or of stroke-inevolution. A completed cerebral infarct is characterized by a relatively otable neurologic deficit persisting for a period of observation of three weeks or vore after the onset of symptoms.

The diagnosis of TIA or RIND is primarily a clinical diagnosis, because frequently the patient is asymptomatic when seen by the physician and no neurologic deficit exists.

The diagnosis of enbolic cerebral infarction is suggested when there is abrupt onset of neurologic deficit within seconds or minutes, particularly when there is a valvular lesion or a twaor in the hearc, cardiac dysrhythmia, or a combination of these, which can cause developwent of a clot in the heart serving as a source for eubolic material.

Thrombotic cerebral infarction is said to occur when there is no evident source for an enbolus to account for the infarct.

For convenience, the symptoms of TIAs and RINDs may be divided into those affecting anterior circulation and those affecting posterior circulation. With regard to the anterfor circulation, or carotid system, the most characteristic symptoms are those of amaurosis fugax, which is frequently described as being like the drawing of a shade or curtain over one eye; contralateral hemiparesis; and aphasia, if the dowinant henisphere is involved, or nonoparesib. For the posterior circulation, or vertebral basilar system, the symptoms may include unilateral or bilateral visual field defects, diplopia, ataxia, dysarthria, or rarely, "drop attacks." Vertigo may also occur as a transient sympton related to the posterior circulation, but it is such a common intermittent symptom in benign disorders, it is not considered to be TIA when it occurs alone. Since symptoms of TIA and RIND can be caused by pathologic processes other than atherosclerosis, these processes also require diagnostic consideration.

Symptows that occur with IIA and RIND may also occur in association with cerebral infarction. It is the timing and persistence of symptoms that are different. The nature of the symptoms depends on the location of the infarct.

Benign anaurosis fugax may occur in a young person. Occasionally it occurs in patients with migraine or with no other disorder. When this symptom occurs in a young person, it should not autcosatically be considered to be IIA, but it is important enough to require ophthalmologic and neurologic consultation.

Transient global amesia (TGA) is an episode of anesia of varying severity which usually persists for 2 few hours. Although in nost instances it is probably due to an ischeoic process, it is unusual for guch episodes to recur or to lead to an incapacitating stroke. This should not be considered to be in the same category as TIA. Patients with IGA should undergo neurologic evaluation, including EEG and psychometrics, for evidence of residuel abnormality.

OTHER RELEVAKT DIAGNOSTIC CRITERIA AFTECTIMG PROGHOSIS

The majority of TIAs and RIDs are due to extracranial ulcerative or 
occlusive disease, although Identical symptoss occur with "tight" stenosis or conplete occlusion of intracranial arteries. In addition, transient aeurologic deficits sinulating IIfs of brein due to atherosclerotic vascular disezse are seen in other pathologic processes. These include:

1. other vascular discrders such as cranial arteritis, fibrowscular dysplasia, or wigraine

2. compressive lesions such as weningioas, basilar iapression, and late onset Arnold-Chiart Syndrome

3. marked reduction in cardiac output due to dysrhythmia or asystole. though reduced cardiac output usully does not produce focal neurologic deficits

4. cardiac aboli, as in association with atrial fibrillation and iftral valvular disease, postuyocardial infarciton, ventriculat aneurysm, prolopse of the nitral valve, sinoatrial nodal rhythm defects, atrial myxoms, nonbecterial thrombotic endocarditin, and bacterial endocarditis

5. hyperviscocity of blood in disorders such as thronbocytosis and polycythenis vera.

There are other disorders which wight winic a completed stroke. These include:

1. Todd's paralysis

2. Intracranial neoplasm

3. subdural heatcoa

4. brain abscess

5. hyeterle

6. global cerebral 1scheala sssociated with heart block

Hypertension plays a role in the development of cerebral infarction or in the developant of TIAs or RIIDs. Irauna to a blood vessel may produce cerebral infarction and rould not be expected to recur.

If the source of cardiac eboll is corrected, the coadition should be considered to be cured. When ischenic eplsodes occur in association with fibrcauscular dyoplesia, the vascular condition should be thought of as a self-liniting condition which will resolve in tine. Resolution of the vascular lesion can be determined by artertography.

Other risk factors which way be associated with ischemic cerebrovascular cisease include:

1. Funily history

2. eleveted blood lipids

3. diaberes sellitus

4. Cbesity

5. cigarette sooking

6. oral contraceptives in wowen 
The presence or absence of these risk factors man affect the decision concerning flying status.

RELEVANT DIAGNOSTIC PROCEDURES WHICH AID IN DETERMNING FROGNOSIS

6 neral Diagnostic Procedures

Procedures which may help in maiking a judgment about the conditions associated with cerebral ischemia Include:

1. funduscopic examination

2. auscultation over the cervical arteries and over the globes of the eyes

3. biood pressure determination

4. urinalysis

5. complete blood count

6. serological test for syphilis

7. serum glucose, urea nitrogen, and serum lipids

It is important that the detafls of the history and physical examination be recorded, and that the diagnosis of the type of cerebral ischemia be confirmed by a neurologist. Cardiologic consultation is desirable to determine whether a cardiac lesion is the source for an ischemic cerebral lesion.

Special Diagnostic Procedures

Studies with the pujor purgise of identifying a correctable disorder and minimizing the likelthood of recurrence of the ischemic cerebral symptoms include:

1. x-ray of the chest and skull

2. computed tomography of the head (CT scan)

3. electroencephalogram

4. isotope brain scan

5. spinal fluid exemination

6. electrocardlogram

7. echocardiogram and/or sector scan

PROGIOSIS RELATTVE TO SUDDEN OR INSIDIOUS INCAPACITY

Patients with TIA have a $20 \%$ risk of stroke occurrence in the first year and approximately $5 \%$ to $10 \%$ per year thereafter. In addition, sone patients with TIAs continue to have them in spite of treatment. The risk of death in patients with IIA ic about $8 \%$ to $10 \%$ per year.

Fatients with cerebral infarctions have $20 \%$ to $30 \%$ initial mortality, and 207 to $30 z$ of them have no residual incapacity when they have recovered from the episode.

A patient with a cerebral infarction has a $5 \%$ to $10 \%$ risk of recurrence per year. The risk of death in survivors of cerebral infarction is 87 to $10 \%$ per year. The risk of recurrent embolic cerebral infarction depends upon the type of lesion causing the emboll, but generally it is in the same range as that for cerebral infarction. 


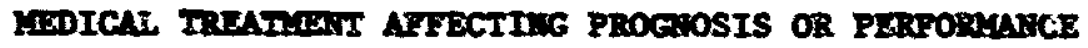

In patiente with extracrmalal occlusive diesese who have TIAs or RIDs, oral inticoagulent therapy or antiplatelet ageregation therapy any reduce the probabillty of stroke. When a cardiac leston is the cauce for cerebral ischevia, correction of the cardiac leston would be reason to judge that the patfent vas no longer at an increased risk for stroke. Patients with TIAs or RIiDs nay be eandidate for antikypertensive therapy, which nay reduce the probability of further stroke.

\section{SURGICAL TREATHDIT AFTECTIVG PROESOSIS OR PERTORIAMCE}

\section{Extractanial Reconstructive Vascular Surgery}

Cerotid endarterectony any reduce the risk of stroke occurrence in patients vith TIA, or of stroke recurrence in patients with ainival restival neurologic deficit.

Extra- or Intracranial Anastomotic Procedures

These procedures inslude superficial temporal-aiddle cerebral artery anastomoses and occipital-posterior inferior cerebellar artery anastomoses. They are performed in patients with wild peurologic deficit following a completed stroke, or in patients who have had TIAs or RINDs, and may reduce the risk of stroke occurrence or recurrence.

Either medical or surgical theragy, as deacribed, may decrease the risk of stroke, recurrent stroke, or recurring TIA. In most instances, the risk would still be great enough to disquilify a person from fiying status, but there could be exceptions based upon reevaluation of the person and passage of tine.

\section{OTIER COASIDERATIONS}

\section{Asymptconatic Carotid Bruit and Internal Carotid Stenosis}

In an occasional person, a bruit will be detected in the cervical region in the absence of any cerebral 1schemic symptons. If the bruit is diffuse over one side of the neck, there is no resson to believe the person is at Increased risk for stroke. If the bruit is well locallzed over the region of the conxa carotid artery bifurcation, there is a high 1ikelihood that it is sssocfated with stenosis of the internal or the external carotid artery. There Is some evidence those patients with asyaptomatic internal carotid stenosis may be at an increesed risk of stroke. Some authorities recoinend no treatment for such patients. The dats are insufficient to judge whether carotid endarterectoany in such patients will decrease their risk of vorbidity and nortality.

A patient with an asyptosatic bruit at the carotid bifurcation should be reevaluated every six months. Reevaluation should include assessment of history by a neurologist and ay include exanination of the optic fundus for esboli and noninvasive studies to assess perfusion or pressure in the carotid circulation. 
Asyoptomatic Occluston of en Extracrantal Artery

When a patient is being evaiunted for other syptcas or for cervical bruits, aptography ull oscastonally detect complete occlusion of a carotid or vertebsal artery. Such a condition appenrs to have a good prognosis, and It is recomended thet flying status not be denied because of this finding.

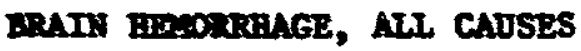

DIAGNOSTIC ERTTIES (ETIOLOGIES OP BRATI HENORRAGE)

Primary brain henorxhage is usally hypertenefve and way be:

1. putanemal

2. thalenic

3. cerebellar

4. pontine

5. subcortical

Heworrhagic disorders may be related to:

1. Ieukemia

2. anticoagulant therapy

3. Ifver fallure

4. sepsis with vasculitis

5. collagen vascular disease

6. hemophilin

7. disseminated intravascular cosgulation

Other entities in differential diagnosis include:

1. trauma

2. cerebral aneurysm

3. arteriovenous miformation

4. neoplasm

5. hemorrhagic Infarction

6. causes of subarachnoid hemorrhage (see 1 ist, p. 12)

\section{MINIDIN CRITERIA FOR DIAGTOSIS}

Brain hemorrhage within one week of lctus cm be diagnosed by the presence of intraparenchyan hontona on the plain CT scan. Presuptive diagnosis of brain hemorrinage can be made on the basis of rudden beadache and focal neurologic signs, usually assoctated with blood in the cerebrospinal fluid (CSF). In some cases, bruin hewrrhages too sall for detection on CT scan ray produce blood with ranthochronia in the cerebrompinal fluid; these findings can $a l s o$ be caused by priasy subarachnold heworthage. In the absence of CT 8 can data in the first week, there nay be difficulty in distinguishing Infarct and heorrbage. 


\section{ETIOLOG}

Hypertension nay be accepted as the cause of brain hemorrhage when one encounters:

1. hypertension

2. CT scan evidence of heworrhage in basal ganglis or cerebellum

3. an approprlate clinical syndrose with spontaneous onset

4. no evidence of trauna

5. normal coagulation studies

When these criteria are not satisfied, other etiologies should be sought.

Henorrhagic disorders wil be detected by congulation studies, and specific entities such as leukenia may be diagnosed by complete hematologic evaluation. Trauma as a cause will generally be evident irom history and physical findings. Cerebral aneurysms and arteriovenous malformations can generally be detected by angiographic evaluation of the entire intracranial circulation; these entities are considered separately in this section. Intracranial neoplasms are usually detected with CT sean with and without contrast aterial, or anglography, and these lesiuns are likewise dealt with separately. In scme cases, no specific etiology will be found. Pathologic evaluation way show a cryptic angioma in such cases.

\section{OTHER RELEVANT DIAGIOSTIC CRITERIA AFEECTING PROGNOSIS}

Since the disability from brain henorrhage almost always appears with the initial illness, the nost important prognostic factors relate to the neurologic examination after convalescence from the initial illness. Size and location of henatoma on $C r$ scan can help predict outcome: clearly a patient with a suall cerebellar clot and no deficit is expected to fare better than the hemiplegic with a large putamenal hemorrhage.

Diagnostic aids in assessing disability nay include quantitative neurological examination and psychological testing. CT scan and lumbar puncture (IP) can assess developient of hydrocephalus. EEG can help assess the possibility of seizures.

It is rare that a orain henorrhage will recur. Risk factors for recurrence would include uncontrolled hypertension, anticoaguiant therapy, liver failure, blood dyscrasia, and intracranial vascular anomaly or neoplasm. In the noohypertensive young adult, every effort ought to be made to find a cryptic arteriovenous malforwation (AVM).

\section{RELEVANT DIAGIOSTIC PROCEDURES AIDING DIAGNOSIS AND ASSESSYERT OF PROGNOSIS}

Computerized Tomographic (CT) Scan

This is the procedure of choice for the diagnosis, localizing, and sizing of intracerebral henatcass. Unenhanced CT 3 can rellably denonstrates significant intracerebral heworrhages within one waek after the ictus. CT scar after intravenous contrast naterial sonetimes can denonstrate a vascular anomaly or tumor whlch caused the hemorrhage. CI scan also gives a precise indication of residual hesatcen and other difturbences, such as edesa or hydrocephalis, after sedical or surgical therapy. After the acute IIIness 
is over, CT scan peraits assessment of chronic pathology, such as porencephalic cyst, local ventricular dilatation, cortical atrophy, and hydrocephalus.

\section{Coagulation Studies}

Every patient with spontaneous intracranial hemorrhage should have a platelet count, prothroubin time, and partial thromboplastin time to assess disorders of coagulation, which cccasionally can lend to brain hemorrhage.

Lumbar Puncture (LP)

LP is sometines needed to confirm small intracerebral hemorrhages. LP is needed much less often since the advent of CT scan; moreover, LP is sometimes misleading or even dangerous. LP may be helpful in evaluating hydrocephalus late after intracerebral hemorrhage.

Cerebral Arteriography

When CI scan is available, angiography is used principally to exclude a vascular anomaly or neoplasm as the etiology for heanorhage.

Electroencephalography (EEG)

This may occasionally be of use in the chronic phase of illness to assist in assessment of seizures.

PROGNOSIS RELATIVE TO SUDDEN OR INSIDIOUS INCAPACITY

After convalescence from brain henorrhage, the risk of new incapacity is relatively slight. This assumes that relevant risk factors such as hypertension, blood dyscrasfas, anticoagulation, intracranial vascular anomalies, and neoplasms are corrected. The likelihood of hydrocephalus is low overail, except for cerebellar hemorrhage in which hydrocephalus may develop early. The likelihood of selzures is low except when the cortex has been involved. CT scan can indicate rather precisely the locus of the leston and thus suggest the likelihood of these complications. When no cause for hemorrhage can be found, the 1ikelihood of recurrence is low, but no precise figure is available.

\section{MEDICAL TREATMENT AFFECTING PROGNOSIS OR PERFORMANCE}

Management of the initial manifestations is designed to stop hemorrhage, limit mass effect, and prevent complications. Therefore, standard therapy includes control of hypertension, restoration of normal coagulation, limitation of edema with corticosteroids or mannitol, and avoidance of seizures by anticonvulsant administration. In long-term management, control of blood pressure and maintenance of normal coagulation minimize the already low risk of recurrent hemorrhage, if surgical lesions are not present. Continuing anticonvolsant therapy for 6 to 12 months can minimize risk of selzure. Rehabilitation way be helpful, including physical and speech therapy. 


\section{SURGICAL TREATIBAT AFTECTIMG FROgROSIS OR PERPORHANCE}

When a hypertensive or traumatic brain heorrhage causes progressive deterforation, surgical evacuation of the henorrhage can be iffe-saving. Whether eventual worbidity can be lessened by removal of a hematom in a patient with a stable deficit has not been established. In patients with cerebellar hearrhage, heatona evacuation say be advisable if done in the first 48 hours after henrrhage, because sudien decline occurs unpredictably. Adequate surgical trentment of aneurysens, AVis, and tuwors greatly decreases the chance of recurrent heworrhage, but preoperative deficit and seizure potential will not be reduced.

\section{SUBARACHIOTD HEPORRHAGE}

\section{DIAGNOSTIC ENTITIES}

Subarachnoid hemorrbage (SAH) may be due to aneurysa or to arteriovenous malformation (AVH). Either diagnosis is cause to remove a filot from fiying status for a period of at least one year.

\section{MINIMIM CRITERIA FOR DIAGNOSIS}

A patient with SAH from an intracrantal aneurysm or arteriovenous alformation may display one or more of the folloring:

\section{History}

1. Nontraumatic headache of sudden onset, with or without nausea and vomiting, altered state of consciousness, or focal neurological deficit

2. Oculosotor nerve paresis, progressive, usually painful. Cinilateral cavernous sinus aneurysm may be excluded, beceuse it does not produce subarachnoid heworrhage

3. Focal or generallzed seizures

4. Continuous nontramstic cranial bruit or AVM

Physical Examination

1. Signs of meningeal Irritation present, eg, stiff nuck, Rernig's sign

2. Subhyalofd retinal heasorrhage

3. Partial or complete oculonotor nerve paresis, ususlly with pupillary involvenent

4. Other cranial nerve palsies or evidence of a mass leston (rare)

5. Crantal bruit or AVM

6. Progressive spinal cord signs, as with cord AVM

\section{Leboratory Examination}

Proof of aubarachnofd heworrhage depends on either of the following:

1. Hontrawatic opinal puncture reveals bloody or xanthochromic fluid, usully mder elevated pressure; if bloody fluid is centrifuged proppty and the oupernatant fluid is zanthochroaic, recent subarachnoid bleeding is estublished 
2. Cr scan, menhanced, say confirm subarachnold, focal, or ventricuiar hewrrhage; CT scan with contrast enhancement is often diagnostic of an arterlovenous malforntion and way demonstrate an aneurysn

\section{Radiological Examination}

1. Proof of aneurysm or AVI requires demonstration of the lesion by adequate cerebral arterlography. hn attempt to visualize all four contributing cerebral vessels is reconended. Since 87 of ansurysus nay not be dewonstrated on the intial study under the best of circumstances, a repeat arteriogram should be performed, usually 7 to 10 days later. Selective spinal angiography may be yinranted, if signs of spinal cord diseuse are present

2. Plainskull $x$-rays may denonstrate curvilinear calcification at the base of the brain, indieating aneurysm, or irregular curvilinear calcification over or within the brain, Ie, an AVM

OTHER RELEVANT DIAGNOSTIC CRITERIA AFFECTING THE PROGNOSIS RELATIVE TO THE IMYEDIATE HEMORRHAGE

Clinical Course

1. The prognosis is related to the severity of the subarachnold hemorrhage and to the presence of an associated intracerebral heworrhage. These factors are clinicsily correlated as follows:

$$
\begin{gathered}
\text { Grade } 0 \text { - Neurologically intact patient without signs of meningeal } \\
\text { irritation } \\
\text { Grade } 1 \text { - Neurologically intact patient with signs of meningeal } \\
\text { Grade } 2 \text { - Mitrotion } \\
\text { consciousness, with signs of meningeal irritation } \\
\text { Grade } 3 \text { - Patlent has wajor neurological deficit, stupor, and signs } \\
\text { of meningeal irritation } \\
\text { Grade } 4 \text { - Comatose patient without response to painful stimuli, } \\
\text { with dilated pupils and respiratory irregularity }
\end{gathered}
$$

Grades 3 and 4 are usually associated with massive subaxachnoid bleeding and/or intracerebral hematoma. Conversely, the outcome of patients in grades 0-2 is usually favorable if rebleeding does not occur.

2. Other adverse factors include:
a. prolonged coma beyond 48 to 72 hours
b. selzure activity
c. persistent or progressing focal neurological deficit
d. repeat subarachnofd bleeding
e. pulmonary or cardiac complications

Laboratory Examination

1. EEG way show focal dysrhythwias associated with progressive deterioration of the patient 
Rediological Examination

1. Cerebral anglography way demonstrate diffuse or segmental vasospasm correlated ofth focal or geseralized neurological deterioration; thfs phenowenon is rare in AVM bleeding

2. Cerebral angiography may demonstrate a ms leston due to hemorrhage or infarcticn, or indirect evidence of hydrocephalus. Occasionally, subcural henatona occurs

3. Technetium brain scan way show coidence of impaired flow time or cerebral infarction

4. CT scan may dewonstrate intracerebral, intraventricular, massive basilar subarachnold or subdural bleeding; hydrocephalus or cerebral Infarction may be seen

RELEVANT DIAGNOSTIC CRITERIA WIICH WOULD AID IN DETERMTHIRE PROGNOSIS

These include examinations one year after recovery fron the last subarachnoid hemorrhage; the fullowing should ba considered before making determinations as to flying status:

Clinical Course

1. Assessment of motor, sersory, language, or intellectual function by a neurologist

2. Clinical history in regard to selzures

3. Assessment of disability secondary to the medical or surgical complications of the acute subarachnold hemorrhage

4. Satisfactory healing of craniotomy site

Laboratory Examination

1. Psychowetric or psychological testing to demonstrate intellectual Impatrment.

2. EEG test for evidence of an epileptiform abnormality as determined by a neurologist (see chapter on Selzure Disorders)

\section{Radiological Exasination}

1. Angiographic proof of exclusion of the aneurysm or arteriovenous nalformation from the arterial circulation. Angiographic documentation. of exclusion way be done any time between three months and one year following the operation. The detection of occlusion of a carotid, vertebrai, or intracranial artery that is asymptonatic and associated vith 8 normal neurological examination is not considered a disability

2. CI scan for evaluation of ventricular size, focal cerebral destruction or infarction, and width of sulci. If available, this should be correlated with the CI scan done adjunctive to the subarachnoid hesorrhage (see discusston of hydrocephalus, chapter 3)

PROGTOSIS REIATTVE TO SYDDEN OR INSIDIOUS INCAPACITY

Presence or peralstence of an intracranial subarachnofd aneurysm or AVM is a permanent contraindication to flying status. This restriction also applies 
to asymtomatic meuryses or AWI discovered incidentally.

Absence of inpairment of sensory, notor, language, or intellectual function, as deternined by a neurologist one year following surgical repair, is associated with an excellent prognosis.

Angiographic demonstration of exclasion of an aneurysm or AVH from the arterial circulation one year from the surgical repair confirms cure.

MEDICAI TREATMENT AFFECTING PROGNOSIS OR PERFORMANCE

There is no definitive medical therapy of patients with aneurysms or arteriovenous malformation compatible with flying status. Other medical treatment would be therapy directed to conconitant pulmonary, cardiac, or renal problems related to the subarachnoid hemorrhage (see report concerning seizure disorders).

\section{SURGICAL TREATMENT AFFECTING PROGNOSIS OR PERFORMANCE}

Operations which exclude aneurysus or AVMs from the arterial circulation are curative. Operations in which there is coating or reenforcenent of the aneurysa, or in : " in intraluninal thrombosis or proximal ligation procedures are done, may be . aeficial but are not considered curative. status.

Heaifing of any crankotony wound is recomended before resumption of flying

SAR without demonstration of an aneurysin or AVM, as indicated in the section about SAll due to neurysm or AVM, includes systemic causes of SAH. Reasonable exclusion of these conjitions is necessary, and approval or denial of flying status should be determined by the specific disease entity being considered.

\section{CATSES OF SUBARACENOID YEMORRHAGE}

Diseases of the Blood - Coagulopathies

1. Bemophilia

2. Thrombocytopenia

3. Leukemia

4. Waldenstrbin's Macroglobinewia

5. Iysiphoma

6. Hyeloma

7. Aplestic anenia

8. Hereditary spherocytosis

9. Sickle cell anemia

10. Perrictors anemia

11. Polycythenia

12. Aftbrinogenenia

13. Fypofibrinogenemia-hepetic disease or malignancy

14. Consumption coagulopathies/dissersinated intravascuiar coagulopathy (DIC)

15. Anticoagulant therapy 
Angiopathies

1. Lupus angitis - Iupus rythenatosus

2. Giant cell cerebral arteritis

3. Dysproteinemias--amyloidosis

4. Hypertension-all cases

5. Atherosclerosis

Infectious Diseases

1. Bacterial meningoencephalitis, as with tuberculosis, leptospirosis, listeriosis

2. Hycotic infection of brain, eq, aspergillosis

3. Rarely, brucellosis, typhoid fever, yellow fever, dengue

4. Viral encephalitis due to influenza, pertusis, herpes simplex or Cyzomegalic inclusion disease

5. Bacterial endocarditis

5. Anthrax

7. Malaria

Intoxications

1. Hypertensive crises - pharmacologicaliy fnduced, as with adrenalin, monoamine oxidase inhibitors, and amphetamine

2. Alcohol

3. Ether

4. Carbon monoxide

5. Morphine, nicot: ne poisoning, hydrocyanic acid, lead, quinine, phosphorous, pentamethylenetetrazo1, amphetamine

6. Snake bites (Bothrops species)

7. Uremia

\section{Allergic Reactions}

1. Antibiotic sensitivity reactions

2. Multiple sclerosis

SUBARACRNOTD HEMORRRAGE ASSOCIATED WITH PREGNANCT

Tumors (see statement on Intracranial Tumors)

1. Gliomas

2. Pituitary tumors

3. Keningiomas

4. Pinealomas

5. Choroid plexus papillomas

6. Angioblastonas

7. Helanomas

8. Metastatic tumors 


\section{Craniacerebral Trauma}

1. Direct or Indirect blcws to head

2. Electrical injury

3. Calsson disease

4. High altitude anoxia

5. Radiation

6. Ultrasound

7. Strangulation

8. Thernsl infury

\section{Intracranial Venous Thrombosis}

1. Oral contraceptives

2. Pregnancy

3. Trauma

4. Infection

5. Coagulopathies

6. Marasmus

Dther Conditions

1. Physical stress-Valsalva's maneuver, as with coitus, defecation, parturition, etc.

2. Vitamin deficiency: scurvy, vitamin $R$ deficiency

\section{ANEURYSMS AND ARTERIOVENOUS MALFORHATICAS}

Sources of subaracinoid hemorrhage which are not visualized by repeated angiography may be:

1. Thrombosed 'berry aneurysu'

2. Atherosclerotic aneurysm

3. Cryptic AVM - thrombosed or otherwise obliterated by hemorrhage

Lack of Diagnosis

In various published series there has been a sizeable group of incividuals presenting with SAE and with negative contzast studies.

Complications

See section on subarachnoid hemorrhage (SAH).

Prognosis

If no cause for SAF is determined, an individual could safely resume fiying scatus, if conditions described in the SAH section are met, with the exception of angiography. The determination should be made one year after the SAI. 


\section{REFERENCES}

1. Millikan CA, Baver RB, Goldschmidt J, et al: Classification and outine of cerebrovascular disease, II. Stroke 6:566-616, Sept-0ct, 1975.

2. Matsumoto N, Whismant JP, Rurland LT, Okazaki H: Natural history of stroke in Rochester, Minnesota, 1955-1969: An extension of a previous study, 1945-1954. Stroke 4:20-29, Jan, 1973.

3. Cartlidge NEF, Whisnant JP, Elveback LR: Carotid and yertebral-basilar transient cerebral ischemic attacks: A comunity study, Rochester. Minnesota. Hayo Clinic Proceedings 52:117-120, Feb, 197\%.

4. Whisnant JP, Cartlidge NEF, Elveback LR: Carotid and vertebral-basilar transient ischemic attacks: Effect of anticoagulants, hypertension, and cardiac disorders on survival and stroke occurrence--A population study. Anin Neurol 3:107-115, Feb, 1978.

5. Adams GF, Merritt $J D_{,}$Mutchinson WM, et al: Cerebral embolism in nicrostenosis: Survival with and without anticoagulants. J Neurol, Neurusurg, \& Psychiat $37: 378-383,1974$.

6. Genton E, Barnett HJM, Flelds WS, et al: Cerebral ischemia: The role of thronosis and of antithrombotic therapy. Stroke 8:150-175, jan-Feb, 1977.

7. Fields WS, Maslenikov V, Myer JS, et al: Joint study of extracranial arterial occlusion. Y. Progress report of prognosis following surgery or nonsurgical treatment for transient cerebral ischeoic attacks and cervical carotid artery lesions. JAMA 211:3993-2003, 1970.

8. Surdt TM, Sandok BA, Whisnant JP: Carotid endarterectony. Complications and preoperative assessment of risk. Mayo Cilnic Proceedings 50:301-306. June, 1975.

9. Veterans Administration cooperative study group: Effects of treatrent on morbidity and hypertension. I. Results in patients with distolic blood pressures averaging 115 through 129 matig. II. Feswles in patients with diastolic blood pressures averaging 90 through $11:$ wnth. JAlfA 202:116122, 1967 and JAMA 213:1143-1152, 1970.

10. Hypertension-Stroke Cooperative Study Group: Effects of antihypertensive treatwent on stroke recurrence. JAMA 229:409-418, 1974.

11. Grillo P, Patterson RH: Occlusion of the carotid artery: prognosis (natural hisiory) and the possibiiities of surgicaj revasculation. Stroke 6:17-20, Jan-Feb, 1975 .

12. Fields WS: The asymptomatic carotid bruit--operate or not? Current Concepts of Cerebrovascular Disease 13:1-4, 1978. 
13. Pakarinen S: Incidence, etfology, and prognosis of primary subarachnoid henorrhage. Acta Heurol Seand (Supplenent 29) 43:1967.

14. Wimn HR, RIchnrdion AE, Jane IA: The Iong term prognosis in intreated cerebral aneurya: I. The inctdence of late howribage in ceretral aneurysa: A 10-year evaluation of 364 patients. An leurol 1:358-370, Apr11, 1977. 
mirsacrantal turozs - PANEL 2

Shelly N. Chou, MD (Chaiman), Richard s. Kramer, MD, William R. Shariro, MD

Cancer frequently affects the nervous system. ${ }^{1}$ Primary tumors of the central nervous system (CNS) are the second most common form of cancer in children, and primary brain tumors in adults are more common than Hodgkin's disease. In the 0.S. In 1977 there were 10,900 new cases of primary CNS vancer and 8,800 deaths. Of 690,000 new cancer cases, 385,000 patients died, and 50,000 of the deaths were directly associated with metastatic cancer to the nervous system. The buik of these consisted of lung cancer, breast cancer, valignant melanoma, lymphomas, and leukemias.

Tumors of the nervous system may be classified by location and pathology. Table 1 classifies intracranial tumors by location, ${ }^{2}$ and Table 2 classifies them by pathology.3,4 The bulk of tumors in the skull metastasize from cancer in other parts of the body. The major tumor of the meninges is the meningioma, and its importance lies in its being a potentially curable lesion. Acoustic neuroma is the most common of the cranial nerve tumors, but neuromas of the trigeminal nerve also occur, and such tumors can be part of the synurome of von Recklinghausens' disease.

Neuroectodermal tumors occur in the cerebrum as astrocytomas, oligodendxogliomas, and the more malignant giloblastoma in itiforme. In the cerebellum, they are represented by the medulloblastoma and the more benign astrocytomas. In the brain stem, they occur as ependynomas or as gliomas. Other locations for tumors in the skull include pituitary tumors, especially the pituitary adenoma, and congenital tumors, like craniopharyngiomas and mixed-tissue tumors. Tumors metastatic from systemic cancer may be found in the cerebrum or cerebellum, or in the meninges in the form of meningeal carcinomatosis. As noted above, they can invade the skull, and occasionally they may be found in the epidural and subdural spaces.

Pathologically, so-called benign tumors ${ }^{5}$ are those that may be defined as slow-growing, with few mitoses, minimal necrosis, and no endothelial proliferation (Table 2). They may arise in the dura, where the most comon is the meningioma, or in the nerves, as with the acoustic neuroma. In the parenchyma, the neuroectodermal "benign" tumors consist of low-grade astrocytomas and oligodendrogliomas. "Benign" astrocytomas and oligodendrogliomas may become malignant.

More "malignant" tumors arise primarily as neuroectodermal cumors, of which the most malignant tumors are the astroblastoma and the primiry reticular cell sarcoma or microglioma. Gliomatosis cerebri is also thought to be a moderately malignant, progressive neuroectodermal tumor. Malignant tumors are characterized by relatively rapid growth, invasiveness, frequent mitotic figures, necrosis, vascular prolifexation, and endothelial hyperplasia. Benign tumors of the dura and serves rarely become malignant and form meningeal sarcomas and neurofibrosarcomas. Occasionally, tumors of neuroectodermal and mesenchymal origin may combine in the form of a maiignant gliosarcoma. 
Table 1: Classification of Intracranial Tumors by Location*

1. Tumors of the Skull

setastatic tumors

eosinophilic granuloma

2. Tumors of the Veninges

meninglome

neningeal carcinonatosis

3. Tumors of the Cranial Merves

acoustic neurona

4. Neuroectodermal Tumors

Cerebral -

astrocytoma

oligodendroglioma

glioblastoma

Cerebellar -

medulloblastoma

astrocytoma

Brainsten -

glioma

ependymoma

5. Other Primary Tumors

pituitary adencesa

congenital tumors

granulonas

6. Metastatic

Parenchymal tumors

*From ref. 2 
Table 2: Classification of Intracrantal Twors by Pathology*

\section{Definitlons:}

"Benign" tuars - slowly growing, with few aftoses, aininal necrosis, and no vascular prolfferation; affect dura, nerves and neuroectoderm.

"Malignant" twors - more rapidly growing and invasive, with frequent mitoses, necrosis, vascular proliferation, and endothelial hyperplasia; affect neuroectoderm, rarely dura and nerves.

Neuroectodermal
astrocytoma
oligodendrogliona
glioblastoma
ependymoma
nedulloblastoma

Other Tumors
neningioma
neurofibroma
neurilenimoma
pituitary adenoma
craniopharyngioma
other congenital tunors
metastatic:

*From references $3-5$ 


\section{CLINICAL MANIFESTATIOKS OF MITACRANIAL TUEORS}

In the discussion that follows, an attempt is ande to establish wedical criteria for functional impairment of alrmen. Four classes of impairment are defined in Table 3, based on the probebility of nedical inpairnent of function likely to affect aircraft control, the probable extent of medical care required, and the likelihood circumstances will produce impairnent of neurologic function suffictent to require medical disqualification from flying status. The following discussion will refer to these classes along with the sympton complex which produces the impairment.

The essential clinical feature of intracranial neoplasms is that they produce progressive symptons. The rate of progression varies, and the course may include acute apoplectic onset following hemorrbage into a neoplasm, a seizure disorder assoctated with cortical stimulation, and a slowiy progressive mental deterioration associated with certain slow-growing neoplasms. The clinical manifestations may be defined as general and specific.

\section{General Clinical Manifestations of Intracranial Neoplasms}

Such symptoms depend on the effect of the neoplasm mass wich produces raised intracranial pressure associated with edema, 6 obstructive hydrocephalus, and generalized cerebral dysfunction of unknown causes.

Headache is perhaps the most conmon geteral nanifestation of intracranial neoplasm. Of special importance are headaches that have recentiy changed in clzaracter, are worse in the morning or wake the patient at night, are of a recurrent nature, and are increased by reduced atmospheric pressure. The occurrence of a headache in a patient not otherwise prone to headaches, or a recent change in headache pattern in patients known to have headaches, orfinarily requires that flight personnel be considered in Class A status (Table 3 ).

Papilledema occurs in about a quarter of the patients with intracranial neoplasms and, thexefore, its absence does not exclude such lesions. It is more likely to be seen with tumors that obstruct cerebrospinal fluid (CSF) flow, and it may be accompanted by visual phenomena, especially acute visual obscuration and "greying out." Papilledema should result in Class C status for flying personnel, who should be referred imediately for medical care and should be temporarily disqualified from operating an airplane.

Generalized convulsions, along with focai seizures (see statement on Seizure Disorders) occur in $35 \%$ of patients with cerebral tumors. 7 They are more likely to accompany slower growing tumors than the more rapidly growing malignant tumors. They are more likely to occur following alcohol usage, after withdrawal of barbiturates, drugs and other sedatives, or with sleep deprivation. Because of their apoplectic nature, they are of crucial importance in flight deck personnel, 2 and the occurrence of a generalized convulsion should place such personnel imediately in Class B status.

Mental changes 8 are frequent clinica? manifestations of an intracranial tumor. They are often subtie and gradual in onset and therefore require the close attention of coworkers and family members with regard to behavorial changes in the patient. Mental changes may include lack of persistence in 
Table 3: Relationshtp of Signs, Syuptoas, Diagnosis and Therapy of Cis Feoplases to Functionsl Prognosis of Personnel in Flight Crew

Class A - Signe, syptcas which do not interfere with function as member of tilight crew. Hedical referral required. Insediate disqualification frow flying not necessarily required.

Class B - Sigas, syptoms definitely impeiring function as member of flight crew. Inediate nedical referral required. Temporary disqualification from flying.

Class C - Signs, symptoas definitely impairing function as wember of filght crew. Extensive edical care required. Tengorary disqualification from flying.

Class D - Signs, syptans definitely impairing function as member of flight crew. Extensive medical care required. Permanent disqualification from flying. 
routine tasks, Increasing irritability, evotional lability, faulty insight, forgetfuiness, reduction in the range of mental activity, indifference to social practices, and reduced initiative and spontaneity. The patient may ccaplain of fatigue, tiredness, dizziness, and/or lethargy. There may be temporal retardation and delay in responsiveness of thinking and motor function, especially in the atmoshpere of a busy flight deck. Such syaptoms progress to confusion, frank denentia, and stupor.

Changes in personality may be described in psychological cerms but should be recognized as symptons of structural brain disease rather than functional anxiety or depression. Thus, the occurrence of sudden flamboyance, loss of inhibition, impulsive behav1or, and the cognitive changes Aascribed above should imediately raise the suspicion of a progressing intracranial neoplastic process. Depending on the severity of the mental changes, flight deck personnel should be classed from $B$ to $D$ in terms of flying status.

Specific or Focal Clinical Manifestations of Intracranial Tumors

These depend on the location and extent of the lesion. The following conditions are of specific interest with regard to airmen. Focal seizures are a frequent accompaninent of cerebral tumors. 2,7 They imply specific cortical irritation from either a benign or a malignant condition and require Class B status. A visual loss, either in terms of direct reduction in visual acuity, field defects or diplopia, implies involvement of the visual apparatus anywhere from the eye to the occipital cortex: flying status, Class B.

Hearing impairment may mean reduced auditory acuity or the occurrence of tinnitus and may be associated with vertigo. Local conditions, especially upper respiratory infections with blocking of the eustachian tubes, may produce temporary hearing changes. Hearing impairment of any duration should be considered grounds for Class B status. Speech disturbances, which may be transient, include dysphasia and dysarthria and should produce Class $C$ status.

Ataxia should be grounds for imediate placement on Class B status. Motor signs include postural disturbances, incoordination, weakness, tremor; flying status is Class B. Sensory disturbances include unusual pains, paresthesias or numbness and require Class B status. Less disturbing, but of importance with respect to local manifestations of cerebral tumors, are anosmia, which requires Class $A$ status and may be associated with infrafrontal meningicoas, and neuroendocrine disturbances, which require Class B status and may be associated with pituitary tumors.

Cerebral hemorrhage into metastatic foci, usually from choriocarcinoma, testicular tumor, melanoma, glioblastoma and, more rarely, other primaries, may manifest as subarachnoid hemorrhages. The apoplectic aature of such an onset would require Class D status. Less clearly defined are those focal features assoclated with temporal lobe neoplasms. Psychological concomitants and minor spells may be the earliest manifestations of neoplasms in this location. They require Class B status.

\section{SPECIFIC DIAGNOSTIC INVESTIGATIONS}

Once there is clinical suspicion an intracranial tumor may be present, specific diagnostic procedures must be employed to confirm its presence and 
exact location. Such investigations are not only neceasazy to maize therapeutic plans, but also tc obtain additional information about the type of txmor present and the potential risks if surgical rewovel of the lesion is to be carried out.

There are any types of diagnostic techniques availables varying in degree of ccaplexity and invasiveness. Depending upon clinicai sanifestations which nay suggest certain type of tumor in a certain intracranial iocation, a siagie study or a sertes of diagnostic studies may be planned. One typs of prosedure way be zore useful in gathering infornation than another, and it is important to seek the aost specific information whenever possible.

Cranial s-ray - This is the most non-Invasive procedure in neuroradiology. A routine examination may yield infornation such as evidence of chronically increased intracranial pressure, the presence of abmormal calcifications, enlargement of the sella turcica indicating a tumor of the pituitary gland or an "ewpty sella," or the presence of osteolytic and/or osteoblastic lesions in the skull, which indicate a metastatic process and call for an extensive search for the primary lesion.

Tomography of the skull can be very useful in further delireating certain intracranial tumors. Usually such tumors are located in or close to the bone and are sellar or parasellar tumors, basal meningiomas, chordomas, acoustic nerve tumors and metastatic tumors, particularly those extending upward from the nasopharynx.

Computerized tcoography (CT scan) - The introduction of CT scan has revolutionized the entire investigative process for intracranial tunors. The procedure is non-invasive and is capable of yielding so much information that it may well be the only procedure necessary to reach a reasonably accurate diagnosis.

Intracranial tumors may appear on the CT scan as radiolucent, radiopaque masses. Frequently, both components are present, with a central radiolucent area surrounded by radiopaque zones forming the so-called "ring sign." Such a mass may cause ventricular shift. A surrounding zone of cerebral edema may also be evident. With a tumor in the posterior fossa, not only can the turror be seen in the CT scan, but also the associated hydrocephalus, if present, can be demonstrated.

Most importantly, the $C T$ scan is capable of demonstrating multiple small metastatic tumors which have heretofore been exiremely difficult to document. Finally, because of the measure's noninvasiveness, it is the logical technique with which to follow intracranial tumors postoperatively, especially for tumor recurrence.

It is to be cautioned that the CT scan, versatile as it is, may still fail to datect certain types of intracranial tumors, like small schwannomas of the cranial nerves and certain infiltrating henispheral gliowas. Also, an area of infarction and a tumor nay appear to be identical on the CT scan. Therefore, other types of contrast studies may still be necessary and important is reaching a radiologically unequivocal diagnosis of intracranial tumor. 
Anglography - CT scan has undoubtediy ade anglography less important in the diagnosis and locallzation of intracranial twors. It is desirable, however, to conduct anglographic studies to vistelize the pattern of vascular supply and drainsge in order to facilitate surgery. In certain basal, highly vascular meningionas, preoperative selective catheterization may be employed to ebolize, and thus drastically reduce, the vascularity of the tumor to make subsequent surglcal removal of the tumor less bloody. The mural noinle of a hevangioblastoma can be brightly shown with anglography. For vascular lesions such as A-V malformations, fistulae, and aneurysms, angiography is obviousiy indispensable for diagnosis and for preopurative planning. Rarely, a giant thrombosed aneurysm way be mistaken for a tumor mass. Vascular lesions are considered in the preceding report.

Pneumoencephalography - Use of this procedure has been significantly curtailed due to wide availability of the CT scan. However, lesions such as chromophobe adenowas with suprasellar extension may require the procedure in order to ascertain whether the operarive procedure showld be transcranial or transphenoidal. Additionally, certain cystic lesions such as porencephaly, and midline anowalies such as cyst of septum pellucidum and cavim vergae, may require pneumoencephalography to differentiate them from tumors.

Nuclear scanning and Emission CT scan - The former is rarely used now because of CT scan, while the latter is a new technique of which the use and value for tumor diagnosis has not been well established.

Electroencephalogram (EEG) - This is not a preferred procedure for diagnosing and localizing a brain tumor, compared with the procedures already described. Patients having brain tumors with seizures as the initial clinical manifestation may or may not have abnormal EEG findings. The EEG may be used in a selected patient as a postoperative followup procedure.

Lumbar puncture - Usual'y lumbar puncture is not used, and in fact it is contraindicated in most patients who have clinical evidence of increased intracranial pressure. In certain conditions such as leptomeningeal carcinomatosis and leukemic infiltrations, CSF chemical analysis and cytologic study may yleid extremely useful information. Shen combined with clivography using pantopaque, small tumors less than $1 \mathrm{~cm}$. in diameter which may evade $\mathrm{CT}$ scanning, like schwannomas, can be demonstrated.

THERAPY OF INTRACRANIAL TUMORS

Surgical Therapy of Intracranial Tumors

Factors influencing the decision to operate - A brief discussion of surgical treatment should perhaps begin by enumerating those factors which influence the surgeon's decision to recomend operative intervention. Since no two patients are identical, medical decisions invariably are multifactorial. The skill with which the neurosurgeon appropriately weighs the several consicerations defines "purgical judgment" and profoundly influences the results; these considerations will be discussed in descending order of importance: 
Profected operative nortality/norbidity - The historical admonition, "Primin, non nocere," uniquely dominates the neurosurgeon"s thinking. Neural tissue is characterized by its vulnerability to permanent injury by compression or retraction, its fragile vassularity, its absolute dependence on maintenance of adequate moment-tomowent perfusion, and its profound lack of regenerative capacity. Neurologic deficits resulting from either deliberate resection or inadvertent compression or devascularization of the brain commonly prove 1rreversible. If the volume of injured tissue is either (a) extensive, or (b) focal, but sttuated in a neural "center" subserving a critical function, such as speech, vision, or respiration, either death or devastating permanent morbidity may be expected. For these reasons, even in skilled surgical hands the location of the tumor is ordinarily the prime determinant of the operative result.

In general, intracranial tumors arising outside of the brain substance, such as extra-axial tumors from the bony skull (benign osteowa), the meningeal coverings of the brain (meningioma), or the cranial nerves (neurinomas), are histologicaliy benign tumors which exert their effect upon adjacent neural structures by compression rather than invasion. Those occurring over the cerebral or cerebellar convexities, most comonly meninglona, are readily accessible and can ordinarily be removed with nearly total preservation of contiguotis brain tissue.

Other benign extra-axial tumors, however, arise deep within the skull in the vicinity of the brain stem, a structure whose functional integrity is vital to survival. Certain areas of the brain stem are essentially inaccessibie and vexingly encircled by an impressive number of critically important vascular structures. Examples of this type of timoz include benign acoustic neurinomas, meningionas situated in the anterior foramen magnum or clivus, and craniopharyngtomas, which commoniy adhere to important neural structures about the third ventricle. Despite the benign character of these lesions, their anatonic location often renders surgical removal hazardous, and total resection is sometimes not possible. Occasionally, benign extra-axial tumors, such as meningiomas, occur in noncritical regions remote frow the brain stem but become so intimately involved with major blood vessels, like the sagittal sinus or a carotid artery, that complete removal is precluded by the risk of major ischemic Injury to the brain.

In contrast, intracranial tumors arising within the substance of the brain, either as primary brain tumors (gliomas) or as metastatic deposits within the brain, are combonly characterized by a variable degree of malignant potential, and surgery rarely provides a permanent cure. Since their removal necessarily involves some resection of adjacent normal brain tissue, their location is a major determinant of operative morbidity.

At one extreme, tumors contained within so-called "silent areas" of the brain can be widely resected with little risk of neurologic impainant; for exxmple, large volumes of tissue can be removed from one or the other of the frontal or temoral lobes or from the cerebellar hemispheres without significant risk of creating afditional deficit. At the other extreme, those occasicnal intrinsic tumors arising within the brain sten, like pontine or medullary gliomas, are rarely attacked surgicaliy because of the high probability of substantial morbidity or mortality. Midway in the spectrum are those hemi- 
spheral tusors Wich happen to involve major motor, sensory, visual, or speech pathways. Jnless the tumor itself has already destroyed these functional areas by wide local infiltration, attempts at surgical resection can be expected to result in further impairment.

Recognizing the high rate of recurrence of intra-axial brain tumors, the aurgeon, wisely, may elect to content himself with subtotal removal rather than Iisk injury to vital functional centers or major blood vessels.

A second, but somewhat less important, consideration bearing on projected operative mortality and morbidity is the size of the tumor. Certainly, the risk of an adverse outcome Increases with the size of a tumor In any given location simply as a consequence of the need for more extensive manipulation of adjacent normal tissue, the higher probability of involvement of vital neural centers or major blood vessels, and the longer probable duration of the procedure itself.

The patient's age and general condition may weigh against surgery, although improved anesthesia and operative techniques have served to extend, in recent years, the "age limit" approprlate to major surgery. In this connection, the patient's physiologic age is a more valid criterion than chronologic age, and the surgeon is more likely to be guided by that elusive quality known as general condition.

The presence of concurrent systemic disease is a factor that bears more on the risk of anesthesia than on that of surgery itself. Certain systenic disordere are benign and self-limiting, such as viral infections, and elective surgery can simply be deferred for an appropriate interval. Others, like emphysema and chronic renal disease, present a serious and persistent risk to the patient but ordinarily can be managed with considerable success throughout the brief operative and postoperative interval. On the other hand, certain stages of advanced or untreatable systemic disease, like widespread carcinomatosis and intractable cardiac failure, may absolutely preclude operative treatment of a coexistent intracranial tumor.

Fina11y, modern anesthesia has made sufficient strides in recent years so as to preclude estimated operating time as a major consideration in the decision to operate, except insofar as evidence suggests the incidence of operative wound infection is directly related to the duration of the surgical procedure. 9

Probability of cure - Balanced against the risk factors delineated above is the surgeon's estimate of the probability of achieving a cure by operative intervention; here, the word "cure" refers not only to neurologic restoration, but also to the permanent prevention of tumor recurrence.

As suggested above, the benign extra-axial tumors, eg, peningiomas and nevrinomas, provide the greatest opportunity for complete resection. Included in this group are benign adenomas of the pituitary gland (mailignant pituitary tumors are extremely rare), which slowly may grow to remarkable size accompanied by progressive impairment of visual and endocrinologic function. Some of these tumors, by hypersecretion of one or another of the trophtc hormones, 
may produce well-defined somatic syndromes, like amenorrhea-galactorrhea, Cushing's disease, and acromegaly which perwit detection earIy in their development, enhancing the probability of complete resection. 10,11

Significantiy fewer intra-axial tuncrs lend themselves to complete resection. Beniga cerebellar herangloblastomas, choroid plexus papillomas, and certain types of intrinsic eystic tumors of the brain, such as colloid cysts of the third ventricle and some "pinealomas," ordinarily prove completely removable. Solitary brain metastases usually are resectable, a1though permanent cure of the underlying systemic malignancy is only rarely reported following selective removal of the primary tumor and a single cerebral metastasis.

The gliomas are oncologically unique, and their surgical wanagement is almost invariably frustrating. Whatever unknown factors induce neoplastic transformation of glial tissue, their effects are exerted more diffusely in the brain than histologic examination of the cargins of a surgically resected glioma would indicate. Consequently, "complete resection" of even a small, focal glioma by no means precludes recurrence, regardless of the malignant potential of the tumor; indeed, recurrence is the rule rather than the exception.

The foregoing discussion properly implies that the decision to operate is significartiy influenced by the known natural behavior of the presured tumor type. Some extra-axial tumors and nearly all gliomas possess the potential for malignant degeneration. Fortunately, in the common extraaxial tumors, such as meningiomas or neurinomas, sarcomatous transformation is infrequent. Similarly, the most benign of the gliomas, the carebellar astrocytoma, rarely undergoes malignant change; indeed, this single tumor among gliomas is ordinarily completely resectable and possesses a very low natural frequency of recurrence, rendering it the only glioma which is almost uniformiy cured by the neurosurgeon.

In contrast, the other common cerebeilar giioma of childhood, the medulloblastoma, which may sometimes be found in adults, is usually hignly malignant, incompletely resectable, and recurs so routinely that survival beyond six to eight years is exceptlonal. The glioblastoma multiforme represents the endstage of malignant transformation of cerebral gliomas and is virtualiy never cured.

Those gliomas intermediate in the spectrum include astrocytoma, ependymoma, oligodendroglioma, and microglioma; these tumors are more or less completely resectable but demonstrate a very high natural frequency of recurrence and, given sufficient time, a significant propensity for malignant degeneration into glioblastoma, ependymoblasisma, oligodendroblastoma, and other forms.

In view of the above, the efficacy of alternative adjunctive therapeutic measures must be weighed in the decision to recomend surgery. Fortmost among these is radiatici therapy, which is considered later in some detail. Intracranial tumors in general are regarded as nore or less resistant to radiation therapy, with the single exception of pituitary adenomas, and this modality is commoniy reserved for palliative or postoperative use. 
Finally, the probability of cure diminishes dramatically with the discovery of multifocal or disseminated tumor. The comon extra-axial tumors such as meningioma, neurincma, and optic glioma may occasionally arise in multiple Iocations, particulariy in association with von Recklinghausen's disease. Among the intra-axial tmors, glionas are rarely multifocal, except in rare cases of tuberous sclerosis and microgllomatos: $:$.

The finding of multiple intracranial metastases from remote malignancy ordinarily precludes surgical intervention. Similariy, certain of the gliomas, such as ependymoma and medulloblastom, ik.. isseminate in subarachnoid pathways throughout the neuraxis from a si $i$ tocus of tumor, a phenowenon similar to meningeal carcinomatosis. ' . or term prognosis in each of these latter instances is poor.

Potential for restoration of impaired CNS Iunction - From the patient's viewpoint, the decision to under 0 surgerv is verhaps most strongly influenced by the perceived prospect for recovery of impaired neurologic function. The neurosurgeon is more often preoccupied with the principle that, in the abscence of any treatment, observed neurologic deficits will invariably worsen. Encased by the bony skull, the intracranial compartment possesses negligible compliance, and as a result, gradual increases in tumor volume ultimately produce increased intracranial pressure. When intracranial pressure begins to approach systemic arterial pressure, a global perfusion deficit becowes manifest as a diffuse encephalopathy, leading to coma and ultimate death; in other words, regardless of degree of malignancy, all intracranial tumors are potentially lethal if left untreated.

In this confection, the prohability of reversing any neurologic deficit occasioned by tumor depends in large measure upon the degree to which the deficit is caused by localized or generalized compression. In fact, it may be stated as a general principle that to whatever extent an observed neurologic deficit is a direct consequence of pressure-related phenomena, it may be surgically reversible; to whatever extent a deficit is secondary to direct i. filtration and destruction of brain tissue by the tumor in question, surgical resection cannot be expected to improve the situation and may, as heretofore noted, produce further neurologic impairment.

Palliative value of surgical decompression - In many instances where permanent cure or reversal of major neurologic deficit cannot be expected, there may nevertheless be considerable merit in undertaking a subtotal resection of the tumor mass for purposes of palliative internal decompression. Patients harboring benign tumors which for one reason or another are nonremovabie may be given added years of useful life by repeated decompressions performed at appropriate intervals. In sontrast, palilative decompression is ordinarily considered only once in the course of treacment of malignant brain tumors, kecause the quality of survival late in the patient's course rarely justifies repeated surgery, 12,13

Tumors occurring in the midline of the brain caudal to the sites of CSF production in the lateral ventricles may obstruct CSF flow which can result in internal hydrocephalus. Some of these tumors are surgicaliy irresectable by virtue of location, snd in other cases removal of the tumor does not invariably relieve the obstruction. Obstructive hydrocephalus is characterized by progressive increase in intracranial pressure, frequently to levels incom- 
patible with Iffe, as spinal fluid accumulates proximal to the site of obstruction. In such instances, surgical decompression is comoniy afforded through a shunt procedure, in inich a conduit usualiy fabricated of silastic tubing is introduced into the lateral ventricle and directed around the point of obstruction into one or another body cavity capable of absorbing or otherwise disposing of the excess cerebrospinal fluid. The most common sinunt procedure in use today is the ventriculo-peritoneal shunt, although such diverse distal sites as the cisterna togna (ventriculo-cisternal shunt), pleural cavity (ventriculo-pleural shunt), aid the heart itself (ventriculo-atrial shunt) may be used for this purpose.

Desirability of histologic confirmation - Frequently the surgeon decilies to operate in order to obtain histologic evidence of the suspected tumor's character. Although modern neurodiagnostic techniques permit the accurate definition of probable tumor type with unusual eccuracy, no procedure available today will invariably distinguish among nonoperative intracranial mass lesions, such as stroke lesions, those which nearly always denand surgical intervention, like brain abcesses, and intrinsic turors, for which surgery may or may not be appropriate depending on considerations detailed above. Furthermore, it may be difficult to distingush by nonoperative means a benign tumor, like meningiowa, which could be removed easily with minimal risk, from a malignant tumor for which there is little hope of long-term survival and little justification for attempted resection.

Even in those instances where the general character of the turor can be predicted with reasosable accuracy without surgical intervention, direct histologic evidence about the precise nature of the tunor usually provides the basis for an intelligent prognosis for both patient and fanily and indicates the probabie efficacy of radiation therapy or chemotherapy.

Operative Technigues - Before discussing in linted detail the various techniques commonly employed in brain tumor surgery, brief mention should be made of certain adjunctive methods used to enhance the conduct of the surgical procedure. Many surgeons enploy high-dose steroids for several days before and after operation, in order to miniwize the cerebral edema which characterizes certain tumors and to reduce anticipated brain swelling following surgical manipulation.

During the course of the procedure itself, additional reduction in brain volume may be accomplished by rapid intravenous administration of osmotic agents such as urea or mannitol. The effect of osmotic agents becomes even wore evident when simultaneous drainage of the spinal fluid is accomplished through an indwelling lumbar catheter. These techniques are most valuable when resection of deep-seated extra-axial tumors would otherwise require significant mechanical retraction of the brain. Their introduction has exerted a profoundly favorable effect upon the surgical managenent of intracranial tumors.

At least equally significant, particularly in the surgery of deep extraaxial tumoss, is the increasing use among neurosurgeons of intra-operative magnification. Specially designed operating aicroscopes now provide ready sterecscopic visualization of otherwise inaccessible structures, substantially magnifled and brightiy illuminated. It is difficult to overestimate the significance of this development; certainiy, the morbidity and mortality sssoctated with surgical treatment of such tumors has decreased dramatically 
in the last decade or $\$ 0$ as a consequence.

Following is a brief description of the surgical techniques generally employed in the treatwent of intracranial tumors.

Craniotony - This is by far the most common approach to tumor in or around the cerebral hemispheres. As used by the neurosurgeon, the expression "craniotony", refers to the temporary removal of a portion of the sku11 en bloc, following incision and retraction of the overlying scalp, in order to provide access to the intracranial compartment. By definition, the "bone flap" is secured in position at the end of a craniotony. The size of the opening is directiy related either to the size of the tumor or to the degree of difficulty anticipated in ito exposure. The location of the opening, for example, in the frontal, temporal, parittal, occipital or suboccipital area, or combinations thereof, is generally determined by the surgical anatomy of the target region and by the curulative experience of generations of neurosurgeons in determining the safest and most expeditious route to a given point inside the head. 14

In general, a craniotomy rather than a craniectomy is parformed whenever the required bony opening is greater than an inch or so in diameter and does not lie beneath a layer of muscle, which could be expected to both protect and conceal the bony defect that would otherwise result.

Craniectomy - This tern refers to the permanent removal of a portion of the bory skull in order to gain access to the intracranlal compartment. Both for protective and cosmetic reasons, elective craniectories for tumor are largely limited to the suboccipital region, where the resultant bony defect is concealed beneath an extremely dense layer of muscle.

of course, an intended craniotomy may become a craniectomy, if for any reason the bone flap must be discarded because of developments during the operation itself. Occasienally in the course of a difficult operation, brain swelling may become so intense that repositioning of the bone flap might resuit in unacceptabie intracranial hypertension. In these cases an external decompression is afforded the brain by loosely grafting the dura and leaving out the bone flap. As another example, meningiowas may invade the overiying skull, requiring that all or a portion of the bone flap be set aside.

When an unacceptably laxge bony defect is left following surgery, elective cranioplasty usually will be undertaken later.

Other operative approaches - Several less commonly used surgical approaches have been developed for the treatment of certain extra-axtal tumors. Among the most important of these is the transsphenoidal approach to certain of the pituitary tumors, some of which are either quite small (microadenomas), or have had intracranial extension directly above the sella.15,16 Occasionaliy, the anatomic disposition of a small pituitary tumor may Iend itself to an alternative transethmoidal approach. 17 A few neurosurgeons who are particularly adept in these techniques have applied thelr use in treatment of other types of parasellar tuwors, such as craniopharyngioma and meninginma. 
The translabyrinthine approach to acoustic neurinomas was originally developed for otologic management of smali tumors contained entirely within the internal auditory canal.18 The operation has been embraced by many neurosurgeons and is sometimes employed in selected cases characterized by limited tumor extension into the intracranial cerebellopontine angle. 19 Like the transphenoidal approach, translabyrinthine surgery is rendered possibie by developments in operative magnification.

Certain extracranial tumors occasionally extend into the cranial compartment, and rarely vice versa; these may require a combined operative approach. The most prominent examples of such procedures are the transorbital/frontal craniotomy approach to optic nerve gliomas extending toward the chiasm, and the maxillofacial/frontal craniotomy approach for the purpose of block resection of malignancies arising in the paranasal sinuses or nasopharyngeal region.

Keedle biopsy - Heedle biopsy of an intracranial tumor way be performed through a very small opening in the skull or trephine. This is a controversial procedure, with numerous advocates. Its conscientious application is generally limited to a patient whose diagnostic studies point to the presence of malignant glioma, for which histologic confirmation of the diagnosis is considered highly desirable, but which has a bleak prognosis rendering ethically untenable a major operative procedure. The controversy arises from the deficiencies in the technique: first, gliomas are characteristically not homogeneous in their pathology, and a small tissue sample may not be representative of the tumor as a whole; second, there is an ever present risk of iatrogenic intracerebral hemorrhage, a complication not easily controlled through the intact skull; finally, opponents of the technique argue there is almost always some measure of benefit to be gained by judicious subtotal resection of malignant gliomas, such as internal decompression, which may prolong survival.

Shunt procedures - The indications for the various shunt procedures are described elsewhere (see "Hydrocephalus and Shunts" section in statement on Head Injuries); the procedures themselves are relatively simple. In all instances relevant to the treatment of intracranial tumors, the purpose is to decompress the lateral ventricles by diverting the CSF formed there around a site of obstruction in the CSF pathways to a location where reabsorption of the CSF can occur continuously. The proximal end of a plastic catheter is directed into the frontal horn of one of the lateral ventricles through a small trephine opening. Ths distal end is then tunneled subcutaneously to the chosen absorption site.

In one such procedure, the ventriculo-cisternal or Torkildsen shunt, this site is the cisterna magna, with the result that the shunt mechanism is entirely intracranial and presumably less subject to malfunction as a consequence of somatic growth, minor trauma, or systemic infection. However, exposure of the cisterna magna requires a small suboccipital craniectomy, and consequently a less tigorous procedure such as ventriculoperitoneal or ventriculoatrial shunt is more frequently employed. Most shunting systems inciude a device by which an estimation of the system function can be made by noninvastue cilinical examination by a physician knowledgeable about the characteristics of that parifular system. 
Cranioplasty - Operations for Intracranial tumors may result in creation of an unacceptably large skull defect. Restoration of the anatomic integrity of the skis11 can be accomplished efther by delayed replacement of the original bone flap, or by fllling the defect with a rigid, nonreactive synthetic waterial which is properly contoured to duplicate the excised sku11. The naterials most commoniy used for this purpose are methyl methacrylate and tantalum alloy, and the operation is referred to as a cranioplasty.

The procedure 18 generally straightforward; eomplications are few and largely related to the propensity of implanted forelgn materials to provide a nidus for the developwent of late infection.

\section{Surgical Complications}

Hemorrhage - Meticulous attention to hemostasis should characterize intracranial surgery, including tumor surgery. Intraoperative hemorrhage during the course of a neurosurgical procedure can almost invariably be controlled, and except for the occasional intrusion on a major artery or venous sinus, the risk of exsanguination during the course of brain tumor surgery is trivial. Of far greater concern is the damage inflicted on the brain by the hemorrhage and particulariy by the surgeon's attampt to staunch it. Especially devastating is the deep intracerebral hemorrhage that can occur away from the operative field as a consequence of traction on the parent artery. Few visions in surgery are more ominous than the explosive expansion of a cerebral hemisphere as a unseen arterial hemorrhage dissects its depths. In such an event, death or a lingering death, is almost inevitaile.

Postoperative hemorrhage, while infrequent, is an ever present threat during the first 72 hours after surgery. Its occurrence is indicated cIínicaIIy in ear'y postoperative hours when a patient fails to arouse appropriately from anesthesia, and later, by gradual reversal in the recovery process, with the development of progressive obtundation and focal neurologic deficit. Because postoperative hemorrhage is usually venous in origin and is subdural or extradural and extrinsic to the brain substance Itself, the gradual accumlation of hematoma is often insidious; deterioration ordinarily proves reversible if surgical evacuation is undertaken without delay.

Brain edema - The brain is depressingly susceptible to the development of alginificant edema in response to a variety of noxious influences. 20 Microscopically, the accumulation of edema fluid may occur in either the interstitial or in the intracellular compartaents ${ }^{21}$; macroscopically; swelling may be so severe as to constitute a significant mass lesion.

Intracranial tumors routinely stimulate the development of edema in adjacent normal brain. This phenomenon most typically characterizes in'raaxial tumors such as gliomas and metastatic deposits, and the inechanism appears to be cytopathic. In general, the volume of edema appears directly related to the degree of malignancy of the tumor and is most intense in the vicinity of metastases and at the margine of glioblastoma multiforme.

Edema is somewhat less frequently observed in neural tissue contiguous to extra-axial tumors, In which cases the pathologic mechanism may be chronic venous corpression. Significant brain swelling can also be simulated during 
surgery by nechantcal retraction, through ischemia and venous compression and by manipulation of brain tissue itself. Intraoperative overhydration may intensify its development.

Edema is aore easily prevented than treated. As discussed above, judicious use of high-dose steroids and intravenous oswotic agents are comonly effective in minimizing this complication. Therefore, surgical decompression by resection of edematous brain is seldom necessary.

Infection - Operative sound infection is a major, albeit infrequent, complication of brain tumor surgery. Because most surgical infections occur as a consequence of alrborne contamination, their incidence in neurosurgery correlates closely with the duration of the operation. The infecting organiom is usually a varfety of gram-positive coccus, notably Staphylococcus. The focus of infection may be superficial or deep, and its clinical presentation may be either dramatic or indolent. Chronic osteomyelitis of the devascularized bone flap is a common site of wound infection.

The risk of infection may be heightened by prolonging the operative prosedure, the implantation of forelgn material, such as cranioplasty or shunt tubing, the presence of concurrent systemic infection, the use of drains for more than a few hours postoperatively, and urglcal failure to debride devitalized t1ssue. Treatment of operative infection should be aggressive, combining the use of appropriate systemic antibiotics and adequate surgical drainage and/or debridement, with removal of forelgn bodies.

The routine use of prophylactic antibiotics in brain tumor surgery is not widespread among neurosurgeons, except when intrusion into a paranasal sinus is anticipated.

Increased neurologic deficit - Transient worsening of a preexistent neurologic deficit is often observed during the immediate postoperative period and relates to certain self-limiting effects of the operative procedure, including neural compression and retraction and focal edema. Perwanent iatrogenic worsening is distinctly less common; although sometimes unavoidable, it must be considered a surgical complication.

Although brain tissue has essentially no regenerative capacity, "plasticity" and complex adaptations within the CNS often pernit progressive functional improvement over a period of many months after injury, rendering obscure the temporal distinction between a transient and a permanent postoperative deficit. Nevertheless, the physician is often called upon to estimate that point in tise at which maxim recovery is ordinarily achieved; in general, deficits persisting 6 to 12 months after the operative experience are likely to be permanent.

Seizures - The probability of a postoperative seizure disorder in "ay given patient is directly related to the occurrence of seizures prior to tumor renoval, a consequence of the fact thot opileptogenic foci are not contained within the tumor itself, but result from irritation of the contiguous brain. Such foct develop far more comonly in the cerebral cortex than in deep structures. Moreover, it has been noted that certain tumors characteristically otimulate the development of epileptogenic foct, for example, meninglomas, gllowas, and metastatic deposits, while other tumors, such as those of cerebellum and pituitary, zarely do 80 . 
The development of seizures postoperatively may also be influenced by surgical technique, because the exuberance of the healing process is thought to be directly related to the volume of injured tissue left behind, with the result that intense gliosis can lead to the development of an epileptogenic cicatrix.

Cerebrospinal fluid leak - Occasionally in approaching an intracranial tumor, the surgeon enters a paranasal sinus or mastoid air cell, either inadvertently or deliberately, as when using a transsphenoidal procedure. If the cormunicating structure is not adequately isolated, and particularly if the dura is not closed "water-tight," It may serve as a conduit for egress of cerebrospinal fluid, resulting in rhinorrhea or otorrhea. Under these circumstances, the bacterial flora of the nasopharynx may gain access to the intracranial compartment; such patients are continuously at risk for development of pyogenic meningitis. Fortunately, this complication is rare in tumor surgery, but its early recognition is mandatory. Appropriate treatment almost invariably requires surgical reexploratior and closure of the leak.

Neuroendocrine disturbances - Most, if not all, endocrine activity appears to be mediated directly or indirectly by the central nervous system through the hypothalamic-pituitary axis. It is therefore not surprising that intram crantal operations, including tumor surgery, occasionally can be complicated by the development of one of several neuroendocrine deficiency syndromes. The risk of such a development increases dramatically when the operation is performed in the region of the third ventricle, hypothalamus, and pituitary itself.

Surgical resection of large pitultary adenomss and other parasellar lesions often results in permanent panhypopituitarism, which requires the patient to be maintained indefinitely on hormone replacement therapy. In contrast, sma11 adenomas can be completely removed using modern techniques with a very low incidence of this complication.

Another distressing complication is diabetes insipidus, which usually results from ainor injury to the hypothalamus or proximal pituitary stalk during the course of craniopharyngioma resection. Fortunately, this complication is often transient and can be maned with relative ease by periodic administration of natural or synthetic vasopressin.

Finally, the syndrome of inappropriate antidiuretic hormone (ADH) secretion is occasionally seen after any type of brain surgery, although it is more commonly associated with generalized head trauma. The mechanisms underlying this syndrome are poorly understood, but its recognition early in the postoperative period is extremely important, because the inappropriate retention of free water enhances the development of cerebral edema and depresses neurologic performance by dilution of extracellular electrolytes. Rigorous fluid restriction is usually sufficient to manage this conaition, which rarely persists for more than a few weeks. 22

Camunicating hydrocephalus - Just as intrinsic midine tumors physically may impede CSF circulation within the brain substance causing "obstructive bydrocephalus," functional derangements of spinal fluid reabsorption also may 
result in progressive accumulation of CSF accompaniad by ventricular dilatation and intracranial hypertension, a condition known as "cowmunicating hydrocephalus." This disorder is soaetimes seen following brain surgery and is presuned to result from the soillage of blood into the subarachnoid pathways, with secondary impairment of CSF absorption by the arachnold villi.

Cosmunicating hydrocephalus probably occurs more often than is commoniy realized, since its effects are subtle and ordinarily self-liniting. However, on occasion the condition persists and requires surgical relief. Predictably, one or another of the shunt procedures provides decompression. The chofce of procedure is somewhat limited by the fact that the absorption defect lies distal to the clsterna magna, precluding the ventriculocisternal shunt.

In any case, the presence of a shunt should not, in and of itself, disqualify an individual from licensure or flight duty. Rather, the underlying disease process for which the shunt was performed, or the development of known conplications associated with the shunt system, like infection or shunt malfunction, should be the prime determinants of an individual's fitness for flying.

In sumary, surgery for intracerebral tumors has five goals ${ }^{23}$ : 1. diagrosis; 2. relief of symptoms, espectally those arising from increased intracranial pressure; 3. debulking of tumor as a form of anticancer therapy; 4. permitting time for radiation and early chemotherapy; and 5. increasing tumor susceptibility for the latter modalities by increasing the relative percentage of active cells. These goals, along with other factors relating to a recomendation for surgery, will be discussed below.

\section{Medical Therapy of Intracranial Tumors}

Corticosteroid hormone therapv for intracranial neoplasws constitutes the most important initial treatment modality. Steroids appear to work by reducing edema and almost always improve general clinical condition. Although somewhat less effective against spectfic clinical manifestations, they may still improve weakness and stabilize ataxia, and they of ten are important in reducing seizure activity.

Anticonvulsants are of obvious importance for patients who have seizures, and any patient who presents with generalized or focal seizures is I1kely to be on anticonvulsants for prolonged periods perhaps extending three to five years. Patients who do not have seizures as part of their initial manifestation of intracranial neoplasm usually do not require long-texm anticonvulsant therapy. Since the likelihood of a seizure following clean neurosirgical intervention is low, it is usually not necesiary to maintain such patients on anticonvulsants. It is cructal wits patients who have frequent seizures, however, to have anticonvulsant blood levels measured regularly and to ascertain their compliance in taking the anticonvulsancs. Seizures occurring late after primary therapy for intracranial neoplasms suggest recurrence of tumor and should imediately lead to reevaluation of the patient's status. 
Endocrine replacement is sonetimes neceasary following treatment of pituitary adenomas and includes anterior pitultary hormores, cortisone, thyroid and androgen, estrogen, and pitressit. for diabetes insipidus as required. Once the pat'ent's condition has stablized, prudent use of replacement therapy need not constitute a restriction to flying. Periodic evaluation at 6 to 12 months intervals should be required.

Badiation therapy (RT) often implies a noncurative situation and is utilized primarily for malignant tumors. 24-29 Such tumors are usually treated by whole-head or large field RT ports for total radiation up to 6,000 rads. RT has been recommended as a form of treatment in low-grade gilowas, $30-32$ but the efficacy of such therapy has not yet been proved. Such radiation is usually limited to the region of the tumor, and total doses rarely exceed 5,000 to 5,500 rads. $R T$ is the therapy of choice for most metastatic brain tumors ${ }^{33}$ and is an important form of treatment in a patient with cancer who develops a metastatic CNS complication.

Certain tumors, for example, pituitary adenoma and dysgerminoma, frequently are cured by radiation therapy.

Late complications of radiation therapy may produce symptoms of brain dysfunction independent of tumor recurrence, and therefore, the use of radiation therapy requires 6 to 12 month follow-up evaluations.

Chemotherapy is still an experimental modality for the therapy of malignant turors, 22-30 and it requires close supervision and frequent medical care. It probably extends survival in primary malignant brain tumors, but its efficacy in low-grade gliomas or metastatic tumors has yet to be demonstrated.

Other modes of therapy include immunotherapy, 45,46 which is used mainly for primary malignant tumors, and still unproved as to efficacy; radiosensitizers 47 with RT; and special forms of RT, eg, neutron capture therapy. 48

\section{OUTCOME OF THERAPY AND PROGNOSIS}

For malignant neuroectodermal tumors, such as glioblastoma multiforme, therapy is palliative and rarely curative. Patients are of ten able to return to gainful employment for a short time, perhaps a year or two. They often heve major residual neurologic deficit from the original tuinor and from the surgery. Late radiation damage can occur and may be responsible for the retura of symptoms, although tumor recurrence by far accounts for most parsents' deterioration. Chemotherapy is immosuppressive and bone marrow depressing and causes infection and bleeding problems. Primary malignant brain tumors tend to be fatal within two to three years. The most recent studies give a median survival time of 52 weeks after surgery, radiation and chemotherapy, with $25 \%$ to $35 \%$ of the patients surviving 18 months.

Following therapy for metastatic brain tumors, short-term results are often good. With a cosibination of surgery and RT, $66 \%$ to $75 \%$ of patients will show substantive anelloration of their presenting symptoms. Many patients will be able to return to work for short perlods of tiane. Median survival of such pacients is spproximately six wonths, with survival for a year Iimited to $10 \%$ to $15 \%$ of the patients. Most patiants do not die of their petastatic nervous system disease, but rather of their primary or systcilc 
cancer. There are occasional long-term survivors of moze than two years.

The prognosis in more benign intracerebral neuroectodermal tumors is better than for the maignant tumors. RT is often helpful, 30,32 in that pacients often have minimal residual neurologic deficit and frequent return to gainful employment for several years. Selzures are likely, but control usually can be obtained. Late radiation changes are possible, but for the most part the incidence is largely unknown. Patients may survive for three to seven years with relatively stable neurologic deficits, until tumor reeurrence or progression occurs when symptons may worsen.

Meningiomas are often curable. There may be residual neurologic deficits including selzures, but their occurrence is variable. The prognosis for survival is excellent, and that for neurologic deficits is good to very good. After surgery for meningiomas, most patients return to full-time employment. The likelihood of recurrent symptoms is rare. Such tumis rarely becone malignant, and most patients can be expected to survive a normal lifespan.

Treatment of acoustic neuromas depends on the size of the tumor. There is a $10 \%$ to $20 \%$ mortality with surgical resection for large tumors, and considerable morbidity. 49 The prognosis in this group is fair, but many patients have residual neurologic deficits, including hearing loss and facial paresis. tyourocephalus may follow suboccipital craniectony for large acoustic neuromas, and such patients may require shunting procedures. Complications following such shunt procedures may further impair eventual return to full function. For small acoustic neuromas, and especially those removed by translabyrinthine approach, the results are excellent, with low mortality and a high percentage of cures. 50 Eighth nerve deficits, including hearing loss and some vestibular difficulty, are possible and may hinder overall functional capacity. Facial paresis is combon and on occasion functionally disturbing.

Pituitary tumors and the occasional craniophar . oma occurring in the adult carry a fairly good prognosis. Most macroscopi-ally obvious pituitary adenomas, $50 \%$ to $60 \%$, come to the attention because of visual failure, 51 while in $20 \%$, headache is the initial symptom. Less commonly, an endocrine abnornality is noted, although microadencmas, occurring primarily in women, are usually diagnosed because of infertility, galactorrhea, or amenorrhea. Rarely, pituitary apoplexy may occur. 52 All such symptoms in fight crews should require Ciass $B$ or $C$ status until diagnosis is made and deftnitive therapy is begun. Persistence of visual failure precludes flying. The prognosis for therapy of pituitary tumors is similar to that of meningiomas, in that most such patients can be cured and returned to full gainful employment. The rare adult craninpharyngioma similarly has a good prognosis, although recurrence is somewhat more common following therapy of such tumors.

Other intracranial turoors generally have a good prognosis, depending upon their location. Cholesteatomas and colloid cysts are usually easily removed with little neurologic deficit remaining, although sowe tumors may not be removable because of danger to surrounding normal brain.

\section{RECOMEENDATIONS}

The following recommendations are based on the medical prognosis of the 
tumors revlewed above and on the likelihood that residual neurologic dysfunction will bignificantly reduce functional capacity. Thus, patients who have a stable, nopprogressive neurologic deficit which does not impair functional capacity, such as unilateral hearing loss or anosmia, are likely to return to full employnent status, and there would be no medical contraind1cation to return to flight status after demonstration of flying proficiency by simulator and/or flight. Significant hemiparesis, ataxia, vestibular dysfunction, visual impairment, or mental impairment would all preclude return to flying status.

Equally important is the potential for acute, incapacitating, recurrent symptomatology, including selzures and recurrent geurologic signs, Intracranial tumors which might lead to such changes would almost always, therefore, prevent return to flying status. Examples of such possibilities include most parenchymal tumors, whether malignant or benign at onset, and some beaign tumors with significant neurologic residua.

Thus, patients undergoing therapy for all parenchymsl neurectodermal tumors have a significant risk of recurrent neurologic symptomatology and should be permanently disqualified from any activity which is 1ikely to be dangerous to themselves or to others. Following the removal of supratentorial meningiomas, patients with no significant residual neurologic deficit, or those with winor residual deficit as defined above, shculd not return to flying status for a minimum of two years. Reinstitution of 1icensure may then be accomplished, if no seizures have occurred, if a CT scan shows no tumor, and if neurologic deficits have not progressed. The clinical evaluation of such patients must be repeated yearly thereafter to retain flying status. Since meninglomas may occasionally be multiple, all such residual examinations must show no evidence of recurrent tumor or new tumor. For infratentorial meningionas, acoustic neuromas, pituitary adenomas, and other benign extra-axial tumors, the same qualifications may be applied, except that restoration of flight status may be corsidered one year postoperatively.

\section{PSEUDOTUMOR CEREBRI (BENIGN INTRACRANIAL HYPERTENSION)}

Pseudotumor cerebri 53 is an illness of unknown etiology which produces increased intracranial pressure without an associated mass leston. Although primarily an illness of obese women in the middle years, it can occur in men and has been reported in children, especially in association with certain antibiotics. The condition is characterized by headache, papilledema, and visual loss. Treatment includes multiple lumbar punctures, corticosteriod hormones, shunting operations, or sometlmes, temporal decompression. The prognosis is generally good, but visual loss can occur and may be permanent. At onset of symptoms, flight deck personnel would be placed on Class C status because of headache, the occurrence of papilledema, and the possibility of visual loss. Under such circumstances, they should not resume flight for at least 6 months after headaches are gone and visual acuit and fields are determined to be normal. 
NEUROLOEIC CORPLICATIONS OF SYSTEMIC CANCER

Neurological complications of systemic cancer are comon, for approxi-

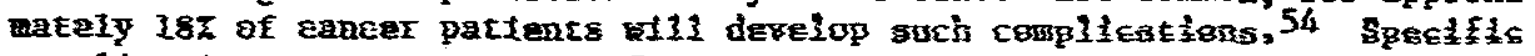
complications may occur more often with certain tumors. For example, Iung cancer is especlally prone to metastatic complications, and Iyaphomas may be associated with unusual infections. Table 4 classifies the neurologic complications of systemic cancer. In general, such complications include metastatic disease, which may be intracranial, spinal, meningeal, or to the nerves, roots, or plexuses. Nonmetastatic complications occur in about half of the patients. Of major importance are those associated with metabolic encephalopathies due to organ failure, drugs, such as narcotics, and substrate disturbances.

CNS infections in cancer patients are likely to have unusual causative organisms, for example, listeria meningitis rather than pneunococcal meningitis. Progressive multifocal leukoencephalopathy, winich has been detarmined to be of viral origin, may occur in leukemia or lymphomas. Stroke syndromes are likely to be associated with disseninated intravascular coagulation (DIC) or nonbacterial thrombotic endocarditis (NBTE); arteriosclerotic cerebrovascular disease is rare in cancer patients.

Complications of therapy for systemic cancer inciude surgical morbidity, radiation encephalopathy, myelopathy or neuropathy, and the neurologic complications of chemotherapy. Much more rare, but of interest, are those remote effects of systemic cancer which affect the nervous system, especially dementia, cerebellar degeneration, myopathy, and the myasthenic syndrome.

Specifin recormendations ara based on the comon occurrence of systemic cancer and on the fact that such patients frequently are able to return to full employment even while receiving various forms of treatinent. Therefore, recommendations are based on likely complications and their associated symptomatology, or on the nature of the therapy. For example, Iung cancer patients have a high incidence of cerebral metastasis. If they are working and apparently functional, such patients should have neurologic evaluation, including CT scan, every three to six months to maintain flying status. Also, specific symptoms in any cancer patient should be suspected as neurologic complications and should place such individuals on class C status. The following are especially important in this respect:

1) headache, visual loss, weakness, or ataxia

2) lethargy, personality change, or other mental changes

3) spinal and radicular pain

4) muscular weakness and fatigability

5.) seizures

6) fever

7) sensory disturbances, including paresthesias

Certain therapy should disqualify patients for flight duty even in the absence of neurologic symptoms, due to the posstbility such therapy could lead to acute illness which might affect functional capacity to control an airplane. Thus, patients with systemic cancer undergoing all types of chemotherapy should not fiy during the course of the treatment. All patients undergoing radiation therapy to the spinal regions or the skull should similarly be disqualified 
from the flight deck, and all patients using narcotics for control of pain from systemic cancer also should be excluded from flying status. 
Table 4: Neurologic Complications of Systemic Cancer

Comp1ications due to Ketastases -

1. intracranial

2. spinal

3. meningeal

4. nerves, roots, and plexuses

Nommetastatic Complications -

1. Metabolic encephalopathy from organ faflure, electrolyte and substrate disturbances, sepsis, narcotics overdose, and intravascular coagulation

2. Infections, brain abscess, meningitis, encephalitis, progressive multifocal leukoencephalopathy (PMI)

3. Vascular or intracranial hemorrhage from tumor or closting disorders, cerebral infarction from disseminated intravascular coagulation (DIC) or nonbacterial thrombotic endocarditis (NBTE), hemorrhage, spinal infarction

4. Complications of therapy or surgery; radiation encephalopathy, myelopathy, neuropathy; chemotherapy veuropathy, encephaiopathy, dermatomyositis, "myasthenic syndrome"

5. Remote effects; dementia, cerebellar degeneration, dyelopathy, gangiloradiculitis, polyneuropathy, dernatomyositis, "myasthenic syndrome" 
REFERENCES

1. Silverberg E: Cancer statistics. Cancer CIin 27:26-41, 1977.

2. Meritt HH: Tumors, Chapter 3 In: A Textbook of Veurology. Philadelphia, Lea \& Febiger, 1973, p 217-313.

3. Russell DS, Rubinstein LJ: Pathology of tumors of the nervous system, 4th ed. Baltimore, Williams \& Wilkins Co, 1977.

4. Rubinstein LJ: Tumors of the central nervous system, in Atlas of Tumor Pathology, Fascicle 6. Washington DC, AFIP, 1972.

5. Walker $M D$ : Brain and peripheral nervous system tunors, in: Cancer Medicine, Holland JF, Frei E (eds). Philadelphia, Lea \& Febiger, 1973, pp $1385-1407$.

6. Fishman RA: Brain edema. New Engl J Med 293:706, 1975.

7. Frankel SA, German W1: Glioblastoma multiforme. J Neurosurg 15:489, 1958.

8. Adams RD, Victor M: Principles of neurology, New York, McGraw-Hil1, 1977, pp 586-617.

9. Wright RL: A survey of possible etiologic agents in postoperative craniotony infections. I Neurosurg 25:125, 1966.

10. Pearson OH, Brodkey JS, Kaufman B: Endocrine evaluation and indications for surgery of Eunciional pituitary adenomas. Cin Neurosurg $21: 26,1973$.

11. Cryer PE: Diagnostic Endocrinciogy. New York, Oxford University Press, 1976.

12. Weit $B$. The relative significance of factors affecting survival in astrocytoma, grades 3 and 4. J Neurosurg 38:448, 1973.

13. Jelswa R, Bucy PC: The treatment of glioblastoma multiforme of the brain. I Neurosurg $27: 388,1967$.

14. Odow GL, Woodhal1 B: Supratentorial skull flaps. I Neurosurg 25:491, 1966.

15. Laws ER, Troutmann JC, Hollenhorst RW: Transsphenoidal decompression of the optic nerve and chiasm. I Neurosurg 46:717, 1977.

16. Hoi S. U, Wilson $C B$, Tyre11 JB: Transsphenoidal Microhypophysectomy in acromegaly. I Neurosurg 47:840, 1977.

17. Mongomery WW: Transethmoidosphenoidal hypophysectomy. Arch Otolarvngol $7 ? 58,1963$.

18. House WF: Transtemporal bone microsurgical removal of acoustic neuromas. Arch Otolarnygol 80:733, 1964. 
19. Webster JC: Anatomical considerations in the selection of the approach to the cerebellopontine angle, in: Neurological Surgery of the Ear. Silverstein, B, Norre11, H (eds), Birwingham, Aesculapius Pub Co, 1977.

20. Katzman R, Poppins HM: Cerebral edeme, Chapter 12 in: Electrolites and Fluid Metabolism, Baltimore, Williams and Wilkins Co, 1973.

21. Klatzo I: Neuropathological aspects of brain edema. J Neuropath Exp Neuro1 26:1, 1967.

22. Katzman, Poppins, op cit, p 297.

23. Jelsma R, Bucy PC: Glioblastoma mulriforme: its treatment and some factors affecting survival. Arch keurol 20:161-171, 1969.

24. Concannon JP, Kramer S, Berry R: The extent of intracranial gilomata at autopsy and its relationship to tecnniques used in raoiation therapy of brain tumors, Amer J Roentg 84:99-107, 1960.

25. Kramer S: Tumor extent as a determining factor in radiotherapy of glioblastomas. Acta Radiol Therap 8:111-117, 1969.

26. Ramsey RG, Brand WN: Radiotherapy of glioblastoma multiforme. I Neurosurg $39: 197-202,1973$

27. Weir B: The relative significance of factors affecting postoperative survival in astrocytomas, grades 3 and $4 . \mathrm{J}$ Neurosurg $38: 448-452,1973$.

28. Simpson WJ, Platts ME: Fractionation study in the treatment of glioblastoma multiforme. Int J Radiat Oncol Biol Phys 1:639-684, 1976.

29. Nakagaki H, Brunbart G, Kemper TL, Caveness WF: Monkey brain damage from radiation in the therapeutic range. I Neurosurg 44:3-11, 1976.

30. Leibell SA, Sheline GE, Wara et aI: The role of radiation therapy in the treatment of astrocytomas. Cancer 35:1551-1557, 1975.

31. Sheline G: Radiation therapy of brain tumors. Cancer 39:873-881, 1977.

32. Greenberger JS, Cassady JR, Levene MB: Radiation therapy of thalamic midbrain and bra.ln stem gliomas. Radiol 122:463-468, 1977.

33. Posner JB, Shapiro WR: The management of intra-cranial metastases, in: Current Controversies in Neuro-surgery, Philadelphia, Morley TP, Saunders WB (eds), 1976, pp 356-366.

34. Posner JB: Management of central nervo:ts system metastases. Sem Oncol 4:81-91, 1977.

35. Wilson, CB: Brain metastases: the basis for surgicai selection. Int J Radiat Oncol Biol Phys 2:169-172, 1977. 
36. Shapiro $\mathrm{WR}_{\text {, }}$ Young, DF: Treatment of malignant glioma: a controlled study of chemotherapy and irradiation. Arch Neurol 33:494-500, 1976.

37. Walker 4D, StIike TA: An evaluation of methyl CCND, BCiv and radiotherapy in the treatment of maligant glioma. Proc Amer Assoc Cancer Res 17:163, 1976.

38. Posner JB, Shapiro WR: Brain tumor: current status of treatment and complications. Arch Meufo1 32:781-784, 1975.

39. Shapiro WR, Young DF: Chemotherapy of malignant glioma with lomustine alone and lomustine conbined with vincristine suifate and procarbazine hydrochloride. Azch Neuro1 33:394, 1976.

40. Brisman R, Eouseplan EM, Chang $C$, et al: Adjuvant nitrosourea therapy for glioblastoma. Arch Neurol 33:745-750, 1976.

41. Wilson $C B$, Gutin $P$, Boldrey $E_{3}$, a1: Single-agent chemotherapy of brain tumors: a five-year review. Arch Neurcl 33:739-744, 1976.

42. Wetr $B$, Band P, Urtasun $R$, et a1: Radintherapy and CCNU in the treatment of high-grade supratentorial astrocytonas. I Neurosurg 45:129-134, I976.

43. Gutin PH, WiIson CB Vansantha RA et a1: Phase II study of procarbazine, CCNJ, and vincristine comination chemotherapy in the treatment of malignant brain tuwors. Cancer 35:1398-1404, 1975.

44. Walker, MD, Gehan EA: Clinical studies in malignant gliomas and their trestment with nitrosoureas. Cancer Treatment Rep 60:713-716, 1976.

45. Brooks WH, Netsky MG, Normalsell DE, Horwitz DA: Depressed cell-mediatad immunity in patients with primary intracranial tumors. I Exper Hed $136: 1631-1647,1972$.

46. B100m EJG, Peckham MJ, Richardson AE, et al: Glioblastoma multiforme: a controlled trial to assess the value of specific inmunotherapy in patients treated by radical surgery and radiotherapy. Brit J Cancer $27: 253-267,1973$.

47. Urtasun R, Band P, Chapman JD, et al: Radiation and high-dose metronidazole In supracentorial glloblastomas. New Eng I Med 294:1364-1367, 1976.

48. Browne1] $\sigma_{2}$, Murray BW, Sweet $\mathrm{kH}$, et al: A reassessment of neutron capture therapy in the treatment of cerebral gliomes, in: Seventh National Cancer Conference Proceedings, Philadephifa, JB Ltppincott, 1973, pp 827-837.

49. Thomsen J: Suboccipital removal of acoustic neuromas: results of 125 operations. Acta Otolaryngol 81:406-414, 1976. 
50. House WR, Hitselberger WE: Acoustic neuromas, in: Handbook of Clinical Meurology, Chaptex 18, Volume 17, Vinken PJ, Bruyn GW (eds). Amsterdam, North-Ho1land Pub Co, 1974, pp 666-692.

51. Martins AN: Pituitarv tumors and intrasellar cysts, in: Handbook of Clinical Neurology, Vinken PJ, Bruyn GW (eds). Anstexdam, Noreh-Holland Pub Co, 1974, Chapter 10, Volume 17, pp 375-439.

52. Broughath $\mathrm{W}$, teusner AP, Adams RD: Acute degenerative changes in adenomas of the pituitary body - with special referenced to pituitary apoplexy. I Neurosurg 7:421, 1950.

53. Johnston I, Paterson A: Benign intracranial hypertension. I. Diagnosis and Prognosis and II. CSF pressure and circulation. Brain 97:289-312, 1974.

54. Posner JB: Neurological complications of systemic cancer. Med Clin $\mathbb{N}$ Aner 55:625-646, 1931 . 
Donald P. Becker, MD (Chairman), Robert G. Grossman, MD, Robert L. McLaurin, MD, William F. Caveness, MD

\section{MINIMUM CRITERIA FOR DIAGNOSIS OF BRAIN INJURY}

A traumatic injury to the head is of major significance to the individual if there is evidence of brain injury. Trauma to the head causing no loss of consciousness and no evidence of focal brain injury may be inconsequential, even if there is evidence of a linear or depressed skull fracture. The minimum criterion for brain injury following head trauma is:

1. loss of consciousness (concussion), ever if lasting only several seconds, or

2. evidence of a neurologic deficit resulting from the trauma, such as weakness or aphasia, or

3. evidence of focal brain damage demonstrated on examination by a physician, or demonstrated by special diagnostic test's such
as computerized tomography (CT scan).

Closed Brain Injury -- The most common cause of closed head injury is sudden deceleration, which occurs when the moving head is suddenly stopped when it strikes an object. Closed head injuries are to be distinguished from perforatits (stab wound) or penetrating (missile wound) injuries to the skull and brain. Closed head injury is more likely to be associated with a diffuse brain injury, while rissile and stab wounds tend to cause a more focal brain injury. 1

Since the result to the patient of brain injury depends on the extent or degree of brain damage, and on the location of the injury, a classification scheme including both these variables is necessary. It is comon to classify the initial brain damage as below.

Mild Brain Injury - There is transient loss or alteration of consciousness but no focal neurologic deficit, and fast return of alertness and orientation. This includes patients who have some evidence of traumatic brain injury and brain dysfunction, but who do not iose consciousness. Post-traumatic amnesia (PTA) will be less than one hour.

Moderate Brain Injury - One hour after injury there is still impaired consciousness or disorientation, but the patient can follow some commands; or the patient may be alert with a focal neurologic deficit. PTA of 1 to 24 hours will usually occur.

Severe Brain Infury - Early after injury, these patients are unable to follow any comands; they may use words, but inappropriately. Their motor responses vary from localizing stimuli to posturing or nothing. If they recover, PTA is usuaily 1-7 days, but may be longer.

Very Severe Brain Injury - Early after injury, these patients have their eyes ciosed even to tatense stimuli; they utter no words or sounds and follow no commands; on stimulation they exhibit either no motor movenent or a posturing response. A patient in this state often dies, unless a clot is 
responsible for the cinical picture and is removed. If the patient lives, it is frequently in a vegetative state. PTA is greater than 7 days and of ten much longer.

A retrospective classification of the severity of the head injury may be based solely on the duration of PTA as follows:

$$
\begin{aligned}
&<1 \text { hour - m1ld } \\
& 1-24 \text { hours - moderate } \\
& 1-7 \text { days - severe } \\
&>7 \text { days - very severe }
\end{aligned}
$$

The duration of PTA is defined as the time after the injury until the zeturn of continuous memory. The ability of the brain to store memory in a continuous fashion is often one of the last clinical functions to return after blunt closed brain injury. 9

\section{RELEVANT DIAGNOSTIC PROCEDURES}

Determining Degree and Extent of Primary Damage

It is of utmost importance to establish whether an actual brain injury has occurred. Once this is done, an individual who has suffered a head injury with no brain or cranial nerve injury may be put into a separate category, while one with brain injury, through ascertainment of duration of PTA and accomplishment of early neurologic examination, may be tested for the degree of injury.

The initial neurologic examination should include determination of the following in all patients, regardless of degree of injury:

1. Status re Glasgow Coma Scale 10, 11

2. Pupillary response

3. Eye movements

4. Motor power

The Glasgow Coma Scale is graded as follows:

Eye Opening $\begin{array}{ll}4 \\ 1\end{array}$

Follows Commands 6

5

Motor Response Withdraws 4

Flexion Posturing 3

- Extension Posturing 2

No movement 1

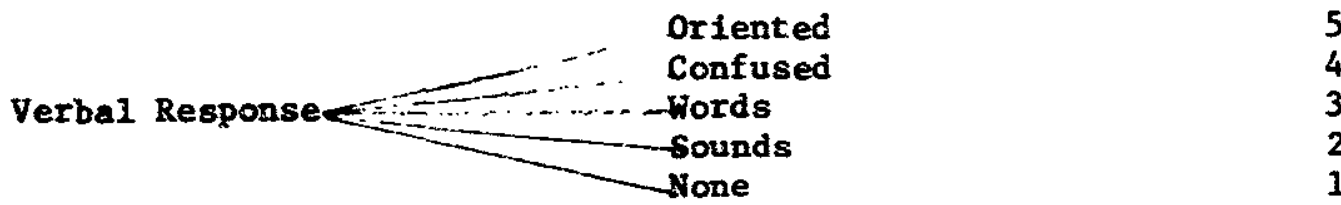


In mild brain injury, no further diagnostic procedures beyond skull $x$-ray, neurologic examination, and clinical follow-up of the patient is necessary. With moderate, severe, or very severe brain injury, every attempt should be macie to define the location, extent, and nature of the Infury. In this way a profile of the individual's brain injury can be constructed, and the expected course and outcome can te predicted more accurately.

Thus, if a diagnosis of moderate, severe, or very severe brain injury is made, the following diagnostic procedures should be performed:

\author{
1. Skull films \\ 2. CT scan (cranial) \\ 3. Electroencephalogram (EEC) and, if available, multimodality \\ evoked potential study \\ 4. Anglography, under the following circumstances: a vascular \\ infury is suspected; CT scan is not available; the patient is \\ unexpectedly not improving; or there is a discrepancy between \\ the clinical presentation and diagnostic studies
}

By combining the findings from the functional studies (neurologic excmination and brain electrical activity) and the morphologic tests (CT scan and anglography), the location and extent of the patient's brain injury can be estimated. Defining injuries at this early stage will permit early prediction to and counselling of employer, family members, and the patient. For example, if there are bilateral dense intracerebral lesions on the early CT scan, a pernaner. handicap is likely. If there are bifrontal lesions, one can predict prominant personality or character alterations. Bitemporal lesions on CT scan indicate permanent iniellectual and memory deficits are likely. 12

\title{
EARLY TREATMENT OF BRATN INJURY
}

The fundamental principles of early treatment of brain injury are (1) to provide an ideal internal environment conducive to the healing of partially damaged brain cells, and (2) to prevent a second brain injury from hypoxemia, hypotension, elevated intracranial pressure, brain shift, hyperthermia, etc. To accomplish this, after injury the patient should be well oxygenated, with intubation if necessary and guarded against arterial hypotension after injury.

Very rapid diagnosis of the presence or absence of an intracranial mass lesion is imperative. This should be done promptly, and if there is a sizabie subdural or intracerebral hematcona with brain shift and elevated intracranial pressure, cranlotany should be perfozmed promptly. Surgery should not be delayed, because any further deterioration, as evidenced by signs of tentorial herniation, for example, may be irreversible. Patients with intracranial masses and brain shift who fall into the moderate brain injury category sometines may be followed but this should be done in an intensive care unit by carefully instructed nurses. 1

If no surgery is indicated, or following surgery, patients should be maintained in a physiologically desirable state: nozmothermic, with noznal serum electrolytes, hematoc: it above $30 \%$, and adequate oxygenation. In patients with "moderately severe" and "severe" injuries, it is desirable to monitor 
intracranial pressure (ICP) and to treat eievations in ICP when over 20-25 wang. 13 Serial studies of neurologic function should be done, and at least one follow-up CT scan is recommended for all such patients. Follow-up CT scans at 14 days and 3 months will be helpful in patients in the "severe" and "very severe" brain injury categories.

Physical therapy and rehabilitation should be started early. The therapy must be individualized to meet the needs of the patient's obvious or predicted handicaps, such as motor-physical, intellectual, behavioral, or communicative.

Expected Course Related to Early Damage

Generally, the greatest portion of recovery after injury occurs within the first 6 months. 7,14 Some believe that all fundamental recovery occurs during this 6 month period, and any further apparent recovery is not true neurologic recovery but represents a training effect and learning how to cope better with permanent handicaps. The more popular idea is that most true neurologic recovery occurs within the first 6 months, but that further improvement in brain function continues up to two years longer in patients over 30 years and up to three years longer in children and young aduits.

The expected course after initial neurologic examination and classification of the patient is not possible to predict in a rigid sense. General concepts, however, are applicabie. For example, the post-traumaic syndrome of subjective menta]. and somatic complaints is seen more commoniy in patients whose initial brain irjuries were mild rather than severe. This may be simply because the patient with an initial severe brain injury has greater deficits to overcome, or because different areas of the brain were damaged, yielding a different psychological attitude. The post-traumatic syndrome is sufficiently common and similarly manifested in patien:s that it cannot be dismissed as "psychoneurotic."

At the other end of the spectrum, it is fair to state that virtually all patients who sustain severe injuries will experience some residual alterations in brain function. These may be subtle and may or may not handicup the injured. Patients with severe injuries may suffer major physical, intellectual, or behavioral handicaps. The ultimate outcome depends on the location, extent, and type of brain injury which occurred initially, and any secondary brafn damage due to complications. Early definition of the injuries in the patient is, therefore, pertinent.

In sumary, patients with mild injuries may recover completely, or less commonly, develop the post-traumatic syndrome. Patients with moderate brain injury may completely recover, or suffer residual deficit if the brain damage was in a critical zone. The post-traumatic syndrome seems less common in these patients, but that may be because post-traumatic complaints are more readily accepted by the physician and family members. Patients with severe or very severe injury virtually always have some permanent alteration in brain function. The degree and type of alteration in cilinical status, including physical behavioral, inteliectual, memory, and communicative skills, will depend on the locations, extent, and types of initial lesions in the patient. 


\section{Sequelae of Mild Injury - Post-traumatic Syndrome}

The major significant sequelae (Table 1) of minor injury is the "posttraumatic syndrome," which is considered below:

I. Definition - The post-traumatic syndrome is a symptom complex which most commoniy follows minor head injury, but wich may occur after more severe injuries. The complex consists of dizziness and emotional and intellectual impairment. The symptoms include irritability and short temper, poor concentration and loss of confidence, nervousness, and fatigue.15, 16, 17 Sleep patterns may also be disturbed, and alcohol intolerance may become manifest.

II. Minimum initial evaluation to be undertaken -

A. History of

1. type and severity of head injury

2. severity, duration and progression of post-traumatic symptoms; duration of post-traumatic amnesia

3. evidence of seizure activity--eg, loss of contact, falling spells, visual or auditory hallucinations

4. motor incoordination: loss of fine movements, ataxia

5. emotional disturbances: memory defects, sleep disorders, mood excesses

B. Examination

3. general physical examination

2. neurologic examination, including funduscopic

3. neuropsychological examination, if emotional and mental impairment are prominent

c. Laboratory studies

1. CT scan for evidence of hydrocephalus or other intracranial pathology

2. EEG

3. Electronystagmography (ENG) if dizziness is prominent; $30 \%$ of patients with dizziness have positional nystagmus, and ENG usually shows it to be of peripheral labyrinthine origin

III. Follow-up

A. Evaluation every month for three months if symptoms persist; then, according to severity

B. Check for

1. excessive use of medication

2. mental and emotional deterioration

3. signs of organic disease, like dementia, ataxia, incontinence

IV. Prognosis for the post-traumatic syndrome

It may take 6 montho to two years for a patient to resolve the post-traumatic syndrome. It is important for the physictan to be understanding and to explain to the patient, family and employer that the sympton complex is a real one for 
Table 1

SEQUELAE OF HEAD INJURY

\begin{tabular}{|c|c|c|c|}
\hline Ment al & $\begin{array}{l}\text { Strongly Related to } \\
\text { Severity of Injury }\end{array}$ & $\begin{array}{l}\text { Less Strongly } \\
\text { Related to } \\
\text { Severity of Infury }\end{array}$ & $\begin{array}{l}\text { Least Related to } \\
\text { Severity of Infury }\end{array}$ \\
\hline & $\begin{array}{l}\text { Apathy } \\
\text { Euphoria } \\
\text { Loss of Soclal Restraint } \\
\text { Intellectual deficits } \\
\text { Marked Memory defects }\end{array}$ & $\begin{array}{l}\text { "Poor Concentration" } \\
\text { "Poor Memory" } \\
\text { "Slowness" }\end{array}$ & $\begin{array}{l}\text { Fatigue } \\
\text { Irritability } \\
\text { Insomia } \\
\text { Nervousness } \\
\text { Anxlety } \\
\text { Depression }\end{array}$ \\
\hline Phystcal & $\begin{array}{l}\text { Dysphasia } \\
\text { Hemianopda } \\
\text { Motor spasticity } \\
\text { Disorders antaxia } \\
\text { tremor } \\
\text { Perceptual } \\
\text { disorders }\end{array}$ & $\begin{array}{l}\text { Ansomia } \\
\text { Vertigo } \\
\text { Eptlepsy }\end{array}$ & $\begin{array}{l}\text { Headache } \\
\text { Sensitivity to nolse } \\
\text { Dizziness (sans vertigo) } \\
\text { Pain at site of injury }\end{array}$ \\
\hline
\end{tabular}

MODIFIED FROM:

Jennett B: Late effects of head injuries.

In Critchley M, O'Leary JL, Jennett B (eds.): Sclentific Foundations of Neurology,

F A Davis Co, Philadelphia, 1972. 
the patient, not an unusus 1 result of mild head trauma, can last for many months, and will usually resolve. Such explanation allays wany anxieties and helps everyone to cope with a difficult situation. A favorable prognosis is less likely in later life, for example, if the injury takes place in patients over 50 years of age.

One prospective study permitted classification of patients with posttraumatic syndrome into two broad groups. One group of patients had synptoms of headache and dizziness at the time of discharge from the hospital. They showed progressive improvoment, and within two years the majority had returned to normal. Complaints in this group were undoubtedily real, for at six months, $45 \%$ of this group showed positional nystagmus; however, only $24 \%$ claimed compensation.

In the other group, symptoms developed only after the patients had left the hospital. At 6 months, only $5 \%$ of the patients with dizziness showed positional nystagmus, yet $50 \%$ of the group claimed compensation. Psychologicai factors seemed to be operative in a higher proportion of patients in the second group, and compensation perhaps played a role. This may not always be true however, and because the post-tramatic syndrome may have a true pathophysiologic basis, it is best for the physician to believe the patient's complaints and to provide reassurance. 15

In the meantime, since the symptoms may be intermittent and very distracting, and the dizziness and headache may be intermittent1y incapacitating, it is wise to limit the activities and responsibilities of the individual until the symptoms are minimal or gone.

Moderate, Severe, and Very Severe Brain Injury

When the injured individual is seen at followup, the degree of the initial injury should be determined, and all information on location, extent, and type of the initial brain injury should be collected. A physiological and psychosocial pre-injury history should be obtained, and a general physical examination and a detailed comprehensive neurologic examination are indicated.

Labcratory studies should include a follown CT scan at six months or one year and an EEG. These studies should be compared with earlier studies for changes. If multimodality evoked potentfal studies are available, they should be obtained, because any abnormality found will be helpful in making decisions and reccamendations.

Disorders nanifested by the patient should be characterized as being either physical-reurological residua or mental disorders. The physical-neurological problems should be described and subdefined as to degree, for dysphasia, or as to nature of the deficit, whether sensory or motor. Since the subfrontal and anterior frontal regions, and the anterior temporal lobes of the cerebral hemispheres, are most prone to damage in sudden deceleration injuries, disorders of personaility-behavior and intellect-memory are far more common sequelae of brain injury than sensory motor deficits or dysphasia. Injury involving cranial nerves I-VIII may be associated with wild, moderate, severe, or very severe concussion. 
PROGNOSIS AND EXPECTED COURSE FOR SEQUELAE OF MODERATE, SEVERE AND VERY SEVERE INJURY

The disabilities which follow brain dawage and are direct 3 y related to injury in specific locations, iike dysphasia, hemiplegia, and disturbances of memory and perception, tend to recover most rapidly during the first 6 months following injury. However, brain-damaged individuals will usually show continued improvement in their adaptability to every day tasis and contact with other people. Many belleve such individuals are only adapting to flxed physical, and intellectual deficits. Others, however, believe significant degrees of recovery in dysphasia, heniparesis, hemiplegia, or sensory deficits can occur as long as two years after injury. In general, little improvement can be expected after two years. 18, 19, 20

Cranial Nerve Lesions

Anosmia - The first cranial nerve is the most coumonly injured nerve in the head injury. Often the injury is only mizld or mocierate. In the more mild injuries, olfaction may often return within three months. In the more severe injuries, loss of olfaction is often permanent.

Optic Nerve Lasions

These can also result from $m^{*} l d$ injuries. An injury may be seen without evidence of fracture into the orb $c$ or optic canal. Deficits in visual function imediately following injury have a poor prognosis.

\section{Extraocular Movements}

Diplopia can occur after rather mild injuries, even without loss of consciousness. Whether the diplopia or eye movenent imbalance is secondary to brain stem injury or to isolated cranial nerve injury, there is a tendency towards improvement. If improvement is not continuing at 6 months, the deficit will usually be fixed. As with the other cranial nerve injuries, those deficits occurring immediately after injury are less likely to recover than those which occur later.

Facial Nerve Injury

A partial facial nerve injury is almost aiways followed by satisfactory recovery. A complete lesion seen immediately after injury and associated with an 8 th nerve lesion has a poor prognosis. Facial palsy which occurs in a delayed fashion has a $90 \%$ or better recovery rate.

\section{Eighth Nerve Injury}

Auditoxy and vestibular function disturbances are common after mild or severe brain injuries. Abnormalities moy be reveaied oaly by special audiological and neurai-otological testing. The comon complaints of vertigo and hearing abnormalities following head irjury were often consijered neurotic until more formal testing was applied to head-injured patients. Neurogenic deafness tends to be permanent. Conductive deafness tends to inprove, because it is often cue to middle ear bleeding. Or it may be due to dislocation of the ossicles, and surgical intervention cas restore hearing. 3 
Yental and Neuropsychologic Disorders Following Head infury (Table 2)

These are the most common sequelae of mild, moderate, severe, or very severe head injury. The three general categories of mental disorder are those of (1) personsility, (2) intellectuai performance, and (3) memory. 14, $21,22,23$

In evaluating the patient for mental alterations following head injury, it is important to obtain as clear a picture of the patient's prexorbid psychological and intellectual functioning state as possible. In obtaining the history, it is also imfortant to speak to the ramily in sone detail about the patient's performance. Very often the injured individual will clain there are few changes or difficulties with his adapted behavior, whereas the family wili describe major personality changes. The opposite can also be seen, particularly when the patient is feeling hyperirxitable and generally nervous. Individuals experiencing sequelae in personality, inteilectual function, of menory should undergo psychometric-neuropsychological evaluation.

Head injury has produced a wide range of deficits in intellectual level. 24 information processing, 25 memory, 26 perception, 27 and motor function. 28 Psychiantic sequelae of head injury have varied in severity from mild anxiety and depression to conditions of psychotic proportions. Thinking disturbance, social withdrawal, and psychomotor retardation are particularly sensitive to severe ciosed head injury, while mild anxiety and depression are not uncomon findings after head injury which produces iittle or no neurologic dysfunction. 29

Although the characteristics of pest-trautic behavioral deficits have been amply documented, few studies have systematically analyzed neuropsychological impairment in relation to indices of injury severity. Recovery of neuropsychological functioning may continue for at least three years after a severe closed head injury, depending upon the severity of trauna and the specific ability wich is evaluated.24

Gronwall and Wrightson 25 found that patients with an ostensibly mild closed head injury, "concussion", exhibited a decline in information processing capacity which persisted for several weeks after injury and was closely related to the auration of both vocational disability and "post-traumatic syndrome." Severe head injury, as reflected by duration of cona, Glasgow Coma Scaleio score, and neurologic deficit often results in varying degrees of prolonged social and vocational disability, accompanied by persistent cognitive inpairment and psychiatric manifestations. 30 However, there is still considerable uncertainty with regard to early prediction of neuropsychological recovery after head injury.

Assessment of fitness for flying in pilots who have sustained head injuries is a particularly conplex problem which raises several methodological issues (Table 3). Appropriate evaluation should consider that the role of a pijot has increasingly become that of a decision-maker in a complex man-machine system.31 Capacity for integration of information fron severai sources, and adaptability to changing situations are characteristics of a proficient pilot.

Recent stedies have shown that capacity for divided attention in a situation of time-sharing between two tasks is positively zelated to fiying proficiency, 32, 33 Employing reaction time and compensatory tracking as preäictors of success in filght troining, North and Gopher found dual task perfornance 
Table 2

MENTAL SEQUELAE OF HEAD INJURY*

\begin{tabular}{|c|c|}
\hline $\begin{array}{l}\text { 1. General organtc dementia } \\
\text { (non-spectf } 1 \text { ) }\end{array}$ & disoráers of $\underbrace{\text {-intellect }}_{\text {memory }}$ \\
\hline $\begin{array}{l}\text { 2. Local organic syndromes } \\
\text { (specific) }\end{array}$ & $\begin{array}{l}\text { frontal-severe behaviorai problens } \\
\text { right hemisphere-viouo-spatial deficit } \\
\text { 1eft hemisphere } \begin{array}{l}\text { defective verbal skills } \\
\text { wlthout dysphesia }\end{array}\end{array}$ \\
\hline $\begin{array}{c}\text { 3. Post-concussion syndrome } \\
\text { (Post-traumati!) }\end{array}$ & subjective mental and somatic features \\
\hline 4. Neurosis & $\begin{array}{l}\text { prolongation and exaggeration of } \\
\text { post -traumatic gyndrone }\end{array}$ \\
\hline 5. Psychosis & $\begin{array}{l}\text { depression } \\
\text { achtzophrenta }\end{array}$ \\
\hline
\end{tabular}

*Fron reî 3 
TABLE 3

NEUROPSYCHOLOGIC ASSESSMINT FOR OUTCONE OF BEAD INJURY IN PILOTS

I. Demographic Characteristics and Adjustment to Daily Activities
A. General personal history
B. Flying history
C. Estimate of cognitive functioning
1. Results of standardized tests given prior to injury by Wilitary service or airline
2. Detailed interview to obtain the patient's assessment of recovery and current adjustment to activities of daily living
D. Glasgow Outcome Scale 6

II. Neuropsychologic Evaluation
A. Galveston Orientation and Amesia Test
B. Wechsler Aduit Intelligence Scale
C. Brief aphasia examination
D. Computer-generated paced auditory serial addition task (PASAT)
E. Pursuit rotor manual tracking
F. Divided attention task (PASAT and Pursuit rotor task)
G. Selective reninding test of learning and memory
H. Continuous recognition menory
I. Electronic measurement of motor reaction time
J. Bender - Gestalt
R. Brief Psychiatric Rating Scale 
Table 3 (cont'd)

\section{References-neuropsychologic tests}

Bender L: A Visual Motor Gestalt Test and its Clinical Use. (Visuomotor) New York, The Anerican Orthopsychiatric Assoc, 1938.

Benton AL: Problems of test construction in the field of aphasia. (aphasia examinatior) Corter 3:32-58, 1967

Buschke E, Fuld BA: Evaluating storage, retention, and retrieval in disorder menory and learning (Gestalt Test) (memory and learning) Neurol 11:1019-1025, 1974.

Gronwall D, Wrightson P: (PASAT - Information Processing) Recovery after minor head injury. Lancet 2:1452, 1974.

Gannay HJ, Levin HS, Grossman RG: Impaired recognition memory after head injury. Submitted to Cortex, 1978.

Jennett B, Bond M: Assessment of outcone after severe brain damage. (Glasgow Outcome Scale) Lancet 1:480-487, 1975

Lafayette Instrument Company (Pursuit Rotor Tracking Tasik) Box 179, Lafayette, Indiana 74902.

Marietta Instrument Company (Reaction Time Test) 118 Waple St, Marietta, Ohio 45750 .

Overall JE, Gorham DR: The brief psychiatric rating scale. Psychological Reports 10:799-812, 1962.

Wechsler, D: The Wechsier Adult Inteliigence Scale. New York, Psychological Corp, 1955. 
efficiency was more strongly related to flying ability than was performance of either task alone. Moreover, flying instructors were better able to cope with a time-sharing condition, and to differentially aliocate their attention according to changes in task priorities, than were flight students. Because capacity for Information processing has been shown to be compromised after even an apparently mild head injury, 34 evaluation of this capability would appear to be critical in a head-injured pilot.

Irdividual differences in emotional stability are also related to fiying proficiency. Hayward administered personality tests to pilots and independently evaluated their operation of a computer-assisted simulated flight machine. 35 He found pilots whose attention was engaged by ruminative thinking bad smpaired performance, compared to a control group of patients without enotional disturbance, and to a group of pilots who exhibited a high level of anxiety unaccompanied by rumination. In view of the evidence for psychiatric sequelae of head injury, it is important to assess changes in personality prior to the resumption of flying.

Evaluation of flying proficiency after head injury is complicated by interaction of neuropsychological sequelae with stress factors associated with flying, particularly with respect to commercial and military aviation. Proficiency of performance normally declines as a result of circadian desynchronization related to transmeridian flights.36, 37 sleep loss, noise, heat, and high accelerative force are among the sources of stress in different flight situations. It is plausible that adverse effects of head injury on flying efficiency could interact with such stress factors in such a way that post-traumatic impairment in flight performance might be manifested only under specific conditions.

\section{RECOMMENDATIONS}

Airmen who have sustained head injury classified as moderate, or more severe, should be required to undergo simulator or filigh testing under conditions of maximum expected fifigt stress before being returned to flight status. If there is indication of impairment of flight capability, or if the alrman or his family give a history of intellectual impairment or behavioral disturbance, then wore detailed neuropsychological testing is recomended.

If an airman fails to perform satisfactcrily in simulated fight testing and in neuropsychologic testing, the tests may be repeated every three to six months. However, it should be remenbered that naximum improvement will have occurred within the first 12 to 18 months after injury. Unrealistic hopes for returning to flight status should not be raised in patients who have profound neurologic and neuropsychologic sequellae after severe head injury. 


\section{POST-TRAIMATIC EPILEPSY}

The development, recession, and residua of post-traumatic epilepsy follow natural laws that are imperfectly defined. However, from studies following World War I, 38, 39 World War II, 40, 41 the Rorean Conflict, 42 and the Vietnam War, 43 principles have emerged that warrant attention:

(1) the onset of epilepsy is significantly related to a) local brain destruction, b) its location, and c) diffuse brain damage, reflected by alteration in consciousness.

(2) There has been no manifest change in incidence from one war to another, 44 in spite of marked improvement in patient transport, surgical techniques, medical management, and the prophylactic use of anticonvulsants in Vietnam.

(3) After injuries incurred in combat and support activities, the onset of new epilepsy cases rises sharply, with $4 \%$ to $5 \%$ of the individuals having an artack in the first week, $10 \%$ to $11 \%$ in the first three months, $16 \%$ in the first six wonths, $23 \%$ in the first year, $29 \%$ in the first two years, and a very low, but protracted rate of new cases thereafter. Seizures occurring in the first week are less influenced by agent of injury or local brain damage, eg, there is no difference between missile and nonmissile injuries and no difference between military and civilian injuries. 43,45 Thezeafter, there is a sharp divergence, with the more extensively injured patients providing the greater number with attacks.

(4) in the population at risk, approximately $70 \%$ never have an attack. In those that do, the development varies in degree, according to frequency. The latter ranges from a single attack to a number that defies an accurate count.

(5) As new epileptic cases are accumulating, individuals with eariy epilepsy are having their last attack. When cumulative onset is plotted against cunulative cessation, ie, no attack within two years, it is evident that within 5 to 10 years, half will have ceased having attacks, with or without therapy. Half of the remainder, about $7 \%$ of the injured, will have intractable seizures.

(6) While there is a clear correlation between severity of injury and onset of attacks, there is no correlation between severity of injury and cessation. $4 \hat{2}, 46$

(7) Fron the preceding, two principle determinants must be considered:

a) the constitutional tendency to seizures, probably a multifactoriai genetic trait, 47,48 and

b) the brain damage. In onset of seizures, both play a part, the constitutional factor apparently determining severity of attacks. In the cessation or persistence of seizures, the constitutional factor plays the dowinant role.

The above is drawn frow military experience and attempts to encompass the phencmena of post-traumatic epilepsy in the aggregate. The following pertain to the evaluation of individual cases within the population at risk. 


\section{MINIMUM CRITERIA FOR DIAGNGSIS}

There must be a reliable history of significant trauma according to circumstance of injury, subjective complaints, and/or objective findings. These criteria should include at least one of the following: a) loss or alteration in consciousness, judged by the patient's inability to recali the events of the injury and a measurable period before the injury in minutes, hours, or longer; and/or an account by an observer of the patient's ioss or alteration in response to outside stimuli for a measurable period, in minutes, hours, or longer; b) loss or alteration in motor, sensory, or special sensory function, ie, vision, hearing, smeli; c) laceration or contusion of head, otorrhea, rhinorrhea, depressed fractures; d) open wound of head, with dural tear, or greater violation of brain tissue. The location of the inftial impact has a greater significance for subsequent seizures when it approximates the central sulcus.

There must be a reliable history of a seizure. Every effort should be made to obtain an objective as well as a subjective account of the attack. A few more usual examples of the clinical expression will be listed in the order of their expected recognition:

Primarily generalized convulsive seizures - Occurring in well over half the cases 40,41 such seizures may be heralded by a cry or a blank stare. The body stiffens, falls and jerks rhythinically, though not always symmetrically, for a minute or more, face is suffused, breathing noisy. The tongue may be bitten or sphincter control lost. The movements subside. Coma gives way to sleep or confusion and finally full awareness. A "warning" is recalled by some of the patients, the major portion of the seizure by none. The aftermath usually includes beadache, drowsiness, fatigue, or aching muscles, particularly of the back. One surmises that the discharging lesion is close to the midline, or if near the cortex it is capable of bringing, about sudden, widespread, and massive excitation in a manner that obscures focal phenomena.

Partial seizures with elementary symptomatology - A focal motor seizure may present as a typical "Jacksonian" seizure. Given a discharging lesion in the hand area of the motor cortex, the attack may begin with rhythmic movements of the contralateral thumb, with progressive involvement of hand, arm, face, trunk, and leg. If the "march" continues and crosses the midiine, there will be loss of consciousness and involvement of the entire body in colonic and, to a lesser extent, tonic movements. With more limited spread, the attack may be confined to the upper extremity. Similarly, a restricted discharge from other points along the motor strip may result in an occasional taitching of one side of the mouth $o:$ a few jerks and transient weakness of one leg. Rarely, one may have a limited attack persisting for minutes or even hours, "epilepsia partialia continua." If the lesion is in the prefrontal area, the attack may start with the head and eyes turning to the opposite side, an "adverse seizure." If the seizure is in the dowinant henisphere and clc se to the motor speech area, there can be a momentary Inability to speak. If ascompanied by more obvious seizure phenomena, the postictal phase may lack word production for a while after alertness has returned. Other, more subtle, transient aphasic difficulties may arise from jischarging lesions in the temporal or parietal lobes.

Focal sensory seizures from the sensory cortex may follow the pattern of Jacksonian seizures, with aberrant sensation in place of abnormai 
movements. There may be tingling or numbness in a liwb, simulating impaired circulation; a sensation of warmth or cold, or of wind blowing over a part; or a strange sense that a member is shriveling. Attacks arising from the occipital lobe may be experienced by the patient as flashing lights, balls of color, or other crudely formed visual phenomena. There may be admixtures of the preceding foral, motor, and sensory seizures, and any may progress to a generalized seizure. These local, spreading, and admixed attacks are found in about one--hird of the cases.

Partial seizures with complex symptomacology - "Psychomotor seizures" arise from a discharge mainly within the temporal lobe or lobes. Rarely is the spread sufficient to catise a generalized seizure clinicaliy, these attacks may begin with altered perception of the environment. Objests or sounds will seem too distant or too close, a place too familiar or the opposite. There may be formed visual or audicory patterns unrelated to the environment but occasionally foentified with the past. The motor activity varies and is not usually recalled by the patient. It frequently begins with movements about the mouth, such as smacking, sucking, or swallowing, but principally it consists of repetitive, semipurposeful action of a part or of the entire body. The patient may simpiy pick at a button or continue to stamp out a cigarette, or may rum several blccks. During the attack the patient will seem confused but may not be impervious to outside comands. Recognized psychomotor seizures will be found in less than one-sixth of the cases.

Generalized seizures wich impairment of consciousness as their main manifestation It should be remembered that fragments of any attack may occur naturally or as the resuit of incomplete control by medication. Dnrecognized seizures which occur during sleep may have a waking state expression of transiert loss in awareness. "Petit mal" attacks, with classical repetitive, brief interruptions in awareness and a typical spike and wave electroencephalographic (EEG) pattern, have not been seen in the Korean or Vietnan War veterans under :tudy.

Status epilepticus, a succession of major attacks without intervening recovery of consciousness, is occasionaliy the first expression of post-traumatic epilepsy.

Though these fatterns sound complex, the recognition of attacks will usually be facilitated by the repetitive occurrence of an abnormai movement and/or a loss or alteration of contact with the environaent.

\section{OTHER RELEVANT CRITERIA FOR DIAGNOSIS WHICH MAY AFYECT PROGNOSIS}

Transient eplleptic alterations in consciousness may be confused with syncopal attacks. Gidainess, blurring of vision, and loss of consciousness may accompany the vasonotor instability which not infregiently follows head trauma for a limited period. The posture of the pattent, the setting in which the attack occurs, and the nanner of recovery are often helpful in making this distinction. An increase in muscular tone, labored respiration. loss of sphincter control, or postictal headache would be against vasovagal cause. 
Psychic phenomena, without proper attention to periodicity and repetition in pattern, may be misinterpreted. If accompanied by gustatory movements or if there is ar extension into more overt motor phenomena, the epileptic interpretation is clear.

"Idiopathic" epilepsy unrelated to head injury may rarely have to be differentlated from selzures related to head injury. Considering the former, it should be remembered its peak incidence is around puberty, its clinical pattern is classically symetrical, a familial incidence is not uncomon, and when present, a typical spike and wave EEG is confirmatory. Against it would be a focal EEG abnormality or focal seizure pattern. Syraptomatic eţilepsy from other cause must not be overlocked because of too much attention to the infury. The most serious error in this regard would be to miss a brain tumor, an important etiologic factor in epilepsy as midlife is approached.

\section{RELEVANT DIAGNOSTIC PROCEDURES TO AID DTAGNOSIS AND ASSESSRENT OF PROGNOSIS}

The more precise the knowledge of the injury and the neurologic deficit, if one is apparent, the easier it is to anticipate and recognize a seizure pattern arising from the injured area. Routine skull filus will disclose linear fractures and the details of depressed fractures. Spinal fluid examination may reveal blood in the subarachnoid space in injuries otherwise considered trivial. More sophisticated procedures, eg, arteriography and CT scan, delineate such reactions to injury as hemorrhage and brain swelling.

A lucid subjective and objective description of the attack pattern remains the most reliabie criteria for establishing the diagnosis.

The EEG is firm diagnostic confirmation when it shows a focal paroxysmal abnormality which correlates with the attack pattern. Less specific abnormalities are of no diagnostic aid. Nonepileptics show the sane percentage of aberrant electrical activity as epileptics after comparable head injuries. 49,50 Although in children after head injury, generalized high amplitude spikes may se seen up to six months without prognostic significance. 51

\section{PROGNOSIS RELATIVE TO SUDDEN OR INSTDIOUS INCAPACITATION}

The nature of epllepsy includes the abrupt onset of individual attacks, all of which are completely or fartially incapacitating. In practical terms, it may be worthwhile to approach the problem in segments of time following the injury. An arbitrary division would be: within one week, within one year, and beyond one year.

Within the first seven days, $4 \%$ to $5 \%$ of the apparently trivially injured, as well as the more severely injureo, will develop one or more attacks. While some will have a single seizure, 1 of 10 will have stacus epilepticus without regaining consciousness. Because of the significant possibility of seizure during the first week following even mild head injury (see earlier classificatior.), it would appear prudent to restrict alrmen from fiying during this period of time. 
Within the first year, unlike those within the first week, the likelihood of developing one or more attacks is more closely link ad with the severity of the injury in terms of length of unconsciousness and amunt of brain destruction. The risk, adjusted for time, rises rather sharply to approximately $25 \%$ of the injured, in combat and support activities. Injuries from civilian life may be compared, if they corsist of dapressed fractures and acute intracranial hematomas. 45 In less serious civilian injuries, the risk may be halved. Admittedly, this is approximate for lack of more specific observations over an appropriate lergth of time. The prediction of individuals who will develop seizures aside from the estimated probability within the more severely injured group, is difficult. As stated; the EEG will not help, except indirectly as a reflection of the severity of the injury and retained damaged brain. If there was a febrile seizure in childhood, or overt convulsive disorders in the parents, siblings, or offspring, the estimated risk should be increased by a factor of at least 2.

Once attacks have begun, their frequency may be quite helpful in predicting their continuation over time. For example, if there are more than two attacks in the first week, the probability of persistence is $44 \%$; if there are more than three attaciks in the first year, the probability of persistence up to four years is $85 \% .46$ The frequency is far more reliable than the attack pattern, ie, whether the seizure is generalized, focal, or both.

The onset of new seizure cases levels off after one year, and beyond two to three years new cases are rare but do occur. In relating the seizure to the remote trauma, one is more secure if the seizure pattern corresponds to the site of the initial impact, and if there are no other etiological findings. Further, it is worth remembering that overall incidence is judged at $1 \%$, while that for the head injured is $5 \%$ to $30 \%$.

\section{MEDICAI THERAPY AFFECTING PERFORMANCE, INCAPACITATION, AND PROGNOSIS}

Prophylaxis - Ideally, if an adequate anticonvulsant regimen could be established from the time of injury, the first attack would be prevented. In practice, it is not easy to establish an effective blood level on the day of injury, and it is extremely difficult to achieve adherence to a drug reginen once the patient is discharged fron the hospital seizure free. However, there is a current investigative effort to evaluate an early prophylactic regimen. 52 The Vietnan experience did not demonstrate tine effectiveness of a long range prophylactic effort. Until there is further inforwation, prophylactic drug regimens for those without seizures may be reserved for the more severely brain damaged. Cases with fungating cerebritis who carry a very high risk should aiways be placed on a prophylactic drug regimen.

Therapy for established seizures - At present there are many anticonvulsant drugs. The nost effective for post-traunatic epilepsy are phenobarbital and phenytrin sodium. Phenobarbital, 0.1 to $0.4 \mathrm{gm} /$ day, is used generally in cases o: low frequency attacks. For the more difficult problems, phenytoin sodium may be used in doses of from 0.3 to $0.5 \mathrm{gm} / \mathrm{day}$. If this fails, both 
drugs may be tried at maximum levels of toierance. 53 In psychomotor seizures, commonly the most intractable, primione way be added to one or both of these compounds at 1.0 to $1.5 \mathrm{gm} / \mathrm{cay}$. Patients_msy experlence side effects while using these drugs: phenobarbital may cause drowsiness; phenytoin sodium may produce nystagmus, blurring of vision, ataxia, or skin eruption; and primidone may cause drowsiness or gastric disturbance.

Therapy as above, together with the natural tendency toward cessation, will control attacks in $65 \%$ to $75 \%$ of the patients. The remainder will continue to have attacks.

Status epilepticus must be treated as a medical emergency. From 0.4 to $0.6 \mathrm{gm}$ of sodium phenobarbital by vein, or $1.0 \mathrm{gm}$ of sodium phenytoin, or $20 \mathrm{mg}$ of diazepam may interrupt the attacks. Using less medication by other routes only temporizes and frequent repetition complicates the problem with drug intoxication. Comprehensive supportive therapy with attention to a free airway, oxygen supply, fluids, nutrients, and electrolyte balance, increases the possibility of a spontaneous remission.

\section{SURGICAL THERAPY}

Prompt and definitive surgical care is essential in limiting the destructive processes of the injury, thereby limiting this factor in the production of seizures.

Surgery, with intent to remove the epileptogenic focus, should be contemplated only in cases with incapacitating attacks after failuie of a trial, fox at least a year, of optimum medication. Given a demonstrated locus of the discharging lesicn in a part of the brain that may be spared, precise removal should provide better control of the attacks in about $50 \%$ of the cases. 54

\section{EFFECTS OF STRESS OR OTHER STATES RELATING TO PROBABILITY OF INCAPACITATION,} AND PROGNOSIS

As sequelae of head injury, there may be less capable howeostatic controis, evidenced clinically by greater vulnerability to physical and emotional stress, alteration in sleep pattern, diminished tolerance to alcohol, and other indications of endocrine or metabolic dysfunction. Thus, there are several possible precipitants if the seizure threshold is $10 \mathrm{w}$. In the aircraft, the emotional and physical stress of handling excessive air turbulance might precipitate a seizure in a susceptible individual. A less likely, but possible, factor il, lowering the attack threshold is the response to diminished atmospheric oxygen, even in pressurized cabins. Factors in the iffe style of the subject which could be important in precipitating an attack are intake of alcohol to any degree, excessive fatigue, and loss of sleep.

\section{ESTIMATES ABOUT FREQUENCY OF MEDICAI EXAMINATIONS AND RECOMENDATIONS}

In addition to necessary and appropriate managenent of the injury during the acute and convalescent phases, attention to the possible onset of seizures should begin at the time of injury, wich intervals between medical contacts being increased as the risk declines. In practical terms this would wean 
examination during the first week and at the end of one month for mild injury, with additional evaluations at three month intervals for one yeat, and with yeariy contact over two additional years for the moderate and severe injuries. Shouli seizures begin, the contacts should be weekly until they are controlled, or sj.gnificantly modified, with monthly visits for the ensuing six months and half yearly intervals thereafter. Throughout this time period, blood levels of the drug in use should be determined. Should the seizures stop for two years, a gradual withdrawal of medication might be attempted. Appropriate modification in management is necessary in seizures intractable to any form of medication. Over $25 \%$ of patients developing seizures will be intractable to all forms of therapy. The patient who has a seizure years after the head injuxy should be evaluated and managed initially as a patient who is having a first seizure (see statement on Seizure Disorders). Only after ruling out other possible causes should the original head injury be implicated as the cause.

\section{CEREBRAL PALSY}

Cerebral palsy (CP) is a chronic disability characterized by loss or impairment of voluntary tauscie control. It appears early in life and is not the result of recognized progressive diseases. This disability can result from damage to the developing nervous system before, during, or after birth, and its manifestations may be associated with varying degrees of mental retardation, speech defects, or convulsions. The deprivation of oxygen late in pregnancy, during the process of delivery, and in the first days of life is a cormon factor. Hemcrrhage, related to lack of oxygen or to physical injury during the birth process, can severely damage the newborn's brain. Infections of the mother during pragnancy, or of the young infant, such as German measles (rubella), syphilis, cuxoplasmosis, cytomegalovirus, and herpes simplex are among infections which may cause $C P$ and other evidence of brain damage. Although symptoms vary, two comon types of $C P$ are the spastic, characterized by tense, contracted muccles, and the athetoid, characterized by involuntary movements of arms and legs. Physical therapy, bracing, and at times orthopedic surgexy are indicated if the potential for functioning warrants it. Drugs such as diazepam may sometimes be effective in reducing tension and in limiting other problems connected with nerve damage.

Relevance to FAA Regulations

CP is usually well stabilized and without the hazard of sudden change when individuals seek flight crew status. The degree and type of disability compatible with the operation of an aircraft or the functions of other members of the flight crew, however, would have to be considered. Minimun loss in motor function with modest spasticity has not interfered with the operation of a motor vehicle. The patient's mental functioning should be at the usual requirements for a pilot's license.

The patient: s physical handicap should not include athetosis, tremor, spactlclty, or rigidity to a degree that would interfere with the instantaneous handling of control instruments. The sense of balance must not be impaired. Speech must not impeir comunications with ground control. Vision and hearing 
must weet flight standards. An individual subject to convulsive seizures in childhood must have been free of attacks for at least two years off of anticonvalsant wedication. In short, the principal deficit must be 1 inited to minor motor Impairwent within the current requirements for physical fitness.

\section{INFANTILE BRMTPLEGIA}

Infantile hemiplegia is hemiplegta that develops in the first few years of life from a varlety of causes, including congenital defects, birth injury, and early infectious processes. The resultant disability should be assessed in the same mancer as that described for $\mathrm{CP}$.

\section{CHRONIC SUBDURAL HEMATOMA}

I. Definition: A subdural hematome of more than two weeks ${ }^{8}$ duration usually resulting from trauma.

II. Minimum initial evaluation of person who has been treated for subdurai hematoma

A. History of -

1. Injury czusing hematoma

2. Persistence of symptoms like headache; visual, motor, or speech disturbances; ataxia, etc.

3. Selzures and anticonvulsant medication

B. Examination -

1. General physical

2. Neurologic, including evaluation of mental state

C. Laboratory studies -

1. X-rays of skull for evidence of cranial trauna

2. CT scan for evidence of recurrent hematoma

3. EEG

III. Follow-up -

A. Evaluation every three months for six months, then every six months for two years

B. Repeat EEG as above if abnormality present

C. Cieck for symptoms or signs of increasing headacke; increased neurologic cr mental deterioration; and failure of seizure control

IV. Prognosis - Major recovery can be expected by six months, and manmun recovery by two to three years. After several months, recurrence is unlikely. If a satisfactory neurologic recovery occurs, sudden incapacitation or insidious worsening is not to be exnected. 


\section{HYDROCEPHALUS AND SHUNTS}

1. Purpose of shunts - To control intracerebral pressure by prevention of CSF accumulation within the ventricular system

II. Types of shunts -

A. Anatomical considerations

1. Within the CNS: ventricie to subarachnoid space (eg, ventriculostony, Torkildsen) to by-pass ventricular obstruction

2. From CNS to extra-CNS compartment: origin is ventricle or lumbar subarachnoid space (rarely subdural space or intracranial cyst) rerminus is vascular system (right atrium) or peritoneal cavity, carely ureter, pleural space, etc.

B. Equipment - various designs, each using the principle of one-way valve

III. Disease processes leading to shunt

A. Any lesion, congenital defect, scar, tumor, etc., leading to obstruction of CSF pathways

B. "Normal pressure hydrocephalus" - etiology frequentiy unknown but may follow subarachnoid infection or hemorrhage (see statement on Common Demyelinating, Degenerative Diseases)

IV. Minimum initial evaluation of person with shunt

A. History of -

1. Factors leading to skunt

2. Symptoms of shunt malfunction, headache, lethargy, vomiting, increasing ataxia, incontinence

3. Symptoms of shunt infection, intermittent low-grade fever

B. Examination -

1. Ceneral physical

2. Neurologic--including funduscopy

C. Laboratory studies -

1. X-rays of skull and shunt terminus in chest or abdomen to determine position of shunt and confirm lack of separation of shunt elements

2. CT scan of skull to determine size of ventricies

v. Follow-up of person with functioning shunt

A. Evaluation every six months

B. Check for symptoms or signs oi - 
1. Intracranial iypertension

2. Mental deterioration

3. Ataxic gait

4. Low grade infection

vI. Prognosis - Adults with a satisfactorily functioning shunt have a relatively low incidence of shunt failure. Sudden incapacitation from shunt failure is unlikeiy. More likely, symptoms of headache or lethargy will develop gradually, the individuri will recognize sowething is wrong, and there will be ampie time to seek medical care.

Thus, aduits with a history of hycrocephalus previously treated with a shunt and who presently have a shunt in place are not prone to sudien incapacitation from shunt malfunction, and insidious incapacitation over time is also not to be expected. Rather, only mild symptoms may develop with shunt malfunction, which the individual should recognize and which will not, at least over the short course, particularly affect perforance.

Patients with late life onset of normal pressire hydrocephalus (occult hydrocephalus) should be considered to be in a spectal category (see statement on Common Demyelinating, Degerserative Disorders). If nornal pressure hydrocephalus is present, insidious incapacitation may occur even with a shunt in place.

\section{CSF ETSTULAE}

Because there is a comunication between the intracranial space and the atmosphere when this condition exists, major changes in atmospheric pressure should be avoided. If it is possible, CSF fistulae should be repaired. If the leak continues, piloting an airplane is not recomouded. 
REFERENCES

1. Eecker DF, Miller JD, Young HF: Diagnosis and management of head injury in adults. In Youmans I (ed) Neurological Surgery, 2nd ed, Philadelphia, WB Saunders Co, In press.

2. Blonstein $\pi$, Clark E: Further observations on the medical aspects of amateur boxing. Brit Med J 1:362-366, 1957.

3. Jennett B: Late effects of head injuries. In Critchley M, O'Leary JL, Jennett B (eds) Scientific Foundations of Neurology, Philadelphia, FA Davis Co, 1972, pp 441-451.

4. Chason JL, Fernando OU, Hodgson VR, et al: Experimental braiñ concussion: morphological findings ard a new cytologic hypothesis. J Trauma 6:767-779, 1966.

5. Cook JB: The effects of minor head injuries sustained in sport and the postconcussional syndrome. In Walker AE, Caveness $\mathrm{kF}$, Critchley $M$ (eds) The Late Effects of Head Injury. Springfield, Charles C Thomas, 1969, Pp 408-413.

6. Jennett B, Bond M: Assessment of outcome after severe brain damage. Lancet 1:480-487, 1975 .

7. Becker DP, Miller JD, Greenberg R: The outcone in head injury. In Youmans $J$ (ed) Neurological Surgery, Philadelphìa, 2ad ed, WB Saunders Co, in press.

8. Jennett B: In Vinken PJ, Bravyn CW (eds) Handbook of Clinical Neurology. Ansterdam-Oxfcrd. North-Holland Publishing Co, 1976, pP 6E9-68i.

9. Fisher CM: Concussion Amnesia. Neurol 15:826-830, 1966.

10. Teasdale GM, Jennett B: Assessment of coma and impaired consciousness: a practical scale. Lancet iI:8! $-83,1974$.

11. Teasdale GM, Jennett B: Assessment and prognosis of coma after head injury. Acta Neurochirurg 34:45-55, 1976.

12. Sweet RC, Miller JD, Iipper M, et al: Significance of bilateral abnormalities on the $C T$ scan in patients with severe head injury. In press, Neurosurg.

13. Miller JD, Becker DP, War: JD, et aI: Significance of intracranial nypertension in severe head injury. J Neurosurg 47:503-5.6, 1977.

14. Bond MR: Assessment of the psychosocial outcome of severe head injury. Acta Neurochirurg 34:57-70, 1976.

15. Cartlidge, NEF: Post-concussional syndrome. Scot

16. Denker PG, Perry GF: Postconcussion syndrome in conpensation and Iitigation: analysis of 95 cases with electroenc pphalographic correlations. Neurol 4:912-918, 1954. 
17. Rutherford WH, Merritt JD, McDonald JR: Sequelae of concussion caused by minor head injuries. Lancet $1: 1-4,1977$.

18. Evans CD: Aspects of recovery frow physical disability after head injurias. Scot Med J 23:105, 1978.

19. Thomsen IV: Evaluation and outcome of aphasia in patients with severe closed head trauna. J Neuro1, Neurosurg \& Psychiat 38:713-718, 1975.

20. Thomsen IV, Skinhoj E: Regressive ianguage in severe head injury. Acta Neurol Scand 54:219-226, 1976.

21. Brooks DN: Wechsler memory scale performance and its relationship to brain damage after severe closed head infury. I Neurol. Neurosurg $\underline{\text { Psychiat }}$ 39:593-6́01, 1976 .

22. Bronks in: Psychological sequelie of head injury. Scot Med J 23:104, 1978.

23. Parker SA, Serrats AF: Memnry recovery after traumatic coma. Acta Neurochirurg 34:71-77, 1976.

24. Mandleberg IA: Cognitive recovery after severe head injury, WAIS Verbai and performance IQs as a function of post-traumatic amesia duration and time from injury. J Neirol, Neurosurg \& Psychiat $39: 10 n 1-1007,1976$.

25. Gronwall D, Wrightson P: Recovery afte: minor haad injury. Lancet II: 1452,3974 .

26. Schacter DE, Crovitz HF: Memory function after closed head injury: a review of the quantitative research. Cortex 13:150-176, 1977.

27. Levin HS, Grossman RG, Kelly EJ: Aphasic disorder in patients with closed head injury. J Neurol, Neurosurg \& Esychiat $39: 1062-1070,1976$.

28. Miller E: Simple and chcice reaction time following severe head injury. Cortex 6:121-127, 1970 .

29. Levin HS, and Grossmen RG: Behaviorai sequelae of $c^{\prime}$ ssed head injury. In press, Arch Neurcl.

30. Levin HS, Grosswan RG, Rose JE, Teasdale GM: Long-term neuropsychological outrome of ciosed head injury. Submitted to $J$ seurosurg.

31. Moore MS: Complexities of human factors fn aviation. Aviat Space Environ Med $48(5): 471-473,1977$.

32. Gother D, Kahneman D: Individual differsuces in attention and the prediction of flight criteria. Perceptual and Motor Skilis 33:133j-1342, 1971.

33. North RA, Gopher D: Measures of attention as predictors of flight performance. Euman Factors 18:1-14, 1976. 
34. Gronwall D, Wrightson P: Delayed recovery of intellectual function after minor head injury. Lancet II:605-609, 1974.

35. Hayward LRC: Impairment of flying efficiency in snancastic pilots. Aviat Space Environ Mea 48:156-161, 1977.

36. Buck L: Psychomotor test performance and sleep patterns of aircrew flying transweridional routes. Aviat Space Enviror Med 47:979-986, 1976.

37. Klein KE, Wegmann HM, Athanassenas G, et al: Air operations and circadian performance rhythms. Aviat Space Eaviron Med 47:221-230, 1976.

38. Credner L: Kinische und soziale Auswirkungen vori Hirnschadiaging $Z$ ges . Neurol Psychiat 126:721-757, 1930.

39. Ashcroft PB: Traumatic epilepsy after gunshot wounds of the head. Brit Med J 1:739-744, 1941.

40. Russel WR, Whitty CWM: Studies in trawnatic epilepsy: factors influencing the incidence of epilepsy after brain wounds. J Neurol, Neurosurg $\underline{\text { Psychiac }}$ 15:93-98, 1952 .

41. Waiker AE, Jablon S: A follow-up of head injured men of World War II. J Neurosurg 16:600-610, 1959 .

42. Caveness WF: Onset and cessation of fits following craniocerebral trauma. I Neurosurg 20:570-583, 1963.

43. Caveness Wf, Meirowsky AM, Mohr JP, et aI: Work in progress, 1978.

44. Caveness WE, Walker AE, Ashcroft PB: Incidence of post-traumatic epilepsy in Korean vecezans as compared with those from World War I and horld War II. J Neurosurg 10:122-129, 1962 .

45. Jennett B: Epilepsy after Non-missile Head Injuries. Chicago, ĩar Book Medical Publishers, Inc, 1975.

46. Weiss GH, Caveness Wf: Prognostic factors is the persistence of post-traumatic epilepsy. I Neurosurg 37:164-169, 1972.

47. Metrakos JD: Genetics of Epilepsy, The Lennox Lecture. American Epilepsy Society, Dec 3-4, 1975.

48. Nova JJ, Fraser FC; Multifactorial inheritance. In Medical Genetics: Principles and Practice. Philadelphia, Lea and Febiger.1974, pp 221-230.

49. Williams D: Neuroiogical and EEG aspects of head injury. Electroenceph and clin Neurophysiol 7:495, 1955.

50. Narshall $C$, Walker AE: The value of electroencephalography in the prognostication and prognosis of post-traumatic epilepsy. Epilepsia $2: 138-143,1961$. 
51. Coujon, JA: Post-traumatic epilepsy in clinical practice. In Walker AE, Caveness WF, Critchley $M$ (eds): The Late Effect of Head Injury. Springfield, Charles C Thomas, 1969, pP 215-227.

52. Young B, Rapp RP, Perrier D, et al: Early post-traumatic epilepsy prophylaxis. Surg Neurol 4:339-342, 1975.

53. Merritt HH: A Textbook of Neurology. Philadelptia, Lea and Febiger, 1955, pp 658-664.

54. Rasaussen T: Surgical therapy of post-traumatic epilepsy. In Walker $A E$, Cayeness WF, Critchley $M$ (eds): The Late Effects of Head Injury. Springfield, Chaxles C Thomas 1969, pp 277-305. 


\section{COMMON DEMYELINATING AND DEGENERATIVE DISEASES AND EXTRAPYRAMIDAL DISORDERS - PANEL 4}

Charles M. Poser, MD (Chairman), Milton Alter, MD, Robert D. Currier, MD, and Samuel E. Hunter, $M$

\section{EXTRAPYRAMIDAI DISORDERS}

The neurologic diseases which are classificd an "extraryramidal disorders" are in general characterized by the presence of involuntary movements. The structures involved in producing extrapyramidal diseases are, for the most part, the basal ganglia.

\section{PARKINSONISM}

This is the most common of the extrapyramidal disorders; prevalence ss estimated at $1 \%$ of the population over age 50 years, with afproximateiy 36,000 new cases developing each year. The disease is characterized by rigidity of trunk, limbs, and head; by resting or occasionally intention tremor of the head or limbs, usually the hands; and by bradykinesia, or slowness in initiating voluntary movements. Presence of one component of the triad of rigidity, tremor, and bradykinesia suggests the disease and constitutes the minimal clinical criterion for diagnosis.

But the clinical array of signs in Parkinsonism is often much broader than the triad cited, and various other features which affect prognosis can be present in a given case. Patients may suffer from voice disturbances, which can seriously affect communication. The voice may be poorly modulated and soft, and may tend to trail off into inaudibility. Hanawriting assumes a micrographic style, in which lesters may start at normal size but get progressively smaller and become illogible. Presence of the Parkinsonian patient's tremor adds to the difficulty of reading the patient's script. While patients scan well with the eyes, rapid movements of the head and truck are impaired, so that instruments not located directly in front of the patient may be difficult to read. In some patients, there is a slowness of body movements, although intellect is usually well preserved.

Other movement disturbances include difficulty in arising From a low chair and impaired postural reflexes with easy loss of balance or inability to catch oneself, if the certer of gravity is suddenly displaced. Thus, a Parkinsonian patient is more likely to fall if his base is suddenly shifted, as might occur if an aircraft passes through turbulent air. This same postural difficulty gives some patients a hastening gait, in which they setm to "run after their center of gravity." Alternatively, the gait may be shuffling with short steps. If a patient tends to fall backward, the condition is called retropulsion. Saliva cannot be swallowed we1l, and this leads to arooling and sialorrhea in more severe cases.

Besides disturbances in movement involving striated muscles, smooth muscle systems are also affected. Constip: ion is comnon, and muscles innervated by the autonomic nerves can be impaired, producing disturbances in blood pressure, which is usually low, and impaired sweating and body heat 
control. An extrene form of this type of involvement of the autonomic nervous system is known as the Shy-Drager syndrome and is characterized by severe postural hypotension which is quite incapacttating. The latter is particularly disturbing in warm weather or in poorly ventilated compartments and can lead to collapse. Sometimes pyramidal signs are present in addition to the rigidity of extrapyramidal origin.

Diagnostic Procedures

There is ro specific diagnostic procedure other than clinfcal evaluation.

Prognosis for Sudden or Insidious Incapacity

Untreated Parkinsonism is a insiduously progressive disorder whick, over many years, produces incapacitation. From year to year, many patients show only slight worsening, and most will live a normal life span and die from some other cause. With modern treatment, a patients's incapacity can often be reversed, and the condition can 1 improved dramatically. However, available therapy does not arrest the dise ue process. Moreover, as will be discussed, the treatment can result in sudden worsening due to toxicity, or the patient may becoms incapacitated suddenly by what is termed the "onoff" phenomenon, wherein he passes quickly from relative normalcy to rigid incapacitation.

Medical Therapy

One of the most dramatic advances in medical therapy in the last several decades has been the introduction of levo-dihydroxyphenylalanine (L-Dopa). This compound passes readily from the gut through the blood-brain barrier into the nervous system. It is converted to dopamine, the neurotransmitter which is deficient in Parkinsonism. As dopamine levels rise, the rigidity, tremor, and bradykinesia improve, often spectacularly. Long-term follow-up ovar several years indicates that eventually larger doses of L-Dopa are required, ie, the patient becomes refractory to the drug. Because L-Dopa is partially metabolized by oecarboxylase enzymes, large doses are required.

Introduction of a drug combining L-Dopa with a decarboxylase inhibitor has allowed reduction of the amount of L-Dopa needed for therapeutic effect and has lessened the unpleasant side effects of L-Dopa. Nausea was one of the side effects which now occurs rarely during treatment of Parkinsonism. Another important side effect it dyskinesia, mainly of the head, wouth, and neck. This toxic effect is not painful to the patient but, if present, requires reduction of the dosage. A slcw buildup of L-Dopa/decarboxylase inhibitor is indicated and is better tolerated by the patient.

Another drug which may be used efther alone or in combination with L-Dopa/ decarboxylase inhibitor is amantadine hydrochlozide. This drug can ameliorate all Parkinsonian symptoms but is less effective than L-Dopa and seems to lose its beneficial effects rapidly, sometimes in a few months. Amantadine overcosage results in toxic delirium but not in dyskinesia. A skin change called "livido reticularis" may be seen, but this is benign and need not regisire discontinuance if the drug is effective. 
Older though still widely used therapeutic agents for Parkinsonism include anticholinergic drugs such as trihexyphenidyl and benztropine mesylate These drugs are far less effective than L-Dopa but have a place in mild cases or as adjuncts to L-Dopa. Similarly, antihistamines such as diphenhydramine or orphenadrine are of some benefit to the Parkinsonian patient. Side effects include blurring of vision, which can adversely affect the reading of instrumerts. It should be borne in mind that certain drugs induce Parkinsonism. These drugs include phenothiazine compounds and the major tranquilizers.

Surgical Therapy

While surgically placed lesions in the ventrolateral nucleus of the thalamus produced dramatic improvement and, in skilled hands with stereotaxic control, few complications, surgery is rarely performed today in treating Parkinsonism. Like drugs, the surgery does not cure the underlying disorder, and patients subjected to thalamotomy often required further treatment. Moreover, bilateral lesions usually must be placed, with an increased attendant risk of paresis and buibar difficulties, for instance, in swallowing and speech.

Stress

Under stressful conditions, Parkinsonian symptoms usually worsen, tremor becomes more pronounced, and rigidity increases. However, a patient with Parkinson's disease may overcome completely his rigidity and akinesia. For example, when a fire breaks out, the Parkinsonian patient, previously confined to a chair, may be able to leap up and rush from the room. When danger has passed, the immobility quickly returns. Such rare reversals of Parkinsonism are possible because the motor system subserving voluntary movements, the pyramidal system, is spared.

Frequency of Follow-up

The slowly progressive nature of Parkinson's disease allows relatively infrequent follow-up. While medication is being adjusted, weekly visits to a physician are required, and, for convenience, some physicians even hospitalize their patients. After adjustment of medicatinn, a visit to the physician once every four to six months is sufficient.

Recommencations

The diagnosis of Parkinsonism per se need not be disqualifying. Actual performance must be gauged with emphasis upon the following criteria, which should be judged in terms of specific functional incapacitation:

1. bradykinesia

2. rigidity

3. tremor

4. Inaíility to adjust center of gravity

5. rapid eye scanning

6. voice quailty

The above criteria must also be evaluated with regard to the effect of treatment, after the therapeutic regimen has been stable for at least 6 months. 
Finally, the side effects of the treatment itself must be evaluated in terns of orolingual dyskinesia, postural hypotension, and the on-off phenomenon. In many instances, adequate and appropriate meáical treatment does restore full function.

\section{WILSON" S DISEASE}

Inheritance of an enzyme deficiency in protein metabolism results in deficiency of ceruloplasmin, a copper binding protein in the blood. This autosomal recessive disorder results in hepatoienticular degeneration, Wilson's disease. Affected individuals have impaired liver and renal function as well as a movement disorder due to excessive amounts of copper in the tissues. Diagnosis depends on abnormally low levels of ceruloplasmin in the serum and excessive copper excretion in the urine. Demonstration of these defects before clinical signs appear allows the diagnosis to be made and therapy to be instituted. The movement disorder may be dystonic, choreiform, or rigid as in Parkinsonism.

\section{Diagnostic Procedures}

Because copper is deposited around the limbus of the cornea, a slit lamp ophthalmological examination may reveal the diagnosis. This ring-like copper deposit is called the Kayser-Fleischer ring. A liver biopsy will usually reveal cirrhotic changes and excess copper deposits. Penicillamine, a chelating agent, will mobilize copper stores from tissues and yield copper excretion values in a 24-hour urine specimen many times higher than normal. Aminoaciduria is also present.

Prognosis

Untreated individuals experience liver failure or uncontrollable movement disorders and die within several years. However, if treatment to limit copper intake and remove copper stores begins early enough, affected individuals may anticifate a full life span with no limitation in activities.

\section{Medical Therapy}

Copper-containing foods are protibited. Thus, liver and other organ foods must be avoided. Potassium disulfide is taken to form an insoluble copper sulfide in the gut, which prevents its absorption into the system. Penicillamine is given to remove any excess copper stored in the tissue. This regimen often results in reversai of symptoms. There are no indications for surgical treatment, unless hepatic shunting is needed in those who havo dereloped severe liver disease.

\section{Stress}

Stress makes all extrapyramidal disorders worse, and Wilson's disease is no exception. However, the patient under therapy way be expected to respond to stress in normal fashion. 


\section{Medica1 Follow-up}

Evaluation of serum and urine copper, liver function, blood, and urine should be carried out at least two times a year, even in well controlled patients. Initially, monthly follow-up is indicated.

\section{Recommendations}

Semi-annual examinations, along with determination of serum and urinary copper levels in a patient who is under good medical control, should allow for conditional qualification.

\section{GILLES DE LA TOURETTE SYNDROME}

Patients with this affliction show tic-like movements of all parts of the body, particularly the head and trunk. At the same time, they grunt, cough, exhale, and bark. The most bizarre feature includes the uncontrollable uttering of obscenities, coprolalia. The condition begins in childhood or adolescence. The minimal diagnostic criteria include the above signs, especially coprolalia in association with grunting or barking.

The untreated condition last for years, but control is possible with drugs. Haloperidol, $2.5-10 \mathrm{mg} /$ day is effective. No surgical therapy is indicated.

As with ill extrapyramidal disorders, stress makes this syndrome worse. The patient should be seen every 6 months. Absolute disqualification from medical certification is recommended.

\section{DYSTONIA MUSCULORUM DEFORMANS AND TORTICOLLIS (TORISON DYSTONTA)}

Twisting of the trunk, limbs, and head constitute the primary clinical features of dystonia muscuicrum deformans. Twisting of the head and neck alone is called torticollis. This may be the initiai feature of dystonia musculorum deformans. The condition is disfiguring and often forces the afflicted individual into grotesque posturing. Intellect is preserved. Prognosis is better if limbs are affected initially than if the trunk if first involved. Speech is difficult to understand, because the chest and throat muscles are involved in the dystonia. Muscles in chronic contradiction tend to hypertrophy, so it is common to see one sternocleidomastoid muscle bulging as the head is held in torticollis. Retrocollis is another posture sometimes assumed by the patient. There are no diagnostic procedures of value besides the clinical appraisal.

\section{Prognosis}

The disorder incapacitates the victim after a number of years; with persistent torticollis the individual may not be able to function at work even a few months after onset. No effective medical therapy is available.

Surgical Therapy

Basal gangila lesions, usually in the thalamus, have prodiced dramatic improvement in some cases, and individuals with unilateral difficulty seem. 
to benefit most. In general, incising the sternocleidomastoid muscle is not recomended because the disorder is progressive.

Stress, Recommendation

The condition worsens with stress. Absolute disqualification from medical certification is recommended.

BAIITSM (HEMIBALLISM)

Violent, throwing movements of the limbs, usually on one side, is called bailism or hemiballism. The ballism worsens with stress. The condition is usually caused by damage in the subthalamic nucleus. The site of the lesion in the basal ganglia may be inferred by noting "neighborhood" signs, such as those occurring with damage to the adjacent internal capsule or third nerve.

Prognosis and Medical Therapy

Outlook is grave, unless the violent novements can be suppressed by sedation or by large doses of tranquilizers such as haloperidol.

Surgery

A lesion placed in the area of the globus pallidus, ventrolateral nucleus, or thalamus can alleviate the ballism.

Recommendation

Absolute disqualification is recomended, with automatic or conditional disqualification six months after medical-surgical regimen. Disqualify unless surgicaily relieved.

\section{ATHETOSIS}

Most cases of athetosis occur in Infancy because of prenatal, perinatal, or inmediate postnatal injury to the individual. Twisting, writhing movements of the limbs interfere with voluntary movements. Prognosis is for stability of the condition.

Therapy

There is no effective pharmacological treatment. Physiotherapy may help patients overcome sume disability. Surgical therapy, thalamotomy, may be considered.

Follow-up and Recommendation

Annual visits to a physician are sufficient to follow this disorder. Absolute disqualification is recomended. 


\section{ESSENTIAL TREXOR}

Rhythmic, rapid, small amplitude tremor of the hands, and less often the head, constiture minimal diagnostic criteria for essential tremor. Sometimes the voice is affected by tremulousness. There is no procedure which aids in diagnosis. The disorder, inherited as an autosomal dominant trait, has none of the associated rigidity or akinesia characteristic of Parkinsonism.

Prognosis, Stress

The condition is benign in most cases, although the tremor may be embarrassing and annoying. It gradually progresses, although years may pass before this is apparent. Stress definitely worsens the tremor.

Medical Treatment

Propranolo1 hydrochloride is often effective, although undesirable side effects such as cardiac arrhythmias, angina, or depression must be wonitored. There is no surgical treatment.

Recommendat:on

With appropriate therapy, no impairment of function remains and qualification should be awarded. Semiansual reexamination should be required, including an evaluation of the patient's cardiovascular status.

\section{INEECTIONS OF THE NERVOUS SYSTEM}

\section{MENINGITIS}

Meningitis may result from infection by viruses, bacteria, fusgi, and protozna. Acute viral meningitis, for example, due to mums or lymphocytic choriomeningitis, tends to be an acute self-Iimiting 1llness which almost invariably results in complete recovery without sequelae or neurologic impairment.

Acute bacterial meningitis may be due to a host of organisms, the most comon of which in the adult are the pneumococcus and the meningococcus. These conditions, when treated early and adequately, respond to antibiotic treatment and only rarely result in permanent neurologic dysfunction or deficit. In rare instances, and as a result of extension of the weningitis into the brain pareachyma, focal neurologic signs may result, such as heriparesis, spasticity, and occasionally postmeningitic epilepsy.

Tuberculous meningitis is a subacute or chronic iliness which has a tendency to involve the structures at the base of the brain, in particular the optic chiasm and cranial nerves, and may lead to obstruction of the outflow of the CSF of the fourth ventricle and resultant hydrocephalus. If diagnosed early, the disease responds to appropriate antibiotic therapy. It may lead, 
icwever, to severe neurologic sequelae depending upon which structures have ieen affected.

Mycotic or fungai reningitides, especially cryptococcosis and coccidioidomyocis, may be indoient, chronic, and difficult to diagnose, producing nonspecific symptoms like chronic headache, mental changes, and seizures, or focai seurologic signs. Cryptococcous neofomens may invade the brain substance and produce localized destructive lesions. Eariy and appropriate treatment yith amphotericin $B$ is often successful, although it is difficult to know if complete cures are ever achieved.

Sarcoidosis may cause signs and symptoms and CSF findings which are indistingushable from the chronic, fungal meningitides. It is extremely difficult to diagnose but may respond to corricosteroid treatment.

Protozoan organisms produce meningitis in only rare instances and are extremely zare in the united States.

In all of these conditions, the neurologic deficit and dysfunction resulting Erom them are almost invariably apparent a short period after the acute iliness. The only exceptions are the mycotic and sarcoid meningitides, in which sudden snset of neurologic dysfuncion would be extraordinarily unusua1.

Careful follow-up every six months for a period of two years is recommended after the diagnosis of meningitis. An abnormal CSF in cases of mycocic or sarcoid meningitis, in the absence of neurologic signs and symptoms, should not be cause for disqualification.

\section{BRAIN ABSCESS}

A brain abscess results from a localized infection of the brain parenchyma by bacterial organisms extending either from a middle ear and mastoid infection or from the paranasai sinuses. Abscesses may also result from meningitis by way of cerebral thrombophlebitis and cerebritis. Finally, abscesses may result from hematogenous spread from a lung infection or from an infection of the face.

Ajscesses usually manifest themselves either as part and parcel of an infection of the nervous system, such an meningitis, or as a mass clinically indistinguishable from a brain tumor. Brain abscesses may necessitate susficai drainage in addition to antibiotic treatment.

The seçuelae of a brain abscess are determined by size, location, and efficacy of the abscess treatment. Convulsions may result fron such a lesion. The same considerations apply to brain abscess as with meningitis (see above). The CT scan has becone the procedure of choice for the diagnosis and follow-up examination of brain abscess.

It is recommended semiannual examinations be carried out for two years after a brain abscess has been eliminated by means of medical (antibiotic) and/or surgical therapy. Qualification after six months depends upon performance capability. Since many patients will be receiving anticonvuisant therapy, 
criteria applicable to such fndividuals will also have to apply (see Head Injury statement).

\section{ACUTE ENCEPEALITIDES}

By definition, encephalitides result fron invasion by a virus and invoive the cerebral parenchyma. Encephalitides are acute illnesses which, if not fatal, or responsive to treatment, is with herpes simplex and ARA-A, are essentially self-limiting. There are some forms of subacute or chronic encephalitiojes which are extremely rare in adulthood.

Complete recovery is frequent, but mental changes, of ten rather subtle and expressed as changes in personality, way result from encephalitides. Postencephalitic Parkinsonism does cccur but is rare and usually occurs with a delay of months or years, although in some rare instances Parkinsonism has been reported imediately following encephalitis. Convulsions may occur during the acute iliness and aiso as a sequelae. These respond to anticonvulsant medication in the same way as do other convulsions.

It is recommended semimnual examinations for a period of two years be carried out following the resolution of the acute illness. Qualification after 6 months depends on performance capability. Special attention should be paid to psychiatric/psychologic evaluation, as well as to the status of postercephalitic epilepsy and anticonvulsant regimen.

\section{NEUROSYPHILIS}

Neurosyphilis is a disease which may assume a number of different forms as it affects the nervous system, especially congenical neurosyphilis, late latent lues, primary optic atrophy, general paresis, tabes dorsalis, meningovascular syphilis, syphilitic meningitis, and guma of the nervous system. only certain of these types need to be considered.

\section{General Paresis}

This is an insidious disease which occurs anywhere between 15 and 20 years after the prinary infection. In its early stages, it is manifested by mental symptoms, including changes in mood and personality which proceed to severe dementia and psychosis. Progressive impaiment of neurologia function also occirs, in particular, spasticity and paralysis. Seizures may occur, but there are usuaily no other paroxysmal or sudden manifestations.

\section{Tabes Dorsalis}

This form of neurcsyphilis occurs either in a pure state or in combination with paresis (taboparesis). Cinically, it is manifested by at because of impairsent of position sense and affacts mostly the lower extremities. Generally, the patient's gait is affected, and there are few other neurologic symptoms. Of greater relevance is the occurrence of stiden paroxysms of pain, usually in the lower extremities but occasionally involving other parts of tine body as well. If the lower chest and abdowen are involved, 
they are cailed "gascric crises." The lightning pains of tabes are extrenely painful and may be quite disabling. They occur quite suddeniy without warning, may occur in series, and are quite disruptive to the individual's performance.

Meningosvascular Syphilis

This form of syphilis occurs roughly five years after the primary infection. Because it involves the cerebral arteries, its manifestations are quite variable. Acute symptoms resulting from involvement of cerebral arteries are indistinguishable from other forms of vascular disease and may result in the acute, sudden appearance of signs and symptoms.

\section{Diagnosis}

This is based upon a positive serologic test for syphilis (STS) in the CSF. A negative blood rest does not rule out neurosyphilis; examination of the CSF for STS, cells, protein, and IgG is required in an individual suspected of having neurosyphilis. The presence of a positive blood STS is an indication for examination of the CSF to detect asymptomatic forms of neurosyphilis.

In the case of tabes, the CSF-STS may be negative, and to make the diagnosis may require the performance of Fluorescent Treponema Anibody (ITA) test, which should be positive.

All forms of neurosyphilis respond to appropriate and adequate treatment with penicillin, or other antibiotic in case of penicillin allergy. Tabetic lightning pains and gastric crices in most instances cain be abolished by treatment with phenytoin and/or carbamazapine.

Recommendations

1. The diagnosis of general paresis or of taboparesis is an absolute contraindication to the issuing of a pilot's license.

2. In the patient with "pure" tabes dorsalis, the degree of neurologic incapacity must be determined by examination. If the patient's capacity is judged to be compatible with pilot performance, the only considerations should be that lightning pains and/or gastric crises, if present, have been controlled by appropriate medication during the preceding six months, and there are assurances such medication will be continued.

3. In the case of meningovascular lies, reexamination foliowing adequate and appropriate treatment with penicillin or antibiotics should be required. It should be emphasized, however, that even as a result of such treatment the CSF-STS may continue to be positive in spite of the patient's being asymptomatic.

4. In all patients with the diagnosis of CNS syphilis demonstrated by positive CSF-STS, or FTA in the case of tabes, appropriate psychologic evaluation should be mandatory. 
DEMYELINATING CONDITIONS

\section{MULTIPLE SCLEROSIS}

Multipla sclerosis (MS) is a disease with irvolvement of the myelin sheath, the fatty eavelope of nerve fibers within the central nervous syster. The etiology and exact pathogenesis remain unknown. The disease has its onset in young adulthood during the third and fourth decades and is slightly more comon in wonen in the United States.

The pathologic manifestations of MS consist of sharply defined areas of myelinoclasia cailec "plaques," which occur in the white matter of brain and spinal cord but may also be found to extend into the cortex and gray matter. The peripheral nervous system is not involved in this disease. The involvement of the myelin may vary from simple swelling to compiate destruction; while the axon is usually spared, in the more severe lesions it way be destroyed. When the myein sheath is corpletely destroyed as a result of the inflatinatory (glial) response, the plaque becones overgrown with glia and a scar is formed. While myelin which is only swollen may recover, there is scanty evidence for remyelination if the myein sheath is destroyed.

Altholgh plaques of MS may and do occur anywhere in the central nervous system, there are certain areas which clinically seem more likely to be involved. These include the optic nerves and chiasn; the brain sten, in particular the medial longitudinal fasciculus; the carebellar white matter and the spinai corc, in particular the corticospinal tracts and the posterior columns. In addition, the periventricular white matter is classicaliy involved, aithough the clinical significance of these lesions is not yet. :nderstood.

The disease has been characterized as being "cisseminated in time and in space", the latter referring to the fact lesions are scattered throughout the CNS, ranging from pinpoint-size to areas of demyelination several centimeters in diameter; and the form $x$ referring to the fact that during the course of the disease, clinical exacerbations and remissions occur in approximately two-thirds to three-fourths of the patients.

While in many instances the patient returns to normal neurologic status after an attack, tha overall long term course of the disease in most patients is that of slowly increasing neurclogic deficit. This iay take place over two or three years, or during a period of 30 or 40 years. It sinould be emphasized that plaques of MS may exist without pzoducing any clinical manifestations. It is also known plaques may cause dy sfunction only under certain circumstances: t'us, a plaque may not interfere with the concuction of a nerve impulse through a tract under normal conditions, but may reduce the cell's safety margin so that under certain conditions dysfunction will become apparent in a transient manner. 
It is usuaily accepted that nes signs and symptoms represent the formation of new plaques. Although the disease is characterized by exacerbations end remissions, there is little general agreenent regarding not only the nature of exacerbations but also the criteria by which one fudges thein; thus, an episode of diplopia lasting for a few sinutes nay be just as significant as numbness of the and lasting for several days. There is also a tendency to ascribe new symptcons to the underlying 11lness, and patients with MS are just as apt to develop ordinary aches and painis and minor complaints as other individuals. An exacerbation may reprosent a new plaque, an extension of an olu plaque, a physiologic change, for example, due to heat or to a psychophysiologic reaction due to stress, including physical trama. Also, slow and insidious progr - ion of neurologic dysfunction may represent effects of glial scar formation and not extension of the disease itself.

We are primerily concerned with neurologic dysfunction, that is, symptons, rather than objective signs or neurologic examination. Tnese may be divided into two major catesories in their mode of onset: sudden; and insidious and/or progressive. Symptoms may also be described in general groups related to the particular aree of the brain which is involved.

The symptow groups will be discussed individually, and their ciassification in terms of mode of onset will be included:

1. Loss of visual acuity - This may be monocular, or rarely, binocular. The loss is very frequently quite sudden in onset. It not inf requently is sssociated with a certain sount of pain in the affected eye, usually with movenent of the eye. In scme instances, when the loss of visual acuity is minfmal, the patient any conplain of blurring of vision, which then needs to be differentiated froc a mild degree of diplopia. This can be established easily by having the patient close either eye and determine if the blurring dieappears. If indeed it does, then the problem is that of a minial degree of diplopia. Visual field defects like hononymous heninnopsia or bitemporal hemianops la may occur but are quite rare.

2. Loss of color vision - This represents a loss of visual acuity restricted to the fibers originating in the ancular area. When such $10 s 5$ of color vision occurs in one eye, it rarely if ever is symptoma$t i c$, unless apecifically tested for or noted camally w the realt of closing one eye. It does, howerer, occur in both eyes on rare occastons. While it is most of ten transieat, lasting for seconds or minutes, in soce individuals it my becose perment and effectively render then color blind.

3. Diplopia - This is an extraely canos usptom in as and alnost always represents an intermuclear ophthalwoplesta reaultins fros a lesion of the nedial longltudinal fascleulus in the brain sten. The diplogis nay cone on quite addenly without any carnins. While It usually affect: lateral gaze, it nay also at times involve upward gase or be present in the neutral position. This oyapton can be extrenely incapactenting, although it can teaporartly be corrected by closing or occluding cac eye the cost of depth perception. 
4. Oscillopsia - This is an extreaely rare analfestation of nystagmas, a condition wich is usually not symptonatic of sh although it is quite frequent. Oecillopsta means the visual inage oscillates as a result of imbalance between the mopenents of the eyes, due to aystagmus. This is a rare but quite incapacitating condition.

All these visual symptons, with the possible exception of cscillopsia, alnost always occur quite voddenly and way last frem a eatter of a few seconds to days or weeks.

Syoptons of Cerebellar Dysfunction

1. Ataxia of gait - This is a result of inability to coordinate properly the mascles of locosot suddenly, it is aore comonly an insidicas and prosressive symptom.

2. Incoordination of hands and/or feet - The stine aechonian is responsible; this also occurs insidiously and results in inability to perform fine skilled novenents, crershooting, misfudging the notion neceseary to perform certain tasks, or reeching objects wch as control knobs. Intention trear may develop, nost often along with incoordination of the hands. At tines, this trewor becanes quite severe. involving the eatire body including the head and Ieading to total incapacitation. Incoordinstion of the auscles of speech sanses jysarthria, which results in thick, nonotonous, even usintelligible speech, posing sericus counatcation probleas.

Weakness or Paralysis

This any affect one or nore linbs and way occur suddenly, but again it. is nore ccomonly found as an insidicus or progressive problem. The veakress ay vary fres eininal to severe and nay result in variable degrees of inmbility to perfore necessary sotor functioss.

Sparticity

This is almost invariably an accompeninent of scoe degree of paresis and revulte in alking noweneats note difficult and less vell orgmized and

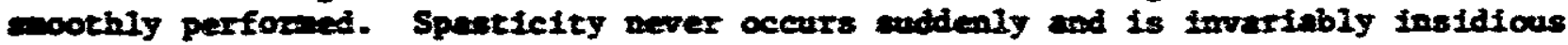

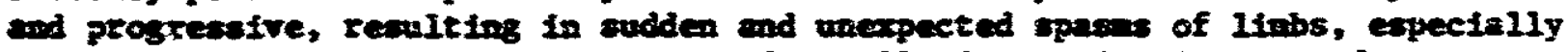
of the lover atronities, and gross and totally incapacitating interference with function.

\section{Sensory Dieterbances}

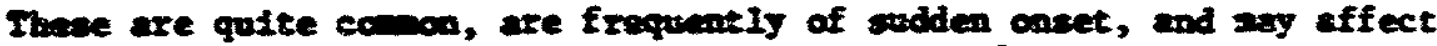
any or ali parts of the body. They verilly coneint of pareathesis which if

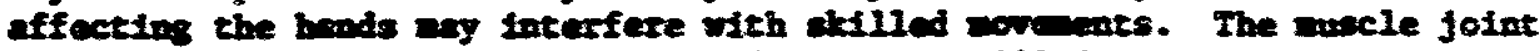

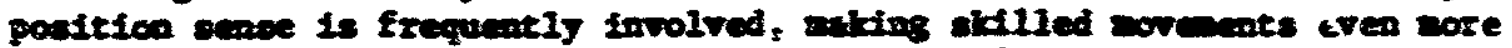
difficalt, particula iy when the wovenet is pexforsed rithout direct visan observation. Patn 10 a extraely rare nonifentation, axcept for a higher

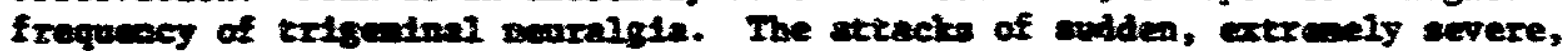
loncfoeting patn in the face cra be seriously disabling unless adequately treatud atther adictinily or eargicaily. 
Vertigo

Such attacks, often associated with nsused and voniting, way occur but are relatively rare.

\section{Corvelsions}

Grand mal and accasionally other types of ceizures occur with a frequency belleved by wost authors to be socewhat higher than can be expected in the general population.

Bladder Problems

These are extresely frequent in ws but invariably are related to the presence of sone degree of apanticity of the lower ext: aniries. Bladder symptons aost frequeatly consist of frequency, urgency, and incontinence, but at tines they include difficulty starting the urinary strem. Similar problens nay involve the bowel but are considerably rarer. These bladder difficulties, particularly the urgency and incontienence, say prove to be quite disabling if not controlled.

\section{Mental Symptons}

These way be extremely difficult to detect clinically, since they may be quite subtle. On rare occasions, they asy be paroxysmal in anture, although wch sore frequently they consist of alterations of nood ranging fro euphorta to depression. Cognitive impaiment is considerally wore comron than sappected, the degree beins roughly correlated vith duzstion of the disease. Difficulties in judgeent are related to alterations of nood as well as to cognitive inpainent. These mental symtons, perticularly in their zubtle form, ay precede other anifestations of the disease.

Minimal Criteria for Diagnosis

WS axy be either extraely easy or extrenely difficult to diagnose, and in exiler stages it way be interpreted as scae kind of payshoscenatic or convereion resction. Jnfortanately, no specific and reliable diagnostic laboratory teat aists for the disease. The diagnosis, therefore, is based prinarily upon clintent considerations, and cases are urually divided into possible, probable, and definite. The generally accepted diagnostic criteris are those progosed by Schuncher et all and are ay follows:

1. There mst be objective abnorwalities on neurologic exminacion attributable to jyafunction of the central nervous systen

2. On neurologic exmination or by history, there nust be evidence of involvenent of two or are separate parts of the Cirs

3. The objective nearologic evidence of ais disense most reflect predoninantiy wite nater invoivenat, ie, fiber tract dasage

4. The involvenent of the nexrexis wast have occurred teporally in coe or the other of the following putterns: 
a) In two or more episodes of worsening, separatsd by a period of one wonth or wore, each eplsode lasting at lesst 24 hours

b) slow or stepuise progreasion of signs and symptons over a period of at least six months

5. The patient's signs and symptons camnot be explained better by some other disease process, a decision which must be ande by a physician competent in clinical neurology

6. Onset between 10 to 50 years of age

Recently, Rose et al ${ }^{10}$ proposed s slight oodification of these criteria which are as follows:

A. Clinically definice ss - four of the following five criteria musi be present; note chotce of no. 1 or no. 2 -

1. relapsing and remitting course, with at least two bouts sepsrated by no less than one wonth or

2. slow or stepurise progressive course extending over least six woaths

3. documented neurologic signs attributable to pathology of more than one site of predoninantly cis white natter

4. usual onset of symptoms between ages of 10 to 50

5. no better aeurologic explanation

B. Probable tis -

1. history of relepsing and resitting syptom, but without documentation of signs; patient presents with only one neurologic aign comonly associated vith is or

2. documented single bout of syuptoen with signs of waltifocal white matter disease and good recovery, followed by variable symptome and signs

3. no better neurologic explanation

c. Possible us -

1. history of relapsing and renteting syptoss without documentation of $818 n s$ or

2. objective aeurologic atgas insufficient to eatablish wote than one site of GiS pathology

3. no better neurologic explanation 
Dssentially, the clinical diagnosis is based upon the abilfty to demonstrate neurologic dysfunction both by history and by neurologic examination which indicates the involvenent of nore than one area of the CNS. When it is possible to demonstrate the presured presence of multiple lesions, one highly suspects the diagnosis, especially if there have been sigificant realssions of some symptoms. On the other hand, the first attack of the disease, particularly if monosymptomatic, poses a difficult diagnostic problen.

A number of procedures and laboratory tests may be of value in either producing evidence of the existence of clinically unsuspected lesions and confiming the existence of an asymptomatic lesion, ur providing laboratory evidence of the presence of the disease.

The use of isochromatic color plates (Ishihara or American Optical Company) may reveal the presence of unsuspected monocular color blindness as evidence of a previous or current mild degree of optic or retrobulbar neuritis.

The Hot Bath Test - Placing the individual into a bath at the temperature of $104^{\circ} \mathrm{F}$. for 15 minutes may produce clinical manifestations which either have been present previously and reported historically, or have been previously undenonstrable. Occasionally, new sywptoms are also manifested. The Hot Bath Test is a completely harmless procedure, because the patfent returns to previous neurologic status upon coolfng. The test ay have great prognostic value in that it indicates syaptoms will occur when the patient is subjected to heat.

Evoked response studies - These are of three types, visual, auditory, and somatosensory. The most widely used ones are the visual evoked responses utilizing either a flash or a pattern reversal stimulus. The visual evoked responses are particularly useful in detecting either an unsuspected lesion in the optic pathway or in confirwing its presence accorjing to aistory or examination. These may have prognostic value in indicating the possibility of recurrences of visual syrptons under certain stressful circumsiances. Brain stem auditory evoked resporses, as well as the Rimura blink reflex, may reveal the existence of an unsuspected plaque in the brain stem. Somatosensory evoked responses are still not ealibrated well enough to achieve clinical status but ye useful in certain circumstances.

The radioauclide brain scan may reveal cerebral lesions, but these must be at least $1 \frac{1}{5} \mathrm{Cm}$ in dianeter to be shown. The yield of this test in MS is extremely low.

The CI scan - either say reveal the actual pleques of uS in the brain, or scowhat are frequeatly wy denosstrate typical periventricular plaques. Other findings like ventricular enlargement and cortical atrophy are not apecific enough in tis to be of diagnostic value. At this time, the very low yield and the expense of the CT scan do not warrant its inclusion in the dingnostic workup for us. 
Special paychological tests - may reveal the presence of clinically unsuspected cognitive impairweat in attern which ay be fairly typical for is, even in the absence of neurologic deficit of any other kind.

Exmenination of the spinal fluid - The CSF Inmunoglobulin (IgG) is elevated in a proportion of cases. This is not a specific test for the disease, because IgG is elevated in a number of other conditions of the nervous system. Nevertheless, it provides sone confizantory evidence when the disease is stspected clinically. In some research laboratories, the demonstration of oligoclonal IgG is said to have a sensitivity over $90 \%$ in patients with MS, but these oligocional bands are found in other diseases of the nervous syster as well. By fudicious combination of the procedures, it may be possible to change first attack, mosymptcatic in patients from the "possible" to the "probable," or even to the "definite" category.

\section{Relevant Diagnostic Procedures Aid1ag Assessment of Prognosis}

The following stople, noninvasive procedures should be carried out:

1) Monocular color vision testing

2) Lot bath test

3) Vistal and brain ster aujitory evoked responses.

Also, CSF exanination and psychological tests are highly desirable. None of these requites hospitalization, but the bot Bath Test should be carried out under observation by a physician or specially trained nurse.

Prognosis Relative to Sudden or insidious Incapacitation

The course of MS is extremely unpredictable. As a very rough rule, the pattern of the disease is usually set during the first three years of the illness. A patient with frequent exacerbations and rentssions will continte with this kind of pattern, while the patient with a single episode followed by a long remission, or the one with a progressive disease, will follow gimilar respective patterns. These patterns, however, are not invariable. of importance is the fact there are symptoms which have a tendency to recur, most probably as a result of efther physiological changes or psychological stresses, including physical traums.

\section{Nedical Ireatment}

There is no generally sccepied fors of bedical treatment for MS . Adrenocortical steroids and/or ACTh have been used extensively, but their efficacy reatins undeternined, and it is not established if the improvenent and disappearance of syaptoms coincidental with their adninistration represent a specific or a placebo effect. It is the feeling of sany neurologists, however, regardiess of the wode of action, steroids are beneficial in a proportion of patients, particulariy in shortening the acute attack.

Adherence to seneral rules of antaining good health, such as avoiding undue facigue and extremes of heat and cold, having an adequate, regular diet, etc. ny be beneficial. Avoiding beat, including hot baths and 
axd showers and exposure to sunlight, is unquestionsbly inportant to those individuals in wha such factors can be shown to play a role in the genesis of symptous.

Certein forns of symptomatc treatwent are ovellabla: use of an eye patch for persistent diplopia, but at the cost in sost individuals of depth perception; antivertiginovs drugs; antidepressants; drugs for the relief of spasticity, particularly the a wly avallable, baclofen; and use of carbamazeapine for the control of some pasaxysal manfestations of the disease, like spastas, trigeminal pain, and unpleasant persistent paresthesias.

Control of bladder problews by means of mechanical devices like Foley and Texas catheters may be sufficient. In wore cooplex urinary probless resuiting from persisting bladder infections, suprapubic cystotomy, or the nca more ropular ileal conduits may be necessary. Medicinal treatment with bethanechol chloride for urinary retention, or propantheline bromide for frequency and urgency, can provide excellent coricrol of bladder problens. Bladder training as a result of judiclous utilization of these drugs and/or mechanical devices may also provide solutions. Prevention of bladder infections is of parawount importance.

Surgical Treatient

Som good results heve been achieved for the severe cerebellar dysfunctions, and in particular the trewors, by stereotactic thalanotosies. Obdurator zerve injection or resection has provided relief of the scissoring of severe spasticity. Urologic surgery for bladder problens has been mentioned but should also include transurethral prostatectowies or surgery fnr transverse bars obstructing the urethra.

It should be exphasized that none of the medical or surgical treatwents mentioned affect prognosis.

Recomendations

1. Individusls diagnosed at the tine of FAA examination as having MS with devonstrable inpairwent of neurologic function wust be rated on the basis of spectific dysfunction as it affects pilot performance. Nedical exanination should be wandatory every six months

2. Individuals with wS and any of the following who are asyoptomatic should be denied a pilot's license

a. If there is a history of sudden visual problem as described abore during the previous $s i x$ wenths

b. If there is a likelthood in the course of their perforsance that they will be exposed to conditions of texperature which have beea found, either by bistory or actual Hot Bath Test, to produce symptom which could interfere with their performance as a pilot 
c. If there 1s a history during the previous 6 months of sudden alteration of sensation affecting hands and arms

d. If there is a history during the past 6 wonths of paroxysmal symotons, or vertigo or convilstons, which have not been adequately controlled by appropriate medication

e. If there is a history during the past 6 months that an enctionally stressful situation brought on an exacerbation of the disease

f. If there is a histoky duriag the past 6 wonths of alteratiors of mood; this would require the administration of specific psychological tests to letermine the presence of extent of impaiment of judgnent and/or cognitive function

Recommendations regarding epilepsy and vertigo should be followed (see statenent of Panel 6 on Seizure Disorders and that of Panel 8 on Dizziness).

3. R vexamination and revaluation is mandatory upon appearance of new syaptons or recurrence of old ones

\section{POST- OR PARAINFECTIOUS DEMYELINATING CONDITIONS}

Acute Optic Neuritis

Acute optic or retrobulbar neuritis is generally consicered to be either a mifestation of $\mathrm{kS}$ or the result of a post- or parainfectious inflammatory myelinopathy.

Various follow-up studies have demonstrated rcughly $25 \%$ of patients with an Initial attack of optic or retrobulbar neuritis will develop other signs and symptoms of MS. There are no laboratory tests available currently which help identify those individuals in wom this is a manifestation of MS. It should be stressed, however, that with tests such as the hot bath, visual evoked responses, and color vision testing of the unaffected eye, auditory and scomatosensory evoked responses any be useful in demonstrating other unsuspected lesions of MS. Follorup after at least two years or longer may reveal the true aature of the diseases.

With rare excepticas, post- and parainfectious optic and retrobulbar neuritis are acute single eyent lilnesses which way end in couplete recovery: the sequelae depend upon the severity of damage and the specific area of the ais involved.

Other Manifestations of Post- Parainfectious Inflamatory Myelinopathy (Acute Disseninted Eacephelongelitis, Acute Dissesinated Vasculoryelinopathy)-

The most cow on of these is tranaverse ayelitis. All the discussion above is applicable to this entity. Almost any part of the nervous system nay be affected as the result of viral infections, or imomizations and vaccinations. These inciude the cerebellum; the brain sten. causing disturbance 
of vestibular function; the oculonotor system; cerebcal white matter, causing mental symptoms; and the erantal nerbes, spine? roots, and peripheral nerves in Landry-Guillain-Rarre syndrome and its variants.

\section{DISTURAANCES OF gIGHER INTELLECTUAL FUNCTIONS}

\section{APHASIAS}

Aphasia is defined as a disturbance in previously acquired language ability, secondary to a lesion in the central nervous system. Clearly, the term "aphisia" must not be applied to a retarded Individual who never was able to use language, and it also should be clear "language" does not refer only to speech. Aphasia is not due to impairment of speech muscles, nor of nerves innervating those muscles, but results frow lesions in those parts of the brain subserving language and represents the loss of a specific acquired intellectual function.

In $99 \%$ of right-handed individuals and more than half of the lefthanded, the language center is in the left cerebral hewisphere, particularly in that part which surrounds the sylvian fissure-the inferior frontal gyrus. Other portions such as the occipital lobe and the corpus callosum are also important. In some Individuals language function is located in both cerebral henispheres.

In order to elicit language disability, the Individual must be rested for comprehension, repetition, reading, output, writing, and naming. Combining the initial letters of these functions, one has the convenfent memonic, "C-R-R-O-K-N." Actually testing is couplex and requires special training, but as a minimal criteria a disturbance of any one of the CRROWN functions allows the diagnosis of aphasia.

The Boston School led by Geschwind and Benson has identified a grouping of aphasic syndromes which is useful clfnically. 3 These include Broca's (nonfluent), Wernicke's (fluent), and conduction aphasia due to lesions in frontal, temporal and subcortical frontotemporal white matter bundle, respectively. These three syndrowes are associated with an inability to repeat, and, in addition, Broca's aphasia is characterized by decreased speech and writing fluency but preserve comprehension; Wernicke's is characterized by a hyperfiuency and disturbed comprehension; in conduction aphasia there is relatively preserved fluency and comprehension but disproportionately defective repetition. Other aphasic syadrowes include isolation of speech area, transcortical aphasia. and agraphia with or without alexia.

\section{APRAXIAS}

Other disorders due to discrete brafn lestons affect higher cortical functions. These disturbances are not attributable to denentia. Cliniclans trained in assessaent of langunge disturbances, the aphasias, are also skilled in detecting the behavforal changes due to other discrete brain lesions affecting learned, skilled notor tasks, the apraxies, and the recognition of maning of objects perceived through the visual, sudirory, or tactile 
stimuli, the agnosias. Skills such as spatial orientation, recognition of laterality, identification of body parts, caiculation, and map reading $a^{r} e$ the examples of higher cortical furctions which can be disturbed by discrete brain lesions.

Apraxia may be defined as loss of a jearned notor skill. The complex coordinated movements of hands and feet needed to fly an aircraft represent practicl functions, and their loss may therefore be an apraxia. of coirse, ar individual who never possessed flying skill cannot develop an apraxia for flying. However, one who does develop an apraxia for this skill can still perform all of the individual motor movesents which that skill entails. Thus, an apraxia differs from a paresis or plegia. With apraxia, the sequence of brain connections needed to perform the learned skill is impaired, while the motor components of that skilled act are preserved.

An Individual with apraxia may have trouble dressing himself (dressing apraxia), oz he may be unable to walk smoothly (gait apraxia), while retaining the ability to move the arms and legs individually without difficulty. Other individuals lose the ability to p:otrude the tongue on comand or even to suck chrough a straw until food is obtained.

Apraxia of a limb may be shown by an individual's difficulty in performing beckoning movements or pounding a aail. When asksd to perform such movements with a nonparetic hand, the individual with apraxia shows gross, primitive stimulations of the skilled movements. Because motor strength and gross motor skills may be intact, the detection of apraxia may be extremely difficult unless specific tests are made.

Apraxia constitutes an absolute contraindication to flying an aircraft.

\section{PARIETAL LOBE DYSFUNCTION}

A series of higher cortical functions believed to be organized in the parietal lobes may be described. Acute or invasive lesions of one or both parietal lobes can disrupt these functions. These include the ability to locate oneself in space (spatial orientation). Symptoms of disturbed spatial orientation include a tendency to get lost even in familiar surroundings. Such individuals may be unable to find the tathroom in their own howe. They may have difficulty travelling from one piace to another, even though they formerly traversed the same route many times. They cennot read a map. No such affected individual should, of course, fly.

Right-left disorientation is another feature of the parietal lobe symptom complex. The afflicted person cannot teli right from left, or is unsure of laterality and easily confused. For example, crossing one arm over the wher makes it exceedingly difficult for an individual with rignt-leit disorientation to pick out one side as opposed to the other.

Finger agnosia is a peculiar inability to recognize and identify a given finger, especially the niddle and ring finger, less often the thumb, 1ittle, or Index finger. While sose can identify these fingers on their own hand, they cannot identify them on another's. 
Dyscalculia is an inability to perfor mathematical functions such as division, multiplication, subtraction, and addition. While wathematical ability is a knack for which proficiency varies widely anong individuals, "dyscalculia" is different in that it is present in someone who once had athematical ability and lost it.

Inability to copy figures or to recognize figure-ground relationships may also occur with parietal lobe lesions. Such individuals may not be able ro construct a simple figure in two planes, for example, using match sticks. They may be unable to detect omissions in an incomplete drawing. They may grossly distort or leave incomplete components in one half of a picture. For instance, they way squeeze all of the numerals of a clock into the right half of the clockface.

The parietal lobe defects described above are absolute contraindications to flying.

\section{ALEXLA WITH OR WITHOUT AGRAPHIA}

Reading and writing are complex learned skills and may be lost with discrete brais lesions. An individual sho knew how to read but lost it is said to be alexic. Sons individuals, uswally males, are believed to have congenital impairment in the brain organization needed for acquiring a readIng skill. They are a special case and are said to have "congenital alexia." Incellect is intact in these individuals and mathematical ability is usually preserved, but they have great difficulty in learning to read. In some, the ability to read may develop after adolescence, but rarely, if ever, do such individuals read for pleasure. They ray, hcuvever, function entirely adequately as fliers as long as they are not required to read new instructions. Interpretation of instrunents, if dewonstrated to be adequate, should be sufficient to permit flying.

Alexia with agxaphia is due to a lesion in the posterior part of the dominant hemisphere. Such a disability would preciude flying.

Soae individuals may be mable to read. Yet, they retain the ability to write legibly. Often they cannot read what they therselves have written. Such individuals have alexia without agraphia, a disconnection syndrome affecting crossing fibers in the corpus caliosu, according to Geschwind and colleagues. Such individuais should not be pernitted to fly. The defect is usually permanent but couid be reassessed annually.

\section{AGNOSIAS}

Ability to see, hear or feel, coupled with failure to appreciate the meaning of the visual, auditory, or tactile perceived object, is called an agnosia. To understand the nature of the disorder, one might consider how a Chinese or Arabic Syubol appears to one not trained in reading these ianguages. While the viewer can trace and otherwise describe the symbol, to the viewer, it has 
no meaning. If at one time the individual could read these symbols and then iost that ability, he would have a visual agnosia. Even less complex objects nay be devold of taning to one with visual 3 gnosia, for exatple, an apple way be seen as round and red with stem and snooth skin, but the viewer still way not know what it is. On the other hand, touching the object, a tactile, stimulus, or hearing someone bite into it, an auditory stimuius, inadiately may enable the individual to discover the nature of the object.

A remarkable subcategory of viswal agrosia is prosopegnosia, in wich the individual cannot recognize faniliar faces by sight. Yet, when the individual speaks, an auditory stimulus, the individual is inmediately identified correctly. In stmilar fashion the agnosia may involve other modalities; for example, hearing may not suffice to identify an object (auditory agnosia), or feeling it may not be adequate for identification (astereognosia).

\section{Diagnostic Procedures}

The advent of radionuclide scanning of the brain and $C T$ scan permits rather precise correlations between various aphasias and underlyiag brais. damage.

\section{Prognosis}

The prognosis depends on the cause of the underiying defect. It should be mentioned that strokes, trauma, tumor, and infections a: included among the causes of brain damage that produce aphasia, agnosia, and aprazia.

\section{Sedical Therapy}

Speech therapy is protably of some benefit in restoring certain degrees of language in aphasic patients. However, the process is painfully slow, and wary clinicians believe that spontzneous recovery, if any, accounts for nost of the improvement. In general, prognosis for full recovery is poor.

\section{Surgical Therapy}

Whether newer teclniques such as extracranial-intracranial bypass, anastomosis of middle mingeal artery to middle cerebral branches, will be effective in restoring perfusion to ischemic langusge centers in the brain is dubious. There is no surgical therapeutic procedure otherwise availabie.

Stress, Followsp

Aphasia worsens under conditions of stress. Clearly, conunication difficulties preclude participation in highly technical tasks such as flying.

Semananal reexamination by a skilled neurologist or preferably, aphasiologist, is recomended, because practically ali the disturbances of higher intellectual functions described above constitute absolute contraIndications for a pilot's license. 


\section{THE SPINOCEREBELIAR DEGENERATIONS}

These hereditary diseases ar cominan or recessive. The dominant forms show comilete or nearly complete penecrance, are of insidious onset, and are characterized by a gradual progression of symptors related to balance, coordination, and speech and eventually, stallowing and thinking functions. Sometimes called olivopontocerebellar atrophies (OPCA), they are characterized pathologically by cell loss in the cerebellum and brain ster. The dominant varieties are of adult onset, usualiy in the $20 \mathrm{~s}$ or $30 \mathrm{~s}$, sometimes as late as the $40 \mathrm{~s}$.

The recessive variety (Friedreich's) usually manifest in the eariy teen years and in obvious form rapidly progresses into severe ataxia. If, however, it ss atypical, and present in a partial form or slowiy progressive it may give gradual disability into the third decade.

Other causes of cerebellar degereration, such as alcohol, drug use, is, metabolic defects, and the rewote effects of cancer should be consicered and ruled out by appropriate testing.

Relevant diagnostic procedures include complete histcry and neurologic examination, skull x-rays, CT scan, preumoencephalography, and possible CSF study with special tests for multiple sclerosis. Sudien incapacitation does not occur. Stress makes the acaxia temporarijy worse. There is no mecical therapy for these disorders at the present $x$ ime. There is no surgical therapy which is useful, including the implantation of electrodes.

If the diagnosis is established, flying may be contraindicated because of imbalance and incoordination. Since judgment defects and upper extremitv ataxia occur later than leg ataxia and imbalance, flying might be possible in the milder and earlier varieties of these diseases.

HENTINGTON'S DISEASE (CEOREA, HD, OR HC)

Evidence of a choreic movent disordar in adult isfe and /or early dementia, with a fanily history of nuntington's disease, is nearly diagnostic. HD is a dominantly inherited degenerative disease with a high degree of penetrance, in wich the basal ganglia, particularly the caudate nuckeus and the cerebral cortex, are affected with celiuiar loss and eventual atrophy, wich produce a choreiform movement disorder with progressive dementia.

The two cifnical elements of the disease may occur together, or one may precede by several years. The onset may be from childiood to old age but is usually around age 30 . The course is one of slow, even progression.

The use of the chorea-inducfing drugs sich as L-Dopa, or the long term use of major tranquilizers, should be considered as a cause of chorea. The several causes of dementia siould be considered. If there is no fanily history, the diagnosis of $\mathrm{HD}$ may be difficult. A diagnostic problen is that of the patient with early or subtie dementia and a positive faxily history: Is this early evidence of the dementia of $\mathrm{kD}$ ? $\mathrm{Or}$ is it anxiety and depression? 
There are no diagnostic laboratory tests, but a thorough history, neurologic examination, and a CT scan of preumonencephaiogram showing sefective attophy of the crudate nucleus may be helpful. Formal psychometric testing may be helpful.

Sudden trcapacitation does not take place but insidious mental incapacitation may. The suiclde rate is abnorwally high, and that possibility should be considered in every patient with tho or BC.

Hedical therapy with the dopamine blockers, such as the phenothiazines or the butyrophenones, is useful in suppressing the wovesents but neither stops the progression of the disease nor influences the mental symptoms and any even worsen the depression. Surgical therapy is not useful. Stress may make this novement disorder temorarily vorse.

In most cases, the diagnosis is disqualifying for flying, but if the only manfestation is wid chorea and there is no desentia, the decision could reasonabiy be for qualification. If an at-risk person has mild mental symetores and the diagnosis is not clearly established, it is felt the patient should be disqualified until diagnosis is extablished. If there are no sfgns or symprons, but rediographic sigas are present, flying may be allowed with a yearly review.

\section{NORHAL PRESSURE GYDROCEPHALUS (OCCULT GYDROCEFHALUS)}

Ts is a disease of insidious onset in aduits, nanifested by mental ieterioration, progressive gait difficulty (gait apraxia), and urinary incontinence. It is caused by intermittent or partial blockage of the spital fluid absorptive or flo mechanisms in the subarachnoid space around the cerebral and/or cerebeliar henispheres, wich produces veptricular enlargement without gyral irophy or sulcal enlargenent. The diagnosis may be suspected in a widdle aged or older person who has the above triac of symptcus which progress gradual.'y over a period of wonths to a year. The disorder follow trauna, infection, or subaracbnoid heworrhage, or may occur wichout apparent cause.

Although not wways, there must be consideration of other causes. The differential diagnosis includes brain tumor, senile and presenile denentia, chronic nentagitis, and subdural bematcana.

The $C T$ scan should be done to help exclude tmor, the dementia due to atrophic disease, and the possibility of bydrocephalus due to ventricular blockage. CSF studies to demonstrate the effectiveness of the spinal fluz $J$ absorption mechanisus are useful, as are CSF radicisotope studies to desonstrate the flow of CSF in and around the brain. Arteriography is sonetines indicated in patients in wo arteriosclerotic brein disease is coneidered, and preusoncephalography also be useful. These studies, particuiarly the CT scan, also may be useful in following the disease after treataent. None, bowever, singly or in cowbination are absolutely diagnostic. 
This is a disesse of insidious but fairly continuous progressive incapacitatioa over eonthe to years. Nedical therapy is not useful in preventing progression of the disease.

Surgical therapy in the form of cerebrospinal fluid shunting is proper but not always beneficial, because of the pcssibiliky of post-surgical seizures and rapid blockage of the shunt.

Stress is unrelated to the probability of incapacitation.

If this disease is present, it is absolutely disqualfying even though the shunt is functioning.

\section{CREUTZFELTT-JAKOB DISEASE}

This is a "slow virus" disease causing a progressive dementia and leading to death in a short gerfod of time, perhaps less than a year. Pathologically, the condition involves the corter, bassl gangiia, pyramids, cerebellum, and possibly anterior horn cells. A typical history of rapidly progressive dementia with the early onset of pyramidal, extrapyramidal, cerebeliar, wyoclonic, or antertor hore cell signs on neurologic examination, an episodic EEG abnormality with nild to woderate signs of brain atrophy by pneumencephalog phy or CT scan, and the absence of other disezse are sufficient for presumptis' diagnosis.

The only critical test for absolute diagnosis is brain biopsy with appropriate aicroscopic and slow virus culture studies in certain capable laboratories. The biopsy should be carried out with the knowledge that this disease is deadly and transmissible, and the agent is difficult to eliminate from the laboratory and equiprent.

CF scan, EEG, pneumoencephalography, and arterlography are appropriate. The EEG will sometimes sinow a moderately diagnostic spike abnormality intermixed with periods of electrical silence. By the time the diagnosis is considered, the patient most likely will be demented to a degree that formal psychologic tests will not be Decessary.

Incapacitation with this disease will be rather rapid but not sudden. There is no pedicil or surgical therapy. Stress is unrelated to incapacitation of prognosis. Once the diagnosis is established, further medical examination is not necessary. Flying is absolutely contraindicated.

\section{PRESEIIE AND SENILE DEAENTA (ALZHEIMER'S DISEASE)}

This is a gradually progressive organic brain syadrome occurring in the absence of any of the known causes of dementia such as depression, drugs, netaboiic encephalopathies, arteriosclerotic denentia, normal pressure hydro cephalus, etc. It is characterized pathologically by cell loss largely in the cerebral cortex, and thus thinking and memory are involved first and primarily and other portions of the nervous systen and other functions 
secondarily and later. The dementia is progressive over a period of years, with other changes on neurologic examination coming after the dementia is established. The disease is usually not hereditary. Senile and presenile dementia differ only in the age of onset: before 65 years it is called "presenile", and after, "senile" dewentia. Pathologically and clinically, they are the same disease.

Diagnostic procedures include skull x-ray, EEG, Cr scan, psychometric exainations, CSF examination, and possibly, pnemonecephalography and/or arteriography. All of these are negative except the CT scan and/or air studies, which should show cortical atrophy with widening of the cerebral sulci and ventricular enlargement, and the psychowetric studies which will show organic changes.

A slowly developing dementia with the typical CT scan findings, and an essentially normal neurologic examination with or without a family history, indicate a presumptive diagnosis of presenile or senile dementia. Since depression may mimic this disease in its earlier stages or be associated with it, psychiatric or psychologic consultation are often necessary and helpful.

The incapacitation is gradual, but the realization of the incapacitation under stress, or the breakdown of memory or thinking processes in a critical situation, may be sudden. A sudden stressfui situation requiring excellent decision making capabilities and/or memory may produce thinking failure and disclose a latent progressive dementia.

Medical and surgical therapy are useless.

If this diagnosis is considered but not established, the patient should be taken off flying status until the diagnosis is clarified. This diagnosis is disqualifying for flying.

\section{METABOLIC OR ORGAN FAILURE DEMENTIA}

Acute or chronic kidney, liver, lung, parathyroid or thyroid disease or failure can lead to reversible or irreversible dementia. The minimal criteria for diagnosis are the documented presence of failure of an organ and a concombant organic brain syndrome. There are usually other neurologic symptoms and signs, which vary with the organ involved. Other causes of chronic brain syndrone should be considered. These inciude all the causes of dementia without organ failure.

Diagnostic procedures related to the organ in question, and/or to rule out the possibllity of unassociated train disease, are indicated. The appropriate biochenical, scanniag, liotope or arteriographic tests of organ function or organ biopsy are indicatel, in addition to the appropriate tests for cerebral function such as psychomet.tCs, EEG, CT scan, arteriography, pneumoencephalography, and spinal fluid exaninations. 
These disenses usually give gradual incapacitation, except for anoxic encephalopathy which is rapid and associated with unconsciousness. The desentia, however, ay becose rapidly or suddenly apparent after a period of minimal mental symptors, especially in the case of kidney, liver, or lung disease. The reason for this rapid decompensation is not clear.

There may be considerable recovery, the extent of which is unpredictable at first. Therefore, an appropriate perlod of time should elapse, which way be a year or wore, before a final determinarion of the degree of permanent dementia is ade.

Surgical therapy is not appropriate for these diseases. The effects of stress are unrelated.

If the diagnosis is being considered, or has been established, medical, neurologic, and peychologic examinations following the course of the underlying disease and gauging recovery are appropriate at yearly intervals. If the diagnosis is suspected but not proven, consideration of suspension of flying status may be appropriate until the situation is clarified.

\section{ALCOHOLIC DEMDATIA (B-VITAMIN DEFICIENCY DEAIENTIA: RORSAROFF'S SYNDRONE)}

The diagnosis depends on a history of long-continued alcoholism accompanied by nutritional deprivation; there should be appropriate neurologic and psychologic findings, possibly inciuding signs and symptoms of the classic alcohol syndromes: Wernicke-Korsakoff, Marchiafava-Bignami, cerebellar degeneration, and peripheral nerve degeneration. Confabulation and severe recent emory loss are hallmarks of the Korsakoff psychosis. It should be stressed these changes are often reversible with treatment of the underlying problem of alcoholism.

Other causes should be ruled out with appropriate neurologic studfes, Iike CT scan, EEG, skull x-rays, lumbar puncture, chemistries, and sero108y. The specific type of alcoholic grain disease is best determined by the clinical neurologic and psychologic examination. Nerve conduction times, liver biopsies, and psychologic studies may be helpful.

Incapacitation, although often rapid, is not truly sudden bit may becone apparent following an alcoholic bout. It way also be insidious with gradual involvenent of menory.

Yedical therapy in the form of abstinence from aicohol and vitamin supplesents is indicated imediately after the diagnosis is established. The reversibility of some of the symptoms may be incomplete, and any prediction as to extent of recovery may be impossible at the onset of treatment. Surgical therapy is inappropriate. 
Stress is imrelated.

At appropriate intervals, such as every 6 to 12 wonths, there should be reexanination to gauge improvement. The various alcoholic syndromes of ten blend together, and since dementia is comon to wost, flying would be prohibited, unless the rental functions clear entirely.

\section{NONSPECIFIC DEMENTIA}

Progressive loss of intellectual capacity in the aged is comon, and the cause is undetermined in more than half the cases. There is a prevalent misconception, even among physicians, that cerebral athercsclercais is a major cause. However, a wide variety of disorders may include dewentia as one of their features. In each there is usually a slow loss of reasoning, memory, comprehension, and in some sases, verbal skills.

Karp analyzed the causes of dementia in 84 of his patients: tumor, 8 arterosclerosis, 8 alcoholism, 6 norwal pressure hydrocephalus, 5 creutzfeidt-Jakob disease, 3 'Euntington's disease, 3 post-traumatic cerebral atrophy, 1 subarachnoid hemorrhage, 1 encephalitis, 1 and cerebral atrophy of unknown cause. 48

A simple office evaluation of mental functions, consisting of testing recall of resent events, ability to perform simple mental arithmetic, and measurewent of abstract reasoning, quickly can disclose evidence of altered mental functions. More formal assessment of intellectual status can be achieved with standardized intelligence tests, such as the Wechsler Adult Intelligence Scale (WAIS). This and other psychometric tests may give clues to localized or potentially treatable causes of intellectual deciline.

Other studies should include a full medical assessment designed to disclose metabolic, endocrine or electrolyte abnormalities, chronic low-grade fungal infections of the nervous system, meningeal carcinomatosis, and primary and secondary neoplasms. Skull $x$-ray, EEG, isotope and CT scan are appropriate, and cerebral arteriography is often helpful.

The prognosis of dementia of undetermined cause cannot be predicted. Medical therapy is entirely determined by the cause. No redication has been shown to improve mental functioning significantly in patients with nonspecific degenerative disorders of the brain, multiple cerebral infarctions, or senile dementia.

Shunting of CSF from cerebral ventricles to another absorptive site such as the peritoneum may correct dementia in patients with normal pressure hydrocephalus. Excision of a tumor, of course, may cure the dementia in patients with neoplasm or other space-taking intracranial masses.

Stress is poorly tolerated, even when dementia is wild. Irritability may be an early hallmark of dementia. As the dementia progresses, followrp becomes unnecessary. :ae suspicion of dementia contraindicates flying until the diagnosis is clarified. 


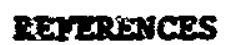

ExTraptrayidal DISORDERS

CERTRA:

1. Medowell FH. Lee JE: Clinical Neurology. Baker AB, Baker in (eds). Hagerstown, Harper and Row, 1976, Chapter 26.

2. Duvoisin R: Clinical diagnosis of the dyskinesiss. Hed CIin yㅡㄹ $56: 1321-1342,1972$.

\section{PARKIISONISY}

1. Delaney P, Fernaglich J: Parkinsonim and levodopa: Five year experience. J C1:m phamacel 16:652-659, 1976.

2. Greenacre JR, Coxon A, Petrie A, Reid JL: Coaparison of levodopa with carbidopa in Parkinsoaira. Iancet $2: 381,1976$.

HWNTINGTON'S DISEASE

1. Barbean A, Chase IH, Paulson GW (eds): Huntington's chorea. Advances in Nearology, New York, Raven Press, 1973, Vo1 I.

2. Alter M, Hyrianthopoulos N: Chronic progressive hereditary chorea of Huntington. In Seientific Approaches to Clinicel learology. Goldensohn ES, Appel SH (eds), Philadelphia, tea and Febiger, 1977.

ESSENTIAI TREMOR

1. Hinkler GF, Young RR: Efficacy of chronic propranolol therapy in action tremors of fmilial, smile and essential varieties. N Eng J Med 290: 984-988, 1974.

2. Fahn S: Differential diagnosis of trenors. Hed Clin N Amer 56:1363-1375, 1972.

GIZLES DE LA TOURETTE'S DISEASE

1. Lucas AR: Gilles de la Tourette's disease: An overview. Yㅗ State I Med $70: 2197-2200,1970$.

DYSTONIA

1. Fahn S: Biochenistry of the basal gang1ia. Adv Neurol 14:59-89, 1976.

WILSOA'S DISEASE

1. Dastur DR, Manghani DR: Wilson's disease. In Scientific Approaches to Clinical Heurology, Goldensob ES, Appel SH (eds). Philadelphia, Lea and Febigex, 1977. 


\section{DIFECTIOAS OF IBE MERVOUS STSTEX}

\section{WMIGITS}

1. Fetter B, Kliniworth G, beadry $1:$ Eycoses of the Central jervous Syctea. Baltisore, BHllias and Bilkins Co, 1967.

2. Fitzsinons J: Tubereulcas meningtis: A follosup study of 198 cases. Tubercle 44:87-102, 1963.

3. Wathat $\mathrm{K}$, Chandy $\mathrm{J}$ : Tuberculous infections of the nervous systen. Clin Reurosurs 14:145-177, 1967.

4. Quade F, Kristensen K: Purelest neningitis: A review of 658 cases. Acta Med Scrid 171:543-550, 1962.

5. Saks A: Complications and sequelae of pyogenic meningitis. Clin Neurosars 14:221-226, 1967.

\section{ENCEPHALITIS}

1. Palmer R, Finley K: Sequelae of encephalitis. Calif Med 84:98, 1956.

2. Scott T: Treatment of encephalitis. Hosp Med 6:88-97, 1970.

3. Elian M: Herpes siplex encephalitis: Prognosis and long term followup. Arch Nearol $32: 39-43,1975$.

\section{BRATH ABSCESSES}

1. Kayenbuhl A: Abacess of the brain. Clin Mearosurg 14:25-44, 1967.

2. Morgan H, Wood H, Hurphey F: Experience with 88 consecutive cases of brain abscess. I Yeurosus? 38:698-704, 1973.

3. Victor M, Bauber B: Brain abscess. Yed Ciin N Amer 47:1355-1370, 1963. NEUROSYPHILIS

1. Hoostand H, Eecobar H, Kopf S: Neuroeyphilis. JAMA 219:726-729, 1972.

2. Merritt H: Textbook of Reurolory, ed 5. Philadelphia, Lea and Febiger, 1973, Pp 109-138. 
DEMELINATING CONDITIONS

\section{MULTIPLE SCLEROSIS}

1. Ansari $R$, Wells $\mathrm{K}$, Vatessery G: Quantitative estiwation of cerebrospinal fluid globulins is multiple sclerosis. Neurol 25:688-692, 1975.

2. Fog T: The course of multiple sclerosis. Acta Neurol Scand 42:608, 1966.

3. Guthrie I: Visual and motor changes in patients with multiple sclerosis: A result of induced change in environmental temperature. Arch Neurol Psychiat 65:437, 1951.

4. Rurtzke J: On the evaluation of disability in multiple sclerosis. Neurol 11:686-694, 1961.

5. Mackay R, Hirano A: Forms of benign multiple sclerosis. Arch Heurol $17: 588-600,1967$.

6. McAlpine D, Lumsdeo C, Acheson E: Multiple Sclerosis: A Repppraisal. Baltinore, Williams and Wilkins Co, 1965.

7. McDonald $W$, Halliday $A$ : Diagnosis and classification of multiple sclerosis. Brit 프 Bull 33:4-8, 1977.

8. Poser C: Diseases of the myelin sheath. Part I: Multiple sclerosis, Baker A, Baker I (eds): Clinical Neurology. New York, Harper and Row, 1978, pp 1-70.

9. Robinson $K$, Rudge $P$ : Abnormalities of the auditory evoked potentials in patients with multiple scierosis. Brain 100:19-40, 1977.

10. Rose A, et al: Criteria for the clinical diagnosis of multiple sclerosis. NeuroI 26: (June, part 2), 20-22, 1976.

11. Schumacher G, et al: Problems of experimental trials of therapy in multsple sclerosis. Ann NY Acad Sci 122:552-568, 1965.

12. Shahrohki F, Chiappa K, Young R: Pattern shift visual evoked responses. Arch Neurol 53:65-71, 1978 .

13. Stockard J, Sharbrough F: Detection and localization of occult lesions with brain stem auditory responses. Mayo Clin Proc 52:761-769, 1977. 


\section{POST - AND PARATNFECTIOJS COAPLICATIUAS}

1. Alter H, Good J, Okihiro $\mathrm{M}$ : Optic neuritis in Orientals and Caucasians. Neurol 23:631-639, 1973

2. Poser C: Diseases of the nyelin sheath. Part II: Diseaninated vasculonyelinopathy, Baker A, Baker I (eds): Clinical Neurology, Few York, Harper and Row, 1978, PP 80-104.

DISTURBANCES OF GIGHER INTELLECTUAL FUNCTIONS

\section{APHASIAS}

1. Goodglass H, Kaplan E: The Assessnent of Aphasie and Related Disorders. Philadelphia, Lea and Febiger, 1972.

2. Schuell $\mathrm{H}$, Jenkins $\mathrm{J}$, Jininez-Psbon $\mathrm{E}$ : Aphasia in AcuIts. Kew York, Hoeber, 1964。

3. Benson DF, Geschwind N: The Aphasias and related disturbances, in Baker A, Baker L: Clinical Neurology. Hagerstown, Harper and Row, 1977, chapter 8, vol 1, PP 1-28.

\section{SPINOCEREBELIAR DEGEMERATIONS}

1. Rinogsingk B, Weiner L: The 0livoportocerebellar Atrophies. Medicine 49:227-241, 1970.

2. Barbeau A: Quebec Sooperative Study on Friedreich's Ataxia. The Can I Neuro Sci 3: 1976.

3. Barbeau A: Quebec Cooperative Study on Friedreich's Ataxia. Ihe Can J Neuro Sci 5: 1978.

gUNTINGTON' DISEASE

1. Barbeau A, Chase I, Faulson G (eds): Huntington's Chorea, New York, The Raven Press, 1973, vol 1.

MORALL PRESSURE HYDROCEPBALUS

1. Karp H: Desentis in adults, Chapter 27 in Baker A, Baker L (eds): Clinical Heurology. Hagerstown, Harper \& Row, 1976.

2. Katman, R: Hoinal pressure hydrocephalus in Wells CE (ed): Deaentia. FA Davis, 1977.

3. Lessert B, Wannenaker: Beappratsal of the adult occult hydrocephalus syndrone. Meurol 24:224-231, 1974. 
GELIRFELDT-JAKOB DISEASE

1. Karp H: Desentis in adules, Chapter 27 in Baker A, Buker L (eds); Clinical Heurolony. Hagersioun, Harper \& Row, 1976.

2. Gjbbs CT, Gajdusek DC: Uncoaventical viruses as a couse of sporadic, epidemic and fantilal chronic dicease. In Pollard H (ed): Perspectives in Virology, Vo1 10, New York, Raven Press (Ir press).

3. Roos RP, Johnson RT: Viruses and Desentia in thells CE (ed): Dementia Philadelphia, FA Davis, 2977.

rRESENILE AND SENILE DEMENTIA

1. Rarp 8: Dementia in adults, in Beker A, Baker L (eds): C1inical Neurology, Hagerstown, Harper \& Row, 1976.

2. Ratzan R: The Frevalence and Malignancy of Alzheimer Disease. Arch Neurol 33:217-218, 1976 .

3. Wells CE (ed): Denentia, Philadelphia, FA Davis, 1977.

METABOLIC OR ORGAN FAILURE DEMTENTIA

1. Rarp H: Denentia in adults, in Baker A, Baker I (eds): Cilnical Neurology, Hagerstown, Harper \& Row, 1976.

2. Chokroverty A, Bruetwan WE, Berger V, Reyes MG: Progressive dialytic encephaloparky. J Neurol, Neurosurg, \& Psychiat 39:411-419, 1976.

ALCOHOLIC DEMENTIA

1. Victor $\mathrm{M}$, Acass RD, Collins GH: The Wernicke-Rorsakoff Syndrome. Piniladelphia, FA Davis, 1971.

2MOASPECIFIC DEMENTIA

1. Strub RI, Black FH: The Megtal Status Expmination in Neurology. Philadelphia, FA Davis, 1977.

2. Wells, CE (ed): Dementia Philadelphia, RA Davis, 1977.

3. Karp H: Denentia in adults, in Baker A, Baker I (eds): Clinical Neurology. Hagerstown, Barper \& Row, 1976. 
COMAON NEUROYUSCULAR DISORDERS AND INJURIES TO THE

PERIPHERAL AND CRANIAL NERVES AND SPINAL CORD - PANEL 5

Willaw F. Collins, Jr, (Chaiman); Richard O. Burns, Jr, MD; Thomas R. Johns, KD; David G. Kline, ID; Paul W. Nyers, ND; George R. Nugent, MD

Table 1 lists the malformations, injuries, tumors and other conditions which we consider in this chapter.

\section{CRANIOVERTEBRAL ABNOFMALITIES}

Craniovertebral abnormalities include acquired and congenital abnormalities of the junction of the skull and cervical vertebral columen and of the upper cervical spinal canal, which can cause dysfunction of the brain stem, cerebellum, and/or spinal cord. The term, "craniovertebral abnormalities," includes the following conditions:

congenital or acquired absence of the odontoid, congenital or acquired non-fusion of the adontoid, basilar impression of the skull (platybasia), Arnold-Chiari malformation, and fusion or closure defects of the upper cervical vertebrae.

The above conditions are usually diagnosed during neurologic evaluation of complaints of neurologic dysfunction of the spinal cord, cerebellum or brain stem, or on the basis of abnormalities found incidentally by $x$-ray examination of the skull and cervical spine. The major findings that are important in evaluating a person with these conditions are historical evidence of previous or present transient or permanent incapacitation and of the duration and severity of this incapacitation, and the ability to document stabillty of the cervical spine, especialiy the C1-C2 articulation and the C1-cranial articulation.

Congenital or acquired absence of the odontoid must be considered as possible cause of both sudden and insidious incapacitation, because sudden flexion or extension force applied to the skull can cause temporary or permanent loss of upper spinal cord function. The diagnosis of the condition is usually made by $x$-ray, particularly by $x$-rays in which flexion and extersion of the skull on the cervical spine are studied. Operative fusion of the skull to the first and second cervical vertebra, or of the first cervical vertebra to the second cervical vertebra, with subsequent denonstration of stability by $x$-ray utilizing flexion-extension and rotational views, can correct the condition of sudden or progressive loss of neural function. Examination and documentation of adequacy of the fusion should be done by $x$-ray examination 18 months after fusion is done. Also, examination should be done to determine the state of neurologic function. Although following such treatment neurologic functional stability is usually assured, neurologic examinations should be made yearly for three years to document this.

Basilar impression or platybasia can be acquired or congenital. The acquired adult variety usually relates to diseases of the bones of the skull, particularly Paget's disease. The condition can cause progressive compromise 
Table 1

Common Neuromuscular Disorders and Injuries to the Peripheral and Cranial Nerves and Spinal Cord

Craniovertebral Abrormalities

Cervical Disc Syndrome

Thoracic Disc Syndrome

Lumbar Disc Syndrome

Spinal Stenosis, Lumbar

Cervical Spondylosis

Spondylolisthesis

Peripheral Nerve Injuries

Peripheral Nerve Tumors

Spinal Cord Tumors

Syringomyelia

Peripheral Neuropathies

Diabetic Neuropathies

Inflammatory Polyradiculoneuropathy

Mononeuropsthies

Heavy Hetal Intoxication

Acute Internittent Porphyria

Diseases of Muscle 
of the sfinal cord or medulia and also can cause hydrocephalus by blocking the exit of CSF from the fourth ventricle. Aduit onset of basilar impression caused by Paget's disease may be treated with calcitonin to reverse the bony progression of Faget's disease. This wili not reverse compressive effects of the basilar impression which, if they are present, may require decompression of the upper cervical and/or occipital portion of the skull. Also, the patient may require shunting of the spinal fluid in order to control the neurologic dysfunction of hydrocephalus. The probability of sudden lacapacitation in this condition is very low, but progressive neurologic dysfunction is high. This progression necessitates neurologic exams every six months to be certain disabling neurologic loss is not occuring.

In congenital platybasia, the onset of neurologic dysfunction is usually jast the fourth decade. Once it occurs, the chances cf reversing it are rather poor, but surgical treatment can arrest the progression. This usually consists of removing the odontoid bone, or decompressing the spinal cord by enlarging the foramen magnum and the $\mathrm{Cl}$ vertebral ring. Following these procedures, evidence of neurologic improvement and bony stability for a period of 18 months should be required before $=$ decision is made concerning ability to fly.

The Arnold-Chiari malformation is the herniation of the lower meduila and cerebellar tonsils into the cervical spinal canal. It is an aimost constant finding in patients with meningonyelocele, but can occur as an isolatfd congerital anomaly or in conjunction with early onset of hydrocephalus or hydromyelia. It is diagnosed by special neuroradiographic procedures of pneumoencephalography and/or myelography. At times, it can be diagnesed with CT scán. It is most commonly asymptomatic, but it can be a cause of hydrocephalus, cerebellar dysfunction, or spinal cord dysfunction. In the patient with a meningomyelocele, it most comonly causes najor impairnent before the end of the first decade. It generally does not cause sudden ircapacitation, but it may cause progressive neurologic dysfunction over a number of years. Surgical decompression of the cervical spine and foramen magnum can stop progression, but it rarely reverses neurologic dysfunction. When hydrocephalus is present, surgical treatment with shunting is usually indicated to control the flow of cerebrospinal fluid. Persons with this diagnosis should have neurologic eraminations every six months, because the incidence of progression, although usually slow, is very high.

Fusion or closure abnormalities of the upper cervical spine are not common and most frequently are diagnosed as incidental fincings on $x$-ray of the skuli or cervical spine. The major problems arising in patients with these conditions are the associated nervous system abnormalities which accompany most of them. These include hanartomas, epidernoid or deraoid cysts of the posterior fossa or upper cervical area, arachnoid cysts, abnormalities of cerebellar formation, and abnormalities of the fourth ventricle and its outlets. The finding of a closure defect on cervical spine $x$-rays does not in itself indicate a serious prcblem, but unly that a careful neurologic evaluation should be done before a license is granted. 
Problaws that accompany vertebral body fusion (Rlippe1-Feil syndrome) are caused by decrease in motion of the neck at the site of the fusion and stress wich notion piaces on adjacent intervertebral spaces. This latter force may cause degeneration of the intervertebral isisc vith spondylosis, radiculopathy and/or melopathy.

The treatment of the conditions above relates to associated neural abnormalities, and their evaluation with regard to limitation of licensure requires no special neasures except as described under the specific condition.

\section{CERVICAL DISC SYNDROMES}

A ruptured cervical disc can cause pain in the neck, shoulder girdle, and upper ilmb, and in addition, compression of a cervical nerve root by a ruptured disc may result in motor weakness, reflex loss, and a sensory loss in the affected linb. Compression of the spinal cord by a midline disc can cause a painless Brown-Sequard Syadrome, paraparesis, paraplegia, or quadriplegia. Since there are aultiple causes for neck pain, the clinical diagrosis of ruptured cervical disc depends on identifying radicular signs and symptoms. Radicular pain may be referred to the scapula and paraspinal region and typically radiates to the arri or forearm. The pain generally does not extend to the hand, but if it does, the most conmon symptom is paresthesias affecting one or more fingers, depending on which root is involved.

\section{MINIMUM DIAGNOSTIC CRITERIA}

Signs and symptoms should be limited to a single cervical root, usually C6 or 77 . In addition to pain and paresthesias, neurologic deficit limited to a single cervical toot also should be present. The pain is increased by neck motion, stiffness of the neck is often present, and the brachial plexus is tender to palpation.

The most comon syndrome is a $C 7$ radiculitis, which results from a herniation of the $66-7$ disc. Paresthesias occur in the second, third, and/or fourth digits, accompanied by weakness of the triceps muscle and loss of the triceps reflex. The second most common syndrome is a c6 radiculitis and consists of paresthesias in the thumb and at times in the index finger. associated with biceps weakness and loss of the biceps reflex.

If multiple roots are affected, the diagnosis of cervical disc is unlikely, and other conditions such as acute brachial neuritis, thoracic outlet syndrowe, and tumor should be considered. Cord compression from a cervical disc is rare, and though the diagaosis may be suspected clinically because of myelopatiny, melography is necessary for confirmation.

\section{DIAGNOSTIC PROCEDURES}

Roentgenograms of the cervical spine should be obtained, but they may be normal or show only loss of the normal cervical curvature or evidence of osteoarthritis. Electronyelography, although not necessary to establish the diagnosis, may show ebnormalities in the muscies supplied by the affected nerve root. Helography also is not necessary to make the diagnosis and 
generally is used only to rule out another condition, such as a tumor, or as an aid to a planned operation.

\section{PROGXOSIS FOR SUDDEN OR SERTOUS INCAPACITATION}

Because of the pain, pilots should not fly when experiencing acute radiculitis due to a ruptured cervical disc. Even in the absence of pain, spinal cord signs are cause for grounding, because of the possibility of developing weakness of the lower limbs. The examining physician should be aware that compression of a cervical nerve root mey cause an important degree of weakness in the upper limb interfering vith a pilot's ability to fly.

FHERAPY, RECOMEINATIONS

Yost patients with cervical radiculitis due to ruptured disc improve with conservative measures, but some will require surgical therapy. When the examiner determines symptoms have been resolved, due either to medical or surgical therapy, flight status may be resumed despite the fact that a certain percentage of individuals will develop recurrent symptoms at a future time. Residual neurologic defects in the upper limb, or residual myelopathy, may impair a pilot's ability, and if such a defect is present, flight testing is necessary to establish flight competence.

If there is motor weakness after the acute symptoms have resolved, reexamination taice at six-month intervals is appropriate to determine the stability of the neurologic deficit.

\section{THORACIC DISC SYNDROME}

These rare protrusions may cause radicular pain, Brown-Sequard Syndrome, paraparesis, or paraplegia. Final diagnosis rests on myelography, and treatment is surgical, which carries sone risk. Residual weakness in the lower limbs after treatment may affect pilot performance, should be looked for by the medical examiner, and should require a flight test.

\section{LUMBAR DISC SYNDROMES}

The typical history may include an episode of sudden onset of low back pain with radiation into the buttock or down one or both legs, superimposed on a history of chronic low back pain. Occasionally, acute strain such as lifting, twisting, falling, or severe flexion can precipitate the syndrome without previous low back pain. Following its onset, pain will usually be accentuated by movenent, coughing, straining, or sneezing, and can be accompanied by numbess or weakness of the distribution of the nerve root involved. The pain may be severe enough to cause incapacitation.

\section{MINIMUM DIAGNOSTIC CRITERIA}

There is usuaily a history of acute onset of low back pain with or without radiation into the buttock or legs; limitation of back motion, especially flexion; lateral flexion towards the side of radiation of pain, 
shown by examination; palpable muscle spasm with convexity of the curvature of the spine, usually towards the side of disc herniation; flattening of the lumbar lordosis on $x$-ray; and tenderness, frequentiy maximal over the spinous process or the paraspinous muscle adjacent to the area of herniation.

Also, there is neurologic loss of a deep terdon ref 3 ex, and of sensation or of motor movement, depending on the nerve root involved. The most common cause is the L5-SI herniated disc, with involvement of the S1 root, decreased or absent reflex, and sensory loss over the SI dermatome. The second most common is an 14-5 ruptured dise, with involvement of the 1.5 root or the L5 and S1 roots. In the former, weakness of extensor hallucis longus may be the only sign, along with some sensory loss over the LS dermatome distribution; with LS and S1 involvement, wexkness of dorsiflexion of the foot, decreased or absent ankle jerk, and sensory loss over 25 and $S 1$ can occur. Stiff leg-raising causes pain radiating down the $l e g$ and is usually limited to the side of the pain, but at times crossed stiff leg-raising cayse pain down the leg with the radiation symptoms.

$x$-rays may be negative or show evidence of osteoarthritic changes or narrowing of the intervertebral space. Hyelogram is not necessary for diagnosis and is generally ordered to explain lack of response to conservative treatinent or to identify accurately the space to be explored with surgical treationt. EAG is not necessary but may be helpful in identifying the root involved.

FROGWOSIS FOR SUDDEN OR SERIOUS IMCAPACITATION

Because of the severe pain which may occur, pilots with acute raciculitis secondary to ruptured lumbar disc should not fly. In those who are recovering or have a history of ruptured lumbar disc, it would be extremely rare to have the incapacitation be so sudden as to present a danger while flying. Weakness of dorsiflexion of the foot may be severe enough to interfere with flying and should require a flight test.

THERAPY, RECORAENDATIONS

Most patients will respond to rest and traction. Some will require surgical excision. Surgical therapy is usually excision of the ruptured disc and should result in relief of pain, but the neurologic dysfunction may remain.

It is recommended that following lumbar laminectomy and disi removal, an examination by a physician be required before the patient returns to flight status. If fusion is used as part of the surgical treatment, no special limitation need be added. If bracing is used as treatment, either with zonservative therapy or postoperatively, flight testing is recommended to ascertain if there is interference with wobility.

SPINAL STENOSIS, LUMBAR

The diagnosis of lumbar spinal stenosis is usually made on the basis of pain in the back and legs upon walking, standing, or in extension, which is relieved by rest. Some patients may also develop numbess, tingling, 
and/or weakness when walking or extension is prolonged. Other relevant diagnostic criteria include degenerative changes in the lumbar spine, as desonstrated by $x$-ray and winimsl or no wechanical signs on routine neurologic exanination. The diagnosis is usually made on the basis of $x$-ray towography to demonstrate the size of the canal, myelography to show encroachwent upon the subarachnoid space, and/or CT scan of the spine.

Activity requiring extended walking, standing in the erect position, or extension of the spine could cause incapacitation. While this can be rapid, it of cen occurs over the course of minutes and the patient is able to adjust. Hedical thezapy is ineffective, but surgical decompression is usually curative and can prevent incapacitation. Sudden incapacttation is rare, although loss of cauda equina function can occur from severe flexion or extension which might occur through injury.

If there is no suxgical decompression, examinations every six months are indicated. With surgical decompression, evidence of stability and loss of symptoms over the following 18 months should be required.

CERVICAL SPONDYLOSIS

The diagnosis of cervical spondylosis is made on the basis of evidence of degenerative disc disease in the cervical spine with osteoarthritis. It is significant when there is evidence of a spinal canal narrowed to less than $13 \mathrm{~mm}$ in the anteroposterior (AP) diameter. There may be neck pain, or evidence of myelopathy and/or cervical radiculopathy. Evidence of radiculopathy and myleopachy is given by neurologic examination showing loss of root function in the upper extremities, symptoms of root irritation in the upper extremities, and/or evidence of long-tract findings, commoniy of the corticospinal tract, in the lower extremity with spasticity.

The diagnosis of cervical spondylosis is made by $x$-ray and/or neurological examination. Confirmation is through EMG and electroneurography to demonstrate radiculopathy, and by finding evidence of spinal cord compression with myelography. Diagnosis is supported by neurologic examination showing impairment of deep tendon reflexes in the upper extremity and/or evidence of weakness, iasiculations, long tract signs, and symptoms of nerve root irritation. Cr scan of the cervical spine may aid diagnosis by showing narrowing in the AP diameter, but laminography or polytomography can also demonstrate this.

Prognosis as far as sudden or insidious incapacitation relates to the degree of involvement of the spinal canal and of the spinal cort. In those patients with evidence of myelopathy, the possibility of sudden incapacitation by rapid extension of the neck is relat:vely high, while in those without evidence of myelopathy it is relatively $10 \mathrm{w}$. In those patients with evidence of myelopathy, insidious incapacitation by progressive myelopathy occurs frequently.

While medical treatsent with imobilization of the cervical spine with a collar may be belpful in some cases, it is of only temporary benefit. 
Surgical therapy, anterior or posterior deccopression th anterior or posterior fusion, may halt the progress of the disease and improve neurologic status. Either or both can prevent the hazards of hyperextension injury, but both require examination to determine that neurologic progression has halted or diminished. When fusion is used, it must be determined by $x$-ray and with flexion and extension that the fusion is stable over an 18 month period.

In those patients not surgically treated, neurological examination every 6 months should be required. In those patients treated with decospression and/or fusion, there should be evidence of stability and fusion by examination every 6 months, for 18 months and, thereafter, by neurologic examination every year.

\section{SPONDYLOLISTHESIS, LUMBAR}

The diagnosis of lumbar spondylolisthesis is suggested by symptoms of pain on standing or lifting and gait abnormalities caused by increased tension in or tightness of the hamstrings, while the criteria for diagnosis consist of $x$-ray evidence of forward slipping of one vertebra on another and the presence of defects in the pars interarticularis on oblique spine films. Diagnosis is usually assured by $x$-ray evidence, but determining the cause of radiculopathy or cauda equina compression may require myelography. Evidence of progressive slipping of the dislocated vertebra indicates an unstable condition which may cause a progressive neurologic loss, but sudden incapacitation is highly unlikely.

Medical therapy, that is, immobilization with cast or brace, flexion exercises and bedrest, can alleviate the immediate symptoms of pain or radiculitis but generally has no significant effect on the basic pathology. Decompression of the cauda equina, with lateral or antexior fusion of the vertebra which has slipped to the vertebra beneath it, is often required for contro1. Stress or minor injury is unlikely to cause sudden deterioration, but because of progression of the disease in a significant number of patients, neurologic examination every year should be required.

\section{PERIPHERAL NERVE INJURIES}

The diagnosis of peripheral nerve injury is usually made by history of injury to one of the extremities, the brachial plexus of lumbar plexus, with the resulting sensory, autonomic, and/or motor deficits being documented by physical examination, and the extent of injury being documented by appropriate electrodiagnostic studies two or more weeks after the injury. Other aspects which may affect prognosis are associated injuries to vessels, bone, spine, chest, pelvis, or head, which of course require $x$-ray studies and/or physical examination of the area to determine the degree of injury.

The permanence of the injury and progression or improvement in neural loss should be documented by serial neurologic examination and appropriate serial electromyographic and nerve conduction electrodiagnostic studies over 
a 6 to 12 months' period. The prognosis of peripheral nerve injury is usually one of immediate post-injury los;, followed by either stability or improvenent. Frogression of loss after the tramediate post-injury period can occur in association with aneurysms or arteriovenous fistulas, when there is injury to vessels close to the nerve. Extensive soft tissue injury, or hemorrhage into compartments such as the volar forearm or the anterior lower leg, can form ischemic infarction of muscles and cause a serious progression within hours or days of the initial injury.

There is no medical therapy, but a significant percentage of patients with peripheral nerve injuries have pain and are treated with analgesics; the amount and type of anaigesic should be documented, because this may be taken in sufficient amounts to produce somolence and decrease in level of function.

Surgical repair of nerve injuries is possible and will affect the prognosis. Exploration, neurolysis, suture or graft repair, release of areas of entrapment, or correction of associated vascular anomalies will of ten improve function, but a period of months to several years is required to determine whether effective regeneration has occurred. A peripheral nerve injury with motor loss which has been stable for more than two years is usually irreversible. If the nerve injury occurred less than 6 months before the initial examination, repeat examination at 6-month intervals for two years should be required. Sudden incapacitation would be extremely rare, as is progressive loss after a one to two year post-injury period.

\section{PERIPHERAL NERVE TUHCRS}

The criteria for diagnosing peripheral nerve tumors is a history of a mass, with pain, paresthesias or deficit in the area of distribution of a peripheral nerve. Usually a discernible, readily palpable mass is present in the nerve, which on tapping gives paresthesias in the distribution of the in volved nerve (Tinel's sign). Sensory deficit is usually more pronounced than motor, but both may be present. In a patient with a peripheral nerve tumor, history of tumor and of familial conditions such as von Recklinghausen's Disease should be ascertained.

Diagnosis is usually made by neurologic examination, but electromyographic and nerve conduction studies can document the deficit and support the diagnosis. The confirmation of the type of tumor is by pathologic study, and while most of the tumors are benign, malignant schwannomas or fibrosarcomas can occur. If the patient has a familial history of peripheral nerve tumors or other critexia of von Recklinghausen's Disease, the precautions for that condition (see below) should be taken.

Sudden incaparitation or severe neurologic loss due to peripheral nerve tumors is rare: rather, the course is usually insidious with slow loss of functions; in particular, motor loss is a late consequence of most tumors. In an occasional patient, trauma to an area containing a tumor and nerve may precipitate the onset of symptoms, but these are usually local. As with peripheral nerve injuries, many of these patients have pain and are given analgesics by their physicians. Side effects from the medications must be 
taiken into account, and the amount and type of medication should be docusnented.

Surgery can remove the tumor wass, often with preservation of wuch nerve function. Valigant tumors may require amputation and the usual precautions, specifically, evaluation at 6-month intervals for metastases. Sudden incapacitation would be extremely rare, but slowly progressive loss of function over the distribution of the involved peripheral nerve is common.

Frequency and type of examination would vary with the tumor type. A solitary benign schwannoma which is believed completely enucleated carries a good prognosis in terms of recurrence. With tumors like neurofibrona, for which enucleation is difficult and sometimes impossible, progressive loss of function is a possibility. Although this may occur slowly, yearly examinations should be required. Malignant tumors would require the type of follow-up given to any maligant disease, to ascertain whether progressive incapacitation is occurring.

\section{VON RECKLINGHAUSEN'S DISEASE}

This is an inherited neuroectodermal disorder with macular tannish areas of the skin (cafe au lait spots) and neurofibrowas of peripheral nerves. Major problems encountered in these patients relate to the peripheral nerves involved and to the loss of function caused by the tumors or their treatment; the frequency of tumors arising on spinal nerve roots, affecting the spinal cord or cauda equina; and tumors arising on cranial nerves, particularly the eighth nerve, with resulting dysfunction from the loss of nerve root or nerve function, or compression of adjacent neural tissue. These patients also have a high incidence of other intracranial and spinal tumors and a high incidence of scoliosis.

The diagnosis is made by recognizing the combination of pigmented skin lesions and neurofibromas, particularly when a family history of the disease is present, and may be confirmed by biopsy of the neural tumors. The presence of the disease does not signify inability to perform as a pilot. However, because of the high incidence of associated neural tumors and neural dysfunction, the affected persons should have yearly examinations, including neurological and eighth cranial nerve examinations. Although the probability of sudden incapacitation is very low, the possibility of insidious incapacitation relating to tumors arising within the central nervous system makes necessary the relatively frequent neurological examinations.

\section{SPINAL CORD TUMORS}

The diagnosis of spinal cord tumor is made on the basis of neurologic aymptoms and signs of progressive spinal cord dysfunction, and is confirmed by myelographic evidence of an intraspinal mass, with surgery and histologic evidence determining the type. Most important in diagnosis and prognosis is the histologic type of tumor. There is no effective medical treatment. Surgery can cure benign tumors such as meningloma and neurilemomas, and some intramedullary tumors like ependyworsas. The histologic diagnosis of the tumor particulariy if it is malignant glioma, is most important in terms of prognosis. 
Neurologic dys nction in the case of excised benign tumors is usually stable or has reached its maximum improvement 12 to 14 months after tumor excision, but with malignant tumors or in any of the intramedullary tumors in which total renoval cannot be accorplished, progressive neurologic dysfunction is the expected course, although this may be prolonged over 5 to 10 years. Radiation therapy can arrest the growth of some of these tumors, but effective chemotherapy or other medical therapy has not been established.

Physical or emotional stress or sudden incapacitation is not a problem in these condicions. In patients in whom benign tumors have been excised, neurologic examination every 6 months for 18 months should be required in order to show neurologic stability or to document improvement. With malignant tumors, neurologic examination every 6 months should be required. The determination of ability to fly is a judgment decision based on the nature and extent of the neurologic deficit, and any neurologic deficit is indication for a flight test.

\section{SYRINGOMYELIA}

Syringomyelia is a condition characterized by gliosis and cavitation of the spinal cord. It is usually congenital in origin but may be acquired in some instances. Occasionally, the process may extend into the medulla and orain ster. The cavity may contain fluid, which under pressure way cause swelling and result in obstruction of the spinal canal. While syringonyelia most commonly involves the cervical portion of the cord, it may occur at any level. Multiple cavities may also occur. It is believed by some that syringomyelic cavities occurring in the cervical cord are the result of an obstructive process causing enlargement of the central canal from the fourth ventricle.

While the signs and symptoms of syringomyelia may be quite variable, depending upon the extent of the gliosis and cavitation, the classic presentation is that of early involvement of the anterior commissure, producing the so-called sensory dissociation, ie, diminution or absence of pain and temperature sensation below the level of the lesion with complete preservation of position and vibratory senses. However, other signs and symptoms of cord involvement, such as localized muscle weakness and atrophy of shoulders, arms, and hands, and signs of corticospinal tract involvement, may also occur. Painless arthropathies and Charcot joints also are seen in this disease.

Diagnosis is through myelography, preferably air wyelography which may demonstrate either a swollen cord or a thin atrophic cord, but myelography also may be normal. Because spinal cord tumor, such as ependymoma, is in the differential diagnosis, the cavity way be revealed by surgical exploration. Syringomyelia is frequently associated with anomalies of the skull and vertebral canal, such as Arnold-Chiari malformation, Klippel-Feil anomaly, and kyphoscoliosis. Tumors of the spinal cord and its coverings may occur in up to $20 \%$ to $30 \%$ of patients. 
Sudden incapacitation is extremely unlikely, except as caused by sudden hemorrhage into a syringomyelic cavity, or hematomyelia, which is almost invariably secondary to trauma at the cervical region. The disease, however, is usually relentlessly progressive, although the course nay be slow. There is no effective medical treatment, although some have reported arrest of the progression by means of radiation. Surgical deconipression of a cyst under pressure, and other methods of draining cavities, have been utilized with ocsasional good results.

Qualification for flight must be based upon performance evaluation with required 6-\$chth re-examinations.

\section{PERIPHERAL NEUROPATHIES}

The peripheral nerves are subject to a wide range of insults, including a large number of systemic, metabolic, and toxic disorders. Some neuropathies may damage primarily the notor fibers in the mixed motor and sensory peripheral neries, while other neuropathies affect both motor and sensory fibers, or produce mainly sensory changes.

Most toxic or metabolic disorders produce a symmetrical polyneuropathy with symptoms and findings which are most intense in the distal portions of the limbs farthest from their cell bodies in the spinal cord. Sensory symptoms often predominate when the metabolic or toxic changes first affect nerve metabolism, but decreased reflexes, weakness, and gradual proximal spread of the symptoms may develop if the cause for the neuropathy is not found and treated.

The diagnosis of a distal symetrical polyneuropathy is made by the demonstration of distal weakness, sensory 10ss, and decreased reflexes in the lower limbs, with similar, of ten less severe, findings in the upper limbs. The diagnosis may be confirmed by electrodiagnostic studies, which show slowing of motor or sensory nerve conductions, of both. The effect of such a neuropathy on performance is highly variable and requires assessment of ability while carrying out tasks similar to air crew assignments. With the exception of the Guillain-Barte; form of polyneuropathy, the disorders rarely if ever produce sudden disability.

The prognosis for recovery from, or worsening of, such a neurcpathy is largely dependent on etiology, and diagnostic evalustion by a neurologist is essential. The precise cause, or the lack of ability to determine such a cause, should not influence the qualifications of the individual for licensure, however; rather, licensure should depend on the degree of disability of the Individual. Evaluation regarding return to flight should be by a neurologist. If there is questionable progression, reevaluation should occur at three to six month intervals.

Charcot-Marie-Tooth Disease - This familial disorder of peripheral nerves produces symptoms of distal, symetrical polyneuropathy which begin very insidiously, often in childhood or in early adult life. The neurologic defects are primarily motor in nature and consist of very slowly progressive weakness 
and atrophy of the distal auscles of the upper and lower limbs. Reflexes are markedly reduced. Sensory changes are usually present but are quite mild. Sudden incapacitation does not occur, but the progressive nature of the symptoms, in particular foot drop, requires reevaluation at 6-montin intervals. There is no medical or surgical treatment for this condition, but a leg brace or posterior splint may atd foot drop.

\title{
DIABETIC NEUROPATHY
}

Diabetic neuropathy is one of the most comon forms of neuropathy. It cannot be considered a single entity, and prognostically it is best considered under the classification described by Thomas:

\author{
Symetrical Polyneuropathy \\ sensory polyneuropathy \\ autonomic neuropathy \\ Mononeuropathy and multiple mononeuropathy \\ cranial nerve lesions \\ isolated peripheral nerve lesion \\ diabetic amyotrophy
}

With the possible exception of diabetic amyotrophy, onset and severity of the neuropathy does not relate to the severity or the degree of control of the diabetes itself. The presence of one type of neuropathy does not preclude development of another type; rather, combinations are likely to occur, which probably are related to the multiple etiologies for the different diabetic neuropathies.

Symetrical Polyneuropathy - This is the most common of the diabetic neuropathies, occurring in $60 \%$ to $80 \%$ of patients with malurity onset diabetes who are controlled with clet. Sensory poiyneuropathy is most commonly found in the lower extremities, and on neurologic examination the most common finding is decrease in touch, vibration, position sense, and pain, with absent or depressed deep cendon reflexes. It ustulily is slowiy progressive and in the vast majority of cases causes little or ro disability. It can, however, progress to almost total loss of sensation leading to skin and joint lesions and marked disability, as well as disability from the discomfort of the resulting paresthesias. Sudden incapacitation is not seen in this syndrome, and there is no medical or surgical therapy. Because of the progression, yearly neurologic examinations shouid be required.

Autonomic neuropathy can appear as an extension of sensory polyneuropathy or can be an early symptom of diabetic neuropathy. The major finding is marked involvement of the autonomic nervous system, with varying degrees of postural hypotension dut to lack of compensatory changes in cardiac output.

Sudden syncopal episodes may occur, particularly under stress or change in position. There is no effective medical or surgical therapy, although the use of vasoconstrictors, fluorinated corticosteroids, monoamine oxidase 
Inhibitors, and L-Dopa in some patients may decrease the orthostatic hypotension. Since the efficacy of such therapy is unpredictable, the presence of this form of autonotaic neuropathy should cause absolute disqualification.

Diabetic Mononeuritis Multiple - This group of neuropathies involves cranial and peripheral nerves, with subacute or acute loss of function most commony involving the third and sixth cranial nerves, the femoral nerve, and less comonly, the radial, percneal and facial nerves. These mononeuropathies appear to be the result of occlusion of the vasa nervora, although entrapment and compression may at times play a role in pathogenesis. In rare instances, the same nerve may be involved more than once. The most important and common neuropathies are those involving the third and/or sixth cranial nerves, which cause diplopia. Fortunately, this is of ten associated with a prodromal period of one or two days, which produces periorbital pain and eye pain with eye movement.

Because of the resulting double vision, flying status should be denied until resolution and stability has been demonstrated for a period of six months. There is no medical or surgical treatment available for these mononeuropathies.

Another form of neuropathy, which is invariably multiple and of ten symetrical, is diabetic amyotrophy, which is now believed to represent a severe involvement of the motor portion of the proximal part of the peripheral nerve, with a dying back phenomenon involving the anterior horn cell. Signs of myelopathy, including Babinski signs and fasciculations, may be found. Improvement and stability of the condition may result from control of the diabetes with insulin.

From a neurologic standpoint, flying status may be granted on the basis of performance testing and evidence of stability for a period of one year. Semiannual re-examination by a competent neurologist, with particular attention to involvement of other peripheral and cranial nerves, is mandatory.

\section{LWFLAMAATORY POLYRADICULONEUROPATHY}

This disorder is characterized by changes not only in the peripheral nerves, but also in the spinal nerve roots and in the cranial nerves. Its onset, which sometires follows a viral illness or inoculation with certain vaccines, is rapid and may produce severe disability over hours or days.

Sensory symptoms may occur early in the upper or lower limbs, but muscular weakness is the principal manifestation. The weakness may begin proximally or distally and in the upper or lower limbs, but characteristically it spreads in a symetrical fashion to involve both proximal and distal muscles of ail limbe, with distal structures in the lower limbs of ten most severely involved. Facial muscles are of ten weak bilaterally, and in severely invclved individuals the tongue, palate, pharynx, and virtually all striated muscle may cease function because of the involvement of their mocor nerves. The muscle stretch reflexes are nearly always markedly depressed or absent. While parestheslas are comon, sensory loss is usually much less evident than the weakness, and a minor degree of distal loss may be the sole sensory finding. 
The diagnosis is based on the clinical history and examination as detalled above. Certain patients may present in such a manner that myasthenia gravis is a serious diagnostic possibility, but such individuals usually have no preserved tendon reflexes and no significant response to anticholinesterase aedication. The classically described CSF changes of elevated protein and normal or only slightly elevated cell count may not occur until the disorder has been present for three or four days, and does not occur at all in perhaps $30 \%$ of cases. Because acute incermittent porphyria, infectious mononucleosis, and diphtheria may produce symptoms indisti iguishable from this disorder, appropriate studies to exclude those entities should be made.

The weakness occasionally may progress and produce respiratory failure and death. The maximum degree of weakness is usually reached within three to seven days, and although it uscally does not threaten life, improvement thereafter may be very slow. Not all patients recover completely, but the vast majority attain functional recovery. Relapse of the weakness sometimes occurs during the recovery phase and rarely after complete recovery; but the usual course is that of steady and permanent recovery.

These individuals are disqualified for flight activities uncil they have made an adequate functional recovery. Any severe disordex of the motor unit may produce long-lasting changes in muscular stamina; therefore, measurement of functional recovery should include sustained activity rather than short bursts of muscle contraction.

\section{MONONEUROPATHIES}

Frequently, single peripheral nerves are affected by a neuropathy, and rather than the distal symetrical neuropathy described previously, the dysfunction is related to a single peripheral nerve. The wost conmon cause for such a mononeuropathy is compression, either from local edewa, as with the carpal tunnel syndrome, or from repeated sinor trauna to exposed and vulnerable peripheral nerves as they pass over boney prowinences. The neuropathies may be progressive and may produce motor or sensory abnormalities. A pressure neuropathy, for example, of the radial nerve, should not produce further sudden incapacitation once it has occurred. Of course, the causes of the motoneuropathies should be determined.

An individual with a mononeuropathy should have a determination of functional capacity and continue with daily duties, if the disability is not too severe. Such a determination and evaluation should be done by a neurologist. If there is to be flight testing, there should be prior evaluation by a zeurologist.

\section{Some examples of mononeuropathies follow:}

Median Nerve - Compromise of che median nerve by compression from structures beneath the transverse carpal 11ganent at the wrist produces a consteliation of symptoms but often few physical abnormalities. Paresthesias, burning and redness of the fingers are the primary symptoms, and they characteristically occur during sleep or during use of the hands. The disconfort may be present constantiy. While usualiy unilateral, the problem may occur on both sides. 
Diagnosis is wade by eliciting the characteristic history, demonstrating weakness of the thenar rascles, and reproducing symptoms with sharp flexion or extension of the patient's wrist. Percussion of the volar surface of the wrist, over the median nerve, will produce tingling in the thumb and index finger (Tinel's sign). Confirmation of the diagnosis often may be obtained by measuring motor or sensory conduction velocities and latencies in the distal portion of the median nerve. While the symptons are annoying, functional disability rarely occurs. Surgical treatment is usually curative when compression is the major causative factor.

Ulnar Nerve - The superficial course of this nerve at the elbow, in the olecranon groove, makes it particularly liable to a pressure neuropathy, sometimes from such apparently innocuous activity as repeatedly leaning on the elbow. The clinical manifestations are primarily motor in nature, and the finger abductors and adductor muscles exhibit weakness and of ten atrophy. There are paresthesias and subjective sensory changes in the fifth finger and the ulnar half of the fourth finger. Avoiding pressure on the elhow may be all that is necessary to alleviate the symptoms in some patients, but surgical transposition of the ulnar nerve to a more protected position on the fiexor surface of the forearm may be necessary. The weakness produced by the entrapment of the median or ulnar nerves may be severe enough to interfere with hand function, and functional evaluation is required.

Radial Nerve - A neuropathy of this nerva often begins abruptly and most commonly occurs during sleep. The etiology is usually compression of the nerve following hanging of the arm over the back of the chair or the edge of the bed. The disorder produces severe weakness of wrist and finger extensor muscles, weakress of the brachioradialis, and subjectively or objectively defined sensory loss in the web between the thumb and index finger on the dorsum of the hand. The weakness usually renders the hand virtually useless and may persist for six weeks or longer. Once recovery occurs, relapses are not expected. It should be noted that pressure sufficient to cause such a neuropathy is painful and thus occurs when an individual is heavily sedated or intoxicated. An individual with a radial nerve palsy should be removed from flying status until major functional recovery has been established.

Lateral Femoral Cutaneous Nerve - lumbness, tingling, prickling, and occasionally, burring sensations in the anterolateral thigh, develop insidiously in this neuropathy, because of the entrapment of the nerve somewhere in its long course, most frequently as it crosses the inguinal ligament. The symptoms may be annoying, but no other neurologic symptoms or signs occur. No specific treatment is needed, and there are no associated disabilities. Treatment with phenytoin or carbamazepine may be beneficial in prolonged cases. The condition, of itself, is not considered to be disqualifying.

Peroneal Nerve - r.sabling foot drop and sensory changes of the foot may occur from compression of this nerve immediately below the lateral tibial tuberosity. The most comon cause is chronic leg crossing or other activities which resuit in compression of the nerve against the fibular head at the knee. The symptoms and findings include weakness of the extensors of the toes and 
ankle (foot drop) and decreased sensation of the dorsum of the foot. The ankle jerk remains normal. The foot drop resulting from this neuropathy may produce disability, and functional evaluation should be made before qualification is granted.

\section{BEAVY METAL LNTOXICATION}

Heavy metal intoxication of the nervous system can be acute or chronic and most of ten is caused by lead, arsenic, mercury, manganese, or thallium. All of these conditions are relatively rare in adults, unless exposure is through crime or related to hobby or work. In addition to systemic poisoning, acute and chronic lead and arsenic ingestion can cause polyneuritis: with lead, the polyneuritis is mainly motor, and with arsenic it is sensory at first, with progressive weakness appearing later.

Organic mercury can cause a dystonia and chorea-like syndrome with mental deterioration when ingested over a long period of time, and a mild, peripheral sensory neuropathy also may be seen. Manganese intoxication presents approximately the same way, with less likelihood of peripheral neuropathy. Chronic manganese intoxication has been reported to present with a picture indistinguishable from Parkinson's Disease. The striking features of thallium exposure are alopecia and the fact that in acute thallium poisoning, as with arsenic, the neuropathy is mainly sensory in character. It can, however, include zetrobulbar neuritis, ataxia, and pupillary dysfunction.

The diagnosis of heavy metal intoxication is made by demonstrating the agent is the urine, blood, hair, or nail clippings. While the neuropatinies of lead and arsenic can progress even one to two months after exposure is eliminaited, they usually stabilize or improve when intake is stopped and the pool of heavy metal in the body is reduced with chelating agents. Eligibility for licensure should depend on residual defects and not on the diagnosis per se.

Sudden incapacitation or progression witholt further exposure is not to be expected. Neurologic loss with mercury and manganese is usually not reversible and may progress for months or years. Thus, it should be considered as an indication for disqualification for licensure.

\section{ACUTE INTERMITTENT PORPHYRIA}

Acute intermittent porphyria is a disorder of the metabolism of porphyrin and its precursors. Clinical inanifestations are most frequentiy induced by a large number of medicinal drugs, most prominent among which are the barbiturates and related compounds, but they also may be seen spontaneousiy or after stress, trauma, or unusual fatigue.

Acute porphyria ravely becomes obvious before puberty. Systemic symptoms include acute abdominal pain, anxiety, hysterical behavior, or even acute psychosis. The neurologic signs include those of peripheral neuropathy and, in some cases, a severe Guillain-Barré -like syndrome may develop. During 
the attacks, the urine, especlally when exposed to suniight, develops a reddish brown color. In a number of cases where the true nature of the disease was not recognized, the neurologic signs and symptoms were exacerbated by medical treatment with analgesics for abdominal pain, barbiturates for restlessness or hysterical behavior, and anticonvulsants for the epileptiform seizures which occasionally occur.

During the acute attack, the diagnosis is based upon the demonstra+: $n$ of increased urinary excretion of porphobilinogen and delta aminolevulinic acid. Between attacks, the subjects may be both clinically and biochemically asymptomatic. The definitive diagnosis is based upon the demonstration, during as well as between attacks, of a decrease of more than $50 \%$ in activity of erythrocyte uroporphyrinogen-I-synthetase. Mortality during the acute attack, usually from respiratory embarrassment, can be as high as $30 \%$ to $40 \%$. Recovery with minimal or no neurologic residual occurs in most instances.

Sudden incapacitation is rare, but symptoms can develop rapidly, especially when the various precipitating factors initiate attacks. While neurologic incapacitation would be extraordinarily unusual, such could occur with acute abdominal pain and consequent mental changes. Attacks of the disease are unpredictable and ay be frequent or extraordinarily rare. Treatment consists primarily in recognizing the precipitating factors and in educating the patient regarding their avoidance. In those rare individuals who have had epileptic seizures sssociated with the attacks, appropriate anticonvulsant drugs must be frescribed.

Recommendations: Patients with this diagnosis must be warned about the precipitating factors and given a list of drugs which are known to have such effects. For individuals in whon the precipitating factors are not drig-related, but are related to stress, trauma, or fatigue, disqualification should be absolute. Individuals in whom a specific drug has been identified as precipitating factor, flying status may be awarded after a syndome free period under observation of one year. But there should be permanent disquaification should another attack occur at any time.

\section{DISEASES OF MUSCLE}

Many different diseases of muscle due to a wide variety of causes have been described. In general, they are characterized by muscle weakness, and they interfere with mutor function without any sensory involvement. Three major groups can be identified: the muscular dystrophies, the myopathies, and the myasthenic syndromes. The diagnosis is based upon a combination of the characteristic history, the neurologic examination, electrodiagnostic studies and. as often as possibie, study of muscle biopsy materiai by means of light and electron-microscopy with histcchemical techniques. Because of the complexities of these conditions, diagnosis and evaluation regarding perforance should be performed by a neurologist, perferably one with special competence in neuromuscular disorders. 
Progressive Muscular Dystrophies: Four general types of muscular dystrophy are recognized and will be discussed.

1. Pseudo-hypertrophic muscular dystrophy of Duchenne - This is a disorder of males which usually starts in late childhood and is characterized by relentlessly progressive weakness and severe moseie atrophy. The condition affects first the proximal musculature, and eventually leads to almost complete incapacitation, usually by young adulthood. The disease is aIso characterized by pseudo-hypertrophy of the muscles, most prominently those of the calf. Because of the early involvement of the proximal musculature, it is common for the deep tendon reflexes of the knee to disappear before those of the ankles. Sensory and other neurologic signs are absent. The muscles innervated by the cranial nerves, with the exception of those subserved by the V, VII, and XIth nerves, are not involved. The muscles of respiration become involved late in the course of the disease.

There is a fairly high association with mental retardation, this being found in as many as $25 \%$ of patients. The diagnosis may be confirmed by electromyography, which reveals a myopathic pattern, an elevation of serum creatine phosphokinase activity, and the characteristic appearance of muscle tissue by light microscopy. There is no effective medical or surgical therapy. The disease progresses slowly without exacerbations secordary to stress. It is unlikely a patient with this disease would be in condition to ever consider flying, and certification should be denied absclutely with this diagnosis.

2. Facioscapulohumeral and limb girdle types - Many consider these to be variants of the same entitv. As the name implies, the involvement of muscles is somewhat rore localized, to the face, shoulder girdle, and upper arms in the former, and to shoulder and pelvic girdles in the latter. Men and women are equally affected. The disease occurs somewhat later in life than Duchenne's and is not as rapidly progressive; thus there may not be incapacitation until well into adulthood. Some of the more chronic myopathies, such as dermatomyositis and steroid myopathy, may resemble the limb girdle type of muscular dystrophy and must be considered in the differential diagnosis. The diagnosis is made as with the Duchenne type, and the importance of nuscle biopsy cannot be overemphasized. Disqualification must be based upon actual performance, with evaluation on a yearly basis.

3. Welander-Kugelberg-Wohlfahrt Syndrome - This is a disease probably related to the dystrophies, although it is somewhat dificult to classify, the condition may start at any time from early childhood to adulthood. It is characterized by very slowly progressing prcximal muscle weakness and may show some of the features of an amyotrophy, such as fasciculations. The family history is of ten positive. Electrodiagnostic studies may reveal a mixture of myopathic and neuropathic features. No medical or surgical therapy is available. Sudden incapacitation is not expected. Qualification should be based upon performance evaluation on a yearly basis.

4. Myotonic Dystrophy - This is a group of muscle diseases character_zed by the presence of symptomatic or asymonatic myotonia. The myotonic reaction consists of a marked prolongation of the relaxation phase of muscle contraction, present either clinically or electrically, or both. Myotonic reactions 
can be seen in other conditions, such as amyotrophic lateral sclerosis and hypo- or hyperthyroldism.

In myotonic dystrophy, there is a slowly progressive weakness and atrophy wich, in contrast to that of other dystrophies, usually starts in the distal muscles of the extremities. The disease is inherited as a dominant trait. Associated abnormaifties include cataracts, macular degeneration, frontal baldness, and a variety of endocrinopathies, the most common of which are gonadal atrophy and hy/pothyroidism. Early involvement of the masseter and temporalis muscles, giving a characteristic facial appearance, the "tapir" face, is often present. The expression of the disease shows great variability from generation to generation: thus, the parent of a patient with myotonic dystrophy may have no stigmata other than cataracts and frontal baldness, while the patient himself may have the dystrophy but no other abnormalities. The diagnosis is based upon one or more of the following features of clinical ayotonia:

1) The patient is unable to relax a clenched fist quickly, unable to rise from a chair quickly, or incapable of releasing his grip on tightiy held objects.

2) When there is tapping of a muscle group such as the thenar eminence, the muscles of the forearm, o: the tongue with a reflex hammer, a jocalized contraction follows which relaxes very slowly.

3) There is a pathognomonic electromyographic (EMG) pattern of prolonged tetanic contraction following a normal stimulus.

4) Histochemical study of musele biopsy material mery be helpfal.

It should be noted the only reliable diagnostic test is the EMG. The test, however, may also be positive in the absence of clinical myotonic reaction. Both test and patient are invariabiy affected by exposure to cold. It is imperative the diagnosis be established by a competent neurologist.

Two other subtypes of myotonic dystrophy exist: myotonia congenita (Thomsen's disease) usually starts in early childhood and is characterized by pseudonypertropiny of ali muscie groups, this is a benign disease with mila, generalized, and usually nonprogressive veakness. Paramyotonia is technical !y not a disease of muscle, since it consists exclusively of a motonic response which is present only during exposure to cold.

Medical treatment for the myotonic reaction consists of a variety of drugs such as quinine, procainamide, corticosterofds, and phenytoin. Excellent control of the clinical myotonia may be obtained, but the drugs will not alter the progressive muscle weakness and atrophy of myotonic dystrophy. 


\section{RECOMENDATIONS}

A) Individuals with spontaneous clinical myotonic reaction should be disqualified from flying, even if under medical control, since acute stress may produce a sudden exacerbation.

B) Individuals with elicitable myotonia or with electrically induced myotonia may be qualified, if clinical myotonic reaction cannot be produced by exposure to acute and severe stress.

C) For those qualifying under section $E_{3}$ there must be no visual impairment secondary to cataract or macular degeneration.

D) For those qualifying under section $B$, the degree of muscular weakness and/or atrophy must be compatible with operation of the aircraft. Reexamination at three month intervals is mandatory. Since the myotonic dystrophy is a relentlessly, albeit slowly, progressive disease, long term follow-up and treatment are necessary.

Another group of diseases which appear to be related to the myotonias are the periodic paralyses. These are characterized by the sudden occurrence of severe generalized muscle weakness, of ten precipitated by the ingestion of a high carbohydrate meal. The weakness is related to a poorly understood disturbance of potassium metabolism. The serum potassium may be low (hypokalemic type), normal (normal k.lemic type), or elevated (hyperkalemic type). EMG and muscle biopsy may be helpful. Medical treatment, which includes instruction as to avoidance of high carbohydrate meals, is of some value. Acute stress may lead to an attack. Absolute disqualification is recommended, when this jiagnosis is established by a competent neurologist.

The Myopathies: This is a heterogenous group of diseases of diverse etiology, occurring in adulthood and consisting of the acute, subacute, or chronic onset of muscular weakness, which is usually proximal and symmetrical in nature. Cramps, muscular pain, and tenderness may accompany some of the nyopathies. Deep tendon reflexes may be absent in the mild or early cases, but the cranial musculature is usually not affected. Elevation of the serum lactic dehydrogenase ( $\mathrm{LDH}$ ) and creatine phosphokinase (CPX) enzymes occurs frequently. Electromyographic studies are extremely helpful, but the definitive diagnosis requires muscle biopsy. Included in this group are such entities as myopathies secondary to systemic diseases, like hyper- and hypothyroidism, Addison's and Cushing's disease, sarcoidosis, and carcinoma, as well as so-called primary myopathies such as McArdle's disease, nemaline myopathy, central core disease, mitochondrial myopathies, and the rare myopathy secondary to prolonged administration of corticosteroids.

A myopathy may be a part of the complex of connective tissue disorders, or of a vasculitis such as dermatonyositis, or it may result from an infection, as with trichinosis. Polymyositis, an inflamatory myopathy, is the one most characteristically associated with muscle pain and tenderness, although those findings usually are present early in the course. 
The prognosis of the myopathies secondary to systemic illness are dependent upon the establishment of the correct diagnosis and appropriate or specific treatment. Since the cardiac muscle may be involved, special attention must be paid to cardiac function. No treatment is currently available for the congenital myopathies. Polymyositis often responds favorably to corticosteroids, alone or in combination with antimetabolites, such as azathioprine. In the case of steroid myopathy, discontinuation of that drug will lead to recovery. Prognosis is entirely dependent upon the availability of treatment. Because of that, it is imperative that every attempt be made to establish a correct diagnosis as soon as possible. Also, muscle biopsy should be an absolute requirement, with the condition that the frozen biopsy material be reviewed by an expert in the field.

\section{RECOMMENDATIONS}

A) The diagnosis of a myopathy for which no recognized, effective form of treatment exists, should lead to absolute disqualification.

B) For myopathies secondary to systemic illness, or for those such as polynyositis, for which a recognized treatment exists, evaluation of muscular, respiratory, and cardiac function should be carried out every three months during and for a least two years after treatment. Qualification may be granted if such functions are found to be normal at two consecutive three-month examinations.

The Myasthenic Syndromes: Myasthenia gravis is a disease of muscle characterized by weakness and abnormal fatigability, presumably due to a defect of transmission at the neuromuscular junction. While the exact etiology of this disease remains unknown, it is believed that in many if not all instances, there is a disturbance of immune mechanisms. The anatomical defect appears to be an abnormality of the postsynaptic membrane, which reduces the number of receptors for the acetylcholine liberated from the nerve terminal by the nerve impulse. The disease may oicur at any age and is usually insidinus in onset, but it may also present suddenly and dramatically. A patient with this disease is extraordinarily sensitive to many drugs, including the mycin antibiotics. The disease may be exacerbated by even mild intercurrent infections.

In early stages, symptoms may be present only after exercise, and improvement occurs with rest or sleep. As the disease advances, this is no longer true, and the patient may be as weak upon awakening from sleep as he was before. The weakness may be generalized, or it may be confined to a group of muscles such as the extraocular, facial or orophoryngeal. Involvement of the extraocular muscles is most commonly the presenting symptorn. occurring in approximately $40 \%$ of cases. Muscles of the trunk and extremities are involved first in about one-third of the cases, and the palatal or pharyngeal muscles in $20 \%$. The disturbing symptoms, in addition to generalized weakness, are best elicited by exercising large proximal muscles and include 
double vision, lid ptosis, difficulty in swallowing, and difficulty in breathing. The symptoms, and thus the muscle groups involved, may vary from day to day.

\section{DLAGNOSIS}

This is based upon one or more of the following criteria: the characteristic history of weakness with effort, and dramatic improvement not always with resting, or particular muscie groups, such as the extraocular, faclal-oropharyngeal and limb-girdle. When not all the groups are involved, the differential diagnosis varies accordingly. The tendon reflexes tend to be preserved.

Corroborative tests, not always positive, are:

A. Immediate response of a weak muscle or muscles to the intravenous injection of edrophonium chloride (Tensilon), or to the intravenous or intramuscular injection of prostigmine.

B. A positive Jolly test, consisting of the electromyographic abnormality of rapid decline in the height of muscle action potentials evoked by repetitive nerve stimulation at rates less than 15 per sec. This particular test is positive in about $50 \%$ of cases, but it may be negative in those patients in whom the disease selectively and exclusively involves the extraocular or oropharyngeal muscles.

C. Single fiber electromyography, not yet generaliy available, is fositive in about $95 \%$ of cases.

D. Provocative tests such as intravenous d-tubocurarine, are rarely necessary.

Myasthenia gravis may be associated with the presence of other conditions, including thymoma, hyperthyroidism, collagen disease, and polymyositis. The course is unpredictable, remaining stable in some patients, progressing rapidly in others, and going into prolonged remission in still others.

\section{TREATMENT}

A number of forms of treatment are available. Removal of a thymoma is mandatory, if such a neoplasm is discovered. This may lead to permanent remission of the disease, although associated diseases may lead to disability. Removal of thymus tissue is recomended espe ially in persons with onset under the age of $\hat{s 5}$. Radiation of the mediastinum is littie used.

The appropriate and fudicious utilization of cholinesterase inhibitors like neostigmine and pyridostigmine rarely produces complete control of symptoms. The most auccessful form of treatment at the present time consists of the longterm administration of high doses of prednisone in various recommended resimens 
Even though the patients' symptoms appear to be under excellent control with the use of appropriate medications and/or corticosteroids, stress, unusual exercise or fatigue, wild intercurrent infections, emotional upset, minor physical trauma, or the ingestion of any of a large number of drugs, may cause the sudden reappearance $z i$ symptoms. This is much less likely in patients who haye responded favorably to prednisone. Sudden death in otherwise well controlled, asymptomatic patients has occurred. At the present time, long term treatment with high doses of corticosteroids before or after removal of thymic tissue appears to provide a stable condition in many patients with this disease.

\section{RESOMMENDATIONS}

Patients with myasthenia secondary to a thymoma may be certified, provided that examination one year following the removal of the thymoma shows they are sympton-free and a Jolly test is completely normal.

Patients with myasthenia gravis who are dependent upon any of the cholinesterase inhibitors for control of symptoms must be disqualified.

Patients whose symptoms have been completely controlled by prednisone alone for a period of three years after the dosage of corticosteroids has been stablized, and whose Jolly test is completely normal at that time, may be qualifieć for noncommercial Flying.

Individuals who have been completely symptom-free and have received no medication whatsoever over a year's period, and have a completely normal Jolly test, may be qualified for noncomercial flying.

Individuals with the diagnosis of myasthenia gravis who are qualified under the conditions above should be reexamined every three months indefinitely.

Myasthenic Syndrome (Eaton-Lambert Syndrotne) - This rare disease superficially resembles myasthenia gravis in its clinical presentation, with the major difference that the extraocular muscles are rarely involved. The pharmacologic tests utilized to establish the diagnosis of myasthenia gravis are not useful in the condition. The EMG pattern is the exact opposite in that there is an actual increase in the size of the muscle action potential with repetitive stimulation. The weakness is largely limb-girdle, and tendon reflexes tend to be absent.

The condition is associated with carcinoma, most of ten of the 1 ung, in approximately two-thirds of men and one-third of women. The appearance of the Eator-Lambert syndrome may in fact precede the discovery of the carcinoma. It has been reported the syndrome can be corrected by removal of the carcinoma. if present. Treatment with guanidine has resulted in improvement of the symptoms in some patients. 


\section{RECOMMENDATIONS}

Those individuals in whom an underlying carcinoma cannot be demonstrated, and whose symptoms are controlled by the administration of guanidine, may be eligible for qualification as noncommercial pilots after a synptom-free period of at least shree years, including mandatory examinations at three-month intervals.

\section{AMYOTROPHIC LATERAL SCLEROSIS (motot neuTOR disease)}

Amyotrophic Lateral Sclerosis (ALS) is a progressive disorder of the motor unit in the brain stem and in the spinal cord. It is characterized pathologically by degeneration of neurons in the motor cortex, motor nuclei in the brain stem, and anterior motor horn cells. The clinical manifestations are a unique combination of upper and lower motor neuron findings in both the upper and lower extremities. The patients so afflicted have weakness, atrophy fasciculations, and spasticity in the muscles subserved by the motor neurons involved. The extraocular muscles are not involved, and there are no sensory abnormalities.

There is no uniform involvement of the motor system with this disorder; in some patients the upper motor neuron symptoms predominate, while in others the anterior horn cells are most severely involved and the "progressive spinal muscular atrophy" form of the disease results. Weakness may begin in the muscles responsible for speech or swallowing, or in the proximal or distal portions of either the upper or lower limbs. While the weakness is occasionally symmetrical, it may be very severe in one Iimb and cause barely detectable difficulty in the others. Fasciculations, musclo cramps, and atrophy as well as hyperactive reflexes in the lower limbs or in all extremities are seen eventually in most patients. Extensor plantar responses usually occur as the disease progresses.

The diagnosis of ALS is made by finding upper and lower motor neuron signs in the structures supplied by the motor cranial nerves. Spinal cord tumors and other compressive lesions of the cervical region may mimic ALS and produce lower motor neuron involvement of the arms and spastic legs, but the lower motor neuron involvement (denervation) is restricted to a few segments in the cranial region.

Laboratory studies - Electromyography is usually necessary to document widespread denervation. Such studies usually include nerve conduction velocity measurement to ascertain that a peripheral nerve lesion is not responsible for the denervation.

Prognosis - AlS usually progresses rapidly, producing severe disability and ending in death or severe disability within 18 to 24 months. Some cases with restriction of disease to the spinal cord may run a slightly longer course. No treatment now available alters its course or outcome. Prolonged or vigorous exercise, predictably, may worsen the weakness already present in the patient. 


\section{RECOMRENDATIONS}

The decision regarding licensure and recertification must be $\mathrm{n}$ de by assessment of the patient's air crew performance. The rapidly progrtssive nature of this illness makes mandatory reevaluation by a neurologist it threemonth intervals. 
REFERENCES

\section{CERVICAL DISC SYNDROMES}

1. Murphy F, Simmons JCH, Brunson B: SurgicaI treatment of laterally ruptured cervical disc. Review of 648 cases, 1939 to 1972 . I Neurosurg $38: 679-683,1973$.

2. Lourie B, Shende $\mathrm{KC}$, Stewart DH: The syndrone of central cervical soft disc herniation. JAMA 226:302-305, 1973.

THORACIC DISC SYNDROMES

1. Patterson RH, Arbit E: A surgical approach through the pedicle to protruded thoracic discs. I Neurosurg 48:768-772, 1978.

IUMBAR DISC SYNDROMES

1. Mixter WJ, Barr JS: Rupture of the intervertebral disc with involvement of the spinal canal. N Eng J Med 211:210-215, 1934.

2. Spurling RG: Lesions of the Lumbar Intervertebral Disc. Springfield, III, C C Thomas, 1953.

3. Gurdjian ES, et al: Results of operative treatment of protruded and ruptured lumbar discs based on 1176 operative cases with $82 \%$ followup of 3 to 13 years. J Neurosurg 18:783-791, 1961.

4. White JC: Results in treatment of herniated lumbar discs with and without spinal fusion. Clin Neurosurg 13:42-54, 1966.

SPINAL STENOSIS, LUMBAR

1. Roberson $\mathrm{GH}$, Llewellyn $\mathrm{HJ}$, Taveras JM: The narrow lumbar spinal canal syndrowe. Radieloey 107:89, 1973.

2. Weinstein PR, Ehni G, Wilson CB: Lumbar Spondylosis. Chicago, Year Bnok Kedical Pub, 1977.

3. Wilson CB: Significance of the small lumbar spinal canal: Cauda equina compression syndromes due to spondylosis. III - Intermittent claudication. J Neurosurg $3 i: 499,1969$. 
4. Verblest H: Neuragenic Intermittent Claudication. New York, American Elsevier Publishing Co, 1976.

\section{CERVICAL SPONDYLOSIS}

1. Adams C: Cervical spondylotic radiculopathy and myelopathy. In Injuries of the Spine and Spinal Cord. Handbook of Clinical Neu: ilogy. Viken PJ and Bruyn GW (eds). New York, Am Elsevier Publ Co, 1976, vol 26, p 97.

2. Crandall PH, Batzdorf V: Cervical Spondylotic-Myelopathy. I Neurosurg $25: 57-66,1966$.

3. Hoff JT, Wilson CV: The pathophysiology of cervical spondylotic radiculopathy and myelopathy. Clinical Neurosurgery. Baltimore, Williams and Wilkins Co, 1977, Chapter 34, Vol 24, p 474.

4. Nugent GR: Clinciopathologic correlations in cervical spondylosis. Neurology 9:273-281, 1959 .

5. Piepgrass DG: Posterior decompression for myelopathy due to cervical spondylosis. Clinical Neurosurgery. Baltimore, Williams and Wilkins $C_{0}$, 1977, chapter 36 , vol $24, \mathrm{p} 508$.

6. Taylor AR: Nechanism of injury to spinal cord in neck without damage to vertebral colum. J Bone and Joint Surg 33-B:543, 1951.

7. Wilkenson M: Cervical Spondylosis. Philadelphia, WB Saunders Co, 1971.

SPONDYLOILISTHESIS, LUMBAR

1. Epstein JA, et al: . Degenerative lumbar spondylolisthesis with an intact neural arch (pseudo-spondylolisthesis). I Neurosurg 44:139-147, 1976.

2. Gill GG: Spondylolisthesis and its treatment: excision of loose lamina and decompression. Spinal Disorders. Ruge and Wiltse (ed). Philadelphia. Lea and Febiger, 1977, chapter 21, P 218.

3. Hensinger RN, MacEwan GD: Congential anomalies of the spine. The Spine. Rothman and Simeone (eds). Fhiladelphia, WB Saunders Co, 1975, chapter 5, p 157.

4. Rothman RH, Simeone FA: Lumbar disc disease. The Spine. Rothman and Simeone (eds). Philadelphia, WB Saunders Co, 1975, chapter 9, p 443.

5. Wiltse LL: Spondylolisthesis and its treatment: conservative treatment; fusion with and without reduction. Spinal Disorders. Ruge and Wiltse (eds). Philadelphia, Lea and Febiger, 1977; chapter 20, p 193. 


\section{PERIPHERAI NERVE INJURIES}

1. Aids to the Investigation of Peripheral Nerve Injuries (1943), Medical Research Council, Har Memorandum No. 7 (revised Ed. 2), Her Majesty's Stationery office, London.

2. Kline DG: Physiological and Clinical Factors Contributing to the Timing of Nerve Repair. Clin Neurosurg. Keener E (ed). Baltimore, Williams and Wilkins Co, 1977, vo1 24, pp 425-455.

3. Nulsea FE, Kline DG: Acuta Injuries of peripheral nerves. Neurological Surgery. Youmans JR (ed). Philadelphia, WB Saunders Co, 1973, vo1 2, PP 1089-1140.

4. Seddon HJ: Surgical Disorders of the Peripheral Nerves. Baltimore, Williams and Wilkins Co, 1972.

5. Sunderland $S$ : Nerves and Nerve Injuries. Edinburg, E\& S Livingstone Ltd, 1968.

6. Woodhall B, et al: Neurosurgical implications. Peripheral Nerve Regeneration. Washington, DC, AVA Monograph, 1957, pp 569-638.

\section{PERIPHERAL NERVE TUMORS}

1. Campbell R: In Neurological Surgery, Youmans JR (ed). Philadelphia, WB Saunders Co, 1973, chapter 79, PP 1537-1543.

2. Batsakis JG: Tumors of the Peripheral Nervous System. Tumors of Head and Neck. Baltimore, Williams and Wilkins Co, 1974, chapter 16.

3. Das Gupta TK, Brasfield RD: Benign solitary schwannomas. Cancer 24:355. 1969.

4. Rubinstein LJ: Tumors of the Central Nervous System. Armed Forces Institute of Pathology, Washington, DC, 1972 .

5. Seddon HJ: Nerve Tumors. Surgical Disorders of the Peripheral Nerves. Baltimore, Williams and Wilkins Co, 1972, chapter 10, pp 153-170.

\section{SPINAL CORD TUMORS}

1. Nittner K: Spinai menlngiomas, neurinomas and neurofibromas and hourglass tumors. Part II, Handbook of Clinical Neurology. Vinken PJ and Bruyn GN (eds). New York, Adi EIsevie: PubI Co, 1976, chapter 7, vol 20. 
2. Greenwood J: Spinal cord tumors. Neurological Surgery. Youmans JB (ed). Philadelphia, WB Saunders Co, 1973, chapter 77, vol 3, p 1514.

3. Simeone FA: Intraspinal neoplasms. The Spine. Rothman and Simeone (eds). Philadelphia, bB Saunders Co, 1975, chapter 12, p 823.

4. Slooff IL, Kerrohan JW, MacCarty CS: Primary intramedullary tumors of the spinal cord and filum terminale. Philadelphia, WB Saunders Co, 1964.

\section{SYRINGOMYELIA}

1. Schliep G: Syringomyelia and syringobulbia. Handbook of Clinical Neurology. Vinken PJ and Bruyn GW (eds). Amsterdam, No Holland PubI Co, 1978, vol 32, DP 255-327.

2. Barnett HJM, Foster JB, Hudgson P: Syringomyelia. WB Saunders Co, 1973.

3. Finlayson AI: Syringomyelia and related conditions. Ciinical Neurology. Baker $A B$ and Baker LH (eds), Hagerstowi, $M$, Harper \& Row, 1977, chapter 32 .

4. Gardner WJ: Dysraphic states. Amsterdam, Excerpta Medic, 1973.

5. Hall PV, Muller J, Campbell RL: Experimental hydrosyringonyelia, ischemic myelopathy, and syringomyelia. J Neurosurg 43:464-470, 1975.

6. Hankinson J: Syringonyelia and the surgeon. Modern Trends in Neurclogy. Williams D (ed). London, Butterworths, 1970, pp 127-148.

7. McIlroy WJ, Richardson JC: Syringomyelia: A clinical review of 75 cases. Can Med Assoc J 93:731, 1965.

\section{PERIPHERAI NEUROPATHIES}

1. Dyci PJ, Kronies PK, Lambert EH: Peripheral Neuropathy. Philadelphia, WB Saunders Co, 1975.

2. Mancail E: Paresthesiae, pain and jeripheral neuropathy. Clinical Concepts of Neurological Disorders. Toole JF (ed). Baltimore, Wiliians and Wilkins Co, 1977, chapter 3. 


\section{DIABETIC NEUROPATHY}

1. Ewing DJ, et al: Mortality in diabetic autonomic neuropathy. Lancet $1: 601-603,1976$.

2. Thomas PK, Eliasson SG: Diabetic Neuropathy. Peripheral Neuropathy. Dyck PJ, Thomas PK, Lambert EH (eds). Philadelphia, WB Saunders Co, 1075, pp 956-981.

\section{INFLAMIATORY POLYRADICULONEUROPATHY}

1. Eiben RM, et al: Recognition, prognosis and treatment of the GuiliainBarre' syndrome. Med C1iㅡ Nㅡ를 47:1371-1380, 1963.

2. Loffel $\mathrm{NB}$, et al: The Landry-Guillain-Barre' Syndrome: Complications, prognosis and natural history in 123 cases. I Neurol Sci 33:71-79, 1977.

3. McLeod JG, et a1: Acute idiopathic polyneuritis: a clinical and electrophysiological follow-up study. J Neurol Sci 27:145-162, 1976.

4. Pleasure DE, Lovelace RE, Duvoisin RC: The prognosis of acute polyradiculoneuritis. Neurology 18:1143, 1968.

5. Poser CM, Fowler CW: The nosologic situation of the Landry-GuillainBarré syndrome. Acta Neurol Scand 39:187-201, 1963.

6. Prineas J. McLeod J: Chronic reiapsing polyneuritis. J Neurol Sci $27: 427-458,1976$.

\section{MONONELROPATHIES}

1. Aguayo AJ: Neuropathy due to compression and entrapment. Dyck PJ, Thomas PK, Lambert EF (eds), Peripheral Neuropathy. Philadelphia, WB Saunders Co, 1975, pp 688-713.

\section{HEAVY METAL INTOXICATION}

I. Heyman A, et a1: Peripheral neuropathy caused by arsenical intoxication. N Eng I Med 24:401-414, 1956.

2. Aring CD, Trufant SA: Effects of heavy metais on the CNS. A Res Nerv E Ment Dis Proc 32:463, 1953. 
3. Abd EL, Naby S, Hassanein M: Neuropsychlatric manifestation of chroaic manganese poisoning. I Neurol \& Psychiat 32:501, 1934.

\section{ACUTE INTERMITTENT PORPHYRIA}

1. Tschidy DP, et al: Acute intermittent porphyria. Ann Int Med 83:851-864, 1975.

\section{DISEASES OF MUSCLE}

1. Campa JF, Johns TR: Weakress, fatigue and muscle wasting: disorders of the motor unit. Clinical Concepts of Neurological Disorders. Toole JF (ed). Baltimore, Williams and Wilkins Co, 1977, chapter 4.

2. Johns TR: Treatment of Myasthenia Gravis: Long term administration of corticosteroids with remarks on thymectomy. Advances in Neurology. Griggs RC (ed). New. York, Raven Press, 1977, vol 17.

3. Mann JD, Johns TR, Campa JF: Long term administration of corticosteroids in myasthenia gravis. Neurclogy 26:729-740, 1976.

4. Sanders DB, Howard JF, Johns TR, Campa JF: High dese daily prednisone in the treatment of myasthenia gravis. Proceedings of the International Donference on Plasmapheresis and the Immunological Basis of Myasthenia Gravis. Boston, Houghton and Miffin, 1979.

5. Walton JN (ed) Disorders of Voluntary Muscle. Edinburgh and London, Churchill Livingston, 1974 . 
SEIZURE DISORDERS AND DISTURBANCES OF CONSCIOUSNESS - PANEL 6

David D. Daly, ID (Chairman), Donald R. Bennett, MD, Paui H. Crandall, MD, Richard H. Mattson, MD, J. Kiffin Penry, ND, and Ted B. Rasmussen, MD

The topics discussed in this section include the epilepsies or "seizure disorders," and disturbances of consciousness. Uncer the term, "disturbances of consciousmess," are reviewed syncope, paroxysmal alteraticas of conscioustiess due to metabolic derangement, hypersomia, and unexplained loss of consciousness. It is recognized that maintaining proper performance of an aircraft requires the full mental and physical capacities of the persons in control of the aircraft. Therefore, any event which impairs the higher cortical functions of one of the aircrew can place the aircraft ard its occupants in jeopardy.

\section{THE EPILEPSIES}

\section{MINIMUM CRITERIA FOR DIAGNOSIS}

Because of the propensity for recurrence, the minimum criterion for diagnosis of epilepsy is the occurrence of a seizure. In taking a history, the medical examiner must know the symptons anc collogulalisms, some regional, related to convulsions or other seizures. Examples are "fits," "spells," "turns," "spasms," "worm fits," "teething fits," "fever spasms," "starts," "falling-out spel1s," and "blackouts." A board certified neurologist, or a physician with equivalent training, should make the definitive diagnosis of epilepsy. An electroencephalogram (EEG) must be part of each evaluation.

It is recognized that the inadvertent ingestion of a convulsant compound, for example, an organic pesticide, may produce one or more tonic/clonic convulsions in any person, and that a single such incident does not per se constitute evidence of a propensity for recurrent seizures.

\section{OTHER RELEVANT CRITERIA FOR DIAGNOSIS WHICH MAY AFFECT TEE PROGNOSIS}

Epilepsy is a multifactorial disorder characterized by recurring seizures. The authors accept the definitions and types of seizures propounded by the International League Against Epilepsy 8 and recomended by the World Health Organization (WHO), the World Federation of Neurology, the World Federation of Neurosurgical Societies, and the International Federation of Societies for Electroencephalography and Clinical Neurophysiology. Because seizures can result from many and diverse causes, the natural histories of the epilepsies vary, but a propensity for zecurring seizures underlies all. For this reason, the panel emphasizes that of equal importance with nosological considerations is the question, "Does a person who has had a single seizure experience an increased probability of subsequent seizures?" 
RELEVANT DTAGNOSTIC PROCEDURES AIDING IN DIAGNOSIS AND IN ASSESSMENT OF PROGNOSIS

The EEG examination must be conducted in a laboratory which conforms to standards of the American EEG Society. 1 Recordings must be interpreted by an electroencephaIographer certified in EEG by the American Board of Qualification or by one with equivalent training, because competent interpretation of an EEG requires extensive experience. The panel cautions that ingenuous or intemperate interpretations of ErGs can cause egregious errors. For example, certain types of paroxysmal discharges have no significant correlations with epilepsy. 4 Conversely, superficially similar types of paroxysmal discharges have high correlations with clinical evidence if seizures. 20,22 The panel recomends that the EEG be used primarily to evaluate the probability of recurring sefzures, rather than as a diagnostic procedure to establish or refute a diagnosis of epilepsy. The use of other diagnostic procedures, for example, CT scan, should be at the discretion of the consulting neurologist.

\section{PROGNOSIS RELATIVE TO SUDDEN OR INSIDIOUS INCAPACITATION}

The panel recomends that the diagnosis of epilepsy constitute permanent disqualification for licensure or recertification. In making this recommendation, the panel calls attention to the following facts. Seizures have various motor, sensory, and mental manifestations, with simple loss of consciousness being the least frequent form. For instarce, a tonic/clonic convulsion lasts approximately 90 seconds, during which time the force of muscular contractions may make it impossible to restrain or move the person. 9 During automatisms of complex partial selzures, a person for severai minutes may exhibit confusion, aphasia, and agitation, and may resist forcibly all attempts at restraint.5 In "absence status," confusion may persist for many minutes or hours. 2 obvicusiy, aberrations of behavior during a seizure can disrupt execution of the responsibilities of other members of the aircrew and jeopardize safety of the aircraft.

A majority of healthy, young aduli males who have had a single convulsion will have another convulsion within three years. 13 Based on this and other evidence, the panel recommends that the occurrence of a single selzure in anyone over five years of age constitutes grounds for permanent disquaification for licensure or recertification.

MEDICAL AND SURGICAL THERAPY AFFECTING PERFORMANCE, INCAPACITATION, AND PROGNOSIS

As menioned, persons with epilepsy have recurrent seizures even after long seizure-free intervals, with or withouc medication or after surgical excisions.14,18,19,23 Using the neuroepidemiologic measure of rate of terminal remission, Hauser and Rurkland found that in epileptic persons followed medicaily for ten years after diagnosis, seizuremfee intervals of two years occurred in only $40 \%$, and seizure-free perions of five years in only $33 \%$ of the epileptic patients. 10 others also have observed low terminal remission rates in children. 11 
Unwsual physiological stresses, for example, sleep deprivation or the abrupt withdrawal of certain neurotropic drugs or of alcohol after a prolonged bout of drinking, may precipitate one or more convulsions in some persons. At some later date, repetition of the same physiologic stresses again may result in one or more convulsions. 3 The panel concludes this constitutes evidence of an increased risk of recurrent seizures and recorrinends permanent disqualification for licensure or recertification.

Occurrence of a single convulsion in a child five years old or less requires particular consideration. If a convulsion occurs in a child after head injury or during any acute identifiable brain disease, such as encephalitis or meningitis, an increased risk of recurrent seizures exists. In children with "complex febrile seizure," the incidence of epilepsy by age seven years is 20 times that of children without febrile seizures.16 Seizures oceurring in children with closed head infury are associated with a much higher incidence of late epilepsy than in the age-matched general population. 12 The panel recommends that a single convulsion on or before age five years need not disqualify for licensure, unless it was associated with identifiable brain disease or injury, occurred as a "complex febrile seizure" as defined by Nelson and Ellenbers, $16^{\circ}$ or was associated with a history of recurring seizures in parents or siblings.

Breath-holding spells of childhood, "cyanotic" or "pallid" syncope, do not constitute epilepsy 15 and do not disqualify for licensure.

\section{SYNCOPE}

In the Conference on Cardiovascular Problems Associated with Aviation Safety, the Task Force on Arrhythmias recommended, "All persons with symptoms of syncope, presyncope sensation, and palpitation are disqualified for initial license and recertification." 7 In concurrence with this, the panel reconmends that proven carotid sinus hypersensitivity constitute disqualification for licensure or recertification.

\section{HYPOGLYCEMIA}

In persons not taking hypoglycemic drugs, confusional states, unconsciousness, or seizures rarely result from hypoglycemia. Glucose tolerance tests do not reliably provide confirmation or refutation of symptomatic hypoglycemia. Proof requires demonstration of symptoms in association with measured hypoglycemia and the alleviation of the symptoms by administration of glucose. The panel recomends that proven symptomatic hypoglycesia constitute disqualification for licensure or recertification, unless it can be permanentiy alleviated, for example, by resection of a functioning islet cell adenoma of the pancreas. 
HYPERSOMNIA

Narcolepsy is the most comon cause of inordinate diurnal sleepiness, which way be accompanied by cataplexy, hypnagogic hallucinations, and sleep paralysis. 6 The mafortty of persons with narcolepsy can be diagnosed by bistory alone. The EBG does not prov1de unequivosal evidence and thus is not recomended as a diagnostic measure. If the diagnosis of narcolepsy is chailenged and inordinate sleepiness denled, the panel recomends use of pupillowetry as an objective measure of vigilance, 21,22 Because narcolepsy does not remit and requires continuous treatment, the panel recomends that narcolepsy constitute permanent disqualification for licensure.

\section{UNCONSCIOUSNESS OF UNIDENTIFIABLE CAUSE}

In a person who has had an episode of unconsclousness, the medical examiner must make every effort to obtain descriptions of the event from all observers, in order to exclude the possibility of a convulsion or other type of seizure. Diagnostic evaluation must include neurological consultation, EEG, electrocardiography, and CT scan. If all tests give normal findings and the event remains unexplained, the panel recommends that the candidate be regarded as disqualified for initial ifcensure, unless the episode occurred more than five years before examination, or for relicensure, until an interval of two years has passed without further symptoms and the above tests again yield normal findings. 


\section{REFERENCES}

1. American Electroencephalographic Society: Guidelines in EEG, 1976 (Executive Office 38238 Glen Avenue, Willoughby, Ohio 44094).

2. Andermann F, Robb JP: Absence status. Epilepsia 13:177, 1972.

3. Bepnet DR: Sleep deprivation and major motor convulsions. Neurology $13: 953,1963$.

4. Chatrian GE: Paroxysmal patterns in "normal" subjects, in Redmond A. (ed) Handbook of Electroencephalography and Clinical Neurophysiology. Holland, Elsevier, 1976, 6A:114.

5. Daly DD: Ictal clinical manifestations of complex partial seizures, in Penry JK, Daly DD (eds): Complex Partial Seizures and Their Treatment. New York, Raven Press, 1975, pp 57-82.

6. DaIy DD, Yoss RE: Narcolepsy, in Vinken PJ, Gruyn GW (eds): Handbook of Cinical Neurology, vol 15. "The Epilepsies", pp 836-852, 1974.

7. Driefus LS (ed): Cardiovascular problems associated with aviation safety. Amer J Cardiol 36:573-628, 1975.

8. Gastaunt H: The clinical and electroencephalographical classificaiton of epileptic seizures. Epilepsia 11:102, 1970.

9. Gastaut H., Broughton R: Epileptic Seizures. Springfield,I1l., Thomas Publishers, 1972。

10. Hauser WA, Kurland LT: The epideniology of epilepsy in Rochester, Minn. 1935-1967. Epilepsia 16:1, 1975.

11. Holowach J, Thurston DL, O'Leary J: Prognosis in childhood epilepsy. New Eng J Med 286:169, 1972.

12. Jennett B: Epilepsy After Non-Missle Head Injuries, ed 2. Chicago, Year Book Medical Publishers, 1975.

13. Johnson LC, DeBolt WL, Long MT: Diagnostic factors in adult maies following inftial seizures. A three year follow-up. Arcin Neurol $27: 193,1972$.

14. Juul-Jensen P: Frequency of recurrence after discontinuance of anticonvulsant therapy in patients with epileptic seizures: a new follow-up study after five years. Epilepsia $9: 11,1968$.

15. Lombroso CT, Lerman P: Breath-holding spells. Cyanotic and pallid Infantile syncops. Pedrlatr 39:563, 1967.

16. Nelson $\mathrm{KB}$, Ellenberg JH: Predictors of epilepsy in children who have experienced febrile selzures. New Eng J Med 295:1030, 1976. 
17. Pratt KL, Matteson RH, Weikers NJ, Williams R: EEG activation of epileptics following sleep deprivation. Electroenceph Clin Neurophysiol 24:11, 1968 .

18. Purpura DP, Penry JK, Walter RD (eds): Neurosurgical Management of the Epilepsies, New York, Raven Press, 1974.

19. Rodin EA: The Propnosis of Patients with Epilepsy. Springfield, I11., Thowas Publishers, 1968.

20. Trojaborg $\mathrm{W}$ : Changes in Apike Foci in Children, in Rellaway P, Peterson I (eds): Clinical Electrcencephalography in Chilaren. Nes York, Grune and Stratton, 1968, Pp 213-226.

21. Yoss RE, Hoyer NJ, Hollenhorst RW: Pupil size and spontaneous pupillary waves associated with alertness, drowsiness, and sleep. Neurology $20: 545,1970$.

22. Yoss RE, Moyer NJ, Ogle KN: The pupillogran and narcolepsy: a method to measure decreased levels of wakefulness. Neurology 19:921, 1969.

23. Zielinski JJ: Epileptics not in trestment. EpIlepsia 15:203, 1974.

24. Zivin J, Ajomone-Marsan C: Incidence and prognostic significance of "epileptiform" activity in the EEG of non-epileptic subjects. Brain $91: 751,1968$. 
MIGRAINE AND OTHER HEADACHES - PANEL 7

Otto Appenzeller, MD (Chairman), Robert Feldman, MD, Arnold Friedman, MD

\section{TEMPORAL ARTERITIS}

Temporal arteritis is a granulomatous inflamatory process usually affecting the temporal or ophthalmic arteries. I It was first described by Hutchinson, 2 who used the term "arteritis of the aged", and his description remains a classic account of a severe case. The entity was associated with a characterisic clinical picture and pathologic findings by Horton, Magath, and Brom, ${ }^{3}$ who added to the description the appearance of remissions and relapses in the course of the illness, emphasized the prominence of headache and difficulty in chewing, and concluded, correctly, that the disease was a focal expression of an unknown systemic disorder.

Temporal arteritis is related to autoimune diseases and is classified as a collagen vascular disease. Imnunoglobulin abnormalities in this condition have been reported, and there is evidence that antigen-antibody complexes are formed. 4 The true incidence of the condition is not known, but an average annual rate of $3 / 100,000$ has been suggested. Women are affected four times more of ten than men. 5 The recognition of milder variants of the condition suggests it is probably more frequent than originally suspected.

Although originally the disease was thought to be confined to the temporal arteries and its branches, it was soon recognized from pathologic studies that other blood vessels, including the aorta and its branches, may be involved, causing death from rupture of an aortic aneurysm or from cerebral infarction. However, widespread involvement of vessels may not be clinically apparent. 6 Because lesions in the blood vessels contain multinucleated giant cells, the condition is also termed, "giant cell arteritis."

Blindness can be a feature of temporal artertitis, and other disturbances of the visual system, including ophthalmoplegia, may occur. The close relationship between temporal arteritis and polyuyalgia arteritica was first recognized when temporal artery biopsies from patients with the latter condition Erequently showed characteristic findings of tetoporal arteritis. 7 The successful treatment of temporal arteritis and the prevention of deterioration of vision with steroids was first reported by Chavany and Taptas, 8 but no controlled double-blind crossover study of their effectiveness has been repo:ted.

MINIMUM CRITERIA FOR DIAGNOSIS

The cause of temporal arteritis is unknown, but fts clinical signs are faixly characteristic and are often localized to the distribution of the carotid artery and its branches. Unfortunately, patients rarely seek medicai care before the onset of headache, which is usualiy the most prominent symptom. The headache becomes acute within a few hours of its appearance, and may be unilateral or bilateral. The patient can clearly differentiate this pain from ordinary headaches. The pain is easily localized to the scalp over the temple and can be distinguished from pain arising in other structures about the head or within the cranium. The headache is intense and 
boring, occasionally stabbing, along the course of the temporal vessels. Pain and tenderness of the scalp may be so intense that sleep is impossible and the patient has to spend the night sitting up in bed.9 Though typical clinical manifestations are easily recognized, patients with nonspecific headaches may have symptons attributed to tension or depression, which prove on further examination to be due to temporal arteritis. Some patients have discomfort on opening the mouth, pain and stiffness in the region of the temperomandibular joint on chewing, or so-called intermittent claudication of the jaw, and increasing tiredness during the progress of the meal. Pallor, wasting, and loss of weight may be present. Muscle pain and joint discomfort in other parts of the body, notably in shoulders and somet imes in the neck and hips, may be present during the early stages of headache. Occasional patients seek medical attention because of depressive episodes, or complain of dyspepsla, fever, and night sweats. Blood vessels supplying the central nervous system may be involved, giving rise to synptoms which depends upon the area rendered ischemic by the disease.

A great variety of neurologic manifestations may be presenting symptoms of temporal arteritis, including delirium, hemiplegia, clinical signs due to Involvement of the brainstem or eighth nerve, and even cransient diabetes insipidus. 10 Some patients may show thinning of the hair at the temples, but it is not clear whether this is an Ischemic phenomenon or due rather to the patient's constant rubbing because of disconfort. Red nodules of the temple regions may be noted, the patienrs cften calling them varicose veins. Rarely, gangrene of the scalp has been reported. 11 Tenderness over the temporal arteries is found at some stage in almost every patient.

Acute transient ophthalmomalacia in temporal arteritis has also been reported.13 In this condition, bilateral corneal edema occurs due to ocuiar hypotension. Vision is greatly impaired but may return to normal with appropriate treatment. In some patients, visual field defects remain after treatment. The ophthalmomalacia has been attributed to involvement of the long ciliary arteries. In $50 \%$ of patients with confirmed temporal arteritis, visual fallure developed due to involvement of the posterior ciliary or other branches of the ophthalmic artery, giving rise to ischemia of the optic nerve.

Visual involvement may be preceded by episodes of transient blurring of vision, but more usually, visual loss is abrupt in onset and first noticed on awakening in the morning, presumably related to a sudden change in posture. Paradoxically, the loss of vision may herald a lessening or even total disappearance $\mathrm{cf}$ headache. The visual impairment is often described as a mist or a dark vell ovez part of the visual field of one eye which, within 12 to 24 hours, becomes dense until all light perception is lost. Only rarely does visual deterioration occur over several days. 9

Ophthalmoscopy soon after the onset of visual symptons may be normal, but within one to two days, edema of the optic disc may be present. Hemorrhages and exudares have also been observed. As a rule, however, the visual loss is much greater than the ophthalmoscopic findings suggest. Examination of the viaual fields nay show all degrees of impairment to complete blindness. 
Occasionally, edema of the retina may be seen, the involved area corresponding to the extent of the visual field loss. The retina usually is shiny and pale and less distinct than normal. The optic disc shows edema or appears yellowish with considerable blurring of the edge. A cherry red spot has been reported in the macular area in severe eye involvement. The blood vessels of the retina, particularly arterioles, are thinned, with iittle blood flowing through them, and the affected area may show narrowing of vessel caliber. Distention of retinal veins, with beading and irregular fragmentation, has been observed. After some weeks of visual impairment, the retina may again be nomal in color and texture, and the vasculature may return to normal caliber. The cherry red spot may disappear. Occasionally, arteries will be attenuated for months. The disc may remain pale and waxy, indicative of optic atrophy. In a study of 23 badly affected eyes, only two regained useful vision and 13 remained compietely blind. 9

Laboratory diagnosis is nonspecific, but the most useful test is the erythrocyte sedimentation rate (ESR). Almost always the ESR is elevated, a1though initially it may be normal and there have been patients with biopsyproved disease without elevation. 14

There is a hypochromic anemia in most patients, but bone narrow aspirates show normal red cell maturation. The anemia is usually refractory to iron therapy. Occasionally, a slight increase in white cell count has been reported, but most patients do not have leucocytosis or eosinophilia. Coagulation studies and platelet counts are normal. Serum albumin may be decreased in chronically ill patients, but the rest of the serum proteins and globulin are usually normal. Sometimes serum protein electrophoresis shows an elevated alpha-globulin. Slightly increased CSF protein has been reported in an cccasional patient. Immunologic investigation may show significant titers of capillary reactive IgG in patients with temporal arteritis and in those with polymyalgia arteritica, even though arteritic symptoms are not present.15 This is a nonspecific finding which also has been reported in rheumatic diseases, scleroderma, systemic lupus erythematosus, and polymyositis.

The diagnosis of temporal arteritis depends upon the finding of inflammatory cells in the temporal artery wall on biopsy. In 560 temporal artery biopsies, other processes which might lead to ischemia of optic nerves were found. But these did not show the characteristic inflammatory changes and were instead attributed to atherosclerosis. Plasma celis, macrophages, and lymphocytes are usually present within the arterial wall, and eosinophils are found in at least half of the specimens, but polymorphonuclear neutrophils are not common. The entire thickness of the vessel wall is usually involved, but in some biopsies no evidence of medical or adventitial infiltration occurs. The intima usually shows fibrous tissue proliferation, but this again is nst specific and may be seen in biopsies from elderly patients without temporal arteritis. Characteristically, multinucleated giant cells are present, and they tend to aggregate in the disintegrated internal elastic lamina. Occasionally, these cells contain calcified elastic fibers within their cytoplasm. Fibrinoid necrosis is not a feature of temporal arteritis as it is in other arteritides. 
The characteristic pathologic changes of temporal arteritis are nct usually found in biopsies from patients whose visual disturbances result from lesions of the peripheral branches of the ophthalmic artery. PathoIogically, it may be difficult to distinguish between a healed arteritis and degenerative changes due to age, a difficulty wich is often compounded by steroid treatment preceding biopsy. Sometimes a histologic diagnosis is impossible. Isolated foci of arteritis ("skip lesions") may occur, so that if only a small segment of temporal artery is removed at biospy, this may be normal, whereas adjacent parts not examined may show characteristic evidence of disease. By examination of serial sections from temporal arteries from patients, minute skip lesions ( $3 \mathrm{C} \mathrm{mu}$ in length) became apparent in otherwise classic biopsy specimens. It is, therefore, emphasized that long segments of axtery should be removed and multiple histologic sections examined before a definitive diagnosis is made. 16

Because of the close relaticnship of polymyalgia arteritica to temporal arteritis, additional diagnostic aid might be obtained by muscle biopsy, particularly if the clinical picture is suggestive, the ESR high, and the temporal artery biopsy not conclusive.

Ligation of the temporal artery pxior to removal may be contraindicated in the elderly, because of the possibility of widespread atherosclerotic involvement and because an actual or potentially important collateral channel for blood supply to the brain could be obliterated by the procedure. With sophisticated histochemical techniques muscle involvement in polymyalgia arteritica can be differentiated from that of rheumatoid disease or polymyositis. 17

\section{OTHER CRITERIA FOR DIAGNOSIS}

Temporal arteritis is a comwon disorder which should be suspected in a patient over 50 years old whose headaches are of recent onset or have changed in quality or location. If patients also have unexplained anemia, temporal artery biopsy is indicated, particularly if the ESR is elevated.

\section{RELEVANT DIAGNOSTIC PROCEDURES}

The clinical presentation of temporal arteritis may be so varied and unrelated to involvement of the arteries themselves that only continuous vigilance can assure early diagnosis and treatment with consequent prevention of serious sequelae. When the diagnosis is suspected, careful history and examination may support the suspicion, and a tempcral artery biopsy and for msclebiopsy should be carried out. Biopsy is justified even though the arteries are clinically normal.

If the clinical picture and the focal nature of the disorder are appreciated, the diagnosis of temporal arterftis will not easily be discarded even if the biopsy is negative. Further help in diagnosis, when necessary, may be obtained by joint imaging with technetium pertechnate. Joint scintigrams were abnormal in a large proportion of patients with polymyalgia arteritica. In these patients the joints showing abnormal uptake were the shoulders, often asymetricaily affected, in contrast to the predreinantly symetric increased distal joint uptake in rheumatoid arthritis.18 
Treatment

Corticosteroid (prednisone) treatment for temporal exteritis produces dramatic improvement in systemic symptoms, usually within 72 hours, and the ESR should be normal in a week. Ileadache, scalp tenderness, and intermittent claudication of the jaw usually improve, and deterioration of vision, if not present at the start of treatment, will not occur. Trearment is best started with $100 \mathrm{mg}$ of prednisone daily inmediately upon diagnosis.

When headache and systemic symptoms are controlled and the ESR is normal, the prednisone dose may be lowered. Titration of steroid dose depends upon maintenance of normal ESR and clinical well-being. Return of headache or constitutional symptons suggests the need for increasing the prednisone dose until symptoms are controlled again. Attempts to grajually withdraw steroid therapy should be made after about eight months. In those with impaired vision, however, a small daily dose of prednisone for another year is recomended. 6

\section{PROGNOSIS REIATIVE TO SUDDEN OR INSIDIOUS INCAPACITATION}

Satisfactory return to health occurs in most patients if they are adequately treated. On occasion, weight loss, fatigue, muscle weakness, joint pains, and headache fersist for several months but eventually resolve.

\section{MEDICAL THERAPY AFFECTING PERFORMANCE, INCAPACITATION AND PROGNOSIS}

Improvement in viston cannot be expected after commencement of treatment, though progression of visual dysfunction does not usually occur in those on adequate therapy. Pulsation of arteries may return. If the patient has been symptom-free without steroids for at least one year, recurrences are not expected. In a small number of patients the disease progresses though adequately treated, and complications resuit from arterial occlusion and ischemia or disturbances of muscle and joint function. Occasional1y, crippling muscle weakness, back pain, invoivement of peripheral and cranial nerves and skin, and ischemic episodes affecting the viscera occur. In some patients, the disease is so far progressed when diagnosed that steroids do not arrest progression, and death ensues. 19

RECOMENDATIONS FOR MEDICAL CERTIFICATION

Patients with active temporal arteritis should not be issued air medical certificates. Even if having adequate treatment and being in complete remission, they should not have sertification until they have been symptomfree and have had a nornal ESR for at least one year after cessation of steroid therapy. The same criteria apply to those with polynyalgia arteritica alone, in whom concomitant histologic evidence of temporal arteritis has not been obtained.

\section{TENSION HEADACHE (SCALP MUSCIE CONTRACTION HEADACHE)}

ACUTE TENSION HEADACHE

MINTMUM CRITERIA FOR DIAGNOSIS

Acute tension headache is the most comon type of headache. Few are spared 
this condition, but the majority suffer from only transient pain which may be effectively treated by the patient. A percentage of patients, hcsever, have prolonged, intolerable, and incapacitating pain resulting in disruptIon of work capability and other difflculties. In headache clinics, about $50 \%$ of patients suffer from tension headache. It is well recognized that vascular headaches can occur in individuals with tension headaches.

The acute type of muscle contraction headache occurs uring periods of etotional, physical, or other stress, is usually dull and not throbbing, may be occipital, spreading frontally or more generally, and may last one to four hours. Self treatment with analgestes, alcohol, and reduction of stress is usually adequate.

If the acute headache pain persists, it may increase in intensicy and become throbbing, a change attributed to secondaxy vasodilatation of cranial arteries. Once the pain is throbbing, alcohol usually aggravates it, and ergot preparations are not very effective.

MEDICAI THERAPY AFFECTING PERFORMANCE, INCAPACITATION AND PROGNOSIS

This headache is best treated with simple analgesics.

EFFECT OF STRESS OR OTHER STATES RELATING TO PROBABILITY OF INCAPACITATION AND PROGNOSIS

Acute tension headache may be precipitated by emotional factors, repressed anger, rejection, worry, excitement, prolonged mental concentration, boredom, or excessive accommodation("eye strain"), or by prolonging abnormal positions of the neck.

This type of headache should not disqualify from atrman certification. CHRONIC TENSION HEADACHE

MINIMUM CRITERIA FOR DIAGNOSIS

This type is characterized by dull pain, may be present constantly for months or years, and is usually bilateral. The pain may be frontal or occipital, generalized or band-like, and accompanied by posterior pain in the cervical region and by an exacerbation of discomfort on extending the neck. The patient almost always complains of awakening daily with headache, and the severity increases as the day progresses but diminishes towards evening. Occastonal changes to a throbbing ache, with associated nausea, photophobia and intolerance to sound, suggest a vascular component. Sometimes the nausea may be due to medication rather than to the headache. Most patients with this type of headache are "abituated to one or more analgesics or narcotics. Depression is frequenty found and is a useful sign in assessing the nature of the pain. A large proportion of patients tested on the Zung Self-rating Depression Scale had scores consistent with depressicn. 20 A number of studies report repression and dependency characterize these patients. 
OTHER CRITERIA FOR DIAGNOSIS AND EELEVANT DIAGNOSTIC PROCEDURES

There are no helpfil diagnostic procedures in this condition except careful clinical examiation, fncluding extensive neurologic resting and exclusion of underlying conditions which might mimic tension headaches. It generaily may be safely assumed that if headaches have been present for years withou: change in character, and if the patient wakes in the morning with the hraaache but is not wakened by it during the night, they are likely to se of the chronic tension variety. Diagnostic errors may be avolded in the few cases of doubt by appropriate special radiologic examinations, inciuding CT scan.

\section{MEDICAL THERAPY AFFECTING PERFORMANCE AND INCAPACITATION}

In chronic tension headache, analgesics should not be given. Although they may reduce the pain initially, they tend to lead to habituation, tolerance, and rebound headache upon cessation of therapy. The use of tranquilizers is not indicated because exacezbations in the headaches may occur. Physical measures, such as exercises of neck muscles, heat packs, or traction with massage may increase muscle contraction and worsen the headaches. Psychotherapy has not been useful. Biofeedback training using electronyography signals from the patient's neck or scalp muscles has been reported to be useful, but other studies suggest its effectiveness is due to the placebo effect. Many reports of success using tricyclic antidepressants have appeared.

\section{STRESS, INCAPACITATION AND PROGNOSIS}

The role of physical or mental stress in triggering or exacerbating tension headaches, and the frequent abuse of analgesics and other psychotherapeutic drugs by patients, make it undesirable for medical certificates to be issued to patients who suffer from chronic tension headache. Though sudden incapacitation is unlikely, the interference with alertness and reflex functioning caused by chronic drug use should disqualify pilot applicants.

The prognosis for recovery from chronic tension headache is poor, but sudden or insidicus incapacity should not occur unless the headache is related to chronic drug use.

\section{CONVERSION HEADACHES}

This type of headache is characterized by bizarre pain in unusual sites, with severe nonthrobbing and sometime discontinuous pain which is quite different from tension headache. The pain awakens the patient from sleep, way be gentralized or stabbing through the head, and may be described in unusuel terms. The patients use analgesic and narcotics heavily, of ten are depressed, and usuaily are unable to continue their occupations, wich leads to a long history of uemployment.

Conversion headaches say be differentiated from post-traumatic headaches by lack of an antecedent history of trauma. It should be noted, however, some patients with pcst-traumatic headache later may develop conversion features. The preponderance of fewajes with conversion headaches is noteworthy. There is no response to tricyclic antidepressants, and abuse of narcotics and analgesics is widely prevalent. Patients with conversion headaches respond poorly to any treatment and not at all to physical measures or biofeedback. 


\section{Recomendations for Medical Certification}

Conversion headaches are so incapacitating and abuse of drugs so widespread that medical certification should be denied. The likelihood of sudden incapacitation in patients with conversion headache is remote, but the complications of chronic drug intake and the inability to cope with situations requiring alertness disqualify such patients from being in comand of aircraft.

\section{A'TITUDE SEADACHE}

Headache is a prominent feature of all forms of mountain sickness. Altitude headache is unusual below altitudes of 8,000 feet and appears with increasing frequency at higher elevations. Above 12,000 feet, this type is universal in nonacclimated subjects and causes serious discomfort to mountain climbers and other mountain people. Filots in nonpressurized aircraft tray be susceptible if they are not acclimatized.

The pathogenesis of mountain sickness is $\mathfrak{x}$ ot fully understood, and the same is true of headache which accompanies that illness. The headache is not the immediate result of hypoxia alone, because it takes 6 to 96 hours after arrival at the higher altitude before this disabling symptom appears. Moreover, it and other symptoms of acute mountain sickness are not easily relieved by giving oxygen to the subject at high aititude. The headache has been attributed to vasodilatation or brain edema, and evidence exists that both mechanisms are involved.

Aititude headache is throbbing and usually generalized, although it may be predominantly frontal. It is aggravated by exertion, coughing, straining, a sudden jolt to the head, and lying down. Frequently, it is temporarily alleviated by the intake of cold fluids, although paracoxically at sea level, the ingestion of cold food may cause headache. Carbohydrates may have a beneficial effect. The severity and nature of an altitude headache in any individual are usually similar on re-exposure.

While clinical features suggest vasodijatation may be involved in altitude headache, evidence for increased intracranial pressure has also been found. Papiliedema and retinal hemorrhages were observed in mountaineers, and lumbar puncture done during altitude exposure showed increased cerebrospinal fluid pressures above values found at low altitudes in the same subjests.

Acute mountain sickness outlasts a relatively brief exposure to altitude by hours, and the personality, motivation, and variable individual thresholds for pain are important in determining the severity of the illness. 22 Recent observations in the Himalayas have shown that altitude illness and retinal hemorrhages were related to previous altitude exposure rather than to acclimatization alone. Climbers who previously attained altitudes of 18, c00 feet or more, though no longer acclimated, were less likely to develop severe altitude illness on re-exposure then those who reached those altituces for the first time. Thus, there appears to be a "carry over" effect which protects against altitude illness and headache in those with past high altitude exposure. 
Focal neurologic deficits may appear with severe altitude illness. Exposure to altitude of persons with migraine frequently leads to the aura alone or to full blown attacks of migraine. 23

\section{Recomendations for Medical Certification}

The occurrence of altitude illness and headache in unacclimated normal subjects should not be a cause for denial of medical certification. The delay of 6 or more hours in the appearance of altitude illness after exposure makes it unlikely this condition would interfere with operation of an aircraft for brief periods at altitudes normally inducing mountain sickness.

In persons with migraine, who may have neurologic deficits on altitude exposure as part of their aura, altitude-induced migraine attacks should disqualify from certification. Precipitation of migraine attacks by altitude exposure occur within minutes after altitude exposure.

\section{EXERTIONAL HEADACHE}

Exercise in the absence of high altitude exposure may lead to headache. Three varieties of headache are known to be related to effort: acute effort migraine after a short burst of activity; effort migraine with prolonged exercise; and heacache accompanying physical activity, irrespective of the amount of effort expended, or "exertional headache."

Acute effort migraine was first described by Jok 1,24 who observed the condition in himself. Acute effort migraine occurs after short bursts of intense effort, especially when associated with excitement. Many cases of acute effort migraine were observed in highly trained individuals at the Mexico City Olympic Games (elevation 7,000 feet) in 1964. In this setting, altitude contributed ddditional stress which precipitated the attacks. Clinically, scotomata appear immediately after exertion, hyperventilation and nausea follow within a few minutes, and severe pulsatile, retro-orbital, unilaceral pain indistinguishable from migraine is usually present. The pain may last an hour or so, but there may be several attacks after repeated competition.

Prolonged noncompetitive exercise may be associated with vascular headache, usually in individuals who are dehydrated with excessive heat load and hypoglycemic. This headache is also aggravated by altitude. In well trained atiletes, headache of this type is extremely rare. Effort headache following prolonged exercise is increasingly noted by devotees of physical fitness programs after long exertion for which they are not yet trained. The pain is isually intense, sometimes occipital or frontal; there may be nausea, although no vomiting is present at the onset, and focal neurologic disturbance does not occur. The condition is benign and not likely to recur with repeated exertion, provided endurance improves and dehydration, alcohol intake, excessive heat load, hypoglycemia, and unaccustomed altitude are avoided.

In some individuals, exertional headaches occur repeatediy with any activity. This type of pain is less ofter purely vascular. It is usually occipital and throbbing, and nausea may be present. Focal neurologic signs are not found, and the pain is alleviated by support of neck muscles. Marked aggravation of pain occurs with increased effort and reck movement, and the 
headache may remain for hours afker cessation of physical effort. Ordinary analgesics taken before anticipated exertion and endurance training are usually preventive.

Recommendation for Hedical Certification

Headache associated with exertion of any type should not iisqualify from airman medical certification. Incapacitation of a sudden nature with this type of headache is unlikely, and the headache can be avoided if the precipitating factors ore recognized.

\section{HEADACHE ASSOCIATED WITH SEXUAL ACTIVITY}

Sexual activity may be associated with excruciating headache of sudden onset. The severe headache at the time of orgasm (orgasmic cephalgia) can cause considerable anxiety, because subarachnoid hemorrhage has occurred during sexual excitement. Orgasmic cephalgias, however, are usually benign.

Headache may occur at the time of mounting sexual arousal, and clinically it is similar to scalp muscle contraction headache and presumably due to vasoconstriction and contraction of muscle. A purely vascular headache, usually severe and throbbing, may occur suddenly at the height of orgasm. The headache is related to physiologic responses associated with sexual activity, which are mediated through the nervous system. The physiologic responses result in hypertension, vascular congestion, and increased muscle tension. 25

Orgasmic cephalgia may occur in persons of both sexes, but usually it does not recur with each coital event of the patient. The headaches are not related to sexual techniques but are more common during illicit activity and with additional stress, such as altitude. Headache during sexual arousal is different from exertional headache, and patients who have both types can distinguish between the two.

Orgasmic cephalgia is similar to headache in patients with pheochromocytonas. In both conditions, there is an increase in heart rate and blood pressure which may reach very high levels. The sudden increase in blood pressures cause cerebral vasodilatation and pain. This pain, if experienced at altitude, may continue for days in unacclimated subjects.

The inconsistent occurrence of orgasmic cephalgia may be the result of variability in arousal and blood pressure rise. Orgasmic cephalgia is not usually associated with vomiting. If vomiting occurs, it is an indication for extensive neurologic investigation. Some patients with orgasmic cephalgia do vomit; angiography, neurologic examinations, and long term follow-up in such patients failed to show serious disease. 26 Treatinent with B-blockers is usually curative.

\section{Recomendation for Medical Certification}

Orgasmic cephalgia should not be cause for denial of medical certification of pilots. Sudden incapacitation is unilkely, and attacks may be avoided through abstinence before anticipated flights. 


\section{ICE CREAM HEADAC:IE}

This headache can occur in anyone with prolonged cold exposure of the palate. Some individuais, however, are particularly sensitive and the short stimulus can cause intense pain. Ice cream headache is usually on top of the head, but sometimes midfrontal or behind the ear. Cold in the esophagus or stomach does not cause the headache. Migraineurs are more susceptible to ice cream headache, and their susceptibility to symptomatic orthostatic hypotension suggests that ice cream headache may also be vascular. 27

Other foods have been implicated in the genesis of migraine. Monosodium glutamate and sodium nitrite affect blood vessels directly, and it is possible that these food triggers do so through their vasoactive constituents. "The Chinese Restaurant Syndrome" is attributed to monosodium glutamate. Its occurrence depends on susceptibility, pain threshold, dose, and the setting in which the substance is taken. A precipitating factor, in normally resistant subjects, is Chinese soup taken on an empty stomach, which may cause more rapid absorption of the monosodium glutamate. The Chinese Restaurant Syndrome is charactexized by intense Flushing procordial chest pain, and pulsating severe headaches. Subjects may feel a tingling in the arms and chest and often a sense of impending doom. Though controversy about the genesis of dietary migraine exists, there is no doubt that experimental administration of tyramine together with monoamineoxidase inhibitors produces headache and hypertension in otherwise normal subjects.

"Hot dog headache" has been attributed to sodium nitrate in cured meats. This substance is vasoactive and can cause skin flushing also. Hot dog headache is due to the action of sodiun nitrite on the vasculature, but it might also be mediated through platelet aggregation, which could be the final common pathway in the genesis of dietary headaches. 28 Hot dog headache is characterized by bitemporal, sometimes nonthrobbing headache, which may appear within minutes after eating cured meat and lasts several hours. Facial flushing can occur concomitantly.

After excessive alcohol intake, hangover headache occurs. This is due to the direct vasodilatory effect of alcohol. Factors which aggravate this headache are increased pulsatile excursions of extracranial vessels induced by exercise or the migrainous diathesis. Alcohol may then lead to a migraine attack. A number of industrial solvents, glues, and fixatives also can cause severe headache. For example, laboratory personnel using osmic acid, who are also migraineurs, are susceptible to headache which may begin at contamination levels usually insufficient to induce headache in otherwise normai individuals,

Vasodilatation and increased intracranial vessel pulsations perhaps aggravated by sudden rise in blood pressure, are causes of headache during fever, lack of oxygen from any cause, after seizures, and during excessive carbon monoxide exposure. Headache may be a symptom of acute or chronic hypercapnia, but in this case brain edema because of long-standing cerebral vasodilatation may aggravate the pain. The incidence and magnitude of the problem of hypercapnia headache has not been fully assessed. 
The vascular mechanism in these headaches is similar to that with histarine, which upon injection causes vasodilatation in all vascular beds. The systemic vessels, however, contract causing a rebound elevation blood pressure, which induces large amplitude painful pulsations of the still dilated cerebral vessels. If at the same time cerebrospinal fluid pressure is experimentally increased sufficiently to dampen the pulsations, the headache is temporarily relieved. If pulsations of only the scalp vessels are decreased, no improvement in headache occurs, which shows intracranial vasculatire as the source of pain in these headaches.

In some migraineurs the transient changes in intracerebral vessel caliber and pulsations are precursors of migraine attacks. These attacks have been attributed to hormonal agents released into the circulation during blood pressure changes induced by histamine and other similar vasocative triggers. 29

Recommendation for Medical Certification

Pilot medical certification should not be withheld in otherwise normal individuals who have experienced food related headaches. However, migraineurs with severe focal neurologic deficits during auras, when attacks may be triggered by vasoactive substances or anoxia, should not be medicaliy certified.

\section{CLUSTER HEADACHE}

\section{MINIMUM CRITERIA FOR DIAGNOSIS}

Cluster headaches are severe unilateral headaches. They have a tendency to recur on the same side and predominate in males, in whom the prevalence is four times greater than in females. There is usually no prodrome, but occasionally some burning sensation in the forehead is present prior to onset of pain. Only rarely io prodromes occur, which include visual scotomata of very brief duration, hemisensory loss, or weakness. Occasionally, aphasia may be present during the prodrome.

In cluster headache, there is rapid onset of severe unilateral pain. The headache is relatively short, lasting minutes to one or two hours, rarely more. Examination shows dilated extracranial vessels with prominent pulsations. Autonomic disturbances accompanying the headache are flushing of the face. blocked nose with rhinorrhea, and tear secretion. There may be an injected conjunctiva on the side of the pain. Salivation and sweating, or an ipsilateral Horner's syndrome, may be observed. The Horner's syndrome may persist between attacks. There is a tendency for attacks to occur at night related to the REM sleep phase. Cluster attacks also can be precipitated by short naps and are induced by alcohol ingestion, nitroglycerine, histamine injection, tyramine, and emotion. Such triggers usually are effective only during a cluster period and not during headache-free intervals. 
In contradistinction to migraineurs who tend to lie quietly and avoid movement during pain, cluster headache patients pace the floor and engage in bizarre behavior or hysterical activities. The attacks may begin during the teen years, and they tend to come in clusters of as many as 10 to 15 headaches per day for several months. Thereafter, inexplicable periods of complete $\mathbf{f}$ reedom may appear, which as a rule are followed by recurrences without obvious reason. Some unfortunate individuals have no remissions and may have chronic cluster headache.

It is believed cluster headaches tend to recur after a period of stress during the "letdown" phase. Drugs which are effective in the treatment of migraine are also useful for cluster headaches and include ergotamine preparations, methysergide, propranolol, and steroids. Daily ergotamine administration may be indicated until the cluster is over. For chronic cluster headache not responsive to other medications, lithium carbonate has been found to be effective. 30

Compared to migraineurs, cluster headache patients have biochemical and physiologic differences. The drop in blood serotonin level which is thought to be common in classic or common migraine does not occur in cluster headaches. An increased blood histamine level has been found by some investigators in cluster patients but not in migraine patients. Increased intraocular pulsations occur during cluster attacks but not in migraine. The reasons for these differences are not clear, but they tend to support the view that cluster headache is pathogenetically different from migraine, though clearly related to abnormal neurovascular function.

Psychological studies of cluster headache patients have shown then of ten to have hysterical personalities, increased dependency need, and excessive response to pain. Though outwardly they appear manly, they seem to have rather weak personalities. Masculine appearance is also noted in the occasional woman with cluster headache. 31

\section{OTHER CRITERIA FOR DIAGNOSIS}

Cluster headache patients have high rates of gastric acid secretion, and perhaps $25 \%$ may have symptoms of peptic ulceration. Occasional patients have secretion rates similar to those observed in the Zollinger-E11ison syndrome, and some have been found to have polyps of the duodenum.

\section{MEDICAL THERAPY AFFECTING PERFORMANCE, INCAPACITATION AND PROGNOSIS}

The treatment of the acute cluster attack is with ergotamine preparation, preferably given parenterally or rectally. Sublingual tablets are very effective in those who do not have immediate access to injections or suppositories. Soise patients get relief from exercise, 32 or from breathing oxygen for 15 minutes or more. In severe acute attacks, intravenous administration of diazepam or pentobarbital in large doses may be effective. Narcotics should be avoided. Many patients with cluster headache have known cardiovascular disease. Therefore the administration of ergot preparations may be contraindicted. 
Prophylaxis for cluster headache includes ergotanine preparations but these should not be administered over long periods. Many patients can be treated with methysergide, if appropriate precautions are taken against its side-effects. Propranolol has also been found useful, and some patients require large doses for successful prophylaxis. In patients with chronic c? usters resistant to other medications, Iithium carbonate is useful. Patients using this therapy may, upon withdrawal, experlence rebound phenomena with severe cluster headache, or may develop a headache different from cluster in type, termed "Iithium headache." The side effects of 1ithium, though minor, may be incapacitating in some individuals, but they are tolerated in most for fear of recurrences of the pain.

Cluster headache must be distinguished from tic doloureux and migraine. The distinction from tic is based mainly upon the short duration of the pain and the presence of trigger zones in tic, and the longer pain and the accompanying automomic phenomena in cluster headache. Migraine may be difficult to differentiate from cluster, because migraineurs may have consistently unilateral pain like cluster headache patients; however, the usual absence of an aura, and the great intensity of pain and the agitation of the patient, distinguish cluster from migraine.

\section{Recommendation for Medical Certification}

Medical certification should not be issued to patients with frequent bouts of cluster headache and to those with chronic cluster headaches. Patients who have been free of clusters without prophylactic medication for at least two years may be granted medical certification, provided that flying stress does not induce cluster headache. The effect of altitude as a trigger for cluster headache is not known. It is unlikely that a first attack of cluster will impair function of a pilot in command of an aircraft. 
REFERENCES

1. Wilkinson IMS, Russe11 RWF: Arteries of the head and neck in giant cell arteritis. Arch of Neurol 27:378-391, 1972.

2. Hutchinson $\mathrm{J}$ : Disease of the arteries; on a peculiar form of thrombotic arteritis of the aged which is sometimes productive of gangrene. Arch Surg 1:323, 1890 .

3. Horton BT, Magath TB, Brown GE: An undescribed form of arteritis of the temporal vessels. Proc Staff Meet Mayo Clinic 7:700-701, 1932.

4. Murray TJ: Temporal arteritis. J Amer Geriatrics Soc 25:450-453, 1977.

5. Hauser WA, et al: Temporal arteritis in Rochester, Minnesota 1951 to 1967. Mayo C1in Proc 46:597-601, 1971.

6. Appenze1ler 0: Temporal arteritis. Postgrad Med 56:113-140, 1974.

7. Pauley JW: Anarthritic rheumatoid diseases. Lancet 2:946-947, 1956.

8. Chavany JA, Taptas JN: A propo d'un cas d'arterite temporal. Presse Medicale 56:835, 1948.

9. Russell RWR: Giant cell artericis. Quart J Med 28:471-489, 1959.

10. Fisher CM: Ocular palsy in remporal arteritis. Minn Med 42:1258-1268, 1959.

11. Verbos J, Dupuis CC: Necrose cutanee spontanee du cuir chevelu et arterite a cellules giantes. Ann Chir Plast 21:87-95, 1976.

12. Ghose MK, Sensa S, Lerner PI: Arteritis of the aged (giant cell arteritis) and fever of unexplained origin. Amer $\mathrm{J}$ Med 60:429-436, 1976.

13. Verdich M, Nielsen NV: Acute transient ophthalmonalacia in giant cell arteritis: Report of a case. Acta Ophthal 53:875-878, 1975.

14. Kansu $T$, et al: Giant cell arteritis with normal sedimentation rate. Arch Neurol 34:624-625, 1977.

15. Dalessio DJ, Tan EM: The immunologic basis of temporal arteritis. In Dalessio DJ, Dalsgaard-Nielsen T, Diamond S: Proceedings of the International Headache Symposium, Elsinore, Denmark, Basei, Switzerland, Sandoz, 1971, pp 57-59.

16. Klein RG, et al: Skip lesions in temporal arteritis. Mayo Ciin Proc 51:504-510, 1976 .

17. Brooke MH, Kaplan H: Muscle patholegy in rheumatoid arthritis, polymalgia rheumatica and polynyositis. Arch Patho1 94:101, 1972. 
18. O'Duffy JD, Wahner HW, Hunder GG: Joint imaging in polymyalgia rheumatica. Mayo C1in Proc 51:519-524, 1976.

19. Barricks ME, et a1: Opthalmoplegia in czanial arteritis. Brain 100:209. $221,1977$.

20. Kudrow L: Tension Headache (scalp muscle contraction headache). In Pathogenesis and Treatment of Headache, 0 . Appenzeller (ed), New York, Spectrum Publications, 1976, pp 81-91.

21. Budzynski TH, Stoyva JM, Adler C: Feedback induced muscle relaxation, application to tension headache. I Beh Ther Exper Psychiat 1:205-211, 1970 .

22. Appenzeller 0: Altitude headache. Heada ihe 12:126-129, 1972.

23. Exercise and Aititude. Jokl E, Jokl P, S. Karger, Base1, Switzerland, 1968.

24. Jok1 E: Altitude disease, New Eng J Med :1420-1421, 1969.

25. Masters WH, Johnson VE: Human Sexual Inadequacy. Boston, Little, Browr \& Co, 1979 .

26. Lance JW: Headache: Understanding Alleviation. New York, Charles Scribner's Sons, 1975.

27. Raskin NH, Knittle SC: Ice cream headache and orthostatic symptoms in patients with migraine. Headache 16:222-225, 1976.

28. Henderson WR, Raskin NH: "Hot dog" headache: Individual susceptibility to nitrite. Lancet $2: 1162-1163,1972$.

29. Graham JR: Headache related to a variety of medical disorders. In Pathogenesis and Treatment of Headache. Appenzeller o (ed) New York. Spectrum Publications, 1976, pp 49-67.

30. Kudrow L: Lithium prophylaxis for chronic cluster headache, Headache $17: 15-18,1977$.

31. Graham JR: Cluster headache. In Pathogenesis and Treatment of Headache Appenzeller 0 (ed) New York, Spectrum Publications, 1976, pp 93-108.

32. Atkinson R: Physical fitness and headache. Headache 17:189-191, 1977. 


\section{MINDIM CRITERIA FOR DIAGNOSIS}

Trigeminal neuralgia, or tic douloureux, is an episodic syndrome characterized by paroxysmal pain, which begins without warning in a specific location of the face and builds up in a crescendo manner to an intolerable degree be. fore waning, only to recur again. The pains occur spontaneously and also may be triggered by various stimuli, such as a light touch on the face, biting, chewing, shaving, and sudden changes in temperature of substances taken into the mouth, but not swallowing.

The typical pain of trigeminal neuralgia can be described as lancinating, spontaneous, sudden in onset, instantaneous, and repetitive. The condition often occurs in individuals over the age of $50^{1}$ and, if present in a younger person, the differential diagnosis must include other conditions, of which trigeminal neuralgia is a symptom.

The pain occurs in one or two of the three divisions of the trigeminal nerve as it is distributed over the race, most often in the secon ${ }^{-1}$ and third divisions. If the first division is involved, the second and possibly the third division may also be affected concurrently. There may be radiation of pain along the course of the nerve, either centripetally or centrifugally. Between attacks of pain, the patient is free of discomfort or may experience a dull residual ache of much less intensity. The pain affects one side of the face, although a small percent of patients may have pain on both sides, but not simultaneously. Bilateral pain tends to occur in certain families, 2 and in women more than men, $I$ and suggest brain stem disease. 2

\section{OTHER CRITERIA FOR DIAGNOSIS}

Diagnosis of 1diopathic trigeminal neuralgia depends upon the patient's history and the anatomic distribution of the pain. Sensation on the face is usually intact to objective measurement of pinprick and light touch, but more extensive testing may reveal slight sensory impairment on the face in occasional patients. Movements of the jaw muscles supplied by the motor divisions of the trigeminal nirve are normal. Corneal reflexes are intact. Other signs of brain stem function are also normal.

If one finds sensory deficits over the face, other abnormalities in cranial nerve function, brain stem abnormalities, or cerebellar dysfunction, then the facial pain involving the trigeminal nerve distribution must be considered symptomatic of some other underlying condition. In such instances, it is appropriate to refer to the trigeminal neuralgia as "symptomatic trigeminal neuralgia."

\section{RELEVANT DIAGNOSTIC PROCEDURES}

Incapacitation of the patient with idiopathic trigeminal neuralgia is due to pain. The Incapacitation is gradually progressive and is brought on by the fatiguing effects of chronic pain, which rob the patient of sleep and interfere with alimentation. Attention is focused apon fearful anticipation of the recurrence of the next attack, thereby eliminating any creative effort and most attempts 
at prolonged mental concentration. The patient may become depressed, desperate, and even sulcidal after several days of recurrent episodes of lancinating facial pain. The attack usually subsides gradually, reversing the mode of its onset. Although the episodes of shooting pain are intensely distracting, the patient remains fully conscious and retains full voluntary control of his motor activity at all times.

"Symptcmatic trigeminal neuralgla" points to serfous underlying disease of the nervous system. The prognosis is definitely affected when trigeminal neuralgia symptoms are associated with multiple sclerosis, brain stem tumors, and aneurysms. Each patient with symptomatic trigeminal neuralgia should have a meticulous neurologic examination for sensory loss, facial weakness, cerebellar signs, and pupillary inequality. Appropriate investigations should be done to elucidate the meaning of the neurologic findings.

If the patient has symptomatic trigeminal neuralgia, the neurologist should be alert to the possibility these symptoms may be an inftial attack representing the early stages of periapical tooth abscess, obstructed nasal sinus, or sinilar condition. Painful dental conditions do not by themselves produce the clinical picture of true trigeminal neuralgia. However, in some patients, painful teeth may trigger the neuralgia. Conservative management of dental pathology, including caries, pulpitis, prenature occlusion, and periapical abscess, should be included as part of the evaluation and management of trigeminal neuralgia. Incorrect diagnosis will obviously affect prognosis.

of particular interest is a painful syndrome involving the glossopharyngeal nerve, wich is similar to trigeminal neuraigia in its episodic nature, but rarer. 3,4 It is characterized by stabbing and jolting pain in the posterior half of the tongue, the tonsils, and the pharynx. The trigger zone usually lies there and is affected by swallowing rather than by touching the face. Biting is done without difficulty, but swallowing is painful, the reverse of the situation with trigeminal neuralgia. These patients often sleep on the same side so the saliva does not trickle down the susceptible side of the oral pharynx. Talking, yawning, or even touching the side of the neck or washing the ears, can trigger the pain. The pain is not as stabbing or lancinating as trigeminal neuralgia, but burning, continuous, and "sticking." Spicy, salty, or bitter foods, and rarely sweet foods provoke the pain. The pain may occur at night, in contrast to that of trigeminal neuralgia. Attacks usually occur in clusters, lasting from days to months.

\section{DIAGNOSTIC PROCEDIRES}

In patients with idiopathic trigeminal neuralgia, di. ${ }_{6}$ nostic procedures are unnecessary, unless suspicion continues that the symptcms are symptomatic of an underlying condition, in which case evaluation of posterior fossa structures with angiography, pneumonencephalography, CT scan, and CSF examination may be necessary. X-ray examination of the $j$ aw and skull, temporomandibular joint, teeth, and subgingival region is necessary to assess the possibility of a dental etiology. 5 


\section{PROGNOSIS}

The prognosis for idiopathic trigeminal neuralgia is determined by the effectiveness of medications or of surgical procedures (see below). An effective therapeutic trial of carbamazepine may confirm the diagnosis of trigeminal neuralgia.

\section{MEDTCAL THERAPY}

Management of exacerbation of pain requires that the natural history be kept in mind. During acute episodes the patient may be so desperate for relief he may accept procedures which are noi necessary and which will be regretted later. Yet, the unremitting numbness following a neurosurgical procedure may be just as unacceptable and incapacitating as the episodic pain.

Medical management is important, and many orugs have been used. Phenytoin, for relief of acute attacks and for long-term management, has been effective. Doses of 700 to $1000 \mathrm{mg}$ intravenously are useful in stopping an attack, and oral doses of 300 to $600 \mathrm{mg} /$ day lead to pain relief in approximately $20 \%$ si patients. ${ }^{6}$

Side effects include nausea, dizziness, somnolence, ataxia, and skin reactions. For long-term management, phenytoin with imipramine improves the quality of sleep and combats the concurrent depression during an attack. Ample doses of chloral hydrate, diazepam, chlordiazepoxide, or flurazepan are also useful in promoting sleep in the acute stages of the illness.

Carbamazepine has been usefui as a prophylactic medication to prevent the recurrence of attacks. 7,8 Like phenytoin, it may be taken at meals in gradually increasing doses. A few patients receiving less than $600 \mathrm{mg} / \mathrm{day}$ of carbanazepine are relieved of pain. But if improvement is not obtained while receiving 1,600 $\mathrm{mg} / \mathrm{day}$, there is no reason to increase the dose. The side effects of drowsiness and dizziness, and the possible hematopoietic and hepatic toxicity of the drug. make frequent determination of peripheral white counts necessary in long-term users. Other drugs such as mephenesin and clonazepam have been used with varying success. If adequate pain relief is not provided by drug therapy, the patient should be offered treatment by alcohol injection or other type of surgery.

The episodic nature of the attacks should be considered wher advising surgery which leaves defects of sersation on the face. Loss of sinsation in the first division of the trigeminal nerve may leave the eye exposod to undetected trauma with subsequent corneal injury and scarring. Third ijvision numbness makes eating and drinking difficult and riuses the cheek and tongue to be repeatedly lacerated during chawing.

Alcohol injections are advantageous. ${ }^{11}$ This is particularly true when injection of the infraorbital or supraorbital nerve brings relief, but the area of numbness is relatively small and the nerve often regenerates, making it necessary to repeat the procedure at intervais. A successful injection shouid produce numbness with relief of pain for 3 to 6 months. 12 
It is usually necessary to anesthetize the region of the triggering stimulus, but on occasion block of an adjacent nerve will interrupt the pain. If peripheral nerve avulsion, alcohol injection, or rhizotomy is planned, a local block will provide the patient with an interval of anesthesia in the proposed area of denervation. Some patients prefer their pain to the facial anesthesia.

\section{SURGICAL PROCEDURES}

Such procedures as percutaneous radiofrequency trigeminal gangliolysis, 13,14 suboccipital craniectomy with decompression of the trigeminal nerve, 15 and trigeminal tractotomy may be of value. 16,17 The results of trigeminal rhizotomy are considered to be no better than those of gangliolysis, and morbidity with the procedure is higher and the sensory loss more profound. Thus, some consider the operation obsolete.

Percutaneous radiofrequency trigeminal gangliolysis has proved to be safe, reliable for the relief of pain, and least expensive. Large series indicate one-year cure rates of approximately $80 \%$ with complication rates of less than $\mathbf{5 \%} 18,19$ results that are superior to those with rhizotomy series. Long-term pain relief is harder to assess, but it seems to be about $50 \%$ at five years.

Suboccipital craniectomy and decompression of the trigeminal nerve is done by placing a small nonabsorbable sponge between the trigeminal nerve and an aberrant blood vessel or bone. Patients having had this procedure 20 have been reported to have long-term cures with low operative morbidity and no facial anesthesia.

Incision of the descending trigeminal tract near the cerviconedullary junction, trigeminal tractotomy, will reliably cause the loss of pain and temperature in the ipsilateral face and pharynx, and usually will relieve the pain of trigeminal neuralgia. 21 Because of the sensory deficit, trigeminal tractotomy should not be the initial surgical procedure for trigeminal neuralgia.

\section{THE EFFECTS OF STRESS ON RECURRENT OR SUDDEN INSIDIOUUS DISABILITY}

As with any pain, sleep deprivation appears to accentuate the pain of trigeninal neuralgia and may contribute to the lowering of the threshold for triggering an attack. Sleep deprivation and depression may contribute to a reduction in reaction time and alertness. Medications affect these functions as well as those of depth perception and judgment.

Recommendation for Medical Certification

Patients on medication for trigeminal reuralgia, even if controlled, should not be certified. Those having been relieved of pain by surgery with no recurrence over a two months period may be granted medical certification.

\section{ATYPICAL SACIAL PAIN}

\section{MINIMUM CRITERIA FOR DIAGNOSIS}

Although this pais syndrome also affects the face, it is distinguished 
from trigeminal neuraigia by lack of precise anatomic linitation to the areas of the face supplied by the three divisions of che trigeminal nerve. The lancinating character of the pain in trigeminal neuralgia is also absent. Atypical facial pain is apt to invoive the entire side of the head as well as the face, extending into the neck, ear, or throat. It is often constant and may persist for extended periods of time rather than be paroxysmal and instantaneous. The pain is often aching or burning, and it is extremely resistant to treatment. The character, location, and duration of the pain may vary from patient to patient. A major concern is to rule out the existance of mass lesions, infections. and other painful conditions of the hear, sinuses, nose, throat, and teeth.

Differential diagnosis includes cervical arthritis with entrapment, particularly of the second cervical nerve. Temporomaniltular joint dysfuncm tion with malocclusion of the teeth causes pain which radiates into the face, jaw, and ear. 22 The pain is usualiy related to movenent of the $j a w$, occurs at night, and may be asscciated with prolonged chewing of gum, or of foods such as steak. Inflammation of the carot'd artery can be a cause of atypical face pain.23 This type of pain is usually associated with an increased sedimentation rats and with other signs of arteritis.

Inflammation of the maxillary or ethmoid sinuses produces localized facial pain; middle and posterior fossa lesions produce atypical facial pain. These may include meningiomas, neurofibromas, or carcinomas of ethmoidal sinuses growing into the base of the skull. A malignant turor may become evident after initial period of facial pain and leave benind anesthesiz and otner signs of motor involvement.

Although many causes have been postulated for a typical facial pain, including allergy, endocrine disturbance, and vasomotor disease, 24 recent work stresses a psychologic basis for the condition. Several authors $25-28$ agree depression and neurotic traits are important considerations. Lascelles reported significant relief of both depression and facial pain after treatment with phenalzine and chlordiazepoxide. 26

\section{PROGNOSIS}

Because generally no specific etiology is demonstrated despite thorough workup, atypical facial pain presents a very difficult problem in management and may lead to drug dependency. The prognosis for atypical facial pain is much worse than for trigeminal neuralgia.

\section{MEDICAL THERAPY AFFECTING PERFORMANCE AND PROGNOSIS}

A useful treatment for atypical facial pain is analgesic thedication often reaching the potency of narcotics. Patients presenting with atypical facial pain often develop psychological dependence on theitpain, naking therapy frustrating for both the patient and the physician.29,30

\section{Recommendations for Medical Certification}

No certification should be granted to patients with this syndroine, if they require continuous medication. It is unlikely they will become symptomfree for prolonged periods; more likely they will require almost continucus medication to tolerate their condition. 


\section{REFERENCES}

1. Harris $W$; The fifth and $s$ venth cranial nerves in relation to the nervous mechanism of $t=5 t=$ sensation. Brit Med J I:831-836, 1952.

2. Harris W: Analysis of 1433 cases of paroxysmal trigeminal neuralgia (trigeminal-tic) and the end-results of Gasserian alcohol injecticn. Brain 63:209-224, 1940 .

3. Siebert 3: Uber Erkrankungen periphische nerven. Mschs Fsychiat Neurol $49: 364-370,1921$.

4. Harris, $W$ : Persistent pain in leslons of the peripheral and central nervous system. Brain 44:557-571, 1922.

5. Moore DS, Nally FF: The diagnosis and management of paroxysinal trigeminal neuraigia in association with the temporomandibular joint dysfunction. Oral Med 38:874-878, 1974.

5. Iannone $A$, Baker $A B$, MorrelI $F$ : Dilantin in the treatment of trigeminal neuralgia. Neuro1 8: 126-128, 1958.

7. Biom S: Trigeminal neuralgia: Its treatment with a new anticonvulsant drug (G 32883). Lancet 1:839-840, 1962 .

8. Rockliff BW, Davis EH: Controlled sequential trials of carbamazepine in trigeminal neuralgia. Arch Neuro1 5:120-136, 1966.

9. King RB: The value of mephenesin carbamate in the control of pain in patients with tic douloureux. I Neurosurg 25:153-158, 1966.

10. Chendra B: The use of clonazepam in the treatment of tic douloureux (a preliminary report). Proc Aust Assoc Neurol 131:110-122, 1976.

11. Eckes A: Preci e selective alcoholic Gasserian injection for tic douloureux. Recent advances in technic and results. Acta Neurochir 34:241-243, 1976.

12. Falconer MA, Harris Li Surgical treatment of the cranial neuralgias. In: Vinken PJ, Bruyn GL (eds), Handbook of Clinical Neurology. Amsterdam, North Holland Publishing Co. 1968, vol 5, pp 386-404.

13. Rasmussen PP: Facial Pain: A C inical Study with Special Reference to the Symotomatology, Aeriology and Gurgical Therapy. Copenhagen, Munkgaard, 1965 .

14. Anofrio BM: Radiofrequency percutaneous Gassertan ganglion lesions. Results In 140 patients with trigeminai neuralgia. J Neurosurg 42:132-i39, 1975.

15. Dandy WE: Treatment of trigeminal neuralgla by the cerebellar route. Ann Surg 96:787-795, 1932. 
16. Sjosvist 0: Studies in pain conduction in the trigeminal nerve. A contribution to the surgical treatment of facial pain. Acta Psychiat and Neuro1, Supp1 17:1-139, 1938.

17. Hosobuch1 Y, Rutkin B: Descending trigeminal tractotomy. Arch Neuro1 25:115-128, 1971 .

18. Howe $\mathrm{JF}$, Loeser JD, Black RG: Percutaneous radiofrequency trigeminal gangliolysis in the treatment of tic doulcureux. West I Med 124:351-356, 1976.

19. Nugent GR, Berry G: Trigeminal neuralgia treated by differential percutaneous radio-frequency coagulation of the gasserian ganglion. I Neurosurg $40: 517-523,1974$.

20. Jannetta PJ: Microsurgical approach to the trigeminal nerve for tic douloureux. Prog Neurol Surg 7:180-200, 1975.

21. Guldetti B: Tractotomy for the relief of trigeminal neuralgia; observations of 124 cases. J Neurosurg 7:499-508, 1950.

22. Costen JB: Syndrome of the ear and sinus symptoms dependent on disturbed function of temporomandibular joint. Ann Otol Rhinol Laryngol 43:1-15, 1934.

23. Roseman DM: Carotidynia. In: Vinken PJ, Bruyn GW (eds), Handbook of Clinical Neurology. Amsterdam, North Holland Pubifshing Co, 1968, vol 5 , PQ 375-377.

24. Engle Gl: Primary atypical facial neuraliaia: An hysterical conversion symptom. Psychosom Med 13:375-396, 1951.

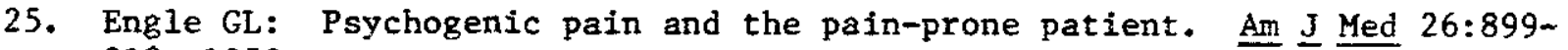
$918,1959$.

26. Lascelles, RG: Atypical facial pain and depression. Brit J Psychiat $112: 651-659,1966$.

27. Dalessio DJ: Some reflections on the etiologic role of depression in head pain. Headache 8:28-31, 1968.

28. Delany JF: Atypical facial pain as a defense against psychosis. Am $J$ Psychiat 133:1151-1154, 1976.

29. Szasz TS:The painful person. Lancet 88:18-22, 1968.

30. Penman J: Pain as an old friend. Lancet 1:633-636, 1954. 
POST-TRAUMATIC HEADACHE

\section{MINIMUM CRITERIA FOR DIAGNOSIS}

Headache is a comoon sequela to head injury which may be present in the immediate post-traumatic period. It usually disappears within a few weeks, but not infrequently it may persist for months or years even after mild head trauma. Various observers report the incidence of headaches as $40 \%$ to $60 \%$ in patients who have suffered head injury of any severity. 1

Although head trauma is frequently associated with a constellation of symptoms which includes dizziness, insomia, concentration difficulties, and mood and personality changes, headache dominates the clinical picture. This symptom complex is often called the "post-traumatic syndrome." Chronic post-traumatic headache may be defined as headache lasting longer than two months.

Because each patient's headache arises from a variety of structural and psychophysiologic mechanisms, the Ad Hoc Committee on the Classification of Headache ${ }^{2}$ of the National Institute of Neurological Diseases and Stroke ${ }^{2}$ designated such head discomfort as the "so-called chronic post-traumatic headache." So-called chronic post-traumatic headache may arise from any one of several mechanisms:

1. sustained muscle contraction

2. recurrent vascular dilatation

3. Iocal scalp or nuchal injury

4. part of a ciinical disorder characterized by delusional, conversion, or hypochondrial reactions

Although in general more is known about the causes, mechanisms, diagnosis, and treatment of headache than were 35 years ago, the headache that persists after head injury remains a puzzling problem.

Description of the Headache

The head pain following cranial injury is characteristically variable from patient to patient, a fact which emphasizes the theory that no single mechanism is responsible for all types of post-traumatic headache. 1 Nontraumatic entities can provoke similarly generated headaches. The headaches usually have their onset coincidental with the return of consciousness, but occasionally they may or may not appear until the patient is ambulatory. They usually decrease in severity, and there are periods of relative freedom which become longer, until after a week or two they become sporadic. More frequently, the headaches are precipitated by stress or by attempts to concentrate. In the majority, the frequency and severity diminish with time, usually disappearing within 6 to 12 months.

We have found no evidence to differentiate headache occurring as an isolated symptom from headache occurring as part of the post-traumatic syndrome. Such headaches may mimic almost any type of chronic, recurring headache. The headache may be generalized or localized, but it is commonly in the area of the head that received the initial impact. The characteristics of the pain are described 
variably as a sensation of expanding pressure, a bandlike tightness invading the head (cardinal's $p$ ), a pulsatile, aching, or sharp pain, or a burning sensation. Pain may be co int or periodic ind have some relationship to physical exertion and change in posture or position. It is usually aggravated by severe emotional or physical tension. Occasionally the headaches awaken the patient out of a sound sleep. Severity varies from patient to patient, and there seems to be no relationship between severity of the injury and that of the headache.

Post-traumatic headache $f$ two or more months' duration is often associated with symptoms like dizziness, fears, anxieties, fatigue, irritability, and inability to concentrate, either singly or in combination. The chronic headaches are frequently seen in the patient who exhibited nervous or neurotic symptoms before injury, and they are of ten associated with other factors, including compensation; marked, immediate emotional reaction to the injury; and scalp lacerations. Chronic headache is less common in professional athletes and in patients whose injuries occurred in recreational settings, or who had very mild head injuries with no measurable duration of coma, disorientation, or permanent post-traumatic amnesia. Whatever views are held as to the nature of post-traumatic headaches, there is no adequate explanation of the early headache-free period which is common after head injury.

Pathogenesis

Denny-Brown emphasized the importance of recognizing both physical and emotional trauma as causative factors in post-traumatic headache. 9 This emphasis arose from observations that headaches occurred after very mild, as well as after very severs, head injuries. The realization that emotional trauma occurs with head injury has led to considerable disagreement about which process is more important: the pretraumatic personality or the psychologic factors brought into play after injury. 10,13

Watts et al ${ }^{15}$ suggested headache and dizziness after head injury are sometimes due to scalp contusions and may be related to scalp arteries. They stated $82 \%$ of headache cases could be correlated with a neurotic personality or subnormal intelligence and not with severity of injuries.

Rowbotham $^{22}$ notes the underlying pathology of post-traumatic headache is extremely difficult to determine. Thus, in the typical case, there are no abnormal neurologic signs, the CSF pressure is within normal limits, and the EEG shows no signs of a space-occupying lesion. Other systems, inciuding the cardiovascular system, are normal. It appears head pain is not due to scalp neuritis, subdural hematoma, hygroma, adhesions, hydrocephalus, or tentorial traction.

of the many views on pathogenesis, ${ }^{10-20}$ there are essentially three different opinions held. Some authors relate post-traumatic headache exclusively to psychologic factors, and some reate it exclusively to organic factors. The majority, though their emphases differ, hold that both factors are present in most cases of post-traunatic headache. In our experience, the vast majority of patients with long persisting or recurring post-traumatic headaches rarely have intracranial abnormalities. We believe the headache is functional, though at some earlier date organic factors probably played a part in its genesis. 
Mechanisms

A variety of mechanisms, which rarely operate exclusively, may be responsible for post-traumatic headache and are listed below. In general, the mechanisms may be divided into those which are due to organic effects of the injury and those which are primarily psychological. Usually there are multiple mechantsms, which may involve intracranial and extracranial structures and neck injury, 1

\section{MUSCIE CONTRACTION}

The most frequent cause of chronic headache after heac trauna is muscle contraction. The fmmediate source of pain in muscle contraction (tension) headache appears to be sustained contraction of the muscles of the neck and scalp conmonly associated with an adverse reaction to stress.

It is known noxious stimulation of structures in one area may refer pain to another area. This is the mechanism involved when pain of a muscle contraction headache spreads from the neck to the face, scalp, and frontal region. Muscle contraction may, in some instances, be local even though the resuitant pain is diffuse. $27 \mathrm{It}$ is believed the arteries of subcutaneous tissie, scalp muscles, and conjunctiva constrict with ischemia in patients with muscle contraction headache, while releasing local catabolites which generate pain.

The severity of this form of headache is of ten related to anxiety attaching to the possibility of brain damage, which is reinforced by a legal advisor who instructs the patient not to resume work or normal activity until the case is settled. 29

Muscle contraction headache is not accompanied by focal neurologic symptoms. Giddiness or light-headedness usually indicates a tendency to over-breathe in times of anxiety. Other symptoms are those of an anxiety state. Exposure to cold with shivering or drafts may precipitate or aggravate the headache.

Examination may disclose tautness of muscles of the neck, scalp, and face. The masseter muscles are usually the first to contract when persons are in a state of tension, and they remain so for long periods of time. Palpation may reveal localized painful nodules or areas of localized tenderness. Occa sionally there is limitation of neck movement. Neurologic examination is normal.

\section{VASCULAAR CHANGES}

Changes in vascular tone and caliber of cranial blood vessels occur in postzraumatic headache. This may give rise to vascular headache of a pulsatile, or of a dull, constant character. Involvement of the temporai, occipital, or middle menlingeal arteries by residua of the trauma, or by superficial or subcutaneous scars, can produce headache. Probably at least two pathophysiologic events must occur concomitantly for headache to develop: 30,31

1. Cranlal arterial dilatation, with increased amplitude of pulsation of these vessels caused by the autonomic nervous system

2. Changes in microcirculation, with the release during an attack of biologically active substances at the site of the pain 
The attacks are shorter in duration than migraine, are not preceded or associated with sharply defined neurologic phenomena, and do not show any of the other symptoms associated with the migraine attack. However, there is a similarity to migraine in that sonophobia, photophobia, and nausea with or without vomiting may occur. The attacks are relieved by compression of the superficial vessels and the use of ergotamine tartrate.

In an occasional post-traumatic patient, attacks of cluster headaches have been observed. It has been suggested such headaches may be related to injury of the greater superficial petrosal nerve and the afferent branches of the sphenopalatine ganglia.

\section{SCAR FORMATION}

If the soft tissue of the head is injured, a visible or palpable scar with a localized render area may result. Neuralgic-type pain also may occur after trauma and is probably caused by involvement of sensory nerve branches enclosed in tissue. This local pain sometimes spreads to cause intermittent generalized headache, the nature of which suggests an origin in increased tension of extracranial muscles. Procaine injected into the tender area often eliminates local headache but not sensations of pressure or ache remote from the area.

\section{ACCUMULATION OF BLOOD IN EXTRADURAL, SUBDURAL, OR SUBARACHNOID SPACES}

Headache occurring during the first few days or weeks after injury is more likely to be due to intracranial damage than headache persisting for months or years. In the early stages after injury, subarachnoid or epidural hemorrhage may be responsible for the headache. However, the character of the headache may not indicate the nature of the process.

Blood accumulation as the result of injury causes traction, displacement, distension or rupture of pain-sensitive blood vessels in the archnoid, which, in turn, produces pain. 32 The meningeal damage and scarring seen in severe brain injury seldom produce headache; however, arachnoidal adhesions and fibrotic clot organization around pain-sensitive structures within the cranium may produce persistent headache. It is significant that sustained headache is uncommon if small amounts of blood are present in the subarachnoid space following neurosurgery or after subarachnoid hemorrhage.

The pain from a localized hematoma results from traction and displacement of pain-sensitive structures, particularly at the base of the brain, whereas the pain from blood in the subarachnoid space is probably secondary to a sterile inflamatory reaction about the meninges and blood vessels. Headache due to accumulation of blood or fluid in the subdural space may persist for weeks, but rarely longer than 6 months. Blood in the subdural compartments may cause progressively greater displacement of the subfacent brain, or it may be absorbed. Another cause for pain is subdural hygroma, which is presumably due to tearing of the subarachnoid membrane.

Pressure or traction on large sensory nerves in the region of the tentorium will produce pain referred to the forehead and the area behind the eyes. 
This can be explained anatomically: a recurent branch of the trigeminal nerve arises from the first ophthalmic division near its origin and supplies the superior portion of the tentorium and falx, so that pain from vessels in these areas of dura is readily referred to the eye and forehead of the same side. 33

Acute hydrocephalus is rarely a cause of post-traumatic headaches; patients show low intracranial pressure more of ten than high. Low pressures, however, can cause headache, particularly if there is continual leakage of fluid externally or into the subgaleal space after skull fracture. Intracranial hypotension usually repairs itself within a matter of days. The mechanism relates to traction by the unsupported brain on pain-sensitive structures.

Intracranial hypertension due to defective absorption secondary to subarachnold hemorrhage, although uncommon, may persist for months and years beyond the traumatic event. The frequency with which normal-pressure hydrocephalus occurs after subarachnoid hemorrhage may be related to delayed recovery after a head injury. In many patients, prompt improvement occurs after ventriculoatrial shunting.

\section{INJURY TO NECK STRUCTURES}

A painful cervical spine can be the cause of headache, but more important, in therapeutic terms, is the pathogenesis of various syndromes of head discomfort due to disorders of the cervical spine per se. 34 Cervical involvement may indeed dominate the clinical picture. In such cases, the cervical symptomatology is often intermingled with the usual signs of physiopathology of cervical trauma. Injury to the superficial and deep structures of the neck, involving muscles, ligaments, intervertebral discs, discs, or nerve roots, can produce nuchal pain referred to the head. Each of these structures has a nerve supply which can cause referral of pain to the upper cervical or trigeminal nerve distribution by means of collateral fibers. Many post-traumatic headaches originate from a fibrositis, with or without palpable nodules of the soft tissues of the head and neck; ie, the origin is in the muscles of the scalp, neck, and the suboccipital region. Procaine infiltration will sometimes eliminate these tender spots and the headache.

\section{WHIPLASH}

In any discussion of headache due to neck disorders, the so-called"whiplash syndrome" must be mentioned. In its simplest terms, this is considered to be the product of rapid to-and-fro motion of the head, with the initiating stimulus generally being the impact of two colliding automobiles. Sudden violent flexion and extension of the head and cervical spine after either major or minor impact can produce this comonon condition. An avulsive and stretching infury of the nuchal ligaments and muscles, and perhaps stretching of the limiting ligaments of the disc, are assumed to occur.

Hemorrhage is probably present in some patients, along with unpleasant sequelae of areas of tenderness, muscle splinting, and classic muscle-contraction or tension headache. It has been suggested the prolonged symptoms are due to damage to the sympathetic and cerebrospinal nervous systems and rupture of stabilizing liganents. 38 
The symptoms are not due to litigation neurosis or to malingering but have an organic basis. The $X$-rays are negative, except that a loss of lordosis of the cervical spine, presumably due to muscle splinting, may be visible. This type of infury, if limited to the reversible pathology just outlined, should respond to treatment or heal with time. Generally, trauma due to cranial impact is related to skull injury, but head pajn also may be due to ar. isolated cervical lesion, as with whiplash infury in a motorist whose car is struck from the rear.

\section{PSYCHOLOGICAL FACTORS}

An understanding of psychologic factors is important in post-traumatic headache and its associated syndrones. The head has a symbolic significance, and injury to it usualiy generates more anxiety, resentment, and fear than injury to alnost any.other part of the budy. Anxiety arises from the threat of danger to the function of the brain and its associated processes of intelligence and thought. This threat constitutes an important psychologic factor in all posi-traumatic headache. 39 Depressive symptoms are usually overshadowed by those of anxiety. Many patients who become depressed have compulsive personalities to whom work has; becone an impor:ant defense mechanism, and typical depressive symp n's follow deprivation of their nomal working patterns. 40

A significant factor in some cases of post-traumatic headache is compensation for the infury--the paradox of the individual who remains sick because of the hope of financial reward (malingering). A pending lawsuit elicits more anxiety and can prolong the headache. In such a case, the conversion mechanism may be used to overemphasize symptoms, even though neurovascuiar or muscular factors were initially active and produce pain in the head area. Contrary to common belief, the end of litigation does not necessarily remove the symptoms. However, it does have a salutory effect by removing one of the factors upon which the patient tends to focus.

Other motivating forces for the perpetuation of the headache are attention, support, and oversolicitude by the family of the patient, or by the attending physician. A patient is unlikely to give up a symptom which provides such comfortable props and does not seek to be healed but to be justified. These individuais tend to assign their feelings and attitudes to those around them and demonstrate great insecurity. In some patients, the psychologic factors may be quite superficial, but in others it may be difficult to uncover the dynamics of the mental processes involved which cause or precipitate the headaches.

The circunstances of the event also play a part in post-traumatic headache. The symptoms are virtually unknown after recreational accidents, while they are encountered in $40 \%$ or more of those claiming compensation for traffic or industrial injuries. Here, two planned studies of patients after head injury are relevant, the first in Boston, with civilians, 41 and the second in New York, with veterans from World War II and the Korean War, 42 The studies were not undertaken for comparative purposes, and only a fraction of the variables and cases could be analyzed statistically. Other patients were seen at Montefiore and Presbyterian Hospitals in New York City, including some from a metropolitan police department, and in private practice. The civilians and veterans tended 
to have been injured in an off-duty setting, whereas the pnisse were injured in Ine-of-duty incidents.

Observations in these groups indicated there was no significant relationship between severity of injury and characteristics and duration of headaches. One difference was noted, however: the pretraumatic personality disturbances of the civilians were greater than those of the veterans or of professionals like policemen. The veterans had a higher frequency of dizziness and a longer duration of trauma-associated headache than the other groups. It would appear socioeconomic factors can prolong the symptoms of headache once they have developed.

OTHER CRITERIA FOR DIAGNOSIS

In diagnostic evaluation of a patient with post-traumatic headache it is first necessary to exclude operatively correctable lesions. If no such lesion is found, the headache may be attributed to other pathogenetic mechanisms. The description of the headache may be helpful, but by itself this will usually not determine triology. The duration of symptoms nay also be useful in excluding lesions like post-traumatic hematomas. The neurologic examination may detect evidence of focal yeurologic deficit or intracranial hypertension. It may also detect evidence, particularly in the nuchal area, of a muscle contraction headache. 3

\section{RELEVANT DIAGNOSTIC PROCEDURES}

Ro antgenography of the skull and cervical spine is important in excluding fractures. A calcified pineal gland or choroid plexus may indicate displacement of intracranial structures. Rarely, the presence of air within the cranial vault indicating cerebrospinal fluid leakage, or a calcifled hematoma, may be visualized. If a shift of the midline structures is suspected, echoencephalography may be helpful.

CT scan is very effective in the demonstration and differentiation of a wide variety of traumatic lesions of the brain, and in the evaluation of posttraumatic conditions such. as atrophy, subdural and extradural henatomas, hemorrhagic contusion, cerebral edema, post-traumatic obstructive hydrocephalus, and porencephalic cysts. CT scans made during the acute phase permit accurate assessment and evaluation of progress.

Isotope scanning may be used to detect areas of increased permeability of the blood-brain barrier. An EEG can detect focal or generalized dysrhythmia. Angiography may be necessary for expanding surgical lesions, and air encephalography is essential if normal-pressure hydrocephalus is considered.

The diagnosis of post-traumatic headache is generally made by history, because positive physical findings are usually lacking. A psychologic diagnosis for the cause of headache should not be made by exclusion but rather through findings on psychologic examination. 
MEDICAL THERAPY AFFECTING PERFORMANCE, INCAPACITATION AND PROGNOSIS

Management

In discussing the management of chronic post-traumatic headache patients, certain guidelines will be emphasized, and instances in which major injuries predominate will not be considered. If only one rule could be given, it would be: Treat the whole patient.

The problem of good headache management must be approached comprehensively, and the physician must heip the patient to determine aspirations and values and to work out frustrations and conflicts. Without a continuing understanding of the patient, the physician will not make much headway. Coustructive listening plays an important part in treatment of the headache patient's psychological problems. The patient with chronic headache not only talks atout the headache but also drops hints and requests help with other aspects of the illness and with life in general. Thus, the physician should consider well the patient's words and weigh carefully their diagnostic or therapeutic significance.

The usual post-traumatic patient is anxious. But acceleration of convalescence reduces the usual sequence of symptons, including headache, by minimizing anxiety about the seriousness of the injury. The nanagement of a patient with post-traumatic headache should involve the use of pharmologic agents, physical medicine, and psychotherapy.

Pharmacology

Nonaddictive analgesics are recommended in the symptomatic treatment of chronic headache of moderate intensity, although these cherical agents are inferior in their analgesic potency to addictive drugs suct as codeine and meperidine. ${ }^{3}$ The latter groups should be used with extreme caution because of the hazard of addiction.

Nonnarcotic analgesics include salicvlates, the p-aminophenol derivates, phenacetin and acetaminophen, and propoxyphene hydrochloride. Hypnotics, sedatives, and tranquilizers are less effective în relieving pain than analgesic agents, but they may reduce anxiety, restlessness, nausea, and vomiting. Combined with analgesics, they provide an effective treatment for chronic headache, not only by raising the pain threshold but also by reducing the patient's anxiety and reaction to pain.

For treatment of an attack of vascular headache, ergotamine tartrate, which may be combined with caffeine, sedatives and/or analgesics, is recommended.

Prophylactic drug therapy for post-traumatic heationes is of value, because the sedating and tranquilizing dzugs reduce emotional stress, anxiety. and depression, and allow the patient to handle the life situation more effectively. Diazepam, chlordiazepoxide, meprobamate, and barbituates may be beneficial, by reducing anxiety and temporarily improving the patient's ability to handle stressful situations. A combination of a beliadonna alkaloid, a barbiturate, and ergotamire (one tablet three times a day) has been used as a prophylactic agent for post-iraumatic headache of vascular origin. 
Physical dependency may develop with any of the drugs mentioned above, limiting their usefulness. Furthermore, they cannot influence the patient's basic conflicts and tensions or help the patient gain insight into the psychic basis of the headache. The clinical effect of muscle relaxants taken orally is chiefly sedating or tranquilizing. Because reduction of anxiety plays an important part in pharmacotherapy, such agents may have a place in treatment. The clinical course of the patient with all agents will depend on the nature of the structural and psychological disturbances as well as the dose of the orug and its effect.

For patients subject to depression, antidepressants are more effective than anxiety-reducing drugs. Amitriptyline and imipramine hydrochloride are the most effective antidepressants in post-traumatic headache. Their cholinergic-blocking properties cause cryness of the mouth, palpitation, blurred vision, retention of urine, and, paradoxically, excessive sweating. It is therefore essential that any patient taking these drugs be seen frequently after clinical evaluation to adjust cosages.

\section{Physiotherapy}

Physiotherapy has a useful but limited role in the treatment of chronic post-traumatic headache. Overtreatment by building anxiety may do more to increase the chronicity of the problem than to relieve it. After the initial phase of therapy, range-of-motion exercises and resistance exercises may be instituted under guidance. Heat and massage help alleviat muscle-contraction headache if muscle splinting and tenderness are present. The use of ethylchloride spray and the injection of $1 \%$ procaine hydrochloride into the tender area of muscle or scar formation can relax the muscle and relieve pain. Diathermy, ultrasonic bombardment, and iontophoresis are occasionally helpful adjuncts. Mechanical devices such as a collar and head traction may prove temporarily useful.

Autogenic Techniques

A variety of nonpharmacologic techniques have been used during past decades to treat headaches. These started with Jacobson, who devised techniques of verbal instruction. to teach patients suffering from stress related disorders to relax their skeletal musculature progressively. The nore recent development of biofeedback with improved instrumentation and programing equipment has popularized the use of this technique. This includes the use of EMG relaxation techniques combined with autogenic processes. In this method of treating cension and vascular headaches, however, the influence that suggestion, motivatior, and emotional bias play in reducing anxiety and pain should not be discounted. Controlled studies and more years of observation are necessary before an opinion can be given about the effectiveness of such techniques.

Acupuncture analgesia has limitations in producing long periods of analgesia and appears to be a method of hypnoanesthesia which uses needies instead of words. 


\section{Psychotherapy}

There is little or no disagreement about the importance of psychogenic factors in chronic post-traumatic headache. The person with recurring headache without structural cause is using body language to express personal and interpersonal conflicts. This concept forms the basic permise of psychological treatment of headache patients. 44 Yet it is impossible to fit all post-traumatic headaches into the same pattern, because there are many kinds of emotional concomitants to headache. It is necessary, therefore, that the physician understand the nature of the headache and the role the symptom plays in relation to the patient's personalicy and environment.

During the study of the patient, the establishment of a positive patientphysician relationship is critical. The essence of this relationship is the physician's encouragement of an attitude of hopeful expectancy, and every measure taken to enhance the relationship, and this hopefulness will foster therapeutic progress.

A physician can give considerable relief by allowing the patient to speak and ventilate suppressed frustrations and resentments. Time so spent also gives reassurance of the therapist's desire to help. The reduction of emotional pressure which follows may markediy reduce the frequency and severity $\mathrm{Jf}$ headaches. As therapy progresses, a review with the physician of life's goals, and of environmental factors, can greatly help the patient handle tensions. Whenever possible, however, the patient should develop his or her own insight into tension-producing situations and then try to rearrange life situations and responses appropriately. Objectivity must be part of the therapist's role, for certain situations cannot be handled by the patient, and therapeutic goais must be realistic for both patient and physician.

In some patients, denial of problems is so strong that any therapy is consciously or unconsciousiy rejected. These patients are usually inhibited or withdrawn and require more directive techniques of management. Definite instructions to help them manipulate their environment and alter stress-producing situations are necessary.

Psychotherapy, like all medical therapy, may cover a broad spectrum, from supportive to long-tern uncovering psychotherapy. The clinician must approach each patient with post-traumatic headache as an individual in whom therapy wil vary with the patient's insight, resistance, and personality structure. In some situations, long-tera uncovering psychotherapy will be necessary, and the patient should be referred to a psychiatrist. For othexs, short-term therapy can do a great deal to reduce or eliminate the symptoms, and the results of such treatment is rewarding to both patient and physician.

For patients who will accept psychological factors as being responsible for their headaches but reject psychotherapy, it is necessary to develop a good patient-physician relationsinip, and to use drug therapy and physical therapy to circument resistance. The possibility remains of psychotherapy at a future date. 


\section{Prognosis}

Changes in intracranial pressure, EEG, or neurologic signs, and the degree or extent of scalp or intracranial injury, do not give adequate indication of subsequent susceptibility to headache. Although the presence of coma, disorientation, and amnesia correiate with headache, the duration of these states is not related to the incidence of prolonged headache. Furthermore, although there is a high incidence of headache among patiants with scalp lacerations, the degree or extent of scalp injury is not related to later development of headaches. Headache, however, is appreciably less common in those witnout an initial disusder of consciousness.

Post-tratmatic headaches may develop in patients who have previously shown a normal adjustment to life, but they are more apt to occur in patients who were neurotic before injury.

Headaches after head injury usually begin with rezurn of consciousness and are severe and persistent, but they may not appear until the patient is ambulatory. In most patients, the frequency and severity of the headaches diminish with the passage of time, and the headaches usually disappear within 6 to 12 montbs; however, they may persist for years. If the trauma occurred when the patient was undar 20 years of age, recovery is usualiy more rapid with fewer sequelae. Post-traumatic healaches lasting longer than 12 months tend to continue for many years in most patients and may betome a way of life. But under the guidance of an understanding physician, the patient way learn to avoid factors that precipitate the headache and so break the pattern of chronic recurrences.

\section{EFFFCTS OF STRESS OR OTHER STATES RELATING TO PROBABILITY OF INCAPACITATION}

No clear-cut clinical description or single mechanism can cover all the aspects of chronic recurring neadache following trauma. The posttraumaric syndrome in which headache plays a prominent part hes no known pafhologic concomitants and is more frequently associated with minor than with major trauma. While severe cases of post-traumatic headache have occurred after minor injuries without loss of consciousness, major injuries may leave no headache in their course.

\section{Recomendations}

To establish criteria for acceptance or return to work of civiiien air crew members with headache after a head injury is difficult. Prolonged post-traumatic headache tends to be the most persistent symptom in the posttraumatic syndrome, which is composed entirely of subjective complaints. Much depends on the evaluation of the examining physician. Because so nany factors are involved, rigid rules for aircrew members with post-traumatic headache would not be useful, but the following general criceria are recomended: 
1. Airmen should be free of symptoms for 30 to 60 days before returning to flying after a head injury in which there was a momentary or no loss of consciousness, with headache as an isolated symptom or as part of the post-traumatic syndrome.

2. There should be no return to flying if the airman is on prophylactic medication for the headache. This restriction includes pedication of any type, such as analgesics, sedatives, vasoconstrictors, CNS stimulants, as...idepressants, antianxiety drugs, etc.

3. Fatients may retur: to fiying status after injury, if the headache history differs $1 j \pm t l e$ from that obtained at the time of acceptance by the FAA before injury. The occasional headache with occasionas use of aspirin or actaminophen is acceptable, if it was allowed prior to injury. If there were $x_{1} 0$ headashes ano no use of medication prior zo injury, and if the use of dspizin or acetaminophen for headaches after injury does not exceed mor' thas three or four times a month, certification should be granted.

No person should comand an aíplane or fly as a crew member while takjng narcotics and analgesics for chronic post traumatic headache.

4. Headache is cause for permanent suspension from flying, if it is a major symptor associated with a period of unconsciousness longer than 24 hours after trauma, a defressed skull fracture, brain laceration or epidural or subdural hematoma, focal or generalized convulsions, or persistent. neurologic deficits.

Post-traunatic headache is usually part of a post-traumatic syndrome which includes difficulties in concentration and emotional reactions. Although the headache is unlikely to result in sudden incapacitation, because of it the patient may have difficulty coping with emergencies which require alertness and judgment.

5. These recommendations should apply to all crew members, because alertness of all is required for functionisg during routine flights and in emergen:ies. 


\section{REFERENCES}

1. Friedran AP: The so-called pust-tramaicic headache in Walker AE, Caveness WT, Critchley M(eds): The Late Effycts of Head Injury. Springfield, IL, Charles C Thomas Publisher, 1969, Pp 55-71.

2. Ad Hoc Comittee on Classification of Headache. Arch Neuro1 6:173-176, 1962.

3. Nick J, Nick CS: Chronic post-traumatic headache, in Friedman, AP(ed): Research and Clinical Studies in Headache. Basel S Karger, 1939, vol 2, PP 115-168.

4. Schaller WF: After-effects of head irjury: the post-traumatic concussion state (concussion traumatic encephalopathy) and the post-traumatic psychoneurotic state (psychoneurosis, hysteria): a study in differential diagnosis. JAMA 113:1779-1784, 1939.

5. Woltman HW: Late neurologic complications of injury to the nervous syster. Wis Ned J 41:385-391, 1942.

6. 5remer $F$, et al: Le syndrome comotionel tardif dans les traumatismes fermes due crane. Rev Otoneuroophthal 10:161-224, 1932.

7. Penfield $W$, Horcross NC: Subdural traction and post-traumatic headache, study of patients and therapeusis. Arch Neurol Psychiat 36:75-101, 1936.

8. Ross WE, HeNaughton FL: Head injury: Study of patients with chronic post-traumatic complaints. Arch Neurol Psychiat 52:255-269, 1944.

9. Denny-Brown D: The sequelae of war head injuries, New Eng J Med 227:771$780,813,821,1942$.

10. Symonds CP: Discussion on differential diagnosis and treatment of postcontusional states. Proc Roy Soc Med 35:601-607, 1942.

11. Russell WR: Cerebral involvewent in head infury. A study based on the erawination of two hundred cases. Brain 55:549-603, 1932.

12. Kozol HL: Pretramatic personaifty and psychiatric sequelae of head injury. Arch Neurol Psychiat 53:358-364, 1945.

13. Lewis A: Discussion on differential disgnosis and treatment of post-contusional states. Proc Roy Soc Hed 35:607-614, 1942.

14. Wolft EG: Beadache and Other Head Pain. New York, Oxford, 1963, pp 243-245.

15. Wates $\mathrm{J}$, Wiley $\mathrm{WB}_{2}$ Groh RH: Relation of contusion of scalp to posttraumatic beadecte and dizziness. Assoc Res Nerv lient Dis Proc. 24:562$577,1945$. 
16. Jones OW Jr, Brown HA: The treatment of post-traumatic head pain. I Nerv Yent Dis 99:668-671, 1944.

17. Raney AA, Raney RB: Headache: a common symptom of cervical disk lesions; report of cases. Arch Neurol Psychiat 59:603-621, 1948.

18. Krede1 FE: Headache from lesions of scalp nerves. Ann Surg 122: 1056$1059,1945$.

19. McConne11 AA: On certain sequelae of closed head injuries; the pathological basis of the post-traumatic syndrome. Brain 76:484.

20. Siegal LJ: Cerebral traumata, concept and valuation of psychophysiologic afterwaths. Dis Nerv Syst 14:163-171, 1953.

21. Walker AE, Jablon S: A followup of head injured then of WorId War II. J Neurosurg 16:600-610, 1959.

22. Rowbotham GF: Acute injuries of the Head. Baltimore, Williams \& Wilkins, 1964.

23. Lewis T: Pain. New York, MacMillan Company, 1942.

24. Hinsey JC: Observations on the innervation of the bloct vessels in skeletal muscle. J Comp Neuroi 47:23-65, 1928.

25. Friejman AP: Muscie-contraction (rension) headache. J Indian Med Prof 12:5375, 1965. pp 2-4.

26. Ostfeld AM, Reis $D J$, Wolff EG: Studies in headache: bulbar conjunctival ischemia and muscle contraction headache. Arch Neuro Psychiat 77:113-119.

27. Elliott FA: Tender muscles in sciatica; electroaryographic studies. Lancet 1:47-49, 1944.

28. Onel $Y$, Friedman $A P$. Grossman $5:$ Muscle blood flow studies in muscle-contraction headaches. Neurol (Mim) 11:935-939, 1961.

29. Miller E: Accident neurosis. Br Yed J I:919-925, 1961.

30. Friednan AP: Migraine pathophysiology and pathogenesis, in Vinken PJ, Bruyn GN (eds): Elandbook of Cifnical heurology, Vol 5. Anstercam, North Bolland Publithing Co, 1968, pp 37-44.

31. Ostfeld AY: The Common Headache Syndrones. Springfield, Charles C Thoeses, 1962.

32. Friedan AP, Rarschoff J: Post-traumatic headache. Trauna (Hed Anat Surg) $5: 33-61,1964$. 
33. McNaughton FL; The innervation of the intracranial blood vessels and dura sinuses. Proc Assoc Res Nerv Ment Dis 18:179-200, 1937.

34. Schlesinger EG: Role of the cervical spine in headache and head pain, in Friedman AP, Merritt HH (eds): Headache: Diagnosis and Treatment. Philadelphia, Davis, 1959, pp 349-365.

35. Barre JA: Sur un syndrome sympathique cervical posterieur et sa cause frequente, I'artrite cervicale. Rev Neurol (Paris) 1:1246-1248, 1926.

36. Vijayayan N: A new fost-tramatic headache syndrowe; clinical and therapeutic observations. Headache 17:19-22, 1977.

37. Soriano V: Post-traumatic headache (abstract). Proceedings of the 8th International Congress of Neurology, Vol 1. Vienna, 1965. pp 47-58.

38. Schutt CH, Dohan FC: Neck injury to women in auto accidents. JAMA 206:2689-2692.

39. Xolb LC: Psychiatric and ps;chogenic factors in headache, in Friedman AP, Merritt HH (eds): \#eadache: Diagnosis and Treatment. Philadelphia, Davis, 1959, pp 259-298.

40. Ellard J: Psychological reaction to compensable injury. Med J Aust 2:349-391, 1944 .

41. Brenner C., Friedman AP, Merritt HH et al: Post-traumatic headache. J Neurosurg 1:379-391, 1944.

42. Frietman AP, Mikropolous H: Post-traumatic leadache, in walker AE ano Jablion S(eds): A Follow-Up Study of Head Wounds in World War II. VA Medicai Monograph. Washington, Government Printing office, August $1,1961$.

43. Friedman AP: Drug treatment of migraine, in Vinken PJ, Bruyn Gw (eds): Handbook of Clinical Neurology, Vo1 5, Ansterdam, North Holland Publishing Co, 1968, pp 96-103.

44. Frazier SH: Psychotherapeutic approach to patients with headache. In Friedman AP (ed), Yodern Treatment: Treatment of Beadache. New York, Rarper \& Row Publishers, 1964, pp 1412-1424. 
MIGRAINE

\section{MINIITM CRITERIA FOR DIAGNOSIS}

Migraine, one of the most common neurologic disorders, is characterized by variability of symptoms and perfodicity. The word "migraine" is French and means one sided headache. It is a term used by many cliniclans for a variety of headache types, including In this group all cases of chronic recurring headache, tension headache, and those in witch no adequate cause can be found. This approach to headache problems blurs all classifications to a point that they are meaningless.

A definition of migraine which is mainly descriptive, but also based on mechanisms, is that of the Ad For Committee on the Classification of Headache ${ }^{1}$ of the National Instieute of Neurological Diseases and Blindness (NINDB):

1. Vascular Readaches of Migraine Type. These are recurrent attacks of headache, varying widely in intensity, frequency, and duration. The attacks are comonly yailateral in onset; are usually associated with anorexia and, sometimes, with nausea and vomiting; in some are preceded by, or associated with, conspicuous sensory, motor, and mood disturbances; and are of ten familial. Not all of the above are necessarily present in each attack or in each patient.

2. Iisted below are particular varieties of headache, each sharing some, but not necessarily $: 11$, of the above-mentioned features:
A. "Classic" wigraine
B. "Comon" migraine
C. "Cluster" headache
D. "Hemiplegic" and "Ophthalmoplegic" migraine
E. "Lower-half" headache

The World Federation of Neurologists' Research Group on Migraine and Beadache bave proposed similar criteria:

Definition: A fanilial disorder characterized by recurrent attacks of headache widely variable in intensity, frequency, and duration. Attacks are commonly unilateral and are usually associated with anorexia, nausea, and vomiting. In some cases they are preceded by, or associated with, neurologic and nood disturbances.

Hot all of the above characteristics are necessarily present in each attack or in each patient.

A. Conditions which are generally accepted as falling within the definition are:

(1) Clatsic aigraine

(2) Ronclasic migraine 
B. Conditions wich may or may not fall within the category of migraine are:

(1) "Cluster" headache

(2) "Facial" migraine

(3) "Opthalmoplegic" migraine

(4) "Hentplegic" migraine

The NINDB definition is useful and 111 be adhered to in this report. It is not all-encompassing, for theze is no mention of basiler artery migraine nor of "complicated migraine." Also, variations in the clinical manifestations of certain types of migraine may depend on the blood vessels involved and the duration of the vascular distention.

Nefther the headache nor the visual or sensory aura preceding it signals the true beginning of a migraine attack, for the symptoms are but the end point of a series of physiologic changes brought about by the patient's reactions to a varlety of stressful situations. Thus, the symptom of headache is part of an evolving process rather than an isolated event.

\section{Epidemiology}

Studies from a large number of sources using similar techniques give varied figures for the prevalence of migraine. 2 There is a tendency to accept $5 \%$ to $10 \%$ as an incidence range in the general population. However, incidence is difficult to evaluate because about half the migraine sufferers do not consult a physician.

While migraine is genetically determined in many instances, the exact mode of inheritance has not been clearly defined, nor has the specific abnormality been identified. The inherited abnormality may be an instability of the regulation of the autonomic nervous system including the hypothalamus, an inborn metabolic defect, or a hypersensitivity to a circulatory enzyme. Familial Incidence has been estimated between $65 \%$ to $90 \%, 3,4$ and both atosomaldominant 5 and autoscmal-recessive tralis have been proposed. 6 Thus, the diagnosis is more secure if there is a family history of migraine. It is also possible enviromental and heredicary factors are important in familial occurrence.

Women are more likely to be affected than men, although the ratio varies considerably in published reports. In our experfence, there is a ratio of three females to two males.

Migraine frequently begins in childhood at 6 to 8 years of age or after pubexty. However, It may occur at any time from early childhood to late life. In young children, wotion sickness or attacks of cylic vomiting way be precursors or equivalents of migraine. In women, there is frequently a relationship between attacks of migraine and menstrual periods. After the first trimester of pregnancy, wost wowen report they are free of attacks.

Attacks tend to lessen in frequency and intensity past midale age, but many nigraineurs continue to have headaches into late life, which are usually combined vascular and wuscle contraction headaches. Henopause frequently brings

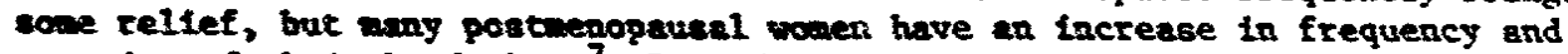
severity of their headaches. 7 Procedures to induce early menopause are to be 
discouraged as treatment for the migraine patient, because exper sence has indicated they are not effective in preventing the condition. The natural history of mipraine is one of remissions and exacerbations for years, and migraine can reappear in later life after decades of quiescence in both females and males.

\section{Etiology and Pathogenesis}

Although the primary cause of migraine still eludes us, one key to a migraine attack lies in the central nervous and central autonomic systems. The inseparabiltty of psychic phenomena and physiologic changes is vell illustrated by this disorder, and the patient's behavior and personality are closely related to the onset of the migraine attack. The prodrome of classic migraine, especially the visual and other sensory and wotor phenomena, are further indications of central nervous system origin for migraine. A posstble sequence of events has been suggested by direct measurements of cerebral blood flow, which show an initial phase of vasoconstriction involving the Intracranial arteries, with a reduction of blood flow of sufficlent degree to produce the initlal symptoms and the ischemic changes associated with the prodrome of the attack, followed by a phase of vasolilatation, primarily of the extracranial arteries, during which the hesdache occurs. ${ }^{8-11}$

But the two phases are not sharply separated. Some cortical areas show vasodilatation at a stage when vessels in other areas are still constricted. This would account for those cases of migraine in which the usual temporal profile of an aura followed by headache is disturbed and symptons of the aura continue into the headsche phase or sometimes even follow the headache. The pain of migraine, traditionally considered due to extracerebral vasodilatation and increased blood flow, may not be due to these phencnena alone. Studies suggest the dilated migrainous artery is hyperpermeable and is involved in a sterile, local inflamatory reaction in wich vasoactive substances and platelets participate. 12

Biochemical processes involved in the migraine attack have been under investigation, particularly the roit of exdogencus and exogenous vasoactive agents wich control the microcirculation by influencing the tone of vascular smooth muscle and altering blood flow. But before conclusions can be made about the role of hworal agents in migraine, it would be necessary to deternine the levels of these agents in blood perfusing the cranial vasculature during a migraine attack.

Evidence for the role of vasoactive substances in migraine is fragmentary. It appears plasma serotonin levels fall at the onset of a migraine artack. Serotonin will constrict scalp arteries in man, and a fall in its levels may play a part in the extracranial vasodilatation of migraine.

The ieported increase in plasms serotonin level during the prodrome and its subsequent decresse during the readache phase parallel the Increase in platelet aggregation during the prodrome and 1 ts decrease duriag the headache phase. While the exact role of platelets in migraine 18 still to be deterained, they do contcin all the serotonin present in the blood and relesse it during 
aggregation. It ia possthle changes in plasma serotonin in migraine are secondary to changes in platelet aggregation. Such findings would indicate that pharmacologic inhibition of platele: aggregation could prove helpful in the prophylaxis of migraine and other vascular headaches.

During the last decade there have been vigorous bicchemical studies of migraine, but the problem has been complicated because we do not know precisely how the organien responds blochemically to the stresses that precede and possiblz provoke migraine.

Other physiologic disturbances occur in a migraine attack which are not related to the involved cranial arteries. These include cyclic changes in the distribution of fluids, manifested by edema and electrolyte retention and by diuresis as the headache begins to subside. Attempts to produce headache by overhydration with the use of antidiuretics, or to relieve headaches with diuretics, have not been successful. 20 We believe it is justifiable to conclude these physlologic changes are not the cause of the attack of migraine but are among its manifestations.

Observations over the years have indicated some migraine paifents are prone to physiclogic abnormalfties, like abnormal caplllary loops in fingers or mucous membranes, high incidence of essential hypertension, abnormal vasomotor responses to heat and cold, increased incidence of toxemia of pregnancy, abnorwal monoamine oxidase function, and abnornal blood clotting. How these events are related to the migraine process has not been established.

Psychologic Factors

Although it is tempting to try to establish the "migraine profile" and flt the patient to it, not all patients share the same personality traits. The personality of the migraine patient has been described as compulsive, overconscientious, and ambitious, with an outstanding performance due to the emphasis on perfectionism. 21

There are no published psychologic studies of migraine patients utilizing controls of simflar age, sex, and socioecononic background. Some studies suggest migraine patients were not permitted to express emotions of anger or rage as children and that love and approval could only be won by suppressing their true feelings. 22, 23 Later in life, prolorged stressful situations, such as puberty, leaving home, and meeting the responsibilities of a job, merriage, and parenthood, could trigger serles of migraine attacks in such individuals.

In light of the above, it is not surprising that when the situations in wich headaches occur and recur are analyzed in relation to their psychologic, social, and ewotional significance to the patient, we can often relate the occurrence of headache to a paychologic or enotional stress.

It aust be emphasized that stress in itself does not necessarily precipi= tate nigraine; rather, the method of resolving the stressful event is believed to play the key role. Reaction patterns are wore likely to occur in situations either symbolic of, or directly connected with, the Individual's own goals, 
the mode of attaining them, and the confilicts thus created. We have seen many instances where this can be clearly demonstrated by identifying the imnediate situation which provoked the attack.

\section{Nonspecific Provoking Factors}

On occasion, nonspecific stimuli that may not be stressful for the average person can produce an attack in the migrainous individual. Such attack-trigering factors include fatigue, bright or flickering lights, fasting or missed meals, certain chemicals in prepared foods and beverages, some drugs, metereologic Influences, and atmospheric changes, exercise, exposure to high altitude, menstruation, contraceptive inedication, and physiral factors such as heat, light, sound, and smell. And, a tendency to overreact appears to produce physlologic changes which render the patient sensitive to a wide range of stimuli, many of which had no direct connection with the patient's predisposing situations and conditions in the first place.

Foods and beverages containing tyramine and phenylethylamine, such as aged cheeses, chocolate, yogurt, buttermilk, and so on, have been suggested as possible triggers, 26,27 although this has recently been challenged. 28 The responses of some patients to tyramine-containing foods may be due to deficiencies of tyramine-o-sulphatase. Excess tyramine could act by releasing catecholamines or bradykinin in the tissues. Phenylethylamine has been shown to produce a significant increase in cerebral blood flow in experimental animals similar to that seen in migraine. 29

Nitrites and nitrate compounds, which are added to many foods and impart a cured flavor, are vasodilating agents and can produce a migrainelike headache in some individuals. 30 These additives are found in smoked fish, bologna, salami, frankfurters, bacon, corned beef, pastrami, canned ham, and sausages. Another food additive, monosodium glutamate (MSG), may trigger a pounding headache 20 to 30 minutes after ingestion. 31 Prepared foods that may contain MSG are oriental-style dishes, instant and canned soups, potato chip products, dry roasted nuts, processed meats, instant gravies, TV dinners, etc., and dishes in which gournet seasonings have been added.

The vasodilating effect of alcohol can provoke headaches. 32 Experierce shows alcohol is more likely to trigger an attack at certain times, suggesting a periodic vulnerability at times of fatigue and stress, as with parties and excitement. Certaln drugs are known to precipitate migraine-iike headaches. Reserpine and drug comblnations which contain vasodilating properties to control hypertension may provoke headaches similar to migraine. 33 However, it should be noted that none of these drugs produces the complete attack.

Patients with frequent migraine attacks or headaches should be careful with the anount of caffeine the; take. The cumulative effects of caffeine in coffee, tea, and cola, and widely used medicaments and nonprescription headache medications must be considered. Withdrawal from large amounts of caffeine can produce head pain wh :ch sinulates migraine, or can trigger an attack of migraine. 
The exact effect of food on migraine beadache remains unclear. Some individuals appear reliably vulnerable to certain foods. It is valuable, therefore, to question all headache patients for possible links with food or drug ingestion. However, foods appear to play oaly a small part in the actual triggering of migraine attacks. Careful inquiry Into these situations will usually indicate other emotional factors during the day, or prior to the taking of the food, which might be more closely related to the attacks.

Migraine tends to be worsened in women at times of hormonal changes such as menstruation, ovilation, menopause, during use of contraceptive drugs, etc. 34, 35 In many, oral contraceptives tend to worsen migraine, and their withdrawal may result in marled improvement of migraine in up to $70 \%$ of women using them. On the other hand, it is known that the attacks of migraine occur as estrogen level falls and may be delayed or abolished if high levels are maintained by administration of estrogen. 35 Women aircrew or pilots subject to migraine who take estrog ins should be maintalned on the drugs when flying to avoid the possibility of attacks during the withdrawal phase from estrogens.

Exposure to altitude, 8,000 feet and above, may trigger headache. Migraine patients may develop visual, sensory, or motor aura only, imediately after exposure to altitude, rather than delayed 6 hours or more after exposure as in the nonmigraineur.

Exertion alone may trigger a headache in a migraine patient and is not necessarfly related to the level of physical activity. 36

Correlation between migraine attacks and meteorologic conditions of atmospheric pressure, temperature, and fonfzation has not been established. However, a significantly high incidence of headache symptoms was shown during certain weather phases related to disturbed circadian rhythms. 37

Migraine-like phenomena during and after flights at high altitude have been recognized. 38,39 In many cases, the homonymous scotomata have been remarkably similar to those in migraine. They are of ten surrounded by a scintillating border of light described as zigzag or wavy heat lines. The scotomata way be apparent even when the eyes are closed. There are similarities of such scotomata with the visual phenomena of migraine. They can be altered or eliminated by inhalation of $\mathrm{CO}_{2}$. There is no agreement that persons with a personal or family history of migraine are predisposed to the development of the scotomata as complications of decompression sickness.

Mental symptoms siallar to those occurring in algraine are apparently comon in pilots with the syndrome of dysbarisu. These nay include confusion, restlessness, hallucinations, bizarre behavior, delirium, and annesia. Although the mental changes become severe, the pilot will have no awareness of his problem nor of the extent of his neurologic impairment. Minor mental changes which do not progress could cause a subtle deterioration of judgment which could be a significant hazard to flight safety. Dysbarism in susceptible pilots requires restriction of their flight altitudes to 18,000 feet or lower, and if an attack in flight occurs, there must be imediate return to lower altitude. 
Hyperbaric oxygenation will cause intense vasoconstriction of the cerebral vessels because of the vasoconstrictive action of oxygen. Migrainous patients frequently have attacks of photopsia precipitated by exposure to hyperbaric oxygen in a pressure chamber, and persistent field defects have been reported. 42

\section{Clinical Featuree}

A migraine headache is usually unilateral, but the pattern of each attack may vary or be consistent for months, then change to the opposite side, alternate sidedness, or become bilateral. An attack way occur with visual symptoms, without pain, or head pain without gastrointestinal symptoms, etc.

An attack may begin at any time of the day or night. Nocturnal. migraine awakening the patient with an intense pounding headache is not infrequent. The frequency of migraine attacks varies throughout the lifetime of the patient, and the attack may occur yeariy, monthly, daily, or for periods of days, then go into remission for weeks or ronths. Daily attacks of severe intensity (status migrainous) sometimes incapacitate the patient. The excessive use of ergot, or analgesic dependency with "rebound" vasodilatation pain, can cause a continuous headache. However, daily headaches for months or years are usually not due to migraine, but are caused by anxiety or depressive states or some related condition.

Although certain features follow a recognizable sequence, which permits classification into specific types, the patient's headache may not always have the specific features of classic, common, or ophthalmoplegic migraine or their variants. An individual may have classic migraine, but at other times may have common migraine or headaches which are difficult to classify. It is rare for a patient with migraine not to have tension headache at sometime of life. For purposes of classification the following types of migraine are described, 7,43

Classic Migraine - The heavache is recurrent and periodic. Familial and personality factors appear to be important in pathogenesis. Generally, the prodromes are sharply defined. The aura of classic migraine usually lasts from 20 to 40 minutes before onset of the headache. Contralateral neurologic manifestations, usually visual but sometimes hemiparetic, hemisensory, or dysphasic, may occur in sequesce or concomitantly. The visual symptons include teichopsia, fortification spectra, field defects, and anblyopia. Frequently, the patient can describe not only his visual sensations but alsu the exact date and circumstances of the attack.

The visual scotomata of classic migraine may have different shapes and configurations and are of ten bordered by moving sireaks of light. They are sometias described as jagged in outline or resembling the battlements of a medieval castle (fortificatioa spectra). They are homonymous, and most patients develop a temporary homonymous henlanopia, which begins as a central scotoma and gradualiy spreads out toward the periphery of the homonymous visual fields. Almost all complain of an assoeiated photophobia, sometimes with an aversion for a particular color or black and white (chromophobia). In some patients the visual hallucinations are limited to one eye rather than to one 
half of the visual fleld. Sensory disturbances may develop simultaneously in the fingers and torgue. The headache phase usually begins when the prodromal symptoms fade. The pain is throbbing and lasts from hours to a day or longer, In the later stages often spreading to other parts of the head. Anorexia, nausea, voiniting, sonophobia, and photophobia are concomitant features. Although the prodromal symptoms generally frecede the headache, ophthalmologic and neurologic symptoms may develop during or after the onset of headache. Classic migratne occurs in about $10 \%$ of patients with migraine.

Common Migraine - This is the most frequent type of migraine, occurring in over $80 \%$ of migraine sufferers. The dromes of common migraine are vague and may precede the attack by several hours or days. They vary widely from patient to patient and include psychic disturbances, fatigue, gastrointestinal manifestations, and changes in flufd balance. The actual headache episode lasts from many hours to sever l days. The pain may be pulsating, then persist steadily efther unilaterally or involving the whole cranium. issociated symiptoms and signs include anorexia, nausea, vomiting, fatigue, chills, localized or general edema, and diuresis. The occurrence of nasal signs and synptome may lead the physician to ascribe the headache to involvement of nasal structures. Photophobia and sonophobia are prominent features. This type of migraine commonly occurs on weekends and holidays and during letdown periods.

Cluster Migraine (Ciliary or Migrainous Neuralgia, Histamine Cephalalg la, Petrosal Neuralgia) - This headache occurs in a series of closely spaced attacks; these way be followed by remissions of months or even years. In over $65 \%$ of the patients with cluster headaches, the faclal thermogram reveals multiple spotted areas of dense coolness in one supraorbital region, alyys ipsilateral to the headacke; these areas are not found in other types of vascular headache. 44 Not all agree that this should be included as a migraine variant.

Ophthalmoplegic Migraine - In this rare type of migraine which may occur in the young adult, 45 the pain is moderate, on the same side as the ophthalmoplegia, and accompanied by extraocular muscle palsies usually involving the third cranial nerve. There is pupillary dilatation and external strabismus with diplopia due to paralysis of third nerve function. often the paralysis occurs as the headache subsides, three to five days after onset of a persisting headache.

Repeated ophthalmoplegic attacks may cause permanent infury of the thiro cranial nerve. It is possible the third nerve is compressed by sweIling and edema of the posterior cerebral and superior cerebellar arteries during the stage of vasodilatation. One should be alert for the presence in these patients of an aneurysm of the internal carotid, or of a sphenoidal mucocele on the main trunk or at its Junction with the posterior commuricating artery. Periarteritis with inflassation of the carotid siphon also simulates ophthaimoplegic migraine. It is characterized by a steady, retrobulbar, gnawing pain preceding or following paralysis of the oculonotor nerves. Its course is variable; attacks may last for days or weeks with or without visual deficits. 
Hemiplegic Migraine - The hemiplegic migraine compiex is characterized by neurologic deficits, hemiparesis, or even hemiplegia. The neurologic phencmena of both hemiplegic and ophthalmoplegic migraine may persist for some time after the headache has subsided. Recurrent attacks may occur ove: years or months. Familial hemiplegic migraine is characterized by the familial history and by the fact that attacks always occur on the same side in members of a family. In hemiplegic migraine, incomplete recovery is not excep ional, while in the familial type the symptoms are of relatively short duration anci regress completely.

Basilar Artery Migraine - In this variant of migraine, ${ }^{46}$ the preheadache phase reflects circulatory disturbances of the basilaz artery in the brain stem, thalamic, occipital, and cerebellar regions, all of which are fed by branches of the vertebrobasilar arterial system. The prodromal period may include visual loss and brain stem ymptoms, ranging from paresthesias to vertigo, ataxia, and dysarthria. Ophthalmoplegic, ver autonomic, and bilateral visual disturbances may occur. Severe throbbiag occipital pain and vomiting follow. Transitory loss of consciousness has occurred with the attacks. In young women, the attacks are of ten related to menstruation.

Complicated Migraine - The neurologic symptoms of classic migraine may persist beyond the headache phase. This variant has been called "complicated migraine."47 Permanent sequelae may occur fiter attacks of migraine and occasionally result in major or minor cerebrovascular acridents. 40 These include thrombosis of cerebral or retinal vessels during vascconstriction, and hemorxhage from rupture or diapedesis of the irtracranial or extracranial vessels during vasodilatation. There is usually a failily histcry of migraine in these patients, and previous history of migraine attacks in early iife.

Disturbances of speech are more common in complicaced migraine than is usually estimated. Dysarthria, repetitive expressions of single syllables or simple words, and/or complete aphasia have been noted. Receptive aphasia, dyslexia, dysgrapl.ia, inability of word finding, and amnestic aphasia have also been reported. 47 This important condition may be misdiagnosed as due to ancther CNS condition. Therefore, careful workup of patients with such signs and symptoms is indicated. The use of CT scan should simplify diagnosis.

Migraine Equivalents - A patient who has had rigraine attacks may have these replaced by periodic recurrence of other bodily disturbances. These tave been called migraine equivalents and include paroxysmal tachycardia, vertigo, cyclic edema, and pain in the chest, thorax, or pelvis. 43 They may consist of upper abcominal pain and epigastric tenderness associated with nalisea, vomiting, and diarrhea with little or no headache (abdominal migraine). During the first few attacks, the condition may be mistaken for appendicitis, gastroenteritis, or pancreatitis. In abdominal migraine, the EEG may show small bursts of focal slowing, while in abdominal epilepsy it L.11 show spikes and commonly there will be disturbances of consciousness. 53 


\section{OTHER CRITERIA FOR DIAGNOSIS}

Clinical Examination - Diagnosis and rational treatment of migraine require the physician to understand the basic mechanism of headache, to analyze and interpret the clinical data derived from a careful history and examination, and to make appropriate laboratory tests. The history alone vill often indicate the diagnosis. The physical exanination, including a neurologic examination, may reinforce the first impression or open up other possibilities. The patient complaining of headache warrants complete physical and neurologic examinations. Although often negative, they are basic to the understanding of both the physician and the patient.

\section{RELEVANT DIAGNOSTIC RROCEDURES}

As part of the tnitial physical examination, some ancillary studies are advisable for all headache patients, including blood count, ESR, urinalysis, serology, and selected chemistries. Such laboratory studies heip reassure the patient theze is no evidence of structural systemic disease.

The recommended radiologic examinations are largely atraumatic or noninvasive. An x-ray examination of the skull should probably be made of every patient. While the lateral $v^{i}$ ew gives the most information, the frontal view showing paranasal sinuses, orbits and temporal bones is also important, and a lateral view of the cervical spine is desirable.

EEG is advisable if structural disease or a focal lesion of the central nervous system is suspected. Visual field testing is indicated, if there is evidence of early increased intracranial pressure or hemispheric dysfunction. A spinal fluid examination should te done if there is suspicion of intracranial infection or hemorrhage.

Special studies like CT scan, brain imaging, cerebral angiography, intracranial pneumography, myeiography, and muscle and arterial-wall biopsy are usually reserved for complicated cases in wich one of the preliminary diagnostic tests indicates a structural lesion. No changes were found in CT scans during nigraine attacks in any of 28 patients examed. Although $C T$ scan rarely reveals pertinent information in headache patients with a long history and noncontributory physical and neurologic examinations, the procedure may disclose unsuspected intracrantal pathology in an occasionai patient with vascular headaches and norwal neurologic examination.

\section{Differential Diagnosis}

Migraine nust be differentiated from other conditions producing chronic recurring headache. These include aneurysns and vascular aalformations, in which the recurrent headache is practically always on the same side of the head as the malforwation and in which focal neurologic signs and bleeding way be present. Headaches resembling nigraine with onset in older age groups include those associated with temporal arteritis, hypertension, sarotid and basilar artery insufficiency, and glaucoma. Other disorders to, be considered are pheochrosocytoma, carcinoid, mastocytosis, hypogiycemia, and tumors, particulariy those which are pituitary, parapituitary, or occifital in location. 
Allergic headaches differ from migraine in history, physical characteristics, and response to allergy therapy. Continuous headoche of wonths or years duration should not readily be accepted as algraine; rather, the condition suggests an underlying anxiety and depression.

\section{PROGNOSIS RELATIVE TO SUDDEN OR INSIDIOUS INCAPACITATION}

There is a high incidence of ophthaimic migraine in individuals over 50 years of age, and unless the physician is acquainted with this partial syndrome and pursues the patient's description of the visual symptoms, the physician will probably make the wrong diagnosis, usually that of transient ischemic attacks (TIAs). The usual ischenic attacks of transitory blindness (amaurosis fugax) are auch shorter in duration, seconds to 3 to 5 minutes, usually monocular, rarely hemianopic, and not accompanied by hemianopic fortification spectrum. Visual loss nay be total or partial, and occasionally photopsias consisting of showers of stationary flecks of light that disappear quickly may occur as well as other types of scotomata.

Patients with migraine may have internal carotid artery disease with severe stenosis, and early recognition of the causes of these visual phenomena is important before a catastrophe occurs. The presence of a yellowish, shiny, wholesterol plaque on funduscopic examination may give incication of emboli released from atheromatous plaques in the carotid artery. Intraoptic disorders and the visual phenomena due to retinal disorders, are other considerations.

Altough expanding lesions in the cranium, such as neoplasms, abscesses, and hematozas, are rarely accompanied by headache which simulates migraine, the former obviousiy can occur in sigrainous individuais. Thus, a migraineur with an expanding intracranial lesion may discount his headache and other synptoms as part of the migraine attack.

\section{MEDICAL TRERAPY AFFECTING YERFORMANCE}

The array of pharmacologic approaches proposed for wigraine is more remarkable for diversity than for therapeutic results. The diversity derives from lack of insight into the disease and a subsequent retiance on various empirical treatments. The problen lies mostly with the lack of adequate controls or coxparison groups.

The principal pharmacologic agents suggested for the treatment of migraine Include drugs shich:

1. produce vasoconstriction: ergotamine tartrate, norepinephrine, and other symathominetic anises. 
2. simulate action of serotonin at receptor sites, acting as competitive serotonin inhibitors: methysergide, cyproheptadine, pizotifen.

3. block beta-adrenergic receptors on blood vessels and prevent vasodilatation: propranolol hydrochloride.

4. prevent the depletion of serotonin and possibly other vasoactive amines, such as catecholamines and histamines, by interfering with the action of monoamine oxidase inhibitors.

5. inhibit the uptake of norepinephrine and serotonin, including tricyclic antidepressants, like imipramine hydrochioride, and antriptyline hydrochloride.

6. directly stimulate arterial alpha recepi $: s$; clonidine; studies of this drug have not generally shown a beneficial result surpassing that of placebo.

7. have miscellaneous actions: tranquilizers, sedatives, muscle relaxants, heparin, lithium carbonate, levodopa, bromocriptine, indonethacin, prednisone, estrogens, serotonin precursors (tryptophan and 5-hydroxytryptophan), papaverine, anticonvulsants (diphenylhydantoin).

The Acute Attack

Only a few of the above agents wili be considered. In mild attacks, commonly used analgesics or small doses of codeine may be effective if administered early enough.

of all the agents used and studied, ergotamine tartrate is still the most effective in the treatrent of an acute migraine attack. It is effective in aborting or relieving migraine by constricting scalp arteries, an action which probably is related to the restoration of dilated vessels to a nonpainful, normally constricted state, and restoring the pain threshold to normal.

Caffeine when conbined with ergotamine acts synergistically by potentiating the vasoconstrictor effect of the ergot alkaloid. In addition, caffeine promotes faster, more complete intestinal absorption of ergotamine, thus reducing the total dosage of ergotanine required.

Ergotanine tartrate can be given orally, sublingually, parenterally, or rectally. The recomended oral or rectal dose is 1-2 mg the onset of headache, followed by $2 \mathrm{mg}$ within the hour, but not more than $6 \mathrm{mg}$ for any single attack. In our experience, rectal suppositories of ergotanine and caffeine are effective if administered at the beginning of an attack. A second suppository nay be given after one hour if the headache persists. Ergotamine should not be administered more than a few times a week, and the total weekly dose should not exceed $10 \mathrm{mg}$. Following the aduinistration of 
ergotamine preparations in any form, the patient should be instructed to rest in bed until the headache has subsided.

Side effects of ergotemine are numerous. Ergotism with ischemia of the extremities way follow habitual or excessive use of ergotamine tartrate, and although the condition is rare, the physician wust be alert to its possibility. Ergotamine preparations should be used with caution in hypertensive subjects and are contraindicated during pregnancy and in patients with peripheral vascular disease, angina pectoris, and septic states.

In an occasional parient, status migrainosus may develop as continuous headache lasting for days, accompanied by severe prostration and intermittent voriting and dehydration. Such patients require hospitalization, restoration of fluid and electrolyte balance with intravenous therapy, control of vomiting, and sedation.

Isometheptene mucate $(65 \mathrm{mg})$ is a sympathonimetic agent which in combination with acetaminophen ( $325 \mathrm{mg}$ ) and dichloralphenazone (100 ng) has not proved effective in our hands in treatment of migraine attacks unless of moderate intensity. Meperidine combined with an antimimetic is occasionally necessary for treatment of an acute attack which is refractory to ergotamine.

If migraine attacks are prolonged and not aborted by the usual antimigraine agents, steroids terminate the attacks.

Interval treatment - Most chemical agents introduced for prophylaxis of migraine were first used to treat other disorders and then incorporated into the list of antimigrafne agents. The clinical picture of migraine may include periods of remission and exacerbation, and the patient may respond for short periods of time to any one of a variety of trearments. The effect of drugs is therefore especially difficult to assess. In some studies, a placebo has reduced the frequency of migraine in over $45 \%$ of patients.

Methysergide 58,59 maleate has proved to be an effective prophylactic agent in migraine, suppressing attacks partially or completely in $60 \%$ of patients. It is indicated in patients whose migraine headaches occur more than once a week, but it is of no value in treatment of an acute attack of migraine. The agent is a potent antagonist of serotonin and may act by substituting for serotonin at receptor sites. Side effects are of relatively high incidence. Since these may include conditions from long-term therapy resembling retroperitoneal and pleuropulmonary fibrosis, 60 the drug should not be ased longer than 6 months, followed by two months off before it is resumed. Also, chest $x$-ray, ERG, and appropriate chewical studies are indicated at Erequent intervals.

A compound which can be useful for the prophylactic treatment of migraine and has been accepted by the FDA for the treatment of vascular headaches contains ergotamine tartrate, belladonna alkaloid, and phenobarbital. The dosage is one tablet three times a day. 
Cyproheptadine hydrochloride, which is antagonistic to both serotonin and histamine, has been used for the prophylactic treatment of migraine. While it was not found to be significantly effective in a double-blind controlled test, cyproheptadine has reduced the frequency and severity of headache in some patients. Side effects include drowsiness, stimulation of appetite, and weight gain.

While propranolol hydrochloride, a beta-adreiergic blocker, has been used in patients with migraine, 61,62 some have had only limited success with it. Alprenolo1, $10 \%$ to $40 \%$ more potent as a beta-blocker than propranolol, has shown little or no effect on the frequency of headache attacks when used for wigraine prophylaxis. A caveat about propranolol is the possibility of precipitating or potentiating heart failure or asthma.

Initial pharmacclogic reports suggest a benzocycloheptathioprene desivative closely related structurally to cyproheptadine, has marked antiserotonin and antihistamine effects. 63,64 Although in clinical trial the drug appeared to be safe and effective in the drug preventing migraine, further evaluation is necessary, and is not now available in the v.S.

Tricyclic antidepressants, such as imipramine hydrochloride and anitriptyiine hydrochloride, are more effective than the anxiety-reducing drugs in patients with migraine, who are also subject to depression. 65 These drugs act by inhibiting the uptake of norepinephrine and serctonin in peripheral and central neurons.

Monoamine oxidase inhibitors, which maintain or increase serotonin levels, should generally not be used in migraine because of their potentially serious side effects and the extremely variabie responses they elicit. They are to be reserved for patients who are completely resistant to other forms of medication.

Minor tranquilizers may be beneficial in reducing anxiety, and may temporarily improve the patient's ability to handle stress. These chemical agents should be used only on an interaittent basis. The benzodiazepines appear to have a more specific action against anxiety and are preferable to barbiturates.

Using a combination of dipyridamole and aspirin, which are nonsteroidal antinflamatory platelet inhibitors, resulted in fewer migraine attacks together with the decrease and eventual norwallzation of previously abnormal

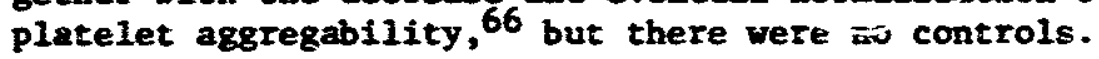

Undoubtedly the contraceptive pill produces an exacerbation in ulgraine In some patients, which takes the form of an increase in the frequency of the severity of the attscks. On the other hand, relief of headache occurs in sowe young wowen sho take oral contraceptive pills. It is known the attacks of migraine occur as estrogen levels fall, and may be delayed or abolished if levels are alntained artifically high by administration of estrogens. Women with migraine on maintenance estrogen therapy may experience a marked 
improvement, if the dose of estrogen is zeduced and cyclic interxuption of therapy is avoided. 35 The use of estrogen therapy in migraine patients must be balanced with the risk of the chrombotic and carcinogenic effects of the estrogens.

Acupuncture - Acupuncture appears to help some patients with chronic recurring headache, but there are many patients who have taken a series of acupuncture treatments without relief. At this point, there are insufficient cata, including controlled studies, making it wise to withhold judgment in evaluating the role of acupuncture in this condition.

Autoregulatory Techniques

Various autoregulatory techniques recently were introduced for treatment of migraine, with variable results. One of the major techniques is biofeedback, a technique using instruments to give a person immediate and continuing signals on changes in a bodily function of which he is not usually conscious. Theoretically, the isput enables the patient to affect and control the "involuntary" functions and systems not usually under voluntary control. Some medical centers use temperature feedback combined with relaxing "autogenic" phrases-a method called "autogenic feedback training. .67

Related to the biofeedback theory are a variety of other relaxation techniques espoused by followers of Zen, Yoga, transcendentalism, and other types of meditation, and by physicians who use techniques of progressive relaxation. It appears some individuais who practice these technique: secure temporary relief from their tension states and migraine. However, patients who use these techniques generally do not understand the factors which produce the tension, so that rather than getting at the cause of the tension, there is a reconditioning or a "covering" rather than improved insight about, or a working through of, the patient"s problem.

\section{Psychotherapy}

Emotional factors frequently precipitate migraine and muscle contraction headaches. The treatment of psychologic aspects is paramount, because the tensions developed by migraine patients over repeated irustrations, hostility, anxiety, and inability to meet personal standards of perfection of ten become the setting in which the migraine attack occurs. 24,68

For these patients, the supportive doctor-patient relationship during the initial phase of therapy is a key step in treatment. If the patient feels the physician is really an interested, understanding, sympathetic person, he or she gains confidence in the physician. It is then possible to explore those factors in the patient's life situation which have led to resentwent, hostility, and self-punishment. The patient must be allowed free expression of conflicts, resentments, and dissatisfactions, in order to gain insight int, how these emotional factors relate to the physiologic basis of the attack. The patient needs reassurance, support, and guidance in redirecting behavior patterns to enable a more effective and realistic dealing with major life probiens. 
Eavirotental seress at howe, at work, or in social situations may bring about wre tension or anxlety than the patieat can endure. One of the first goals of therapy, greatly aided by the confidence engendered by the phystcianpatient relationship, is to rewove as much adverse stress es possible from the patient: 8 enviroment; this alone will probably decrease the number of headache attacks.

On a soawhat nore difficult level, the patient's conflicts wust be ventilated. Often the patient is not aware that tension and anxiety are engendered by anbivaient feelings of combired adwiration and hostility toward a supervisor, spouse, parent, or child. These feelings must be ex;lored, and the patient must be reassured there is nothing umorthy or disgraceful about them. Therapy should include reassurance, suggestion, psychic catharsis, and reeducation.

The physictan should liwit himself to supportive therapy, guidance, counseling, and situational insight. Interpretive insight, uncovering transference, and long-term intensive therapy should be done only by the psychiatrist.

\section{SURGICAL THERAPY AFFECTING PERFORMANCE}

Over the yexrs, various surgical procedures have been proposed for the treatment of migraine, but none has proved to be effective. Therefore. surgical intervention is not recomended.

Summary of Migraine Therapy

The most effective management includes a multiple approach and the following: treatment of the whole patient; removal or reduction of precipitating factors; help in understanding the situational and environmental factors producing emotional tensions; guidance in resolving conflicts; and the selective and judicious use of pharmacologic agents.

EFFECTS OF STRESS OR OTHER STATES RELATING TO PROBABILITY OF INCAPACITATION AND PROGNOSIS, AND RECONRIDNATIONS

Men and women who suffer from migraine in adolescence and early adult life are poor risks for aviation. This is shown in military aviation where, under the stress of flying, the migraine tendency is likely to become more of a problen. Migraine attacks by nature may have long periods of remission or activity and are capricious in onset. They may completely incapacitate the sufferex. Because each crew member has an essential role, severe migraine should bar any from nedical certification. This, of course, includes the pilot, who cannot predict when there will be severe stress.

The patient with classic wigraine and its variants such as ophthainoplegic, ophthalaic, hemiplegic, and complicated nigraine is always at high risk and shoosd not be a pilot or member of a cres. 
A Agradieur who must take prophylactic gedication of any type, should aot fly. Although olde effecte ay be alld, the flyer to functioning pharmacologically, not physiologicaily, and is therefore wore vulnerable to stress. Wowen on estrogen replacesent therapy should as ntain the use of estrogens when they are part of the aircraft crew.

It may be anticipated that headache will recur during a major crisis and during periods of great stress, when the individual is taxed to the lisit. Avosdance of the earlier discussed precipitating factors will reduce the frequency of attacks, but it way be very difficult to achieve personality and situational readjustments.

Positious entalling responsibility, decision making, and constant pressure with litele opportunity for modification will increase the likelthood of an attack in the afgraineur. The signs of a poor prognosis in nigraine are fixed attitudes in the face of an unaiterable situation.

In the main, a better prognosis can be offered to a patient who has had the migraine ynorove for a short tive than to one who has had headaches since childhood. Not 211 wgraine disappears at the menopause in women, and in men at the age of 45 to 50 years. For rigid persons, however, middle life may bring with it Increasing difficulty in adjustment, and migraine way become worse instead of better. Thus, the prognosis for migraine which starts or continues into this period is poor. 
REFERINCES

1. Ad Hoc Comoltee on Classification of Headache. Arch Neurol $5: 173-176,1962$.

2. Waters WE: Prevalence of migraine. J Neurol Neurosurg \& Psychiat $38: 613-616,1975$.

3. Friedwan AP: Current concepes in the diagnosis and treatment of chronic recurring headache. Med Clin N Amex 56:1257-1271, 1972.

4. Dalsgaard-Wielsen R: Migraine and heredity. Acta Neurol Scand $41: 287-300,1965$.

5. Allen $\mathrm{k:}$ The inheritance of migraine. Arch Int Med 13:590-599, 1930.

6. Goodell H, Lewontin R, Wolff HG: Familial occurrence of migraine headache. A study of heredity. Arch Neurol Psychiat 72:325-334, 1954.

7. Friedwan AP: The infinite variety of migraine. In Smith $R(e d)$ : Background to Migraine, Londrn, Heinemann Medical Books, Ltd. 1970, Vol 1, PP $165-181$.

8. Marshall $\mathrm{J}$ : The regulation of cerebral blood flow--its relationshif to migraine. Arch Neurobiol (Madrid) 37 (Supp1):15-25, 1974.

9. O'Brien MD: Cerebral blood flow changes in migraine. Headache 10:139-143, 1971 .

10. Skinhoj E: Haemodynamic studies with the brain during migraine. Arch Neurol 29:95-98, 1973.

11. Mathew NT, Harastnik F, Meyer JS: Regional cerebral blond flow in the diagnosis of vascular headache. Headache 15:252-260,1976.

12. Dalessio DJ: Wechanisms of headache, in Friedran AP (ed), Headache and Related Pain Syndromes. Philadelphia, WB Saunders Co, in press.

13. Kimball RW, Friedman AP, Vallejo E: Effect of serotonin in migraine patients. Neuro1 10:107-111, 1960. 
14. Curran DA, Hinterberger $A$, Lance JW: Total plasma serotonin, 5-hydroxyindoleacetic acid and $p$ hydroxy-w-sethoxy-mandelic acid excretion in normal and migrainous subjects. Brain 88:997-1010, 1965.

15. Rydzewski $\mathrm{W}$ : Serotonin (5KT) in migraine. Levels in whole blood in and between attacks. Headache 16:16-19, 1976.

16. Friedman AP: Migraine, pathophysiology and pathogenesis. In Handbook of Clinical Neurology, Vol 5. Vinken PJ, Bruyn GW (eds), Amsterdan, North Holland Publishing Co, 1968, pp 37-44.

17. Chapman LF, Ramos AO, Goodel B, et a1: A humoral agent inplicated in vascular headache of the migraine types. Arch Neurol 3:223-229, 1960.

18. Anthony $M$, Hinterbergex $H$, Lance JH: Flasma serotonin in migraine and stress. Arch Neurol 16:544-552, 1967.

19. Horrobin DF: Prostaglandins and migraine. Headache 17:112-117, 1977.

20. Friedman AP: Migrafne: Variations on a theme. Bull/Los Angeles Neurol Soc 40:3):83-95, 1975.

21. Wolff HG: Personalicy factors and reactions of subjects with migraine. Arch Neurol Psychiat 37:895-903, 1937.

22. Fromm-Reichmann F: Contribution to the psychogenesis of migraine. Psychoanal Rev 24:26-33, 1937.

23. Selinskg H: Psychological study of the migrainous syndrose. Bull N Acad Led 15:757-763, 1939.

24. Kolb LC: Psychiatric aspects of the treatment of headache. Neurol (Minn) 13:34-37, 1963.

25. Dalton X: Food intake priot to migraine attacks: Study of 2313 spontaneous attacks. Headache 15:188-193, 1975.

26. Sandler M, Youdin MBH, Hannington EA: A phenylethylarine oxidizing defect in migraine. Nature 250:335-337, 1974.

27. Hanaington $\mathrm{E}$, Horn $\mathrm{M}$, Wilkinson $\mathrm{J}$ : Further observations on the effect of tyramine, in Cochrane (ed), Background to Migraine, 3rd ed. London, W. Heinemann, 1970, PP 113-119. 
28. Ryan RE Jx: A clinical study of tyramite as an etlological factor in migraine. Readache 14:43-48, 1974.

29. McCulloch J, Harper AM: Phenylethyiamine and cerebral blood flow. Keuro 27:817-821, 1977.

30. Henderson WR, Raskin NH: "Hot dog beadache." Lancer 2:1162-1163, 1972.

31. Schaumerg HH, Byck R, Gerst1 R, et al; Monosodium L-glutamate; its pharmacology and role in Chinese restaurant syndrome. Science 163:826-828, 1969 .

32. Lance JW: Mechanism and Managesent of Headache, 2nd ed London, London, Butterworth, 1973.

33. Kinball RW, Friedman AP: Further studies of neurohumoral agents in patients with vaseular headaches. Neuro 11:116-119, 1961.

34. Greene R., Dalton X: The premenstrual syndrome. Brit Med $\mathbf{J}$ $1: 1007-1014,1953$.

35. Somerville $B W$ : The role of estradiol withdrawal in the etiology of wenstrual migraine. Neuro 22:355-365 1972 .

36. Appenzeller 0: Cerebrovascular aspects of headache, in Medical Clinics of North Averica. Friedman AP (ed). Philadelphia, W B Saunders Company, May, 1978.

37. Kugler $J$, Laub $M$ : Headache determination by meteorotropic influences, in Friedman AP (ed), Research and Clinical studies in Headache, Vol 6, Basle, S Karger Puilishing Company, 1978 (In press).

38. Engel GL, Web JP, Ferris EB, et al:

A migraine-1ike syndrome complicating decompression sickness. War Hed (Chicago) 5:304-314, 1944.

39. Masland RL: Review of cases of collapse occurring in aititude chambers. NRC, CAM Rpt. No 179, 19 August, 1943.

40. Flinn DE, Womack GJ: Neurological manifestations of dysbarism: a review and report of a case with multiple episodes. Aerospace Med 34:956-962, 1963.

41. Ferris EB, Engel GL, Romano J: The clinical nature of high altitude decompression sickness, in Fulton JF (Ed): Decompression sickness. Philadelphia, UB Saunders Co, 1951. 
42. Anderson B Jr, Heyman A, Whalen RE, et al: Migraine-11ke phenomenon after decompression from hyperbaric environment. Neuro1 (Hinn) 15:1035-1040, 1965.

43. Frlednan AP: Headache, Chap 13, in Baker AB, Baker LH (eds), Clinical Neurology, New York, Harper \& Row, 1976, pp 1-26.

44. Friedman AO, Wood EA: Thermography in vasrular headache. In Medical Thermography Theory and Appllcations. Los Angeles, Brentwood Publishing Corp, 1975 , pp 80-85.

45. Friedman AP, Harter DH, Merritt HH: Ophthalmoplegic migraine. Arch Neuro1 7:82-87, 1962.

46. Bickerstaff ER: Basilar artery migraine. Lancet 1:15-17, 1961.

47. Bruyn Gw: Complicated migraine, in Vinken PJ, Bruyn GW (eds). llandbook of Clinical Neurology, Vol 5. Amsterdan, North Holland Publishing Company, 1968. pp 59-95.

48. Charcot JM: Sur un cas de migraine. Ophthalmoplegique (paralysie oculomotrice periodigue). Progr Med 1:83-86, 91-102, 1890.

49. Connor RCR: Complicated migraine. A study of permanent neurological and visual field defects caused by migraine. Lancet 2:1072-1075, 1962.

50. Gilbert GJ, Rappaport A, Trump R: Retinal degeneration in hemiplegic migraine. Headache 14:77-80, 1974.

51. Lance JW, Anthony M: Some clinical aspects of migraine. Arch Neurol 15:356-361, 1966.

52. Lee $\mathrm{CH}$, Lance JW: Migraine stupor. Headache 17:32-38, 1977.

53. Lundberg PO: Abdominal migraine--Diagnosis and therapy. Headache $15: 122-125,1975$.

54. Hungerford GD, duBoulay GR, and Silkha $\mathrm{KJ}$ : Computerized axial tomography in patients with severe migraine: A preliminary report J Neurol, Neurosurg \& Psychiat 39:990-994, 1976.

55. Mathew RT, Meytr JS, Welsch KM, Neblett CR: Abnormal CT scans in migraine. Headache 16(6):272-279, 1977.

56. Friedman AP: Migraine headache. JAMA 222:1399-1402, 1972. 
57. Berde B: New studies on the circulatory effects of ergot compounds with implications to migraine. In Smith $R$ (ed), Background to Migraine, London, W Heinemann, Ltd, 1971. Vol 4, pp 66-75.

58. Friedman AP, Elkind AH: Appraisal of methysergide in the treatment of vascular headaches of the migraine type. JAMA 184:125-128, 1963.

59. Graham JR: Methysergide for prevention of headache. Experience in 500 patients over 3 years. New Eng J Med 270:67-72, 1964.

60. Graham JR, Suby HL, LeCompre PR, Sadowsky NL: Fibrotic disorders associated with methysergide therapy for headaches. New EngI I Med $274: 359-368,1966$.

61. Weber RB, Reinmuth OM: The treatment of migraine with propranolol. Neurol 22:366-369, 1972.

62. Diamond S, Medina JL: Double-blind study of propranolol for migraine prophylaxis. Headache 16:24-27, 1976.

63. Lance JW, Anthony M, Sonerville B: Comparative trial of serotonin antagonist in the management of migraine. Brit Hed $\mathrm{J}$ $2: 327-330,1970$.

64. Nelson RF: BC-105: A new prophylactic agent for migraine. Four years experience in 75 patients. Headache 13:96-103, 1973.

65. Couch JR, Ziegler DK, Hassanein R: Amitriptyline in the prophylaxis of migraine. Neurol 26:121-127, 1976.

66. Mazal S: Transient ischemic attacks and increased platelet aggregability associated with oral contraceptives. INeurol, Neurosur, \& Psychiat 40 (1): 9-10, 1977.

67. Sargent JD, Green EE, Walters ED: Preliminary report on the use of autogenic feedback training in the treatment of migraine and tension headache. Psychoson Med 35:129-135, 1973.

68. Frazier SH: Psychotherapy of headache. In Friedman AP (ed). Research and Clinical Studies in Headache, Vol 3, Basel. S Karger AG, 1972, pp 194-220.

69. Friecian AP: Migraine: An Overview, in Pearch $J$ (ed), Modern Topics in Migraine. London, William Heinemann Med Books Ltd. 1975. $\mathrm{PP}$ 159-167. 


\section{DIZZINES S AND DISORDERS OF EQUILIBRIUM - PANEI 8}

David A. Drachman, MD (Chafrman), Ronald I, Apfelbaun, RD, and Jerome B. Posner, $\mathrm{ND}$

During the operation of an aircraft, disorders of equilibrium may interfere with the capacity of air crew members to control the aircraft In either of two ways: through the abrupt occurrence or recurrence of episodic dizziness or disequilibriun in an individual whe is normal at other times; ${ }^{1}$ or, through $a$ continuous state of disequilibrium without episodic changes. In either case, dizziness or disequilibrium may prevent accurate control of the aircraft during waneuvers requiring a high degree of perceptual accuracy, such as takeoff, landing, inflight attitudinal changes, instrument flight, etc. The considerations for evaluation of air crew fitness, the predictability of incapacitation, and the consequences of each type of disequilibrium on aircraft control may be quite different. ${ }^{2}$

Entry of air crew members into the following disequilibrium protocol may occur in several circumstances:

1. complaints of dizziness, vertigo, or light-headedness

2. complaints of loss of balance

3. observations by others of episodic or persistent impairment of balance

\section{CLASSIFICATION OF DISORDERS OF EQUILIBRIUM}

Differentiation among the possible causes of disequilibrium and dizziness is often the most difficult aspect of medical managerent. 3 Table I shows the classffication of disorders resulting in disequilibrium and will be used as the framework for discussion. Special laboratory procedures which are of value in assessing disorders of equilibrium are listed in Table 2.

\section{DISORDERS PRODUCING SUDDEN EPISODIC DIZZINESS/DISEQUILIBRIUM}

Vertiginous Disorders - Many conditions may produce subjective complaints of rotation, either of the patient or of the environment. Some are due tc disorders of the peripheral vestibular system, while others axe due to central nervous system (CNS) involvement. While in many cases history alone is suggestive of the correct diagnosis, it is critical to perform a neurologic examination in every case. Peripheral vestibular disorders can be diagnosed confidently only in the absence of eviánce indicating cranial nerve, cerebellar, corticospinal tract, or other brain stem involvement. As appropriate, other stuit ss that should be obtained to distinguish among the vertiginous disorders include CT scan, audiometry, electronystagmngraphy (ENG), and petrous polytomography; and in selected cases, lumbar punsture, and auditory and/or visual evoked responses (Table 2).

Vestibular Disorders -

Benign positional vertigo (BPV) -- This is a true rotational sensation, accompanied by nystagmus, and occuring only on change of head position. 10-13 The "Nylen-Barany" (Hallpike-Dix) maneuver characteristically precipitates the vertigo and nystagurs, which occur after a latent period of several seconous 
TABLE T

I. DISORDERS PRODUCING SUDDEN EPISODIC DIZZINESS/DISEQUILIBRIUM

1. Vertiginous disorders

A. Vestibular disorders

1) Benign positional vertigo

2) Acute peripheral vestibulopathy

3) Acute and recurrent peripheral vestibuiopathy

4) Meniere's aisorder

5) Alternobaric (dysbaric) vertigo

6) Momentary vertigo with hyperactive labyrinths or labyrinthine imbalance

B. Central disorders

1) Transient ischemic attacks

2) Multiple sclerosis

3) Brain stem migraine attacks

4) Vertiginous epilepsy

5) Cerebellopontine angle tumors

2. Hyperventilation syndrome

3. Syncopal events

1) Orthostatic hypotersion

2) Cardiac arrhythmias

3) Hypersensitive carotid sinus

4) Tasovagai syncope

5) Hypogiycemia

4. Acute psychiatric disorders (panic states)

II. DISORDERS PRODUCING CHRONIC DISEQUILIBRIUM

1. Vestibular disorders

A. Nonfuncticning labyrinths

B. Vestibular imbalance

2. Multisensory dizziness

3. Central disorders of equilibrium

1) Frontal lobe disease (Alzheimer's disease, CVA, NPH, etc.)

2) Cerebellar ataxia

3) Extrapyramidal disorders (Parkinson's disease, dystonia, etc.)

4) Congenital nystagmus with oscillopsia

4. Drug effects

A. Drugs to control dizziness

B. Drugs producting dizziness 
TESTS USEFU IN THE DIAGNOSIS OF DIZZINESS/DISEQUILIBRIUM

1. Radiological studies

a) Skull x-rays with Stenver's views

b) Polytorography of the petrous bones

c) CT scan

d) Cervical spine $x$-rays (six views)

2. Neuro-otologic tests

a) Electronystagmography 4-7

b) Audionetry (site of lesion) 8

c) Evoked response audiometry

3. Neuro-ophthalmologic evaluation

a) Routine evaluation

b) Vestibular-ocuiar testing, or head-shaking visual acuity

c) Visual evoked response

4. Five-hour glucose tolerance test

5. Psychometric testing; psychlatric evaluation

6. Thyroid function tests

7. Holter monitoring

8. (A) Noninvasive cerebrovascular studies
a) Oculoplethysmography
b) Suction ophthalmodynamometry
c) Phonoanglography
d) Doppler flow studies

(B) Four-vessel cerebral ankiography

9. Blood gases and $\mathrm{pH}$

10. Peripheral nerve conduction velocities

11. Electroencephalography

12. Others
a) Protein electrophoresis, insunoelectrophoresis
b) Platelet aggregabllity
c) Lipid profile
d) $\mathrm{CBC}_{\text {g }}$ serology; PA chest; etc.
e) Regular medical workup 
and are accompanied by symptoms of subjective rotation, often with nausea and occasionally vomiting. The nystagmus is rotatory or horizontal and beats in the same direction regardless of head position. The vertigo and nystagmus are transient, lasting less than a minute, and decrease in severity on zepeated positional maneuvers. Although in many vertiginous disorders, both peripheral and central, exaggeration of vertigo may be produced by change of head position, it is the exclusive occurrence of vertigo on positional testing which characterizes this condition. 0ther peripheral and central vertiginous disorders should be zijed out using the approprlate tests. Although this condition is most frequently either idiopathic or caused by head trauma, rarely it may be associated with a vascular, demyelinating or space-occupying lesion of the posterior fossa.

The course of BPV is variable. In some cases, there is only a single transient attack and the condition cannot be reproduced thereafter. Other patients have a bout of BPV lasting several months, during which tiue vertigo can be regularly reproduced by assuming the provocative head position. Some patients have a persistent susceptibility to BPV, while in others BVP may subside after several weeks or months, only to recur some months later.

Recommendations -- During a bout of BPV, when position change provokes vertigo and/or nystagmus, the pilot should not be allowed to fly. If, following a sustained bout of 24 hours or longer, the pilot is free of positional vertigo for a year with full recovery, including position testing with ENG, he may return to flying. In recurrent forms, or with continuous episodes of BPV, permanent grounding is recommended.

Acute Peripheral Yestibulopathy (APV); Acute and Recurrent Peripheral Vestibulopathy (ARPV); and Meniere's Disorder - These three entities share in common the occurrence of spontaneously developing bouts of vertigo. Meniere's disorder is defined by an accompanying hearing loss and tinnitus, sometimes with auditory recruitment and diplacusis, which may precede or follow the development of episodic vertigo.14-19

APV is distinguished from ARPV by the occurrence of multiple episodes of vertigo in the latter group. 14 This distinction is somewhat artificial and is best made retrospectively, since many of the patients with APV will have additional attacks within one or several years. The terms, "vestibular neuronitis," "acute labyrinthitis," and others, have been used elsewhere for these conditions. $20-24$

Vertigo may last from minutes to days in these disorders, but usually lasts for hours. Nausea, vomiting, and severe prostration may accompany the disorders. Residual impairment of vestibular function often develops producing a state of chronic disequilibrium which is particularly noticeable when the patient is in motion.

Recurrent episodes of vertigo as well as persistent vestibular imbalance with disequilibrium may occur in patients with these disorders. The rate of recurrence of vertiginous episodes is high in ARPV and fieniere's disorders. About haif of those with APV may have a recurrence within several years. 
Recomeendations -- Pilots with any of these conditions should not be permitted to fly, with one exception: those who bave had APV, have been free of aymptoms for at least a year, and have ao restdual impairment of balance on neurologic examination or significant abnormality on ENG may be permitted to return to flying. The recurrence rates of vertiginous episodes in ARPV and Meniere's disorder ordinarily preclude return to figing.

In patients who have been free of recurrent episodes of vertigo for three years, or whe have been free of vertigo for two years following appropriate surgery, return to flying status may be considered. Because of the possible loss of vestibular sensation due to the natural course of the disease or surgery, these Individuals should be tested for appropriate performance in a flight simulatur.

Alternobaric Vertigo -- In this comon condition, vertigo occurs on change of pressure, often after a forceful Valsalva maneuver to clear the patient's ears, and is accompanied by oscillopsia and often nystagmus. $25-28$ The diagnosis is established by reproducing the patient's symptoms in a pressure chamber during per "ormance of a forceful valsalva maneuver. This form of vertigo is ofien a ssociated with obstruction of the eustachian tube due to adenoidal hypertrophy.

Recommendations -- Pilots, who have untreacied alternobaric vertigo should not be permitted to fly. However, when the underlying condition can be demonstrated to be due to eustachian tube compression by adenoidal hypertrophy, the condition has been surgically repajied or has resolved, and episodes no longer can be reproduced in a presstis chamber, the pilot may be allowed to resume flying.

Momentary Vertigo with Hyceractive Labyrinths or Labyrinthine Imbalance - Occasional individuals may complain of momentary vertigo, lasting from an instant to less than five seconds, which occurs with turning or changing positions. 14 Such individuais may show either hyperactive responses on caloric testing or unilateral vestibular weakness. On ENG, slow phase velocity speeds greater than $50 \%$ sec with cool irrigations, or $80 \%$ sec with warm irrigations, indicate a hyperactive response. A difference, of more than $20 \%$ in the total caloric responses between the two ears indicates a unilateral weakness. 4 Patients with labyrinthine imbalance may also have persistent disequilibrium or other complaints; the consequences of these symptoms are discussed elsewhere.

Recommendations - - When minimal symptoms of vertigo last less than a few seconds and do not produce significant disorientation, as is usually the case with these conditions, they should not restrict pilots' flying capability. However, each case must be judged according to degree of vertigo and disability produced. Testing in a flight simulator, or under actual flight conditions, may be helpful in reaching a decision.

Central pisorders - This group of disorders includes diseases of the cerebral hemispheres, brainstem, and intracranial portion of the eighth cranial nerve, which may produce acute and/or episodic vertigo or disequilibriam. 
Transient ischemic attacks (TIA) - A TIA is an acute, reversible loss of neurological function lasting less than 24 hours, often caused by emboli from the heart or great vessels. 29 Acute vertigo and disequilibrium are symptoms which are said to occux with the TIAs originating primarily from the basilar-vertebral artery circulation. 30 TIAs of ten recur unpredictably and may presage a cerebral or brainstem infarction, which occurs days to yaars after the first TIA. 31 In the great majority of patients with brainstem TIAs, damage to neighboring structures will produce neurologic symptoms or signs in addition to vertigo, facial weakness or numbness, diplopia, dysarthria, or cerebellar dysmetria. These findings distinguish brainstem TIAs from peripheral vestibular lesions. The diagnostic workup should include noninvasive cerebrovascular studies including those of platelet functions, and in certain cases, four-vessel cerebral arteriography.

Recommendations -- A patient suffering one or more TIAs as defined above should be disqualified from flying, pending diagnostic workup and treatment. Several reports indicate that attacks can be controlled by surgical extirpation of offending lestons, 32 by anticoagulant therapy, 31 or by antiplatelet drugs. 33 The conditions and the criteria for return to flight status are discussed in the statement on cerebrovascular disease.

Multiple Sclerosis (MS) - This is a disease of the white matter of the brain, which can produce acute vertigo or disequilibrium of sudden onset and occasionally can produce recurrent attacks. 34 The criteria for establishing this diagnosis are defined in the statement on common demyelinating and degenerative diseases.

Recommendations -- Because there is no effective treatment for this disorder, and because attacks of severe disabling vertigo can occur suddenly and at any time, patients in whom this diagnosis is established by appropriate diagnostic criteria, and who have previously experienced vertigo, should be disqualified from flight status, regardless of their signs or symptoms at the time of examination.

Brainstem migraine attacks -- Acute migraine involving vessels of the brainstem ran produce acute and recurrent vertigo, disequilibrium, and loss of vision. 35 The diagnosis is established by appropriate history and physical examination, as defined in the statement on headache.

Recommendations-- The patient should be withdrawn from flight status until full examination is completed. Various drugs have been reported to prevent the recurrence of migraine attacks in a substantial number of patients. 36 Patients suffering from basilar artery migraine should not be permitted to $\mathrm{fly}$, as detailed elsewhere.

Verfiginous epilepsy - Focal cortical seizures originating in the superior temporal gyrus can produce acute vertigo followed by unconsciousness, with or without generalized convulsious. 37,38

Recommendations -- Patients suffering from vertiginous epilepsy should be withdrawn from flight status pending complete neurologic diagnostic workup. Because seizures can occur at infrequent and unpredictable intervals, even when patients are receiving medical treatment, those suffering from vertiginous epilepsy should be permanently withdrawn from flight status. 
Cerebellopontine angle tumors - These tumors are generally benign lestons involving the eighth nerve, and they produce loss of vestibular function unilaterally. Clinical findings include loss of hearing, factal weakness, facial sensory loss, and ipsilateral cerebellax signs. Petrous polytomograms and CT scan often reveal the invading tumor in the internal auditory aeatus.

Recomendations - Patients with a cerebellopontine angle tumor should undergo neurosurgical removal of the lesion. Studies of the long-term effects of acoustic neurinoma surgery show, however, that standarized batteries of postural equilibrium tests may be abnomal for periods of at least two years after operation. 39 Since abnormalities on such tests may lead to acute vertiginous episodes or loss of equilibzim under vestibulat stress, return to flight status should not be considered until a full battery of tests of equilibrium and vestibular function are carried out, including ENG. If the tests are normal and the extirpated tumor was benign, the individual should be allowed to return to flight status.

Hyperventilation Syndrome - Episodes of acute hyperventilation can occur abruptly in patients with or without a preexisting history of psychiatric disease or severe anxiety. 40 The etiology of the hyperventilation in most instances appears to be enotional, and accoupanied by an acute lowering of $\mathrm{CO}_{2}$ tension in the blood, which in turn reduces cerebral blood flow. Resulting symptoms include dizziness, faintness, positional vertigo, paresthesias of the extremities, and frequently, chest pain. 41 It is rare for patients with scute hyperventilation to lose consciousress, but if the hyperventilation is dccompaied by Valsalva maneuver, syncope azy occur. A patient believed to be suffering from an acute hyperventilation attack must undergo complete general physical and neurologic evaluation, 42 to rule out organic disease of the nervous system and to demonstrate that the symptoms are produced by voluntary hyperventilation.

Recommendations - Patients should be withdrawn from flight status pending rull neurologic ano psychiatric evaluation. If the underlying cause for the hyperventilation is discovered, it should be treated, and the success of treatment of the underlying cause should determine return to flight status. If no underlying cause is found for the hyperventilation, a single attack should not be disqualifying. Repeated attacks of hyperventilation symptomatology should be disqualifying.

Symcopal Events - Orthostatic hypotension, Cardiac arrhythmias, Hypersensitivity of the carotid sinus, Vasovagal syncope-

These conditions have in common a sensation of faintness or impending loss of consciousness. $43-46$ The sensation is typicasiy accompanied by dim vision and a fading awareness of the enviromment and may proceed to actual loss of consclousness. The differentlating charzcteristics anong these four syncopal events are primarily the circumstances under which they may occur: orthostatic hypotension occurs on assuming and maintaining an upright position; cardiac arrhythmias develop abruptly without precipitating events but accompanied by palpitations; carotid sinus hypersensitivity begins upon turning or roving the tead; and vasovagal syncope usually follows a frightening or enotion-filled situation.

The diagnosis of orthostatic hypotension is established by observing the parient's blood pressure in a supine and standing posicion: a fall of $25 \mathrm{rm} \mathrm{Hg}$ 
systolic and 15. Hg diastolic, accomanted by faintness, Indicates the disgnosis. Evidence of cardiac arrhythia may require 24-hour Holter nonitoring, although in some cases the arrhytheila is evident upon cardiac examination or routine electrocardlogram. Unilateral stimulation of the carctid sinus for ten seconds will produce significant slowing of the pulse and symptons of faintness in susceptible individuals. Vasovagal syncope is wre difficult to identify, except by exclusion.

Recomendations -- Syncopal episodes of any etiology resulting in actual loss of consciousness may recur at unpredictable intervals and disable the pilot abruptly and without warning. P1lots with any of these conditions should be disqualified from flying. When the eplsode does not produce complete loss of consciousness but is perceived as dizziness or impending loss of consctousness, disposition should depend on the underlying cause and the degree $0^{\prime}$ disability. Cardiac arrhythmias and carotid sinus hypersensitivity have been judged elsewhere to be disqualifying. Vasovaga? syncope and orthostatic hypotension should be addressed in terms of the underlying cause and the likelihood of recurrence.

Hypoglycemia -- Lowering of blood sugar elther at a rapid rate or below a critical level ( $40 \mathrm{mg}$ ) may produce feelings of faintness and confusion associated with diaphoresis and tremulcusness. In sone patients, this may occur only following a large load of glucose (reactive hypoglycemia), while In others with islet cell adenoas it asy follow prolonged fast. A five-hour glucose tolerance test reveals reactive hypoglycenta, while a blood sugar deternination following a prolonged fast may reveal hypoglycemia due to excessive insulin secretion. Finally, diabetics using insulin or other hypoglzcenfic agents may also experience hypoglycenia.

Recomendations - P1lots with uncontrolled hypoglyciomic episodes should not be pernitted to fly. Reactive hypoglycenia can ordinarily be controlled with an appropriate diet; and islet cell adenomas may be surgically removed or treated with streptozocin. 47 If hypoglycemia is under control, the pllot ay be permitted to return to flyting at the discretion of a physician with special expertise designated by the Federal Air Surgeor.

Acute psychiatric disorders (panic states) --During an acute anxiety attack, 48 patients experience sweating, techycardia, hyperventilation, and confusion. At times they may refer to this complex of symptors as "dizziness," perhaps secause of their own distortion of sensations and the effects of hyperventilation. The diagnosis depends upon a firsthand report of the patient's appearance and actions during the episode; when possible, identifying a precipitating event is useful. Psychiatric eveluation should be obtained, and a psychometric test battery may be of value.

Recosmendations - - Individuals who suffer a single panic state under extenuating circunstances may be pernitred to $\mathrm{fly}$, if it is clear that the precipitacing circunstances no longer exist. Recurrent panic states shculd be evaluated psychiatrically and an require prolonged grounding. 


\section{DISORDERS PRODUCING CHRONIC DISEQUILIBRTUA}

\section{Vestibular disorders}

Nonfunctioning labyrinths - Harked bilateral vestibular hypoactivity or absence of function 14,49 way result from the use of aninoglycoside antibiotics such as streptconycin and gentanicin, or aay occur without known cause. Symptors include unsteadiness of gait and loss of orientation, particularly in the dark, and inability to maintain sccurate visual fixation when the patient is in ootion, for example, while walking or turning the head. Caloric testing with EnG recording will reveal marked decrease in labyrinthise response. In addition, the "yestibulo-ocvlar visual acuity" will decline: ie, the patient's visual acuity will fall markedly when the patient attempts to read a visual acuity chart while shaking the head from side to side.

Recomendations - Pilots with severely hypoactive or nonfunctioning labyrinths should not be permitted to fly. When there is preservation of sone vestibular function, the vestibulo-ocular acuity nay be a critical determining factor in deciding whether or not spatial orientation is sigaificantiy impaired. Testing in $a$ flight simulator may be helpful.

Vestibular Imbalance - Patients with this condition, which nay be a sequel of previous vestibulopathy in sone cases, 14 way experience feelings of unsteadiness on rapid change of position. Walking and turning say precipitate a feeling of vague dizalness. Diagnosis is confictred by caloric testing, which reveals a significant difference between the responsas of the twc ears and a unilateral vestibular weakness. 4-7

Recowendations -- This is described earifer under "monentary vertigo." Some patients with nomentary dizziness upon changing head position are not significantly iandicapped, while others may be. Evaluation for flying fitness way require the use of a flight simulator or in-flight testing.

Kuiltisensory Dizziness - This is a feeling of loss of balance or Iightheadedness noted in patients with multiple sensory disorders, including two or wore of the following: peripheral neuropathy, vestibular imbalance, visual impaiment, cervical spondylosis, or hearing loss. 3 , 14 The more areas of sensory impairment that exist, the more disequilibrium will occur, particularly on motion or change of position. This condition is diagnosed by finding evidence of impairwent in the areas described.

Recomendations - Pilots with sigaificant disability due to this form of dizziness should not be permitted to $\mathrm{fly}$, becanse of severe spatial disorientation under conditions of motion.

Central disorders of equilibrium -- Central disorders of equilibrium represent a variety of diseases of the brain and brain stew which produce chronic but stable abnormalitles of vestibular or cerebellar function. The specific illnesses include:

1. frontal lobe disease, normal pressure hydrocephalus, Alsheiner's disease, cerebrovascular accident, etc.

2. cerebellar atazia

3. extrapyramidal disorders, Parkinsonism, dystonia, etc.

4. congenital nystagurus with oxcillopsia 
Recomendations - Any disease producing chronic frontal lobe dysfunction, cerebellar ataxia, or extrapyranidsi disorders, other than benign esseatial rrewor or congenital ailinal choreonthetosis, should disqualify the pilot from flight status. Patients suffering from benign essential trewor or congenital inisal choreoathetosis should be withdrawn from filght status, pending complece general physical examination and aeurologic evaluation. If It can be established that the condition is stable, nonprogressive, and not currently interfering with neurologic function, the pilot should be resurned to flight status. Patlents suffering from congenttal nystagmus with oscillopsia should be disqualified from flight status.

Brugs to control diziness- Kany of the medication used to control dizziress and vertigo, such as the anticholinergics, scopolatine and atropine, and the antihistantnics, meclizine and diphenhydramine, often produce drowsiness as a prominent side effect. In other forms of dizziness, tranquilizers and antidepressants be used, smong others. Agents for the control of arrhythmias and hypotension ay also be employed. $50^{\circ}$

Recomendations - The need for an individual to remain fully alert and capable of operating an aircraft under all circunstances should be taken into account when considering drugs used to control dizziness. The side effects of each drug, particularly on the individual pilot, nust be considered by an exawiner designated by the Federal Air Surgeon, before the pilot may use then while fiying.

Other drugs producing dizziness - Dizziness is a reported side effect of drugs of almost every category.

Recommendations - The physician must make an individual decision regarding the effects on balance and spatial orientation of medications taken by a pilot.

Discussion - In the preceding classification, an attempt is made to identify two categories of disorders of equilibrium: those producing sudden episodes and those producing continuous states of disequilibrium. Obviously, the first steg in determining pilot fitness is the identification of the underlying condition. Yet, in both the episodic and the continuous disequilibrium disorders, there are difficulties in establishing firm criteria for pilots.

Among the episodic disorders, the rates of recurrence, and therefore the probabilities of sudden occurrence of disabling disequilibrium, are often unclear-for example, in patients wth bentgn positional vertigo in remission, or in those who have apparently recovered frat acute peripheral vestibulopathy. It would be valuable to collect data systemically, using the classifications in this report, to pernit more accurate prediction of recurrence rates of episodic disequilibrium.

Among the disorders producing continuous disequilibrium, the severity way vary from minor annoyance to fajor spatial disorientation because of such entities as labyrinthine imbelance. Because of these variations in degree, and the difficulty in predicting the extent to which they will interfere with pllot perforance, the use of a flight simulator, or actual in-flight testing, should supplewent the data for, and odify any, medical fitness decision. 
Since these conditfons are continuously present, and therefore predictable, It should be possible to assess pilot performance in the face of a demonstrable degree of neurologic and/or vestibular deficit.

Further, it is slear the classiflcation and assessment of disorders of equilibrium in pilots should be undertaken only by individuals with special expertise in the appropriate areas of reurology and neuro-otology.

For these reasons the following general procedures are recomended:

1. Designation of specific individuals or centers equipped to evaluate pilots who have dizziness or disorders of equilibrium

2. Development of a system for accumulating inforwation regarding the long-term prognosis in disorders of equilibrium

3. Use of flight simulation or in-flight testing in persons with continuous disorders of equilibrium, where there is a serious difference of opinion regarding ability to maneuver aircraft under realistic conditions of flight 


\section{REFERENCES}

1. Brown FH: Vertiginous flyer: A review of six years experience of the aeromedical consultation service. Aerospace Medicine 1971, pp 891-893.

2. Orlady HW: Operational aspects of pilot incapacitation in a multicrew airliner. Asmer J Cardiol 36:584-588, 1975.

3. Drachman DA: Dizziness and vertigo, in Beeson PB, McDermott $W$ (eds): Textbook of Medicine, ed 14. Philadelphia, WB Saunders Co: 1975, pp 621-626.

4. Barber Ho, Stockwell CW: Manual of Electronystagmography. St Louis, CV Mosby Co, 1976, p 207.

5. Korres S: Electronystagmographic criteria in neuro-otological diagnosis. J Neurol, Neurosurg \& Psychiat 41:249-253; 254-264, 1978.

6. Eviatar A: Interpretation of electronystagmographic results. Laryrgoscone 1972, pp 1059-1067.

7. Baloh RW, Sills AW, Honrubia V: Caloric testing: III. Patients with peripheral and central vestibular lesions. Acta 0tol Rhinol Laryngol 86 (suppl 43) 24-30, 1977.

8. Rose DE (ed): Audiological Assessment. Englewood Cliffs, PrenticeHall, Inc, $1971, \mathrm{p} 530$.

9. Davis H: Principles of electric response audiometry. Annais Otol Rhirol and Laryngol (supp1 28) 85:1-96, 1976.

10. Harrison MS: Benign positional vertigo, in Wolfson, RJ (ed): The Vestibular System and the Diseases. Philadelphia, Uriversity of Pennsylvania Press, 1966, PP 404-427.

11. Schukneckt HF: Cupulolithiasis. Arch Otolaryng 90:113-125, 1969.

12. Fernandez CAR: Positional vertigo. Acta Otolaryngol (Supp1) $192: 61,1964$.

13. Harrison MS, Ozsahinoglu C: Positional vertigo. Arch Otolaryngol 101:675-678, 1975.

14. Drachman DA, Hart CW: An approach to the dizzy patient. Neurology $22: 323-334,1972$.

15. Williams HL: Meniere's Disease. Springfield, Ill, Charles C Thomaa Co. 1952. 
16. Harrison MS, Naftalin L: Meniere's Disease. Springfield, I1l, Charles C Thomas Co, 1968, pp 1-226.

17. Pulec JL (ed): Meniere's Disease. Philadelphia, WB Saunders Co, 1968.

18. Drachman DA: Meniere's disease, in Cona $\mathrm{H}$ (ed): Current Therapy. Philadelphia, WB Saunders Co, 1973, pp 686-690.

19. Haye R, Quist-Hanssen SV: The natural course of Meniere's disease. Acta Otolaryngol 82:289-293, 1976.

20. Coats AC: Vestibular neuronitis. Asta Otolaryngol (supp1 25i) 1969 in 5-32.

21. Lachman $J$, Stahle $J$ : Vestibular neuritis: A clinical and electronystagmographic study. Neurology 17:376-380, 1967.

22. Stahle J: Vestibular neuritis, in Wolfson, RJ (ed): The Vestibular System and the Diseases. Philadelphia, University of Pennsylvania Press, 1966.

23. Drachman DA: Episodic vertigo in Conn HF (ed): Current Therapy. Philadelphia, WB Saunders Co, 1974, pp 684-688.

24. Spector M (ed): Dizziness and Yertigo. New York, Grune and Stratton, 1967 , p 299.

25. Enders LJ, Rodriquez-Lopez E: Aeromedical consultation service case report: Alternobaric vertigo. Aerospace Medicine :200-202, 1970.

26. Lundgren CEG: Alternobaric vertigo: A diving hazard. Brit Med $\mathrm{J}_{1} 1965$.

27. Lundgren CEG, Malm LU: Alternobaric vertigo among pilots. Aerospace Medicine, 1966.

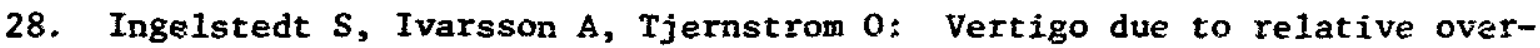
pressure in the middle ear. I. An experimental study in man. Acta Dtolaryng $78: 1-4,1974$.

29. Millikan $\mathrm{CH}$ : The pathogenesis of transient focal cerebral ischemia. The Lewis A. Conner Memorial Lecture. Circulation 32:438-450, 1965.

30. Fisher CM: Verrigo in cerebrovascular disease. Arch Otolaryng 85:529-534, 1967. 
31. Whisnant JP, Matsumoto N, Elveback IR: The effect of anticoagulant therapy on the prognosis of patients with transient cerebral ischemic attacks in a community. Rochester, Minnesota, 1955 through 1969. Mayo Clinic Proc 43:844-848, 1973.

32. Bauer RB, et a1: Joint study of extracranial arterial occlusion: III. Progress report of controlled study of long-term survival in pa:ients with and without operation. JAMA 208:590-618, 1969.

33. Fields WS, et al: Controlled trial of aspirin in cerebral ischemia. Stroke 8:301-316, 1977.

34. Osterman PO, Westerberg CE: Paroxysmal attacks in multiple sclerosis. Brain 98:189-202, 1975 .

35. Lapkin ML, Golden GS: Basilar artery migraine. A review of 30 cases. Amer I Dis Child 132:278-281, 1978.

36. Mondrup K, Moller CE: Prophylactic treatment of migraine with clonidine. A controlled clinical trial. Acta Neurol Scandinav 56:405-412, 1977.

37. Currie $S$, et al: Clinical course and prognosis of temporal lobe epilepsy. A survey of 666 patients. Brain 94:173-190, 1971.

38. Hughes JR, Drachman DA: Dizziness, epilepsy, and the EEG. Dis Nerv System 38:431-435, 1977.

39. Nelson JR: Long-term effects of acoustic neuroma surgery. Arch Otolaryngol $88: 675-686,1968$.

40. Engel GL, Ferris EB, Logan M: Hyperventilation: Analysis of clinical symptomatology. Ann Intern Med 27:683, 1947.

41. Wheatley CE: Bypervertilation sysdrone: A frequent cause of chest pain. Chest 68:195-199, 1975.

42. Kiely JM: Organic disease presenting as hyperventilation synorome. Psycinosom 4:326-329, 1970.

43. Hughes RC, Cartlidge NEF, Millac P: Primary neurogenic orthostatic hypotension. I Neurol, Neurosurg and Psychiat 33:363-371, 1970.

44. Chokroverty S, et al: The syndrome of primary orthostatic hypotension. Brain 92:743-768, 1969.

45. Sobel BE, Braunwald E: Cardiac dysrhythmias, in Thorn GW, et al (eds): Principles of Internal Medicine. New York, McGraw Hill Co, 1975, pp 1187-1206. 
46. Noble RJ: The patient with synoope. JAMA 237:1372-1376, 1977.

47. Freinke1 N: Hypoglycemic disorders, In Beeson PB, McDermott W (eds): Textbook of Medicine. Philadelphia, WB Saunders Co, 1975, pp 1619-1624.

48. Adans RD, Victor $\mathrm{H}$ : Principles of Neurology. New York, McGraw-Hill, 1977, P 342 .

49. Schuknecht HF: Pathology of the Ear. Cambridge, Mass, Harvard University Press, 1974, Pp 273-288.

50. Goodman L, Gilman A (eds): The Pharmocologic Basis of Therapeutics, ed 5. New York, MacMillan Publishing Co, 1975. 
Index of Conditions

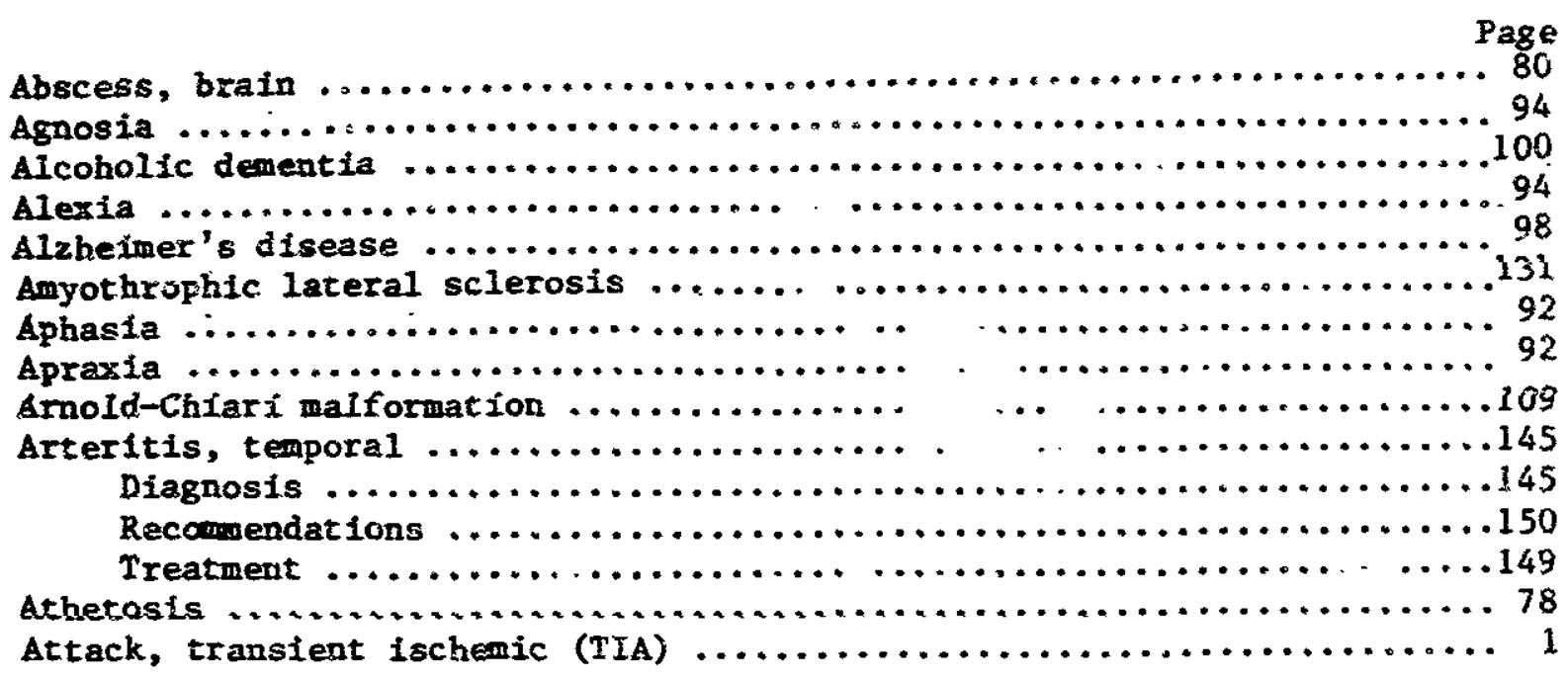

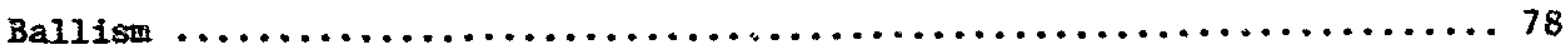

Cerebrovascular disease $\ldots \ldots \ldots \ldots \ldots \ldots \ldots \ldots \ldots \ldots \ldots \ldots \ldots \ldots \ldots \ldots \ldots \ldots$

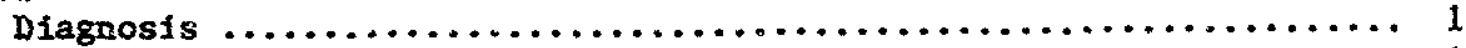

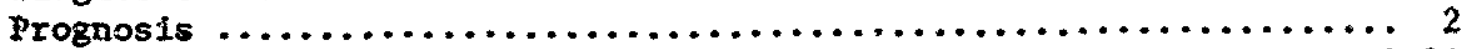

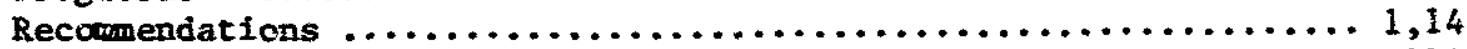

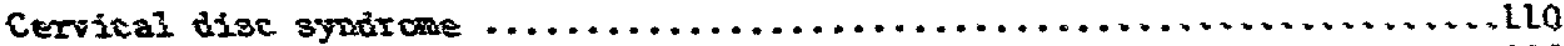

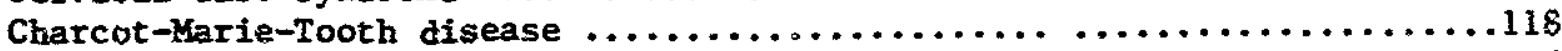

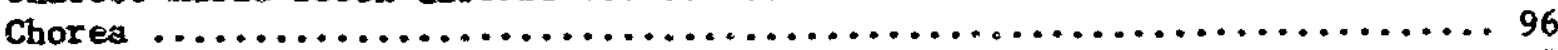

Creutzfeldt-Jakob disease $\ldots \ldots \ldots \ldots \ldots \ldots \ldots \ldots \ldots \ldots \ldots \ldots \ldots \ldots \ldots \ldots . \ldots 9$

De La Tourette, Gilles syndrome $\ldots \ldots \ldots \ldots \ldots \ldots \ldots \ldots \ldots \ldots \ldots \ldots \ldots \ldots \ldots 77$

Dementia, presenile, metabolic $\ldots \ldots \ldots \ldots \ldots \ldots \ldots \ldots \ldots \ldots \ldots \ldots \ldots \ldots . . \ldots 9,99$

Denyelinating conditions, post-infectious $\ldots \ldots \ldots \ldots \ldots \ldots \ldots \ldots \ldots$. $\ldots \ldots \ldots$

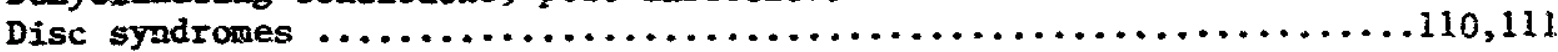

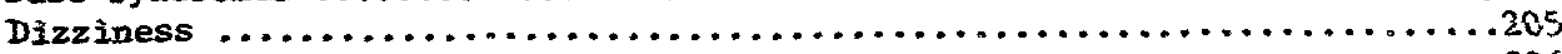

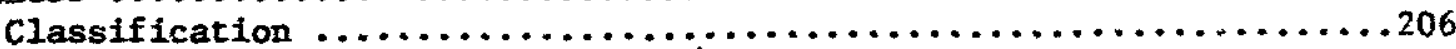

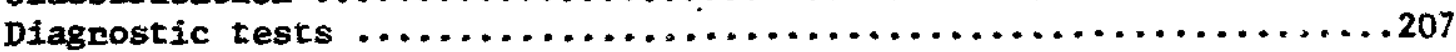

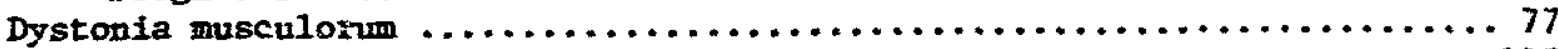

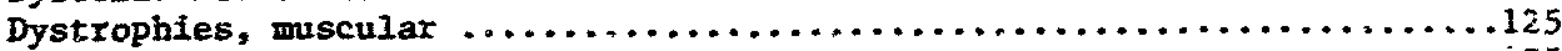

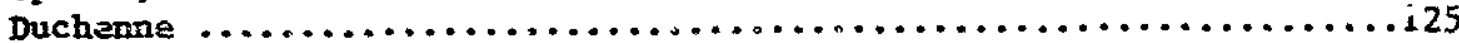

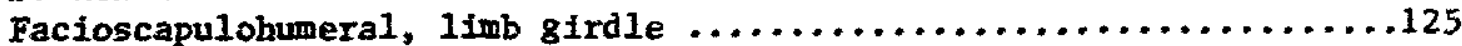

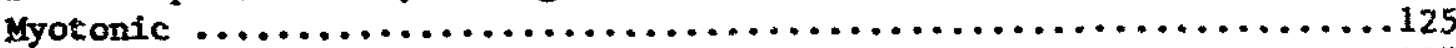

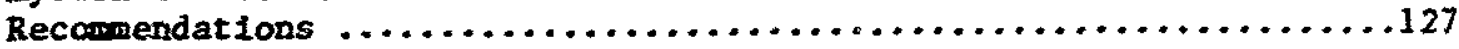

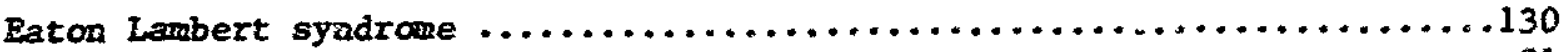

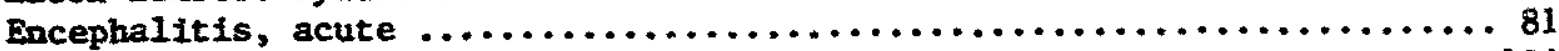

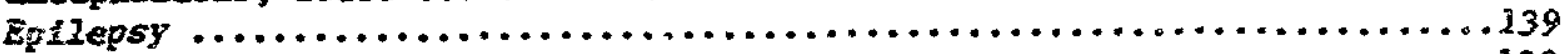

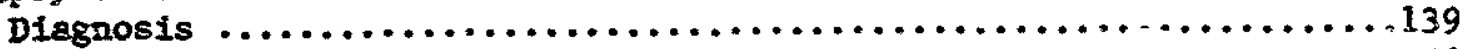

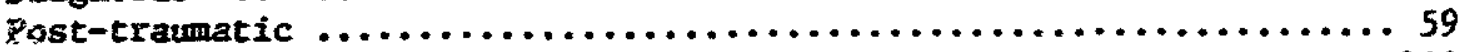

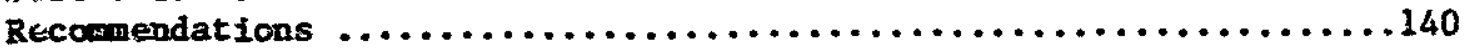

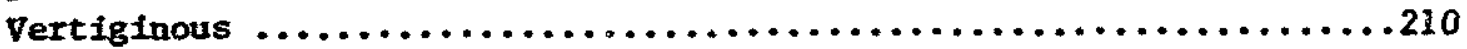

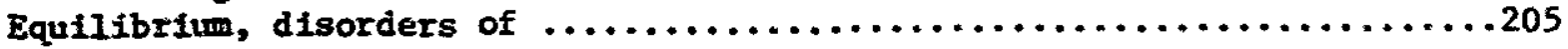

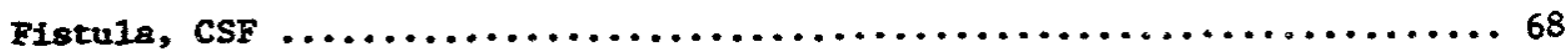




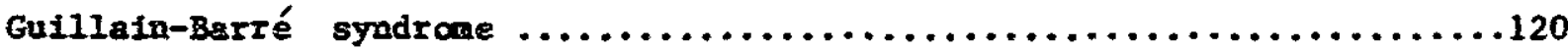

Headache

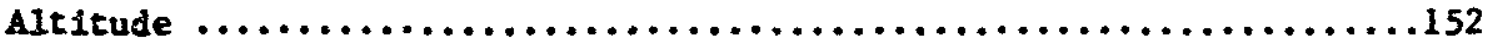

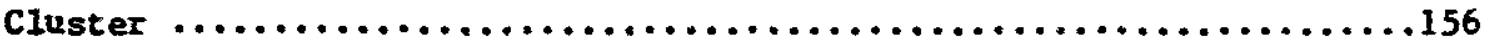

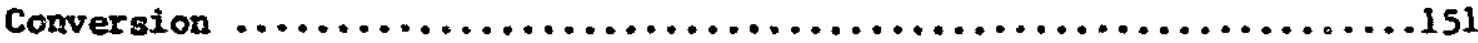

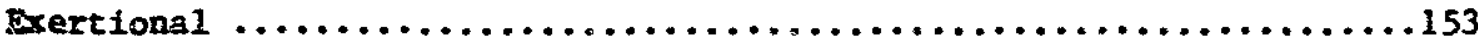

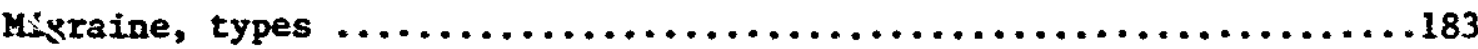

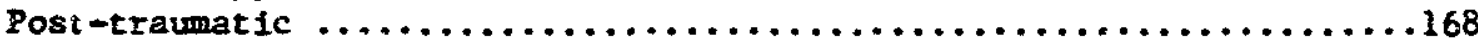

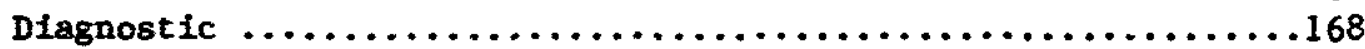

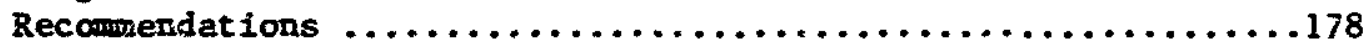

Tension, acute and chronic .........................149,150

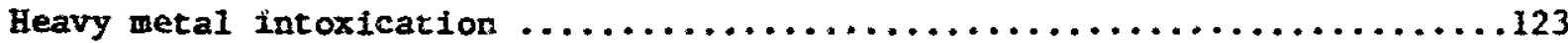

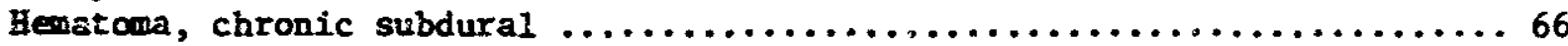

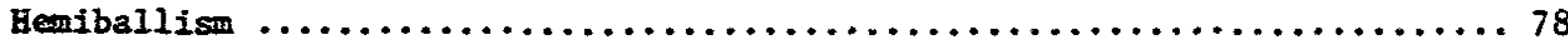

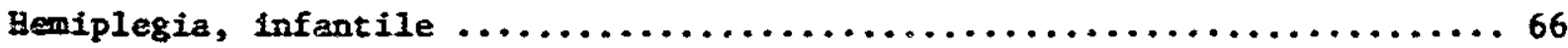

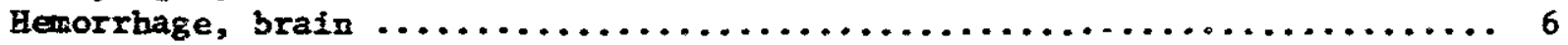

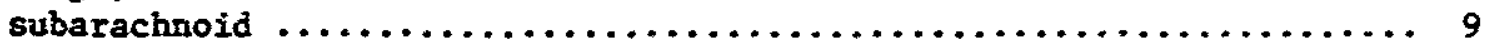

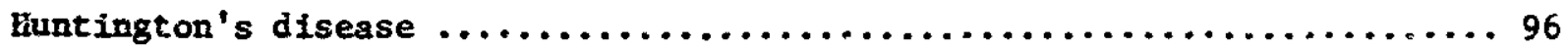

Hydrocephsius, normal pressure (occult) $\ldots \ldots \ldots \ldots \ldots \ldots \ldots \ldots \ldots \ldots \ldots 6,97$

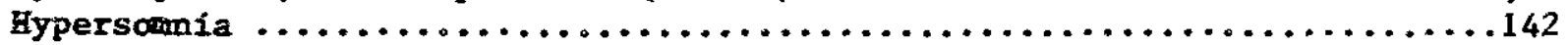

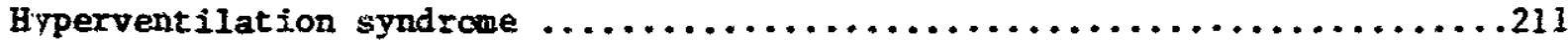

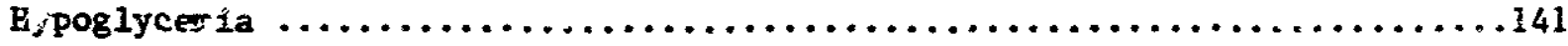

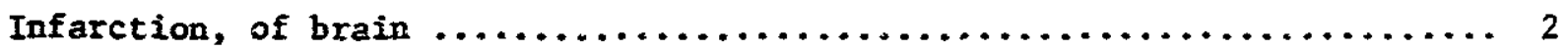
Injuries

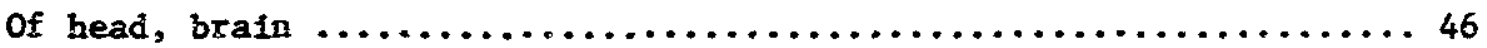

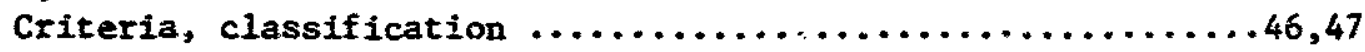

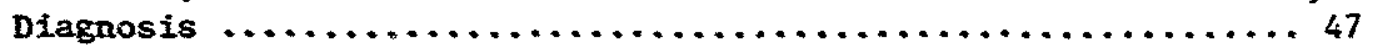

Epilepsy, post-traumatic .......................... 59

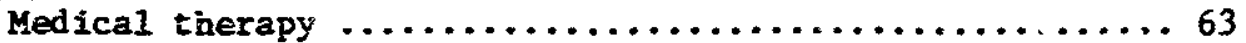

Reccmendations ........................... 64

Mental, neuropsychologic disorders after .............. 54

Post-traumatic syndrone ......................... 50

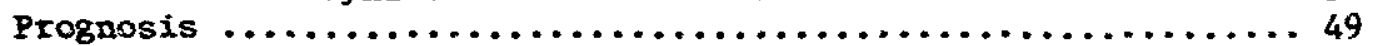

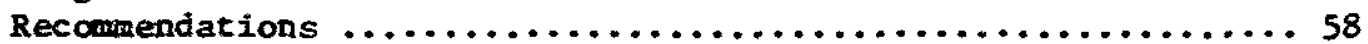

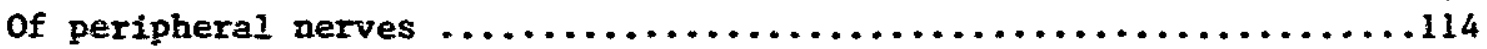

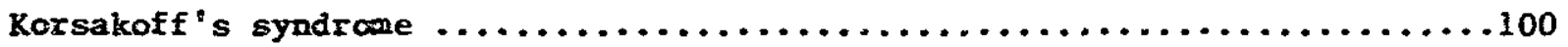

Meniere's disorder .......................................208

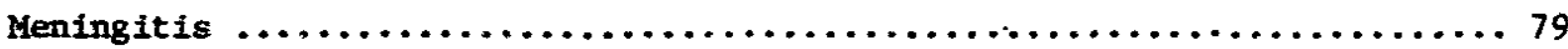

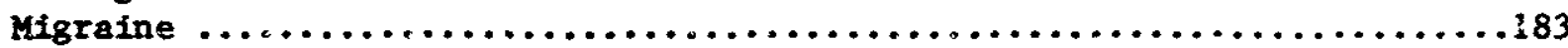

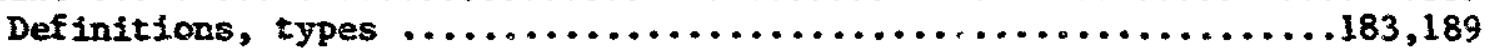

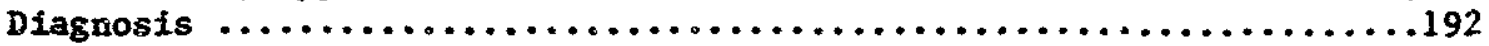

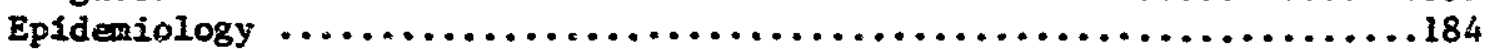

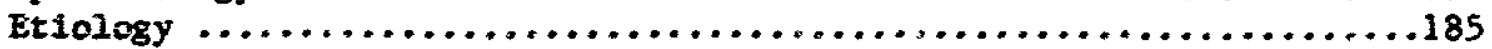

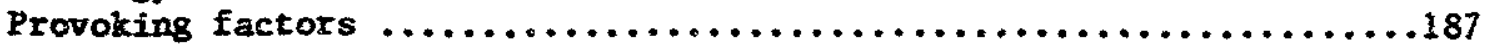

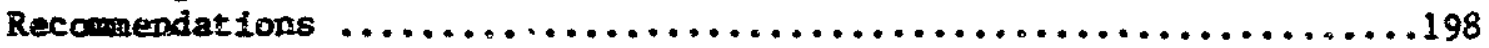

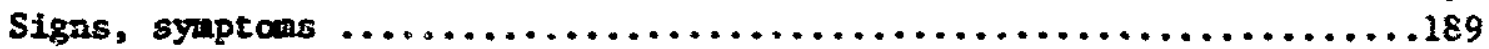

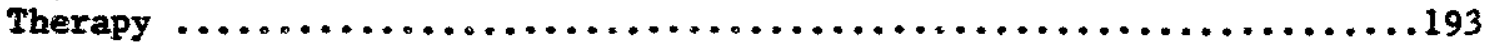

Mononeuropsthy, peripheral nerve $\ldots \ldots \ldots \ldots \ldots \ldots \ldots \ldots \ldots \ldots \ldots \ldots \ldots \ldots \ldots 121$ 
Kultple aclerosis $\ldots \ldots \ldots \ldots \ldots \ldots \ldots \ldots \ldots \ldots \ldots \ldots \ldots \ldots \ldots \ldots \ldots \ldots \ldots \ldots \ldots \ldots$

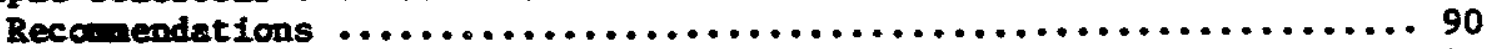

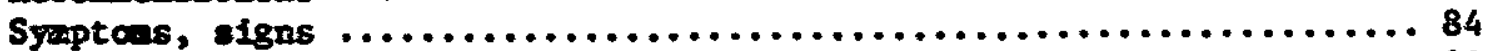

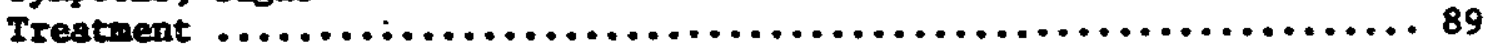

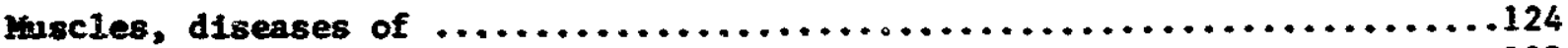

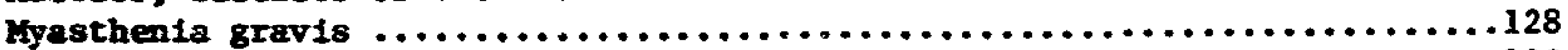

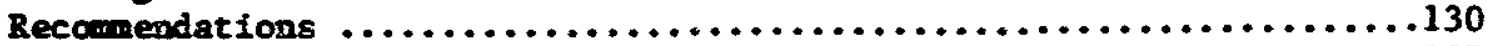

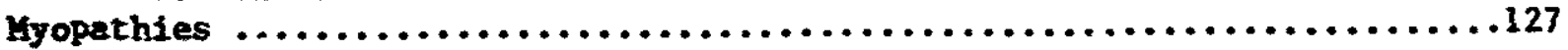

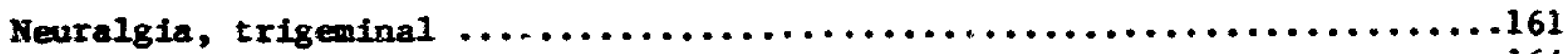

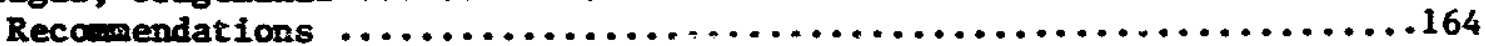

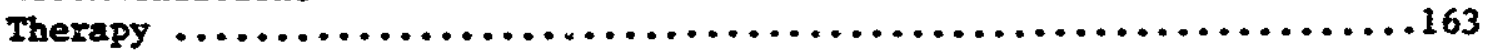

Neuropathy

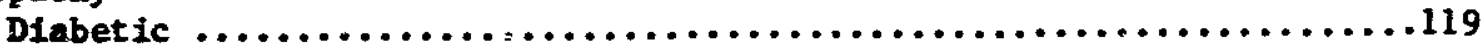

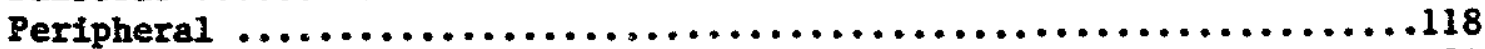

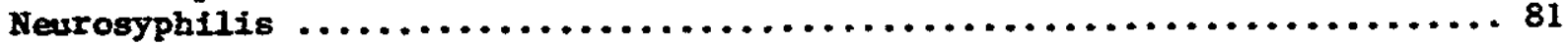

Odontoid

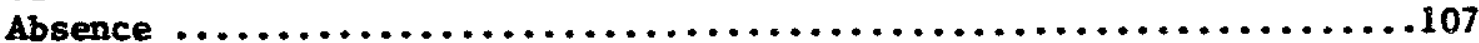

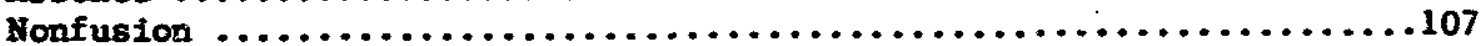

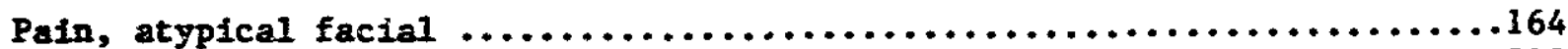

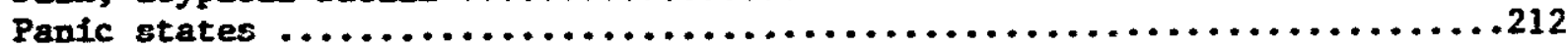

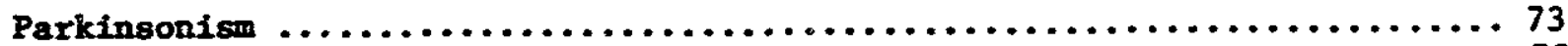

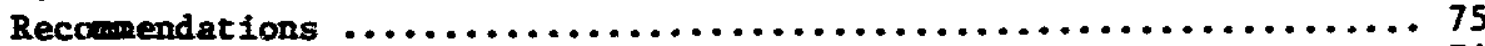

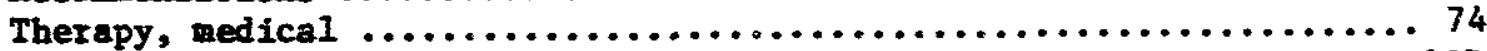

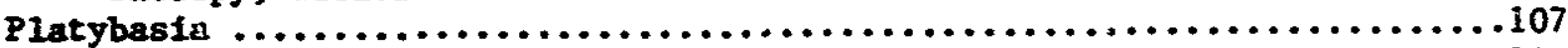

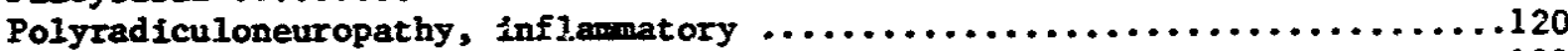

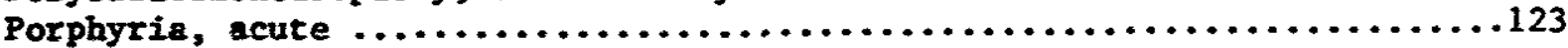

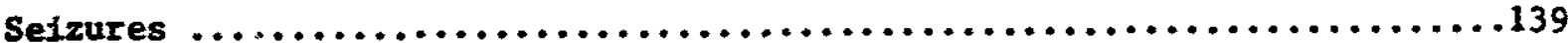

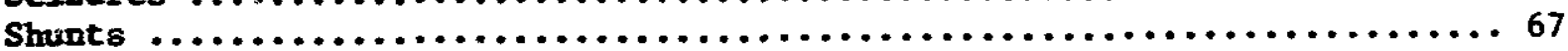

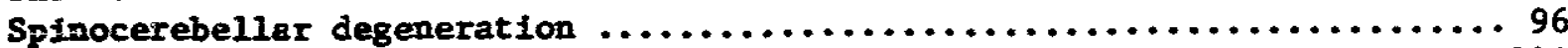

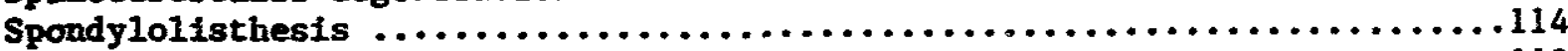

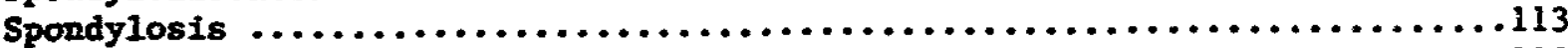

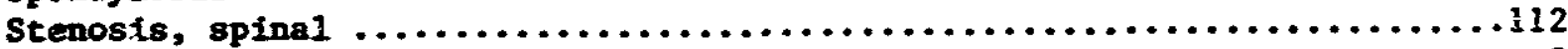

Subarachnoid henorrhage $\ldots \ldots \ldots \ldots \ldots \ldots \ldots \ldots \ldots \ldots \ldots \ldots \ldots \ldots \ldots \ldots \ldots$

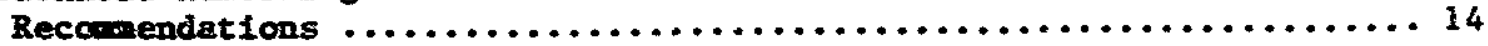

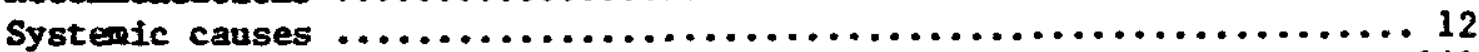

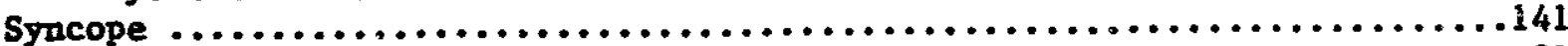

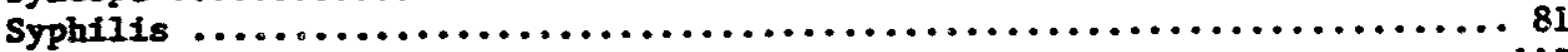

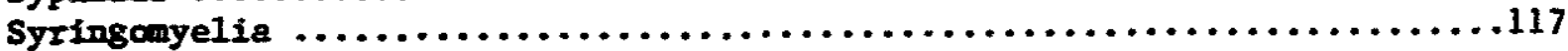

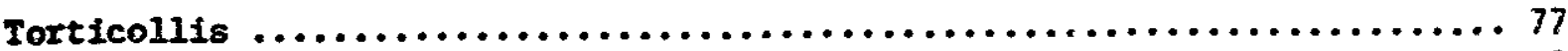

Transient ischemic attack (TIA) $\ldots \ldots \ldots \ldots \ldots \ldots \ldots \ldots \ldots \ldots \ldots \ldots \ldots \ldots$

Trenor, essential ...................................... 79

Tumors

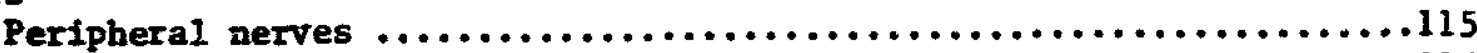

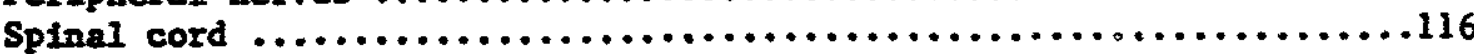


Tumors, intracraniai $\ldots \ldots \ldots \ldots \ldots \ldots \ldots \ldots \ldots \ldots \ldots \ldots \ldots \ldots \ldots \ldots \ldots \ldots \ldots \ldots \ldots 17$

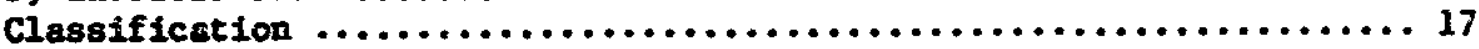

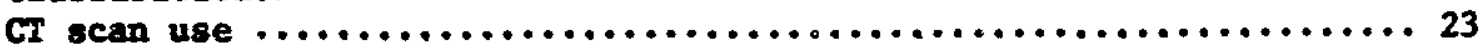

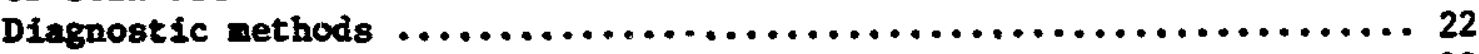

Operative techniqques $\ldots \ldots \ldots \ldots \ldots \ldots \ldots \ldots \ldots \ldots \ldots \ldots \ldots \ldots \ldots \ldots \ldots \ldots \ldots . \ldots \ldots$

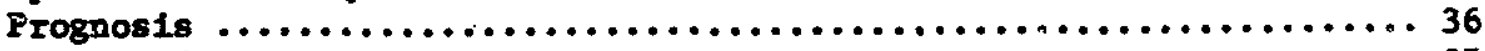

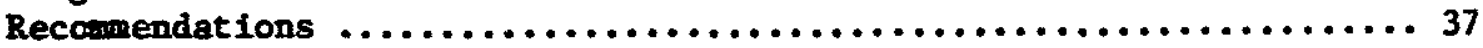

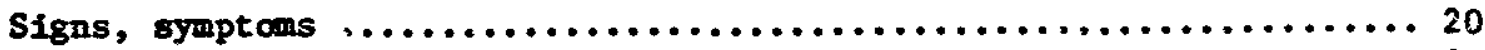

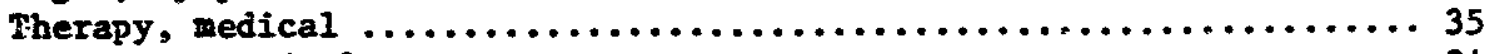

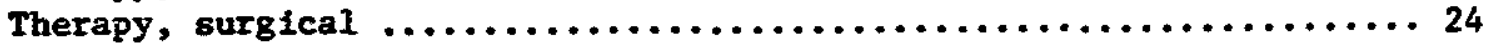

Unconsciousness, unidentifiable cause $\ldots \ldots \ldots \ldots \ldots \ldots \ldots \ldots \ldots \ldots \ldots \ldots \ldots$

Vertigo

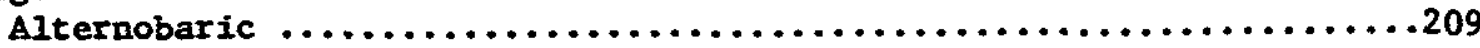

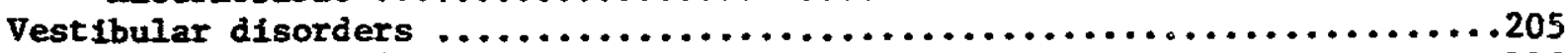

Von Recklingharsen's disease $\ldots \ldots \ldots \ldots \ldots \ldots \ldots \ldots \ldots \ldots \ldots \ldots \ldots \ldots \ldots \ldots \ldots \ldots 116$

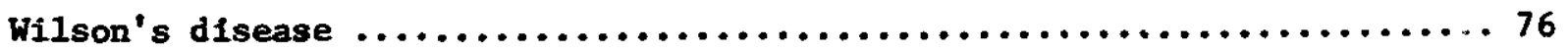

